\title{
جامعة الاسكندرية
}

كلية التربية

قسم المناهج وطرائق التدريس

وحدة مقترحة في علم الاجتماع قائمة على الخيال الاجتماعي لتنمية قيم

المشاركة المجتمعية ومهارات التفكير التحليلي لاى طلاب المرحلة الثانوية.

إعداد

د. دهاء حلمي عبد الحميد أبو نعمة

مدرس المناهج وطرائق التدريس (المواد الفلسفية)

كلية التربية-جامعة الإسكندرية

$$
\text { تاريخ قبول البتلام البحث }
$$


وحدة تعليمية مقترحة في علم الاجتماع قائمة علي الخيال الاجتماعي لتنمية قيم

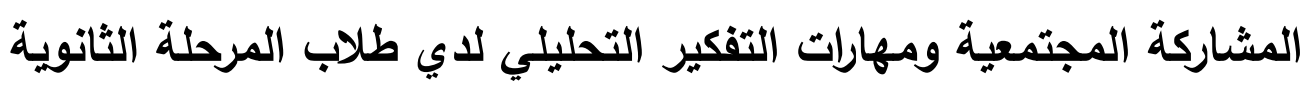

د. هناء حلمى عبد الحميد عيد

مدرس المناهج وطرائق التّريس

كلية التربية-جامعة الإسكندرية.

ملخص البحث: - 20 - 20

يهرف هذا البحث إلى الكثف عن فاعلية وحدة مقترحة في علم الاجتماع قائمة على

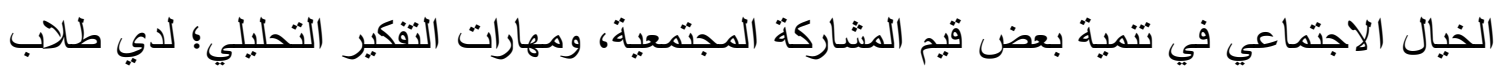

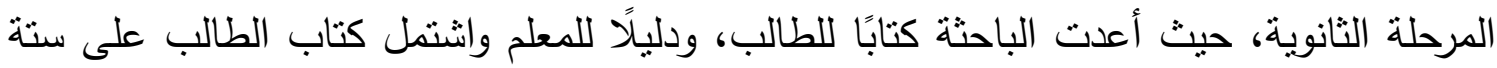

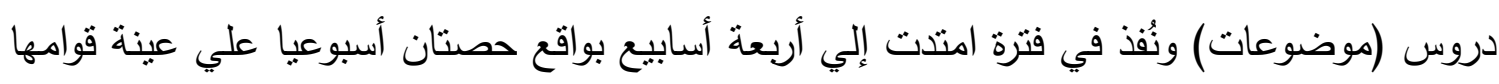

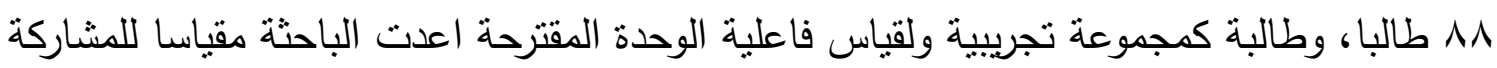

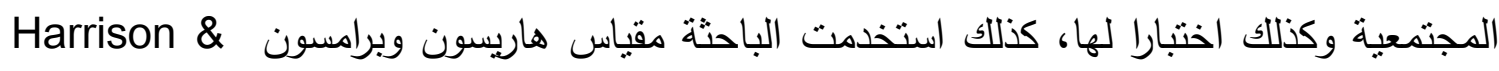
Bramson

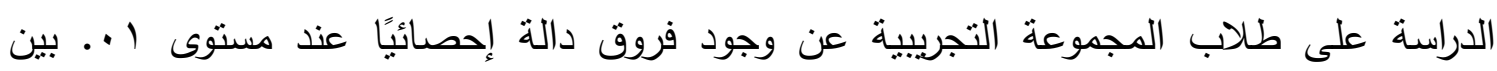

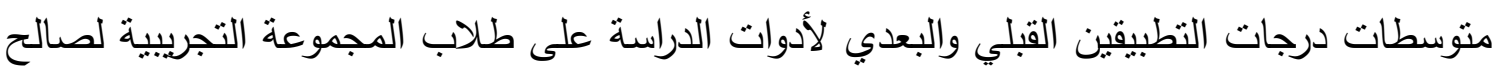

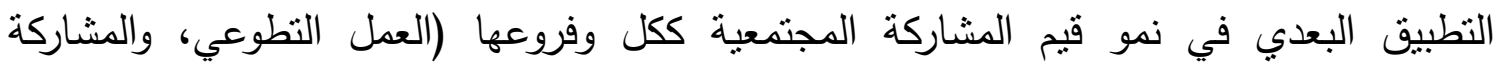
السياسية، والمشاركة الاجتماعية)، وكذللك نمو مهارات التفكير التحليلي ككل. 


\section{Summary}

\section{A proposed unit in sociology based on the social imagination for developing Values of community participation and the skills of analytical thinking of secondary school students}

The aim of this study is to identify the effectiveness of a proposed sociology unit based on social imagination in the development of some values of community participation and analytical thinking skills among high school students. The researcher prepared a book for the student and a teacher's guide. In a period of several weeks, two weeks per week on a sample of 88 students, as a pilot group and to measure the effectiveness of the proposed unit, the researcher prepared a measure for community participation as well as a test, and the researcher agreed to measure analytical thinking. The results of the study after the tribal and remote applications of the study tools revealed that there were statistically significant differences in the level of 01 . Among the average scores of the tribal and remote applications of the study tools on the experimental group students in favor of the post application in the growth of the values of community participation as a whole and its branches Political, and social participation) as well as the growth of analytical thinking skills as a whole. 


\section{وحدة تعليمية مقترحة في علم الاجتماع قائمة علي الخيال الاجتماعي لتتمية قيم}

\section{المشاركة المجتمعية ومهارات التفكير التحليلي لدي طلاب المرحلة الثانوية}

د. هناء حلمى عبد الحميد عيد

مدرس المناهج وطرائق التدريس

كلية التربية-جامعة الإسكندرية.

أولا: مقدمة البحث:

تعيش الهجمعـات العربيـة مرحلـة جديدة تمنلت فيمـا تجناحهـا مـن ثورات تحمل مطالب

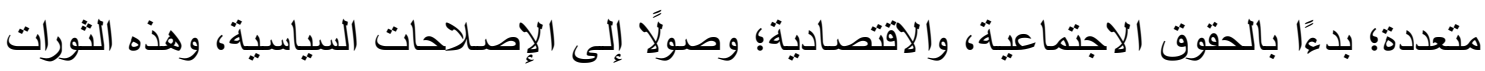

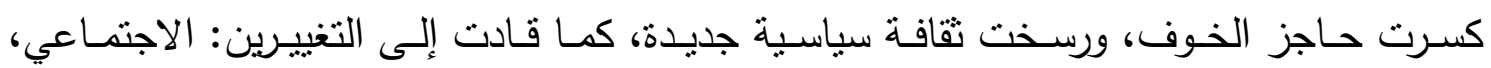

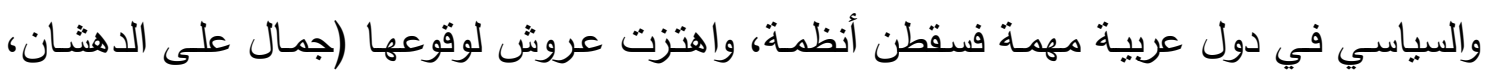
. ( $\varepsilon: r \cdot 1)$

كما أن هذه الثورات - ثورات الربيع العربي- أدت إلى إحداث تطورات سريعة في شتى إنى

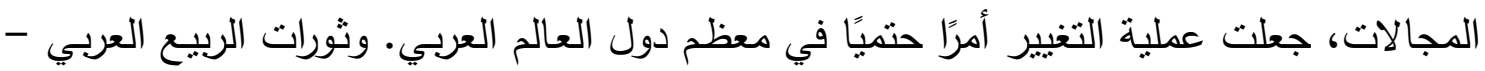

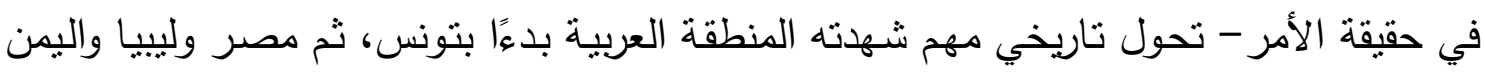

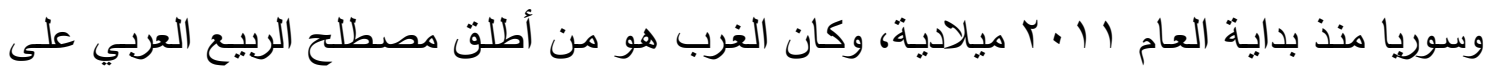

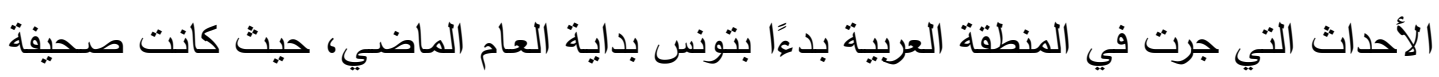
Independent البريطانية أول من استخدم هذا المصطلح.

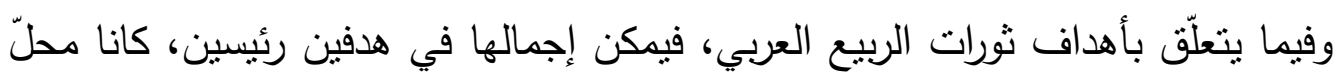

$$
\text { إجماع لمعظم المواطنين العرب، وهما: }
$$

1- الإطاحة بالنظم الاستبدادية بشخوصها، ورموزها كافة؛ مما يتطلّب معه قطيعة كليّة مع الحقبة الماضية المليئة بالأسى، والحزن، والألم، والتخلّف، والفساد. الإنة

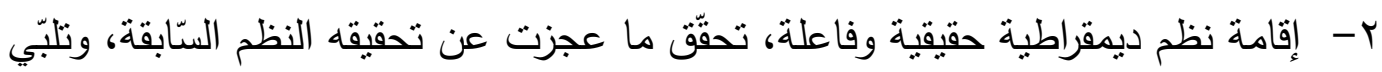

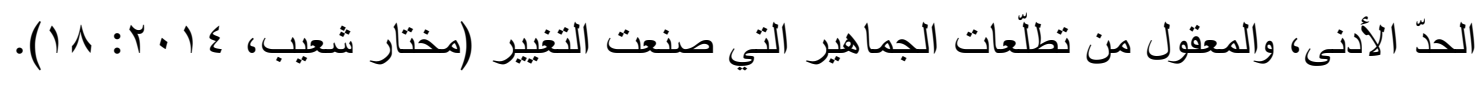

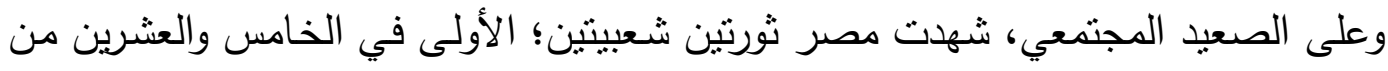

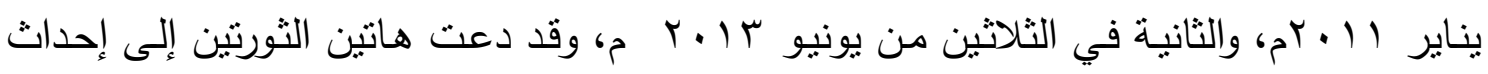

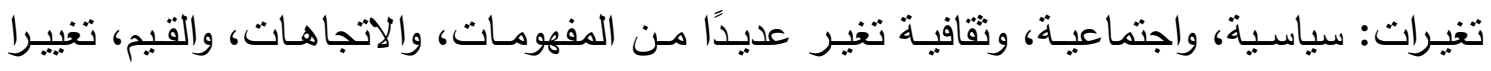

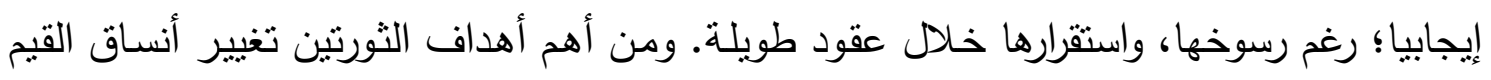

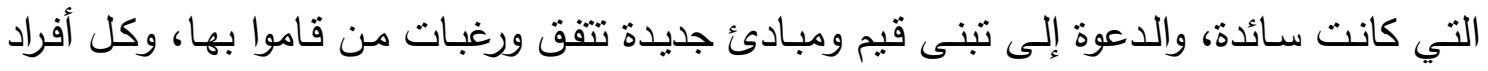


المجتمع، والسعي نحو وضع أسس جديدة؛ لتنظيم علاقة الفرد بمجتمعه، ونظامها السياسي القائم

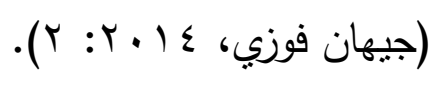

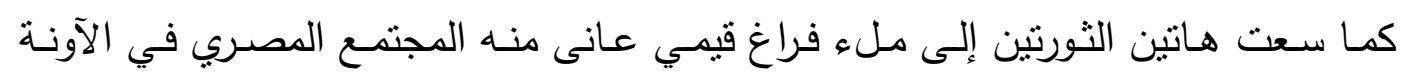

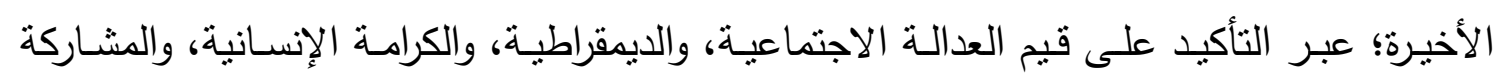

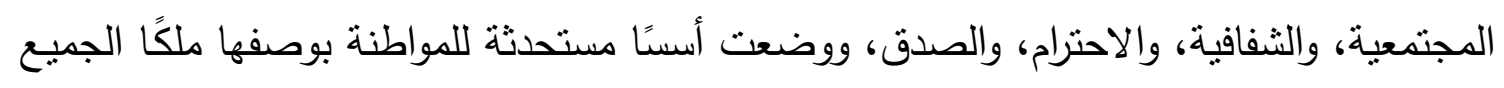

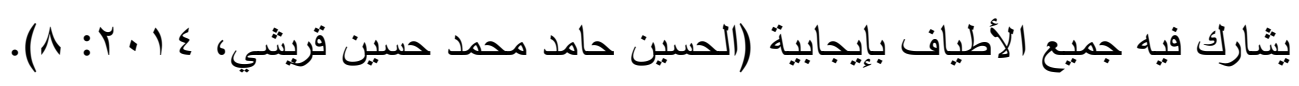

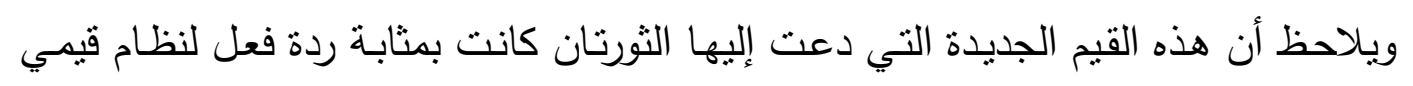

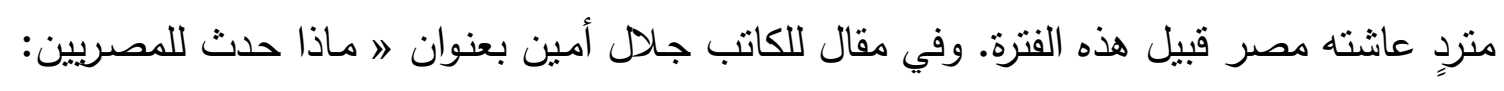

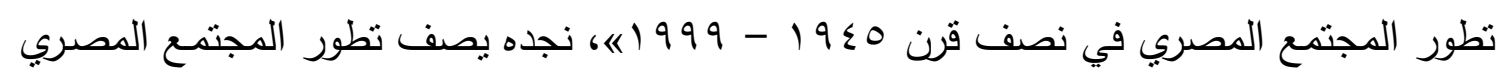

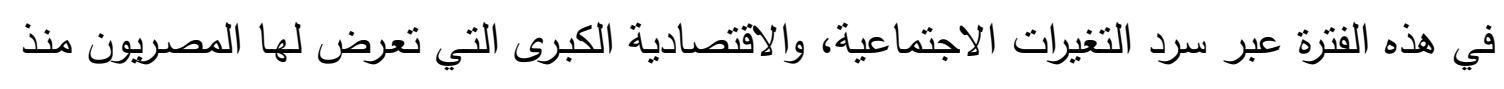
عام 190r، وحتى 19991، والتي قد عجلت الحراك الاجتماعي في مصر بشكل غير مسبوق،

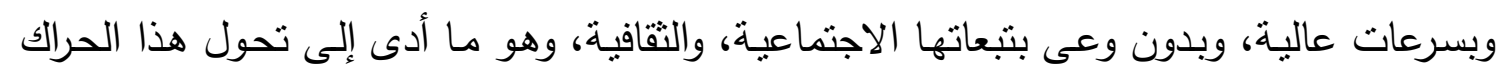

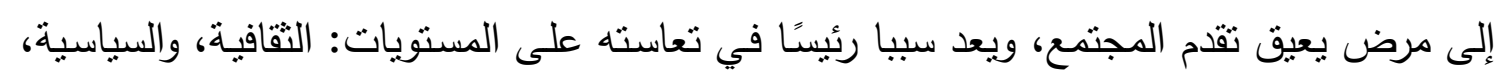

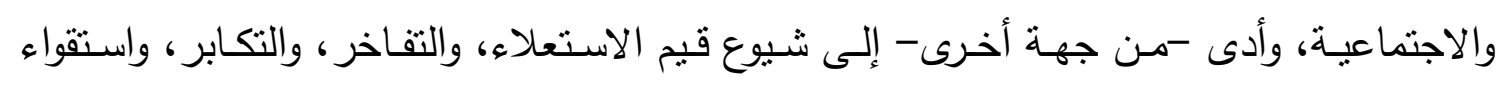

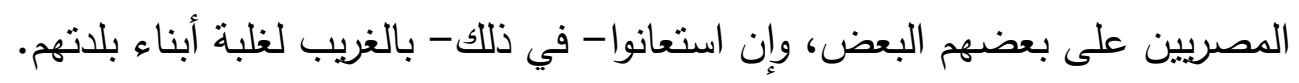

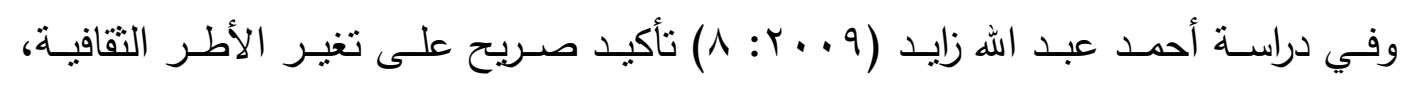

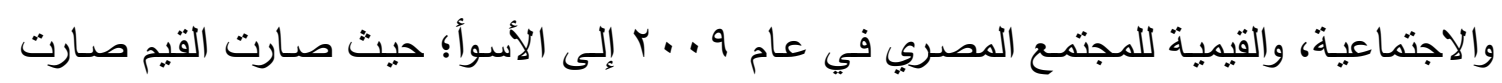

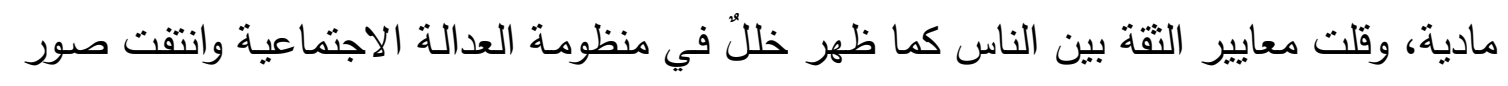

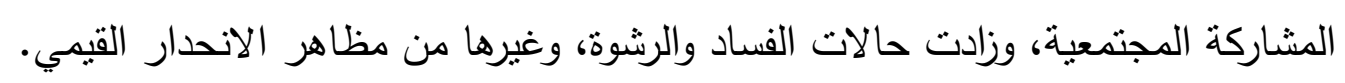

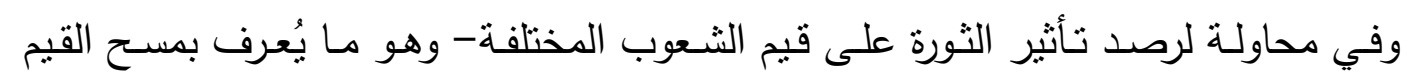

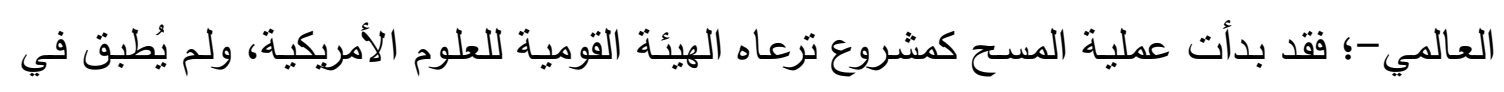

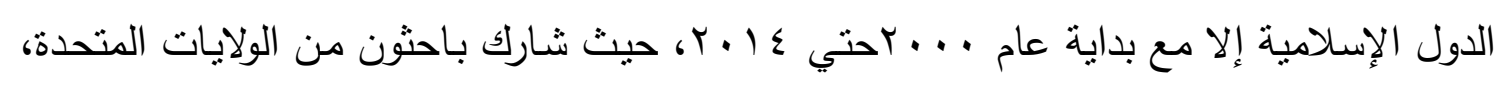

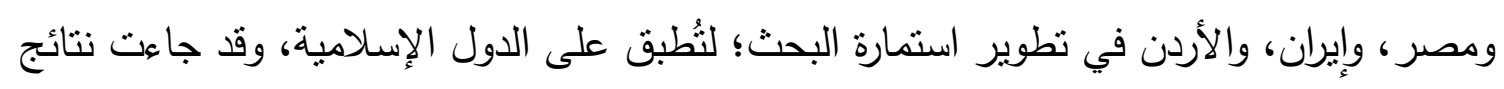

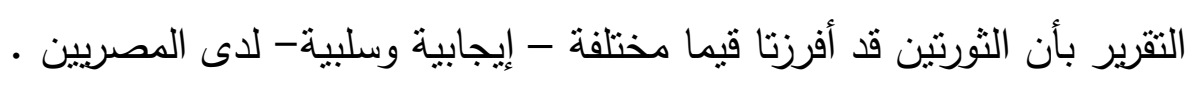

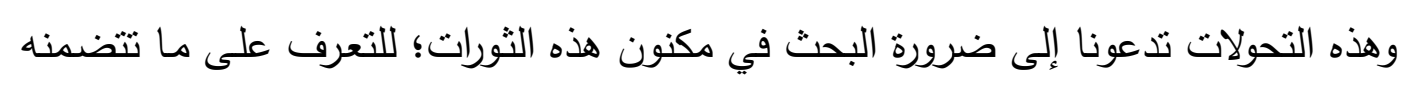

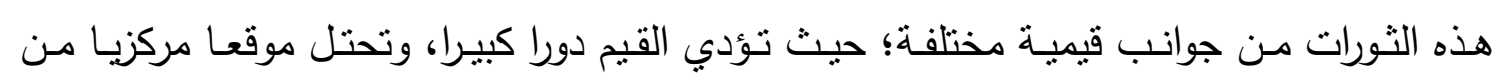

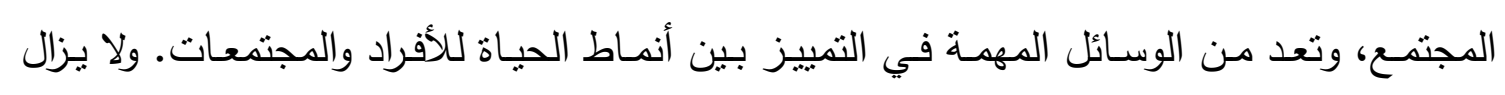

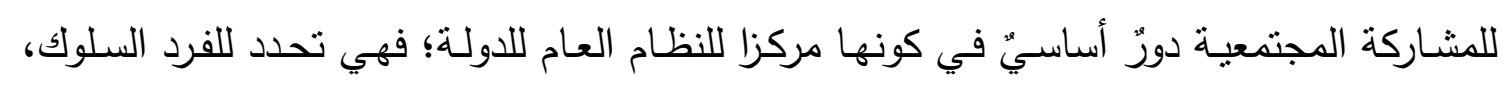

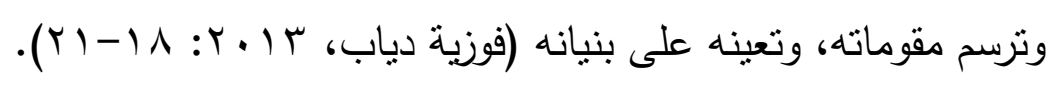


وللمشاركة المجتمعية للشباب أهميتها بالنسبة للفرد والمجتمع؛ فهي تعد من الوسائل المهمة

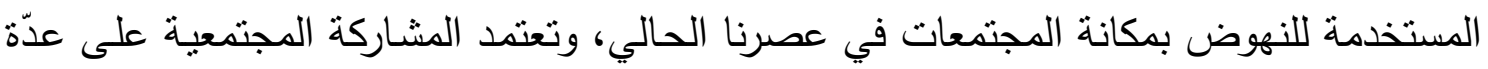

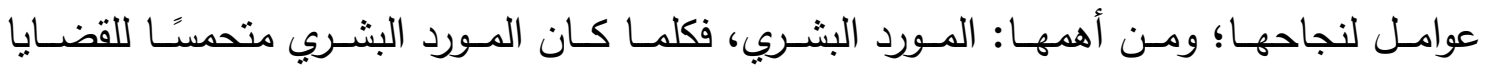

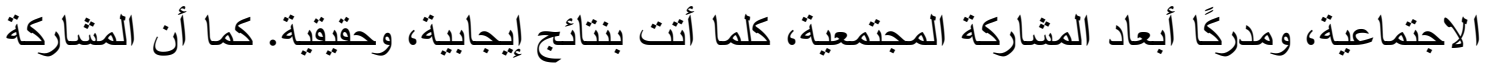

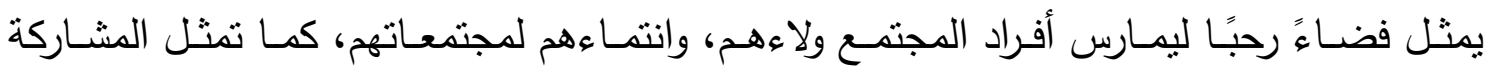

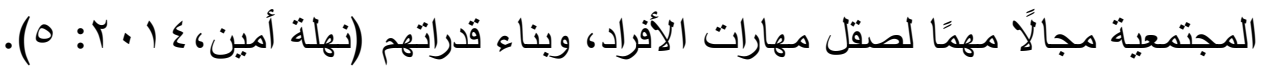

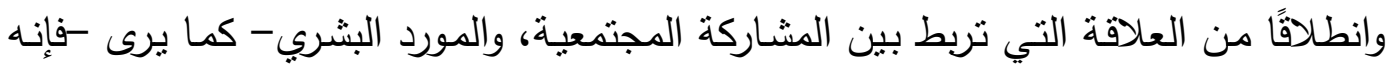

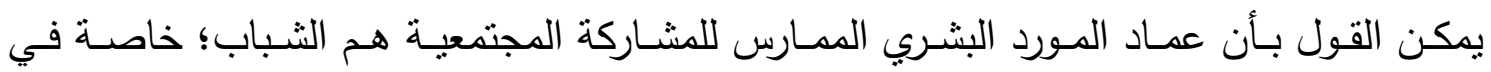
المجتمعات الفتية؛ فحماس الثباب، وانتماؤهم لمجتمعهم كفيلان بدعم المشاركة المجتمعية، والرقي

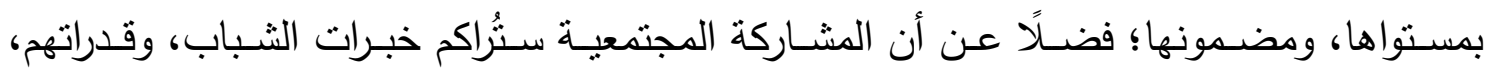

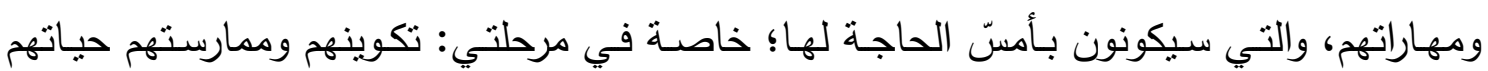

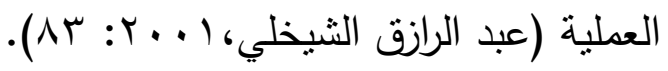

وتعرف المشاركة المجتمعية- في قاموس علم الاجتماع -: بأنها "مشاركة في الجماعات

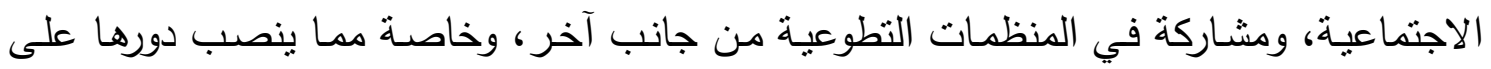

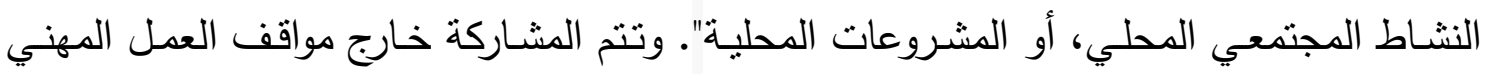

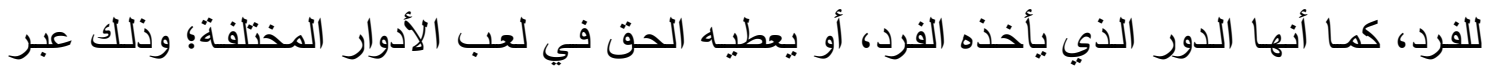

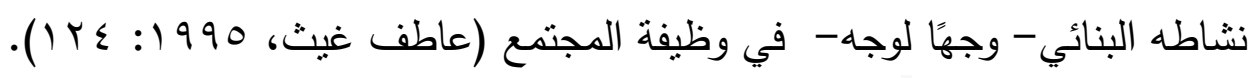

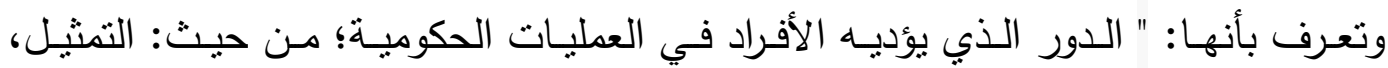
والاستشارات، والاتشتراك في عمليات التتمية". وتوجد المشاركة كنوع من التطوع في كل دول العالم؛ إلا أنها أكثر تطورًا في الدول التي علي درجة كبيرة من الوعي، والعمل في الخدمة المدنية (عبد فيدات

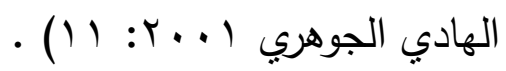
وللمشاركة المجتمعية دور مهم في تحقيق ما يلي: لاهي:

1 أتمية المجتمع؛ فالتتمية الحقيقية الناجحة لا تتم دون مشاركة شعبية . r.تعليم المواطنين - عبر المشاركة- كيف يحلون مشاكلهم. r. انترالك المواطنين في عمليات التتمية، ومساندتهم تلأك العمليات، والعناية بها،

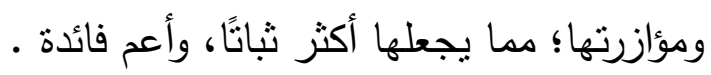

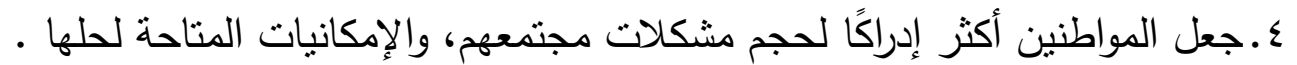
V. فتح مشاركة المواطنين الكاملة بابًا للتعاون البنَّاء بين المواطنين، والمؤسسات الحكومية الدية

كما تفتح قنوات التواصل السليمة بينهما 1. تقليل شعور الأفراد بالانعزال، والسلبية، والمشكلات الاجنماعية، والثخصية. 
9 ـ تحقيق فهم متكامل، وإمكانية كبيرة في التعامل مع المشكلات؛ لأن المشاركين هم ون

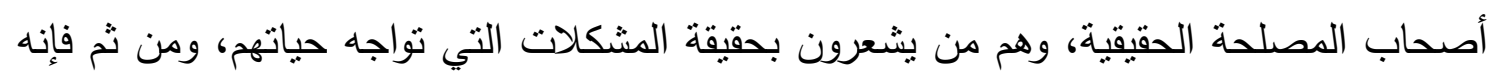
من المنطقي أن يشتركوا في حلها.

• ا. مساهمة الناس في صنع التغييرات المهمة التي تجري بمجتمعاتهم، والسبطرة عليها؛ مما يسهم في تحقيق أهدافهم المشتركة، وتتظيم مجتمعاتهم.

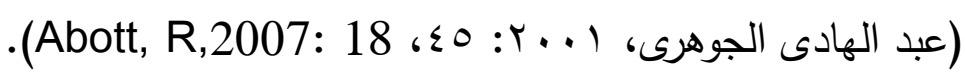

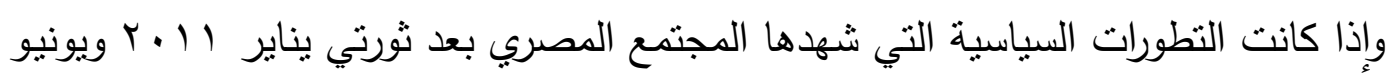

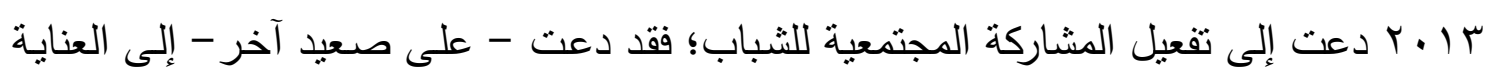

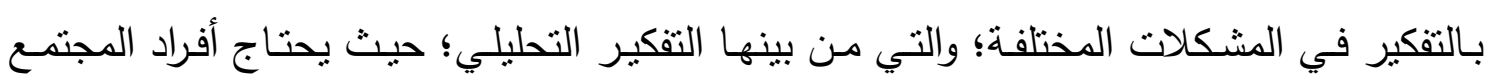

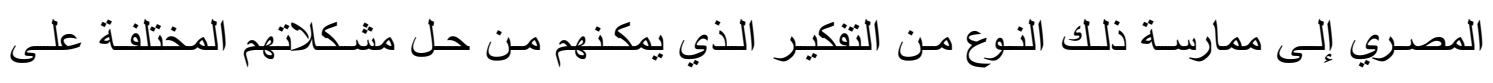

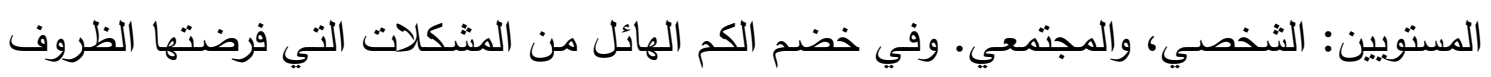

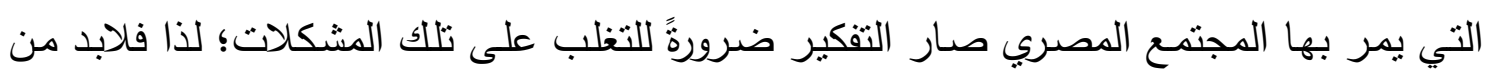
توافر قدرات تفكيرية تحليلية لدى الإنسان على اختلاف موقعه ومستواه تمكنه من حل مشكلاته

المعلقة.

ويقصد بـالتفكير التحليلي بأنـه: " قدرة الفـرد على مواجهـة المشكلات بطريقـة منهجيـة،

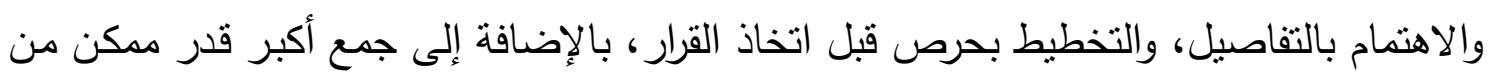

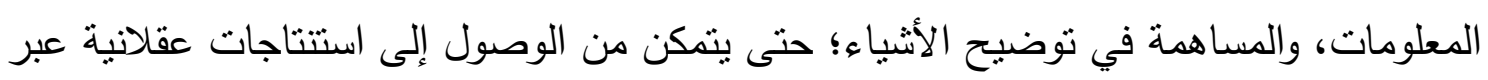

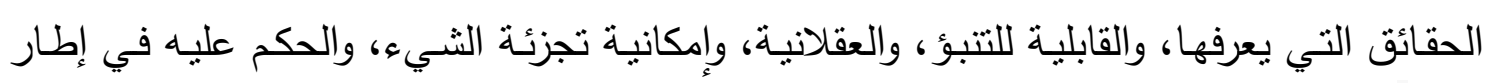

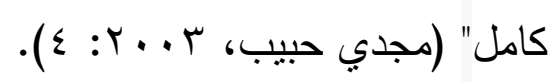

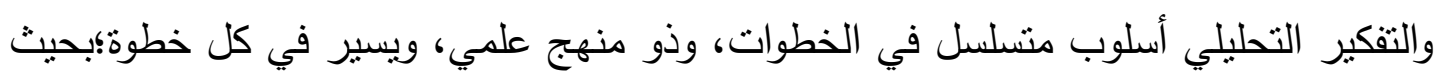

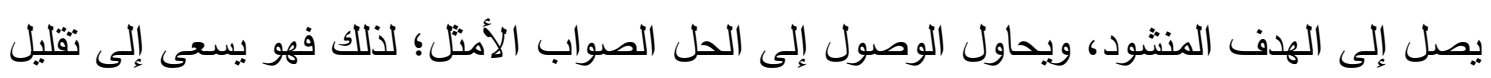

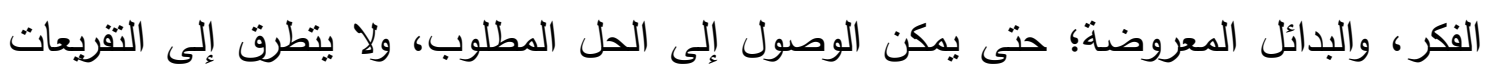

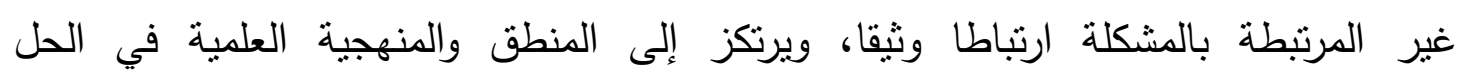

(Renuwat, P, 2009: 15)

وترجع أهميـة تتميـة مهارات التفكير التحليلي إلى أنـه يمثل ركيزة أولى لأنواع التفكير

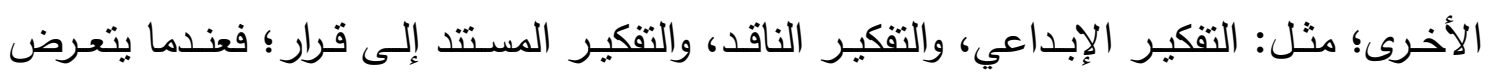

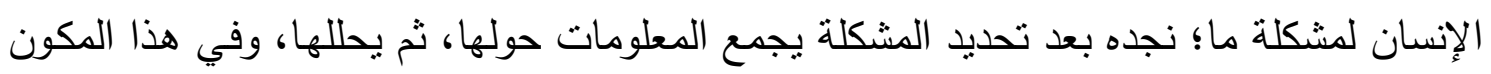

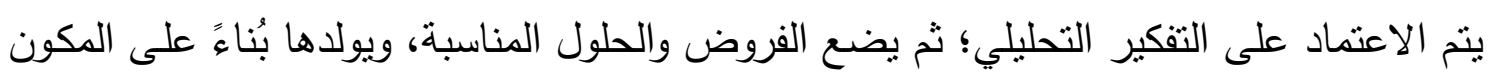

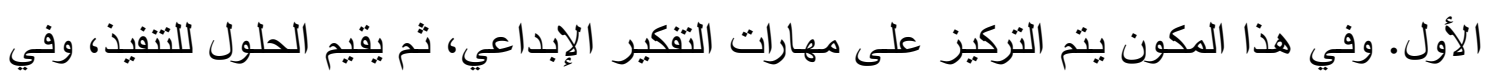

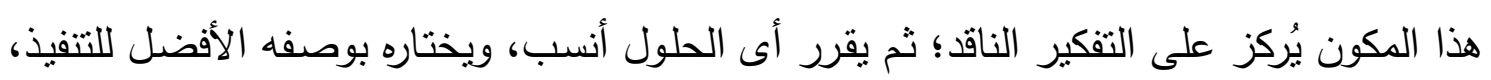


وفي هذا المكون يُركز على مهارات اتخاذ القرار ؛ لذلك يُعد التفكير التحليلي القاسم الششترك بين أكثر من عملية من عمليات التفكير

( Marzano, R \& Kendall, J, 2008: 24-28)

ولا شك أننا في حاجة ملحة اليوم إلى تدريب طلابنا في مدارسنا المصرية على اكتساب قيم

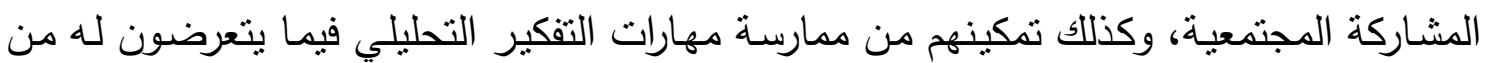

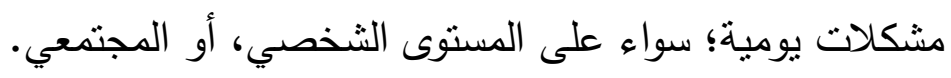
وتعد تتمية قيم المشاركة المجتمعية، ومهارات التفكير التحليلي لدي طلاب المرحلة الثانوية التية

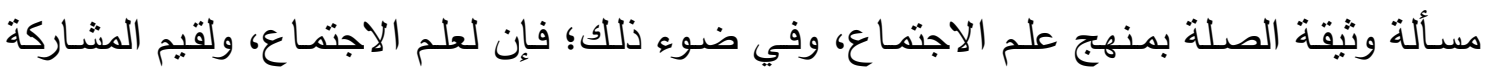

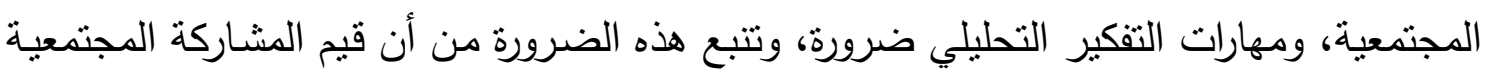

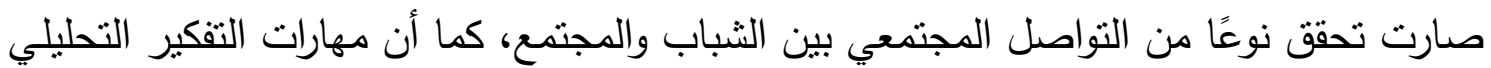
تعنى ببحث المشكلات التي تعترض الإنسان في مجتمعه، وفي حياته اليومية؛ وبذلك يتسع مجال

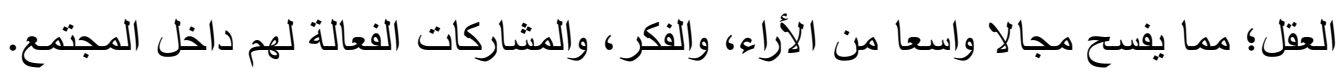

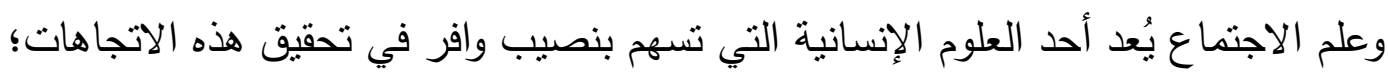

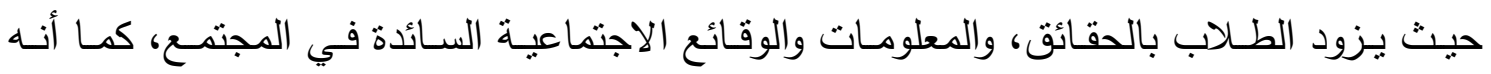

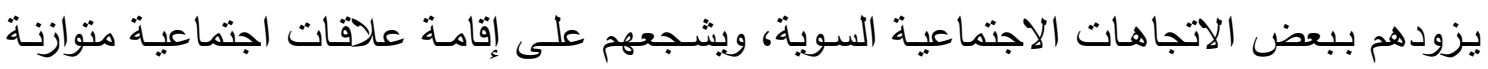

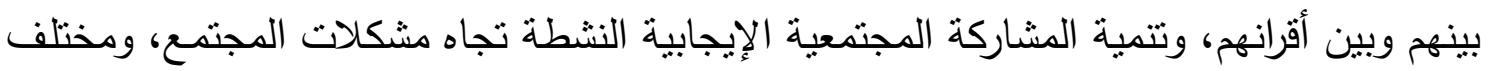

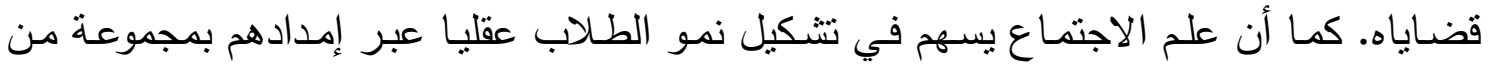

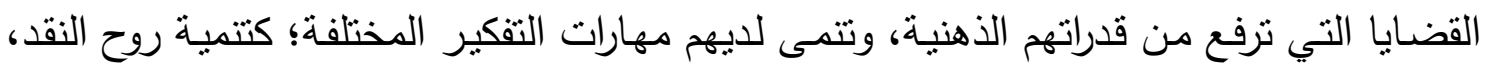

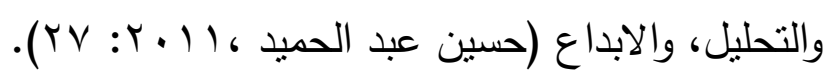

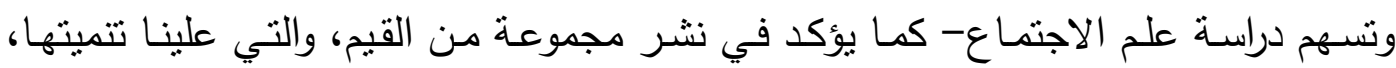
ورعايتها؛ لتحقيق أخلاق عالمية، وتفاعل كوني لحضارة الإنسان الجديدة المعنلة فيما يلي: 1- الوعي بالحقوق الإنسانية مع الإحساس بالمسؤولية الاجتماعية.

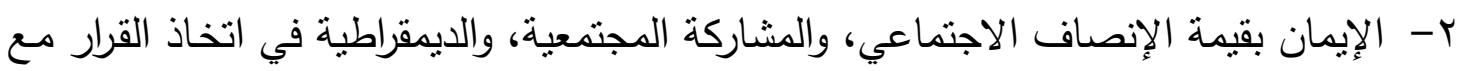

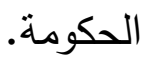

r- فهم المشكلات الاجتماعية المختلفة؛ عبر تحليلها تحليلا دقيقا يسهم في حلها.

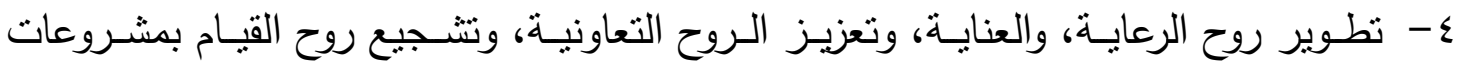

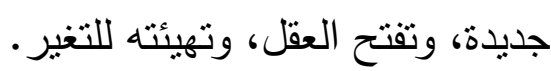

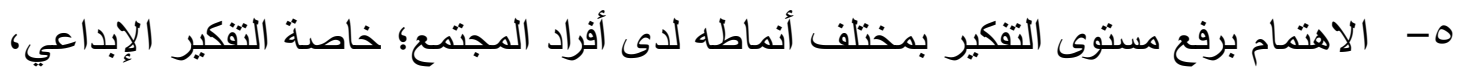

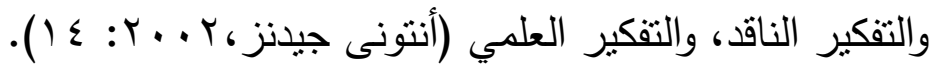


فعلم الاجتماع يسهم في بناء المتعلم كباحث لا ينوقف عن البحث، والتفكير في ما نشأ

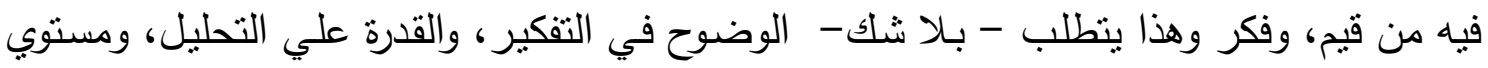
كبيرًا من المرونة العقلية، والنقد، وإبداء الآراء، ولن يتمكن الطلاب من امتلالك تلك المهارات إلا

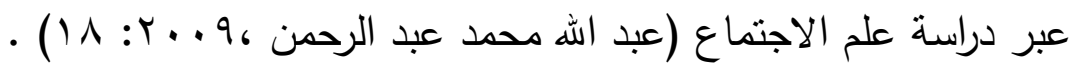

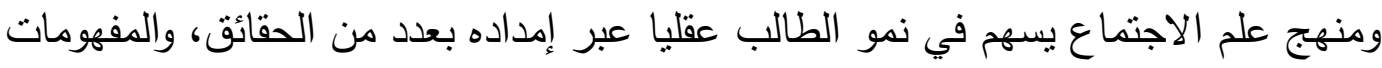
التي تزيد من وعيه بقضـايا المجتمع، ومشكلاته، ونظمهـ: السياسية، والاجتماعية، والاقتصـادية،

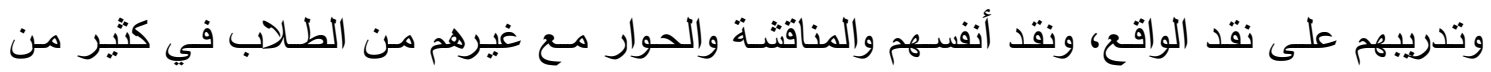
القضايا، والمشكلات الاجتماعية بينه وبين أقرانه قوامها التعاون، والتنافس الثريف، وروح المشاركة

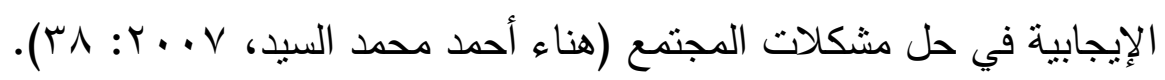

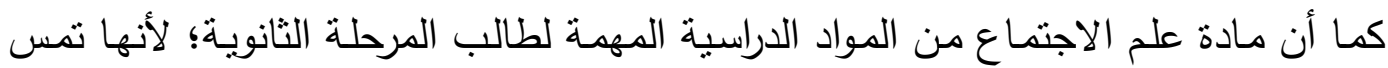

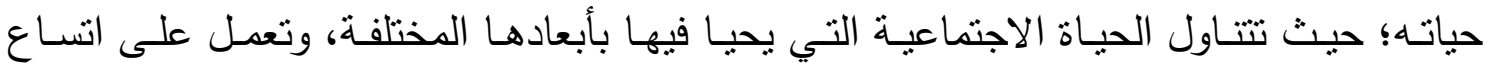

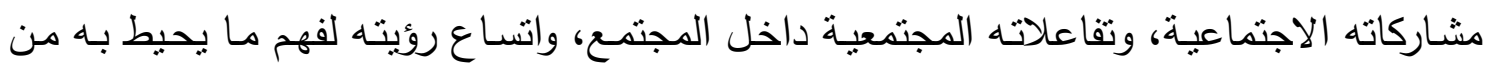
شُئون المجتمع، وتقسير ما يشاهده، والعلاقات القائمة بين الظواهر الاجتماعية، والقدرة على التتبؤ بما يمكن أن يكون عليه مستقبل المشكلات الاجتماعية. كما نسهم دراسة علم الاجتماع في إعمال

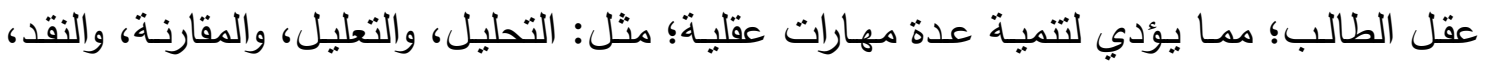

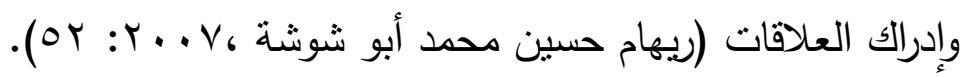

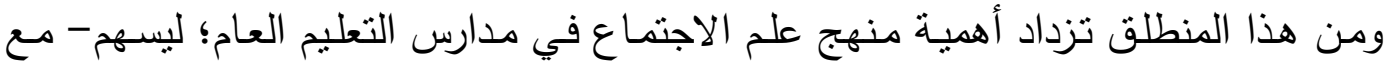
غيره من المناهج التعليمية- في تحقيق الوظيفة الاجتماعية للتعليم في تأدية التعليم لدوره في تربية التئية

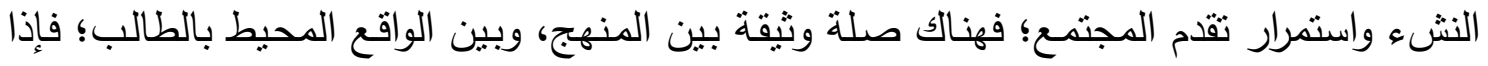

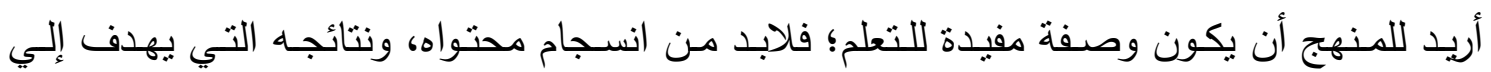

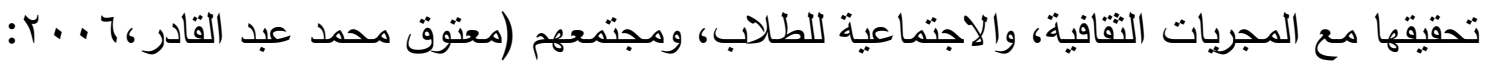

باسنقراء ما سبق نجد أن علم الاجتماع يرتبط ارتباط مباشر بالمشاركة المجتمعية وأنماط

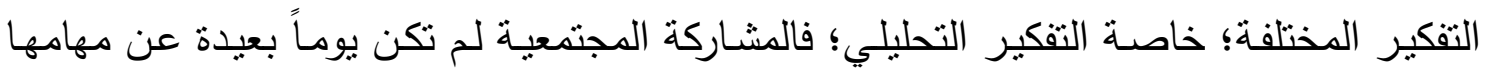

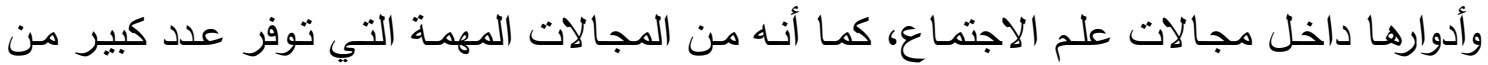
القضايا والمشكلات الاجتماعية التي تتطلب تفكيرا تحليليا دقيقا يسهم في حلها.

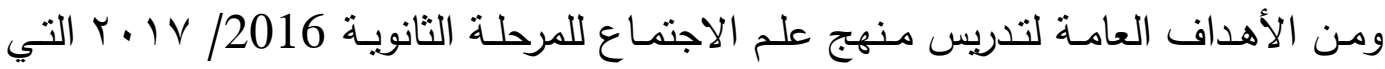
تعين الطلاب علي استخدام التفكير التحليلي و تحثه على المشاركة المجتمية: 1. تزويد الطلاب بالمنهج العلمي في دراسة قضايا الفرد، والمجتمع، وحفزهم على الاقتداء بالفكر العلمي، والمنهجي في معالجة هذه القضايا. 
r.تعّرف الطلاب على بعض مشكلات الفرد، والجماعة؛ لمساعدتهم في فهمها، وتفسيرها، وتحليلها؛ تمهيدًا لمواجهتها، والتحكُم فيها.

r. التأكيد على دور المشاركة الفردية، والمجتمعية، والثعبية في مواجهة مشكلات المجتمع.

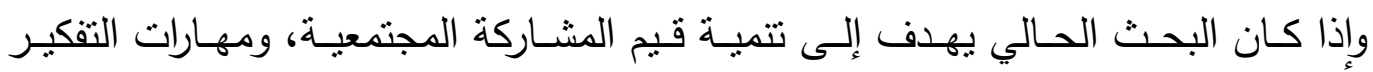
التحليلي؛ فإن ذلك يتطلب مدخلا متميزا يُمكن الطلاب من تحقيق ذلك؛ لذلك سوف يرنكز المدخل

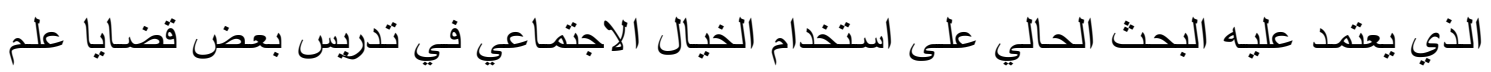
الاجتماع.

ويربط الخيال الاجتماعي بين مستويين من مستويات التحليل: مستوى المجتمع أو (البناء

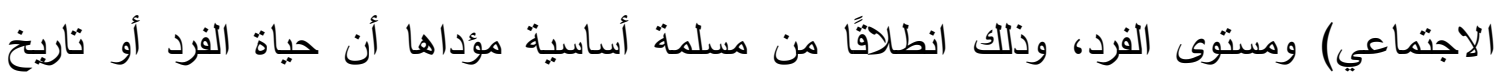

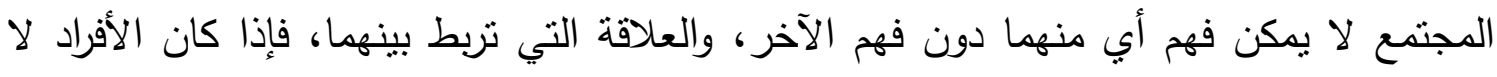

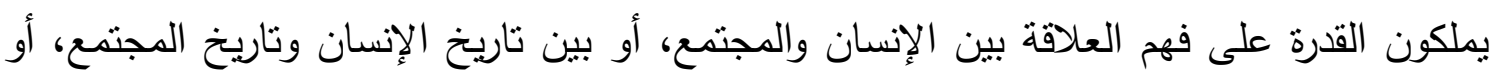

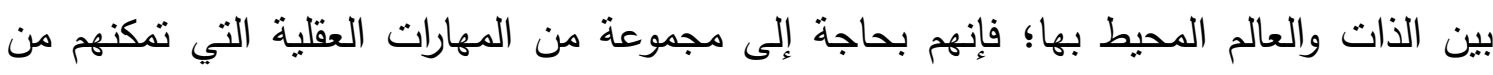
تكوين فكرة جلية لما يدور حولهم، وما سوف يحدث لهم نتيجة تأثرهم بهذا العالم، هذه القدرة العقلية نسمي بالخيال الاجتماعي، أو السوسيولوجي.

(Mills, W,1970, 2-4)

ويعرف رايت ميلز الخيال السوسيولوجي :بأنه" الذي يُمكن صاحبه من فهم الإطار التاريخي

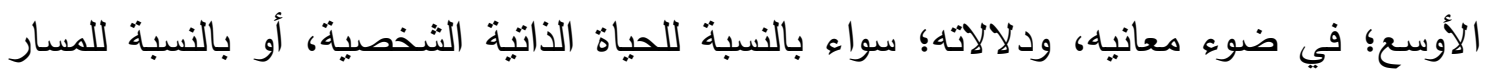

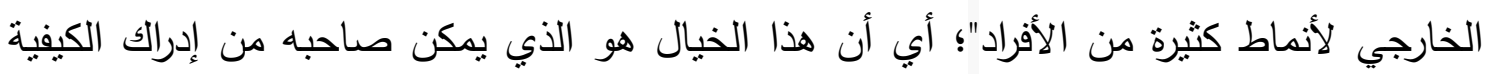

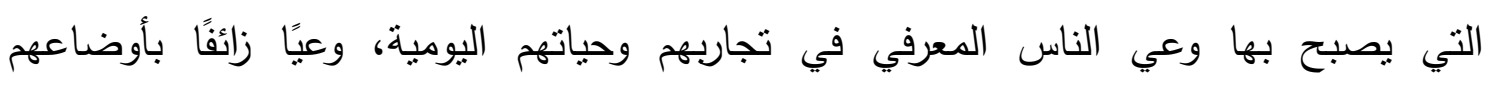
الاجنماعية (Sztompoka, P,2016: 18)

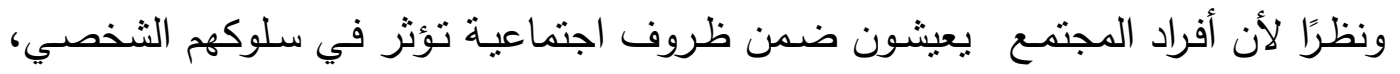

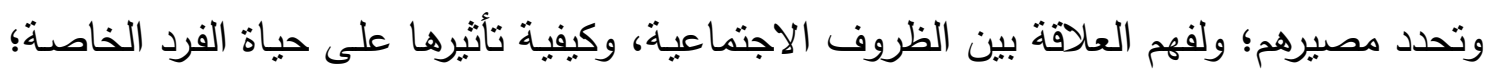
فقد اقترح رايت ميلز Wright Mills الخيال السيسيولوجي؛ لفهم العلاقة بين البناء الاجتماعي

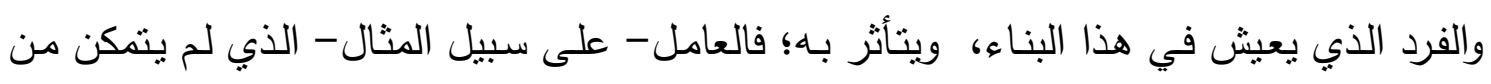

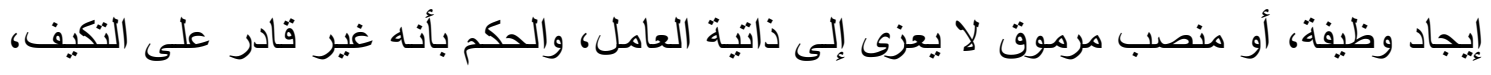

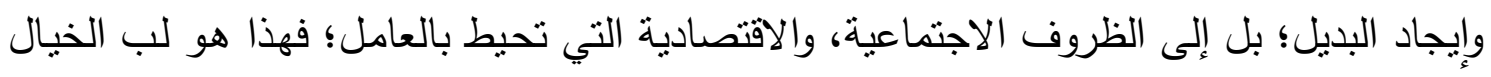
الاجتماعي لدى رايت ميلز باختصار شديد بما يمنل فهم العلاقة بين البناء والفرد.

(Lang, S, 2005: 28)

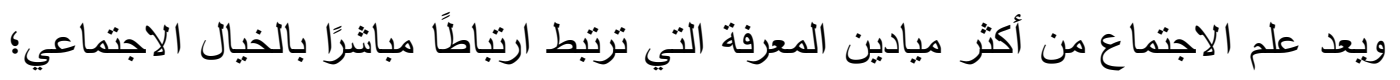

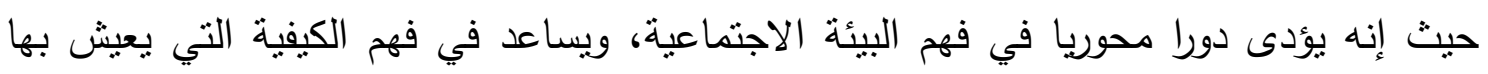


الناس، ويوضح لهم اختلاف ظروف الحياة من وقت إلى آخر ، ومن مكان إلى آخر ، كما أنه يسهم

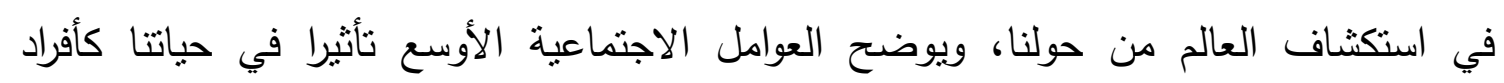

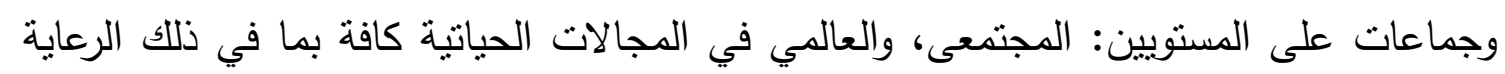

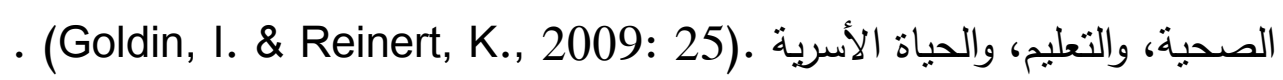

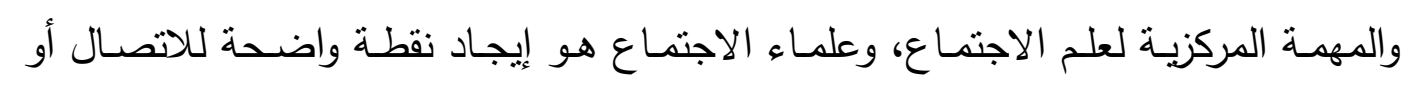

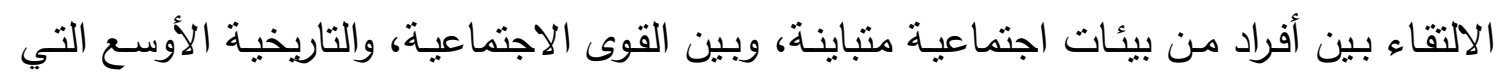

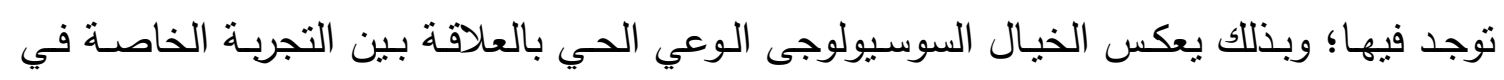

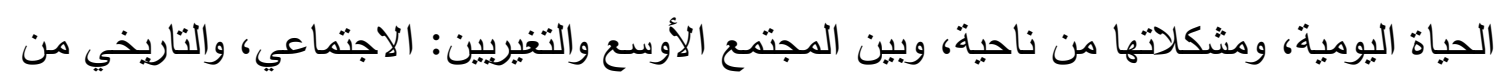
ناحية أخرى؛ ومن ثم يمكن تحويل المشاكل الثخصية إلى قضايا عامة.

.( Mills, W ,1959: 12)

كما أن علم الاجتماع يسهم في فهم العالم الذي نعيش فيه، ويطرح أسئلة متعلقة بالحياة،

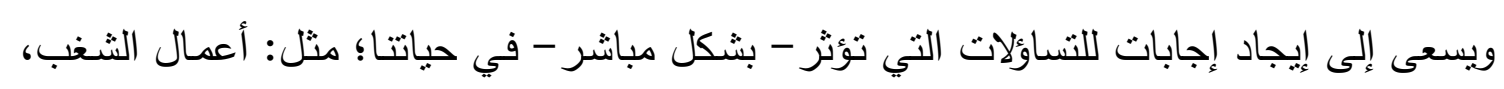

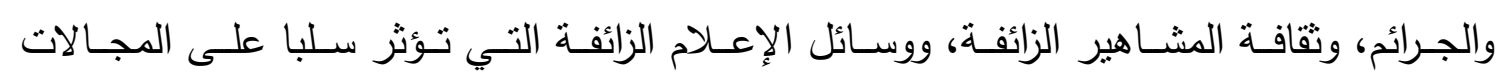

الاقتصادية والاجتماعية والسياسية الني قد تمر به المجتمعات كافة (Martell, L. 2010:18)

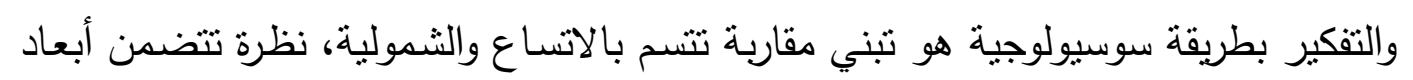

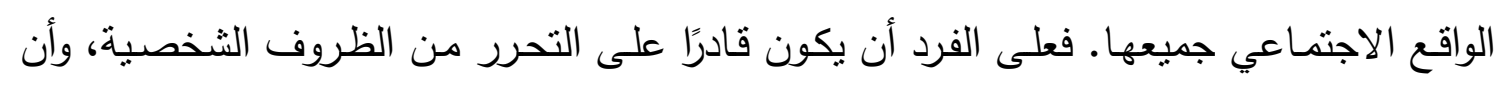

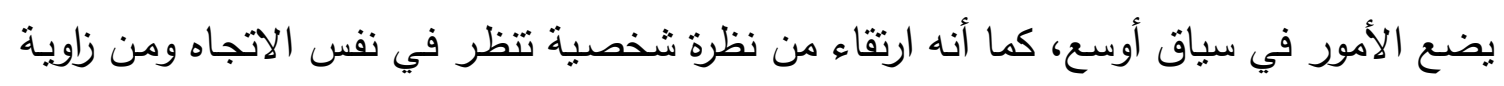

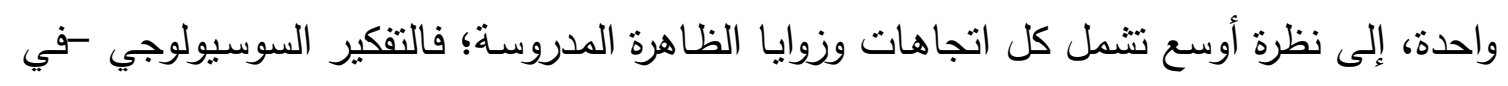

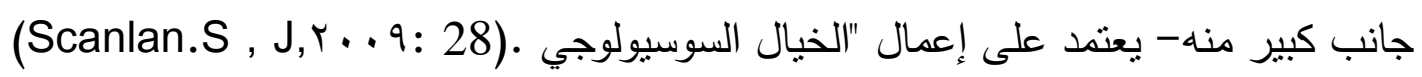

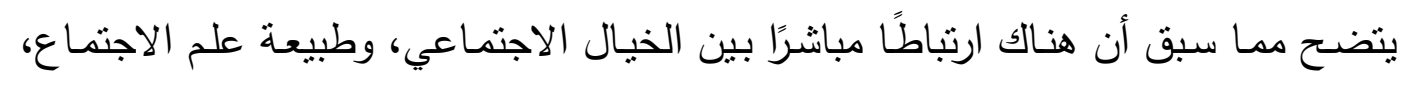

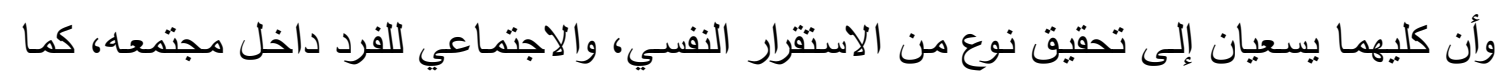

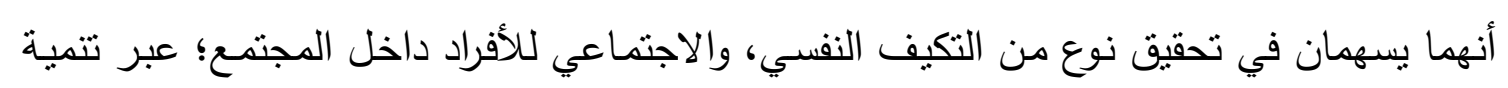

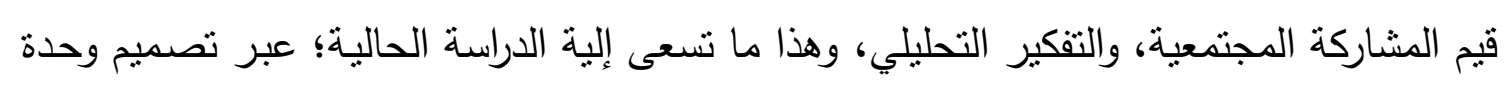

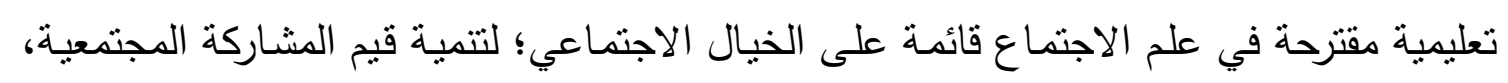
والتفكير التحليلي؛ لدى طلاب المرحلة الثانوية.

مشكلة البحث: - مئر

بالنظر إلى واقعنـا التعليهي؛ نجده يفصـح عن وجود فجوة كبيرة بين التطورات المعرفيـة

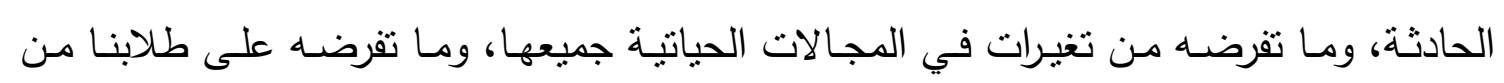

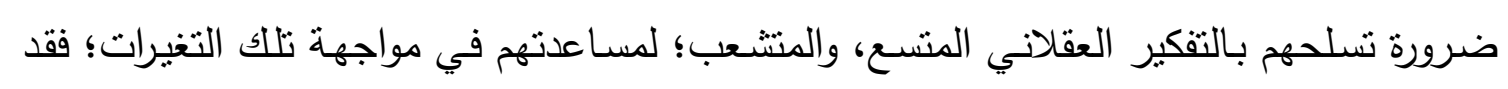

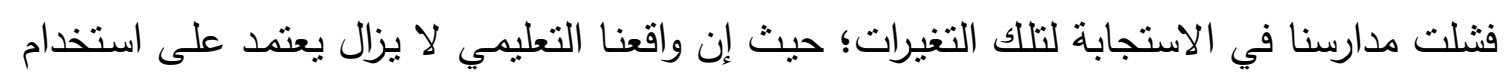


الطرائق التقليديـة في عملية التدريس في معظم المواد الدراسية أو جميعها بصفة عامـة، وعلم

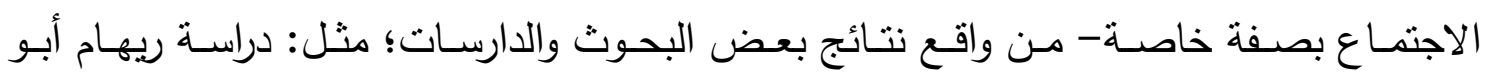

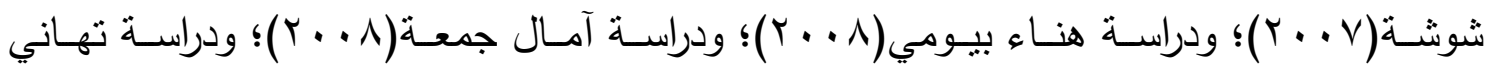

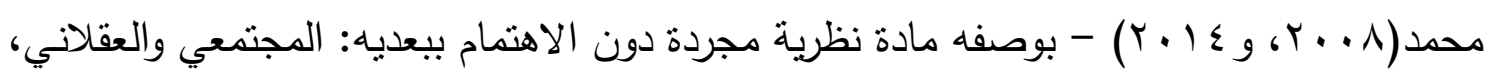

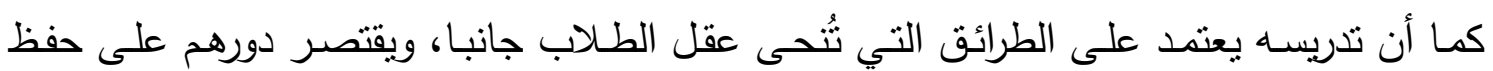

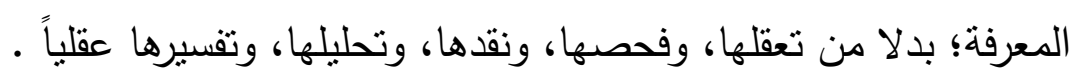

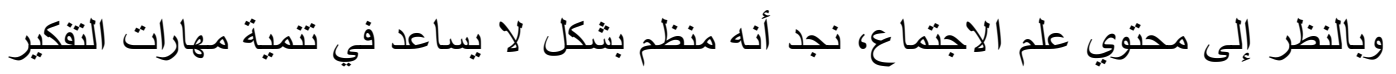

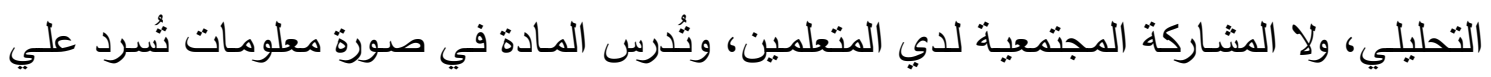
الطالب بطريقة تقليدية تلقينية لا تناعد في تحقيق ذلك؛ فلا تتعدي حدود معرفته واستفادته من المادة خارج نطاق الكتاب المدرسي. ولا تصبح المعرفة ذات معني، ووظيفة في حياته؛ فلا يقارن، ولا يستتبط، ولا يمتلك القدرة على اتخاذ القرار السليم إلي غير ذللك من مهارات التفكير الضرورية؛ مما أدي لعدم تحقيق المنهج لأهدافه.

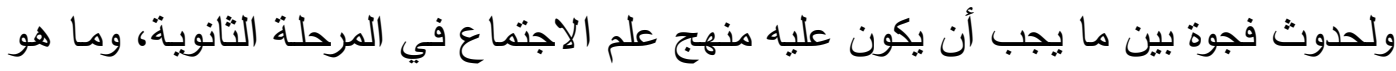

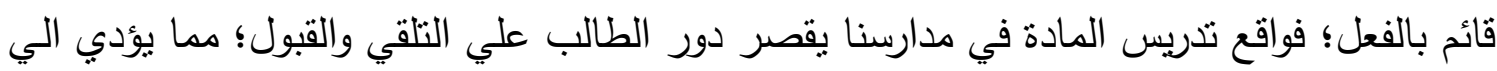

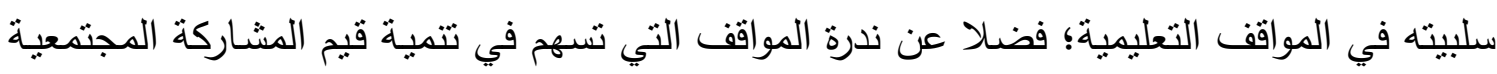

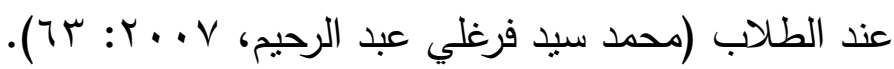

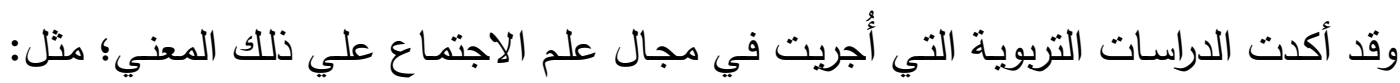

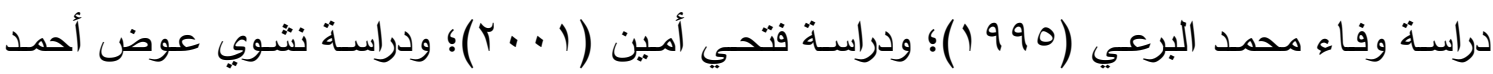

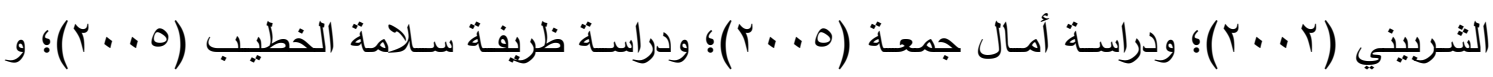

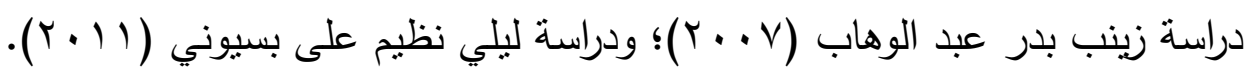

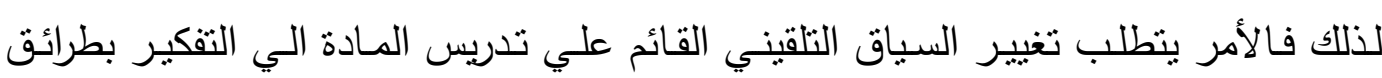

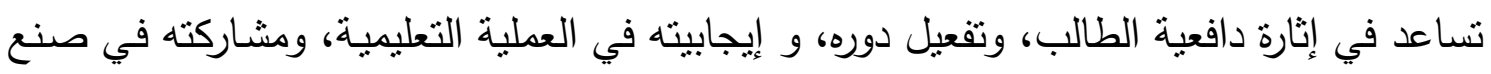

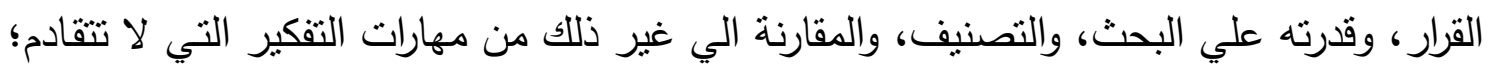

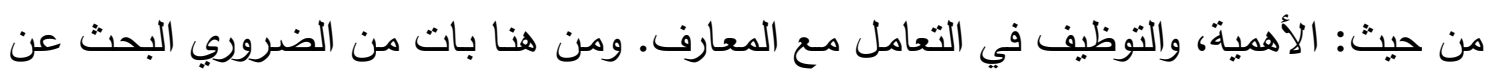

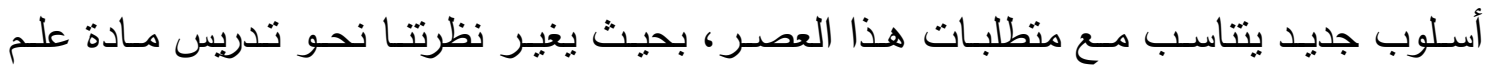

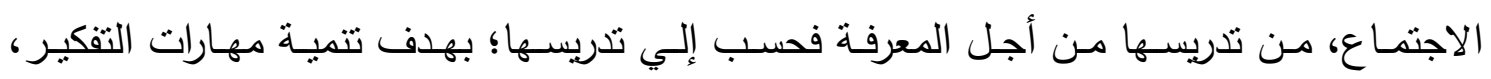

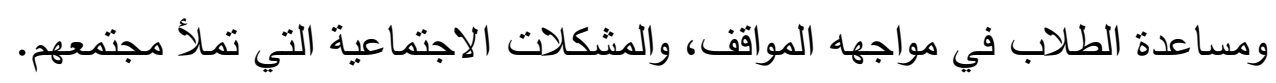

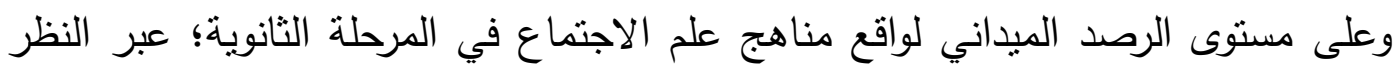

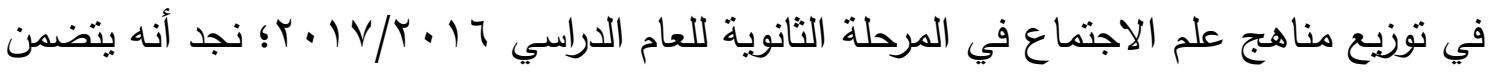

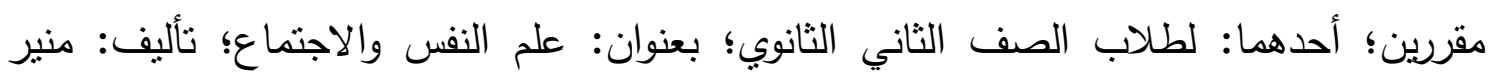


بسيوني حسن العوضي وآخرون، والثاني: لطلاب الصف الثالث الثانوي؛ بعنوان: علم النفس والاجتماع. تأليف: محمد أحمد صالح وآخرون، وقد استخدمت الباحثة أسلوب تحليل المحتوي الكيفي لموضوعات هذين المقررين (الجزء الخاص بعلم الاجتماع فقط)، وكانت فئة التحليل هي الموضوع، أو القضية؛ لمعرفة ما تحتويه هذه المقررات من موضوعات عن المشاركة المجتمعية ومهارات التفكير التحليلي، ووحدة التحليل هي الفكرة التي تدور حول قضية معينة، أو موضوع محدد؛ وقد تبين من عملية تحليل المحتوي: إغفالهما لقيم المشاركة المجتمعية ومهارات التفكير التحليلي رغم تركيز أهداف تدريسهما على كل منهما، ويمكن تفصيل ذلك فيما يلى: ا - عدم وجود أية موضوعات عن التفكير التحليلي في محتوى المقرر . ץ-الاشـارة السطحية لبعض قيم المشـاركة المجتمعية دون الاثـارة إلى مدلولها، ومعناهـا؛ فالكتابين يتعددا إغفال الدور الحيوي للثباب في النهوض بالمجتمع عبر المشاركة المجتمعية ولم يفردا بنودًا واضحة للطلاب توضـح سمن خلالها- أبعاد المشاركة المجتمعية، أو ملامحها ولكنهما قدما رصدًا لمفهمومات هذه المشكلات وأسبابها، وكيفية مواجهتها من قبل مؤسسات الدولة المختلفة دون الاشارة إلى الدور الحيوي الذي قد يؤديه الثباب في مواجهة تلك المشكلات عبر المشاركات المجتمعيـة النشطة التي قد نسـه بشكل إيجابي في تشكيل وعيهح بمشكلات مجتمعهم، وكيفيـة

مواجنها

ب-لا بطرح الكتابـان أسـئلة مفتوحسة تقيس قدرة الطالب على التفكير التحليلي، بمهاراتـه المختلفة (كالمقارنة، والتصنيف، والاستقراء، والاستتباط، وتحليل الأخطاء)، وهذا يعنى أن أسئلة كتابي علم الاجتمـاع تقليدية لا تتناسب مـع طبيعته على الإطلاق؛ مما يزيد الفجوة بين محتوى

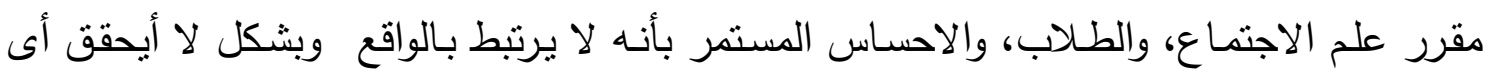
هدف من أهداف تدريس علم الاجتماع؛ وفي مقدمتها إكساب دارسيها القدرة على فهم المشكلات، وتقسيرها، وتحليلها؛ تمهيداً لمواجنتها، والتحكُم فيها.

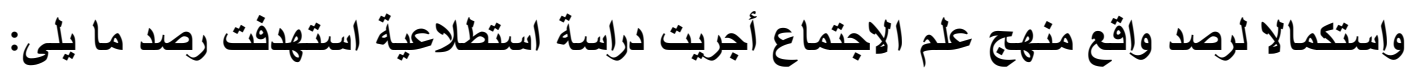
أولًا: آراء الطلاب في المرحلة الثانوية نحو مدى اهتمام منهج علم الاجتماع، وطرائق نعليمه بتتمية قيم المشاركة المجتمعية، ومهارات التفكير التحليلي لديهم. ثانيًا: آراء معلمي علم الاجتماع في المرحلة الثانوية نحو مدى اهتمام منهج علم الاجتماع، وطرائق تعليمه بتتمية قيم المشاركة المجتمعية، ومهارات التفكير التحليلي لدى طلابهم. ولتحقيق هذين الهدفين؛ صُممت استبانتان( •) تضمنتا بعدين؛ البعد الأول: يتعلق بمدى تضمين محتوى كتاب علم الاجتماع لطلاب الصفين: الثاني، والثالث الثانوبين لبعض أبعاد التفكير 
التحليلي والمشاركة المجتمعية؛ بواقع مفردة. والبعد الثاني: يتعلق بمدى نجاح(فاعلية) طرائق

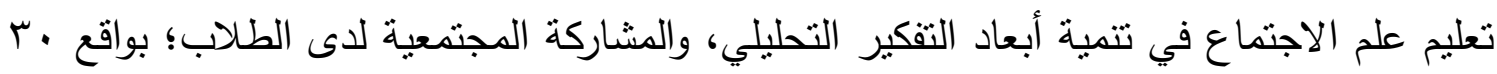
مفردة. وطبقت هاتان الاستبانتان على عدد من الطلاب والطالبات من طلاب الصاب الصفين: الثاني

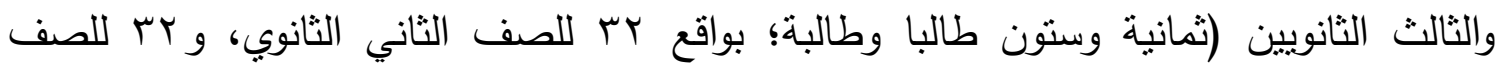

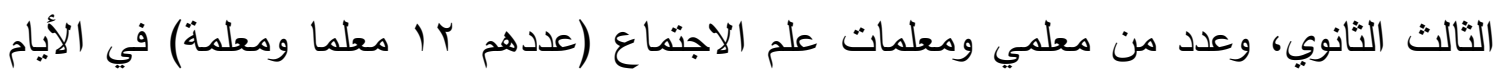

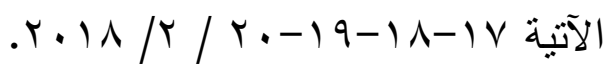

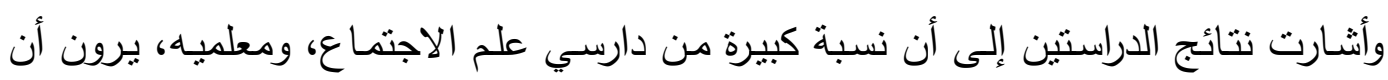

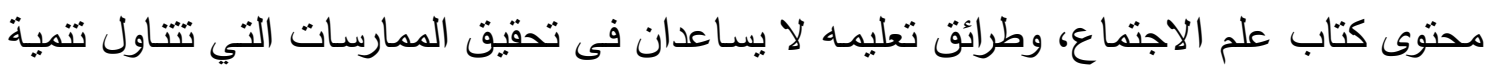
قيم المشاركة المجتمعية، ومهارات التفكير التحليلي.

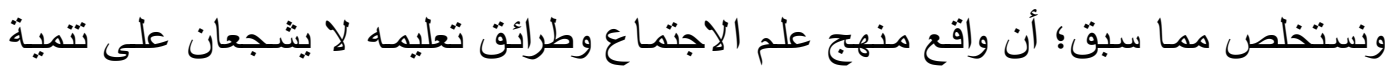

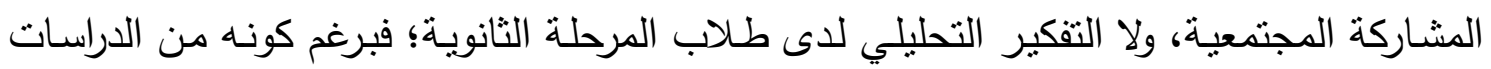

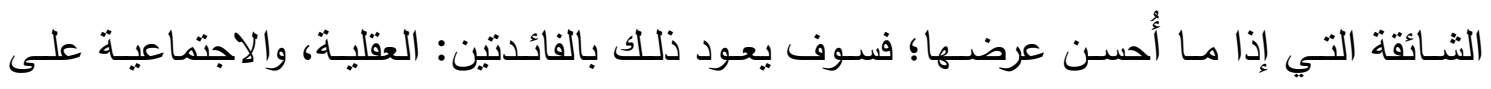

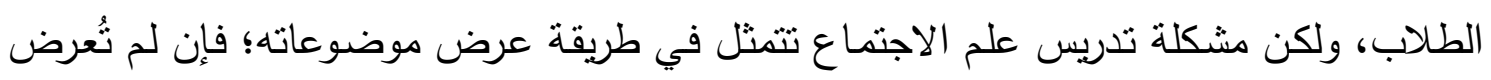

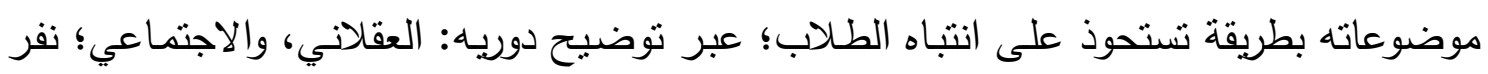
منه الطالب، ولم يستطع استيعاب موضوعاته؛ ومن ثم تفوته الفوائد العقلية والاجتماعية التي يمكن تورن أن يجنيها من دراسة علم الاجتماع. ومما سبق، يمكن صياغة مشكلة البحث في السؤال الرئيس التالي:

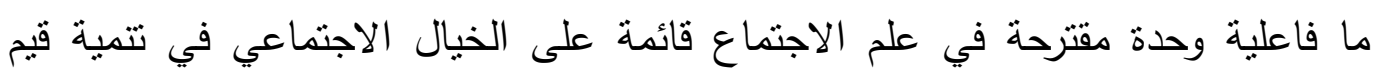

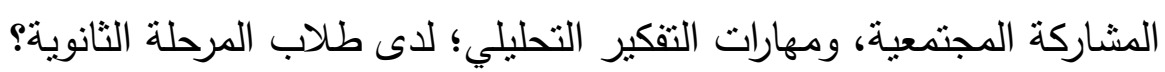
ويتفرع عن هذا السؤال الأسئلة التالية:

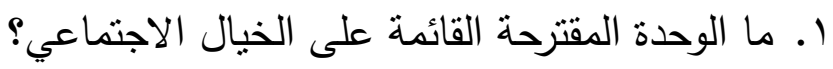

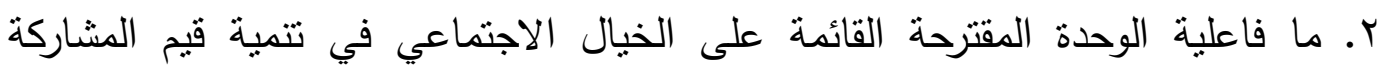

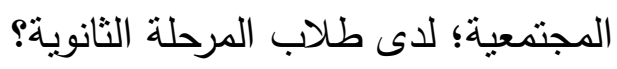
r. ما فاعلية الوحدة المقترحة القائمة على الخيال الاجتماعي في تتمية مهارات التفكير التحليلي؛ لدى طلاب المرحلة الثانوية؟ مأبه

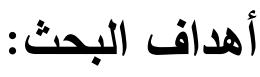
1. إعداد قائمة بأبعاد الخيال الاجتماعي. باء. r. بناء وحدة مقترحة في علم الاجتماع قائمة على الخيال الاجتماعي لدى طلئلاب المرحلة

r. تعرف تأثثر الوحدة المقترحة على تتمية قيم المشاركة المجتمعية . 
ع. تعرف تأثثر الوحدة المقترحة على تتمية مهارات التفكير التحليلي.

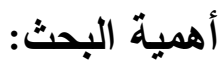

تمنلت أهمية البحث فيما يلي: البح:

1- استجابة مباشرة لكثير من توصيات البحوث والدراسات خاصة على المستوى العالمي التي

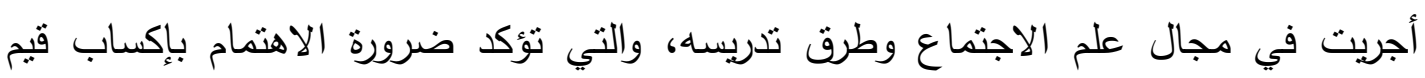

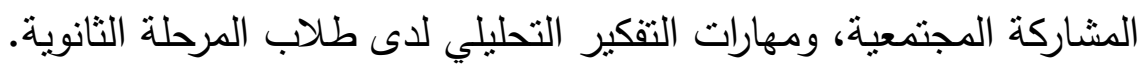

ץ- محاولة لتدريس علم الاحتماع بما يتضمنه من موضوعات شيقة ومثيرة لأذهان الطلاب في

ضوء طبيعته، وخصائص طلاب المرحلة الثانوية.

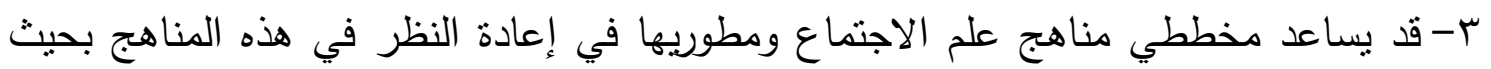
تركز على الجانب المجتمعي والتفكيري فيها.

ع- نوفر بعض أدوات القياس التربوية التي تتمنل في مقياس التفكير التحليلي، واختبار المشاركة

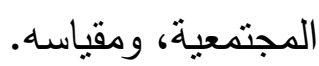

أدوات البحث، ومواده التعليمية:

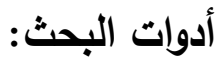

1. بائمة قيم المشاركة المجتمعية (إعداد الباحثة). r. قائمة مهارات التفكير التحليلي (إعداد الباحثة). r. بائمة أبعاد الخيال الاجتماعي (إعداد الباحثة).

ع. مقياس قيم المشاركة المجتمعية لاى طلاب المرحلة الثانوية (إعداد الباحثة). ه. اختبار قيم المشاركة المجتمعية (مواقف) لدى طلاب المرحلة الثانوية (إعداد الباحثة).

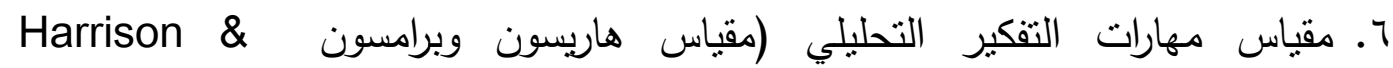

(Bramson

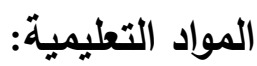

1.وحدة مقترحة في علم الاجتماع قائمة على الخيال الاجتماعي (كتاب الطالب). r.دليل المعلم في استخدام الوحدة المقترحة.

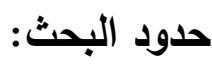

\section{يقتصر البحث الحالي على ما يلى:}

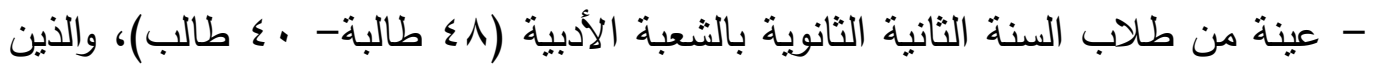
يدرسون مقرر علم الاجتماع بمدرستي ثنانوية الكويت للبنات، وحسين طه للبنين بإدارة المنتزه 


\section{منهج البحث وإجراء|ته: \\ أ- منهج البحث: البحت}

نظرًا لطبيعة البحث، وأهدافه؛ فقد استخدم البحث المنهج الوصفي في الجانب النظري من الدراسة،

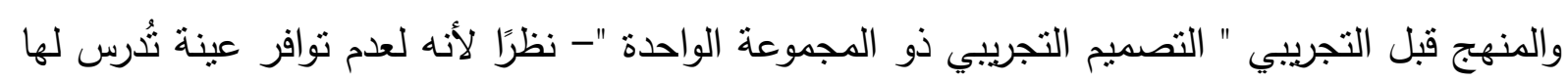
هذه الوحدة المقترحة-؛ لتعرف مدى فاعلية الوحدة المقترحة في علم الاجتماع القائمة على الخيال

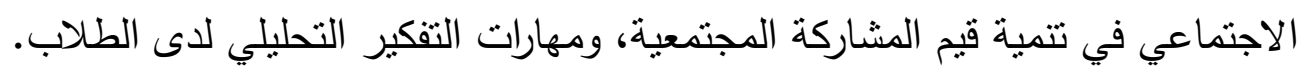

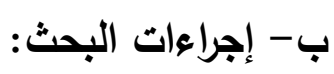

للإجابة عن تساؤلات البحث سيتبع البحث الخطوات التالية: (1) (الإطار النظري للبحث؛ ويشمل:

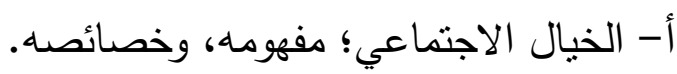

ب- المشاركة المجتمعية؛ مفهومها، وقيمها.

ج- التفكير التحليلي؛ مفهومه، ومهاراته.

د- عرض الدراسات السابقة ذات الصلة بموضوع الدراسة، ودهانه

(Y) إعداد أدوات البحث الميداني ومواده التعليمية، وتثثمل:

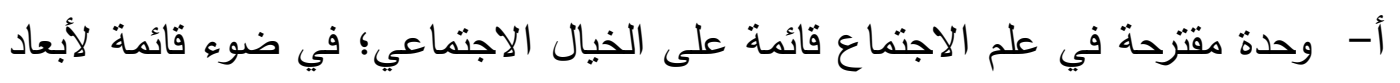

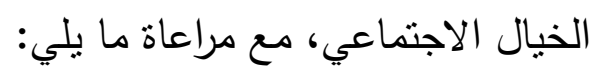

\# تحديد الغرض من دراسة الوحدة المقترحة.

| |

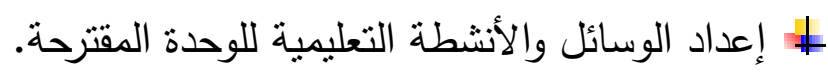

\# تحديد استراتيجيات التدريس الملائمة لموضوعات الوحدة المقترحة. \# تحديد أساليب تقويم الملائمة لموضوعات الوحدة المقترحة.

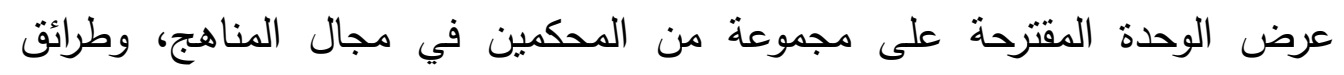

التدريس؛ للتأكد من صلاحيتها.

ب- قائمة بقيم المشاركة المجتمعية في صورتها الأولية، وعرضها على المحكمين، ثم

ضبطها في ضوء أرائهم، وإعدادها في صورتها النهائية.

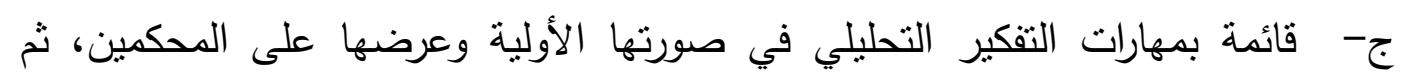
ضبطها في ضوء أرائهم، وإعدادها في صورتها النهائية. 
د- مقياس مهارات التفكير التحليلي (المقياس الفرعي للتفكير التحليلي لكل من هاريسون

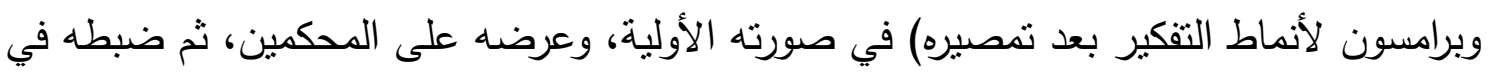
ضوء أرائهم، وإعداده في صورته النهائية.

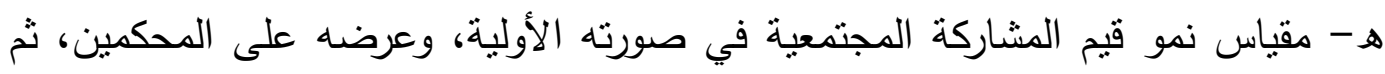
ضبطه في ضوء أراءهم، وإعداده في صورته النهائية.

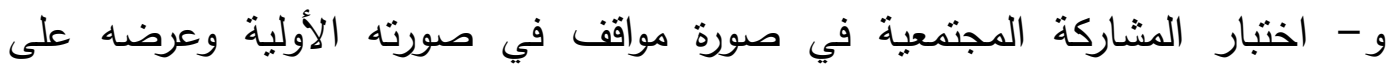
المحكمين، ثم ضبطه في ضوء أراءهم، وإعداده في صورته النهائية.

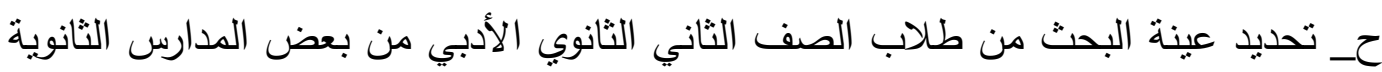
في محافظة الإسكندرية. ط - التطبيق القبلي لمقياس نمو قيم المشاركة المجتمعية، واختبار المشاركة المجتمعية (اختبار مواقف)، ومقياس مهارات التفكير التحليلي على عينة البحث؛ لتحديد مستواهم قبل التطبيق

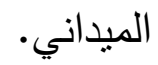
ي - النطبيق الميداني للوحدة المقترحة. ك- التطبيق البعدي لمقياس نمو قيم المشاركة، ومقياس مهارات التفكير التحليلي، واختبار المشاركة المجتمعية (اختبار مواقف) على عينة البحث، لتحديد مستواهم بعد التطبيق الميداني.

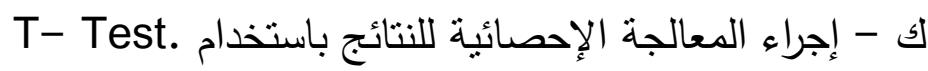

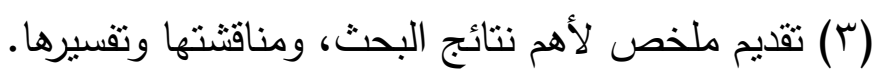
(ع) تقديم بعض التوصيات والمقترحات؛ في ضوء ما يسفر عنه البحث من نتائج.

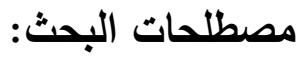

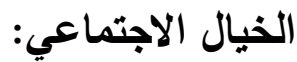

يتبنى البحث الحالي تعريف رايت ميلز Wright Mills للخيال الاجتماعي (1909) -لأنه يتمشى مع طبيعة البحث الحالي ومتغيراته - بأنه: " قدرة الفرد على فهم حياتهم (سيرهم) الذاتية عبر السياق الاجتماعي، والتاريخي الأكبر منهم، والمحيط بهم. فهو محاولة لروئية العالم من حولنا بحيث يساعد على اتخاذ قرارات شخصية أكثر حكمة وأصوب فكرًا، وأكثر فعالية في حياتتا كأفراد

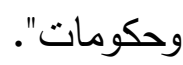

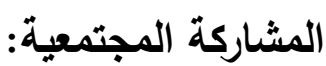

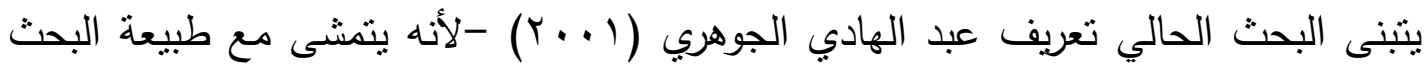

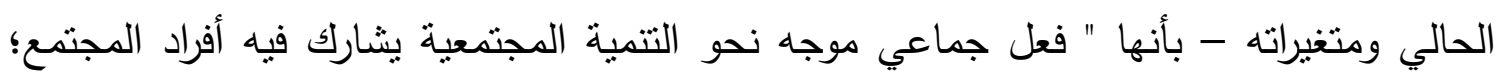

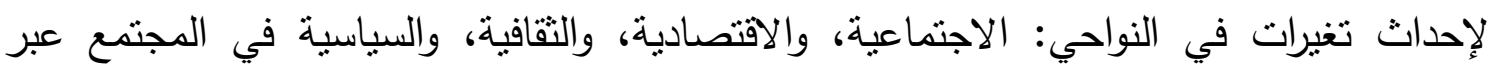
المشاركة في تحديد الأهداف، والأولويات، والموارد، ووضع الخطبة والئه المناسبة، وتتفيذها، وتقويمها. 
التفكير التحليلي:

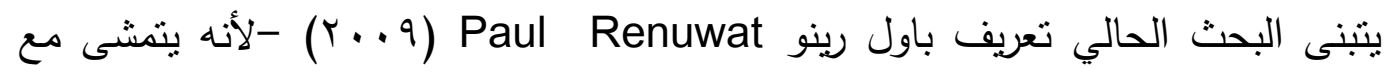
بيعة البحث الحالي ومتغيراته - بأنه " وهو القدرة العقلية التي تمكن الفرد من تفحص المشكلة، وفِكرها، وأجزائها، وحلولها، وتقسيهها إلى أجزاء، أو مكونات صغرى فرعية؛ مما يؤدى إلى فهر المشكلة بشكل أكبر".

ثانيا: الإطار التظري للبحث (الخيال الاجتماعي، والمشاركة المجتمعية، والتفكير التحيلي). ينقسم الإطار النظري إلى ثلاثنة محاور رئيسة، وهي: المحور الأول: يتضمن عرضًا لطبيعة الخيال الاجتماعي، ومفهومـه، وأبعاده، وعلاقته بعلم

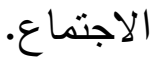

أمسا المحور الثاني: يتضمن عرضًا للمشاركة المجتمعية؛ من حيث: مفهومها، وأبعادهـا، وعلاقتها بعلم الاجتماع.

والمحور الثالث: يتضمن عرضًا للتفكير التحليلي، ومهاراته، وخصائصسه، وطرائق تتميته، وعلاقته بعلم الاجتماع. وفيما يلى تقصيل ما سبق: المحور الأول: الخيال الاجتماعي. يعرض هذا القسم مفهوم الخيال الاجتمـاعي، وأهميته، وعلاقته بعلم الاجتمـاع كعلم من الن جهة، وعلاقته به كمادة دراسية من جهة أخرى. أولا: مفهوم الخيال الاجتماعي. ينطلق مفهوم الخيال الاجتماعى من فكرة مؤداهـا أنه يستلزم فهم حياتتا الثخصية عبر السياق الاجتماعي، والتاريخي للمجتمع الذي يعيش فيه الفرد، أي الجمع بين الثخصية والتاريخية، والربط بين القضايا الكبير للمجتمع، والقضـايا الصغيرة للفرد، وبذللك يمكننا الخيال الاجتماعي من فهم التاريخ، والسير الذاتية، والعلاقات بينهما داخل المجتمع (8) : Mills, W,1959) و يعرف بأنه طريقة أو وسيلة للتفكير النقدي حول العالم تمكننا من فهم الكيفية التي يعمل بها المجتمع، وهو دراسة للمشه الاجتماعي للمجتمع الذى نعيش فيه؛ عبر دراسة الحقائق، والقوى الاجتماعية التي تؤثز علينا جميعا؛ لمعرفة معنى التغيرات التي تحدث حولنا جميعا . (Kennedy.K,2010: 4)

كما أنه نمط غير تقليدي من التفكير الإبداعي يُمكن الفرد من النظر للظاهرة الاجتماعية بوصـفها نتاجًا لعوامـل اجتماعيـة محددة نسـتلزم البحثث، ومحاولـة فهم الأسباب الخفيـة الثقافيـة، والاجتماعية، والاقتصادية التي تمارس تأثيرات متتوعة على الحياة الاجتماعية داخل المجتمع؛ ومن ثم تؤثر في حياتهم الثخصية(Abe, K,2008) 320) 
كما يعد نمط من التفكير الذي يساعد الأفراد فى ممارسة التقييم النقدي للأحداث التي تجري

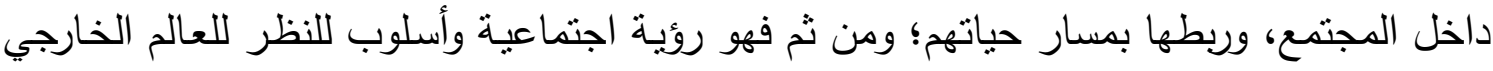

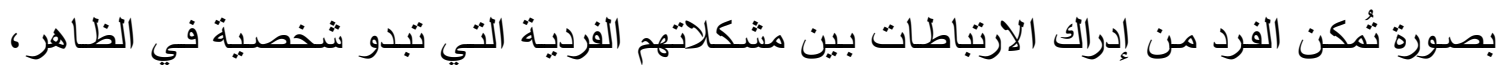
ولكنها اجتماعية، أو مجتمعية في باطنها (Germov, J , 2009:13 ). ويعرفه رايت ميلز Wright Mills بأنه: محاولـة تسـاعدنا في التمييز بين المشكلات الثخصية، والقضايا العامة في المجتمع؛ فالخيال الاجتماعي يربط بين حياتتا، وتجاربنا الثخصية،

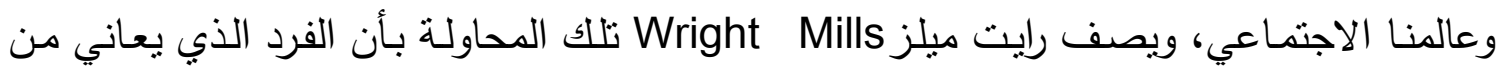
بعض المشكلات الثخصية؛ فإنها حتما تقع ضمن نطاق علاقاته مع الآخرين، وطبيعة المشكلات

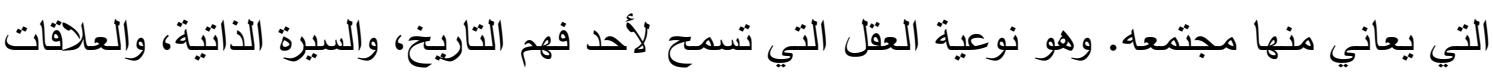
بين الاثثين داخل المجتمع (8) : Mills, W, 2000). ويتخذ جيم كميني Jim Kemeny من التعريف السابق للخيال الاجتماعي تعريفًا يوثق

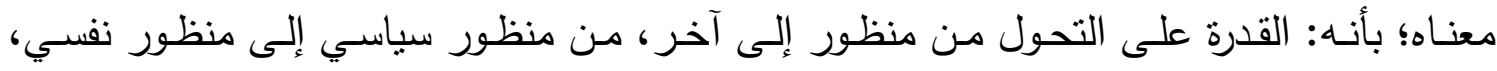

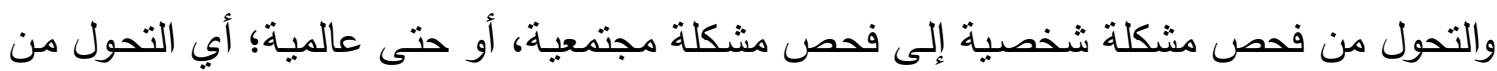

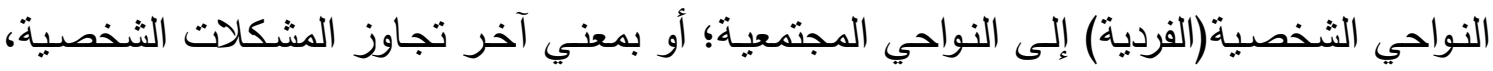

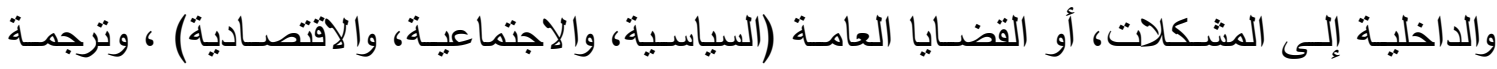
البيئات الثخصية إلى هياكل اجتماعية واسعة النطاق؛ بحيث تتداخل فيها هذه البيئات، وتتتـابك؛ لتشكل الهيكل الأوسع للحياة الاجتماعية، والتاريخية (Kemeny, J, 2008: 12 ). ويضرب لنا رايت ميلز Wright Mills عرض مشكلة البطالة، فالفرد العاطل عن العمل يعتبر ذلك مشكلته الثخصية، وحل بطالته ينطوي

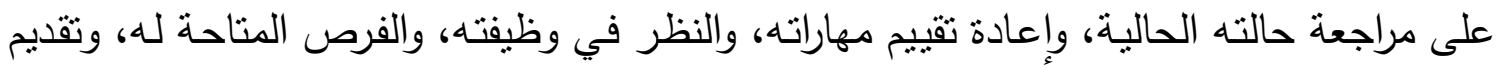
السيرة الذاتية له لأرباب العمل مرة أخري؛ فإذا توفرت له وظيفة جديدة فمشكلته قد حلت، ولكن ماذا

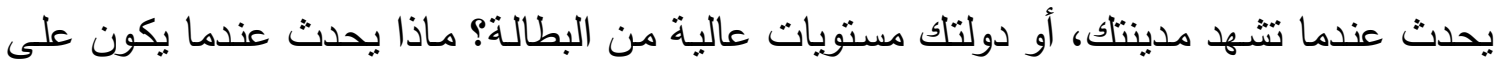

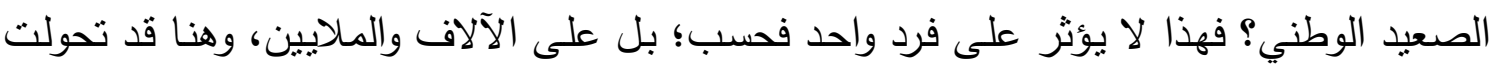

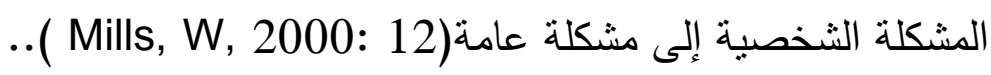
باستقراء التعريفات السابقة نجد الخيال الاجتماعي يساعد الفرد في قبول مشكلاته دون أدني

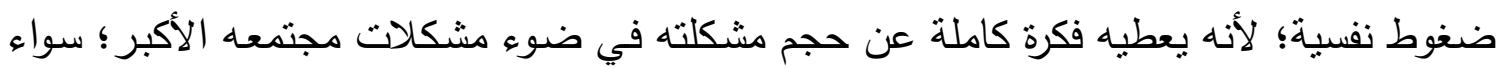

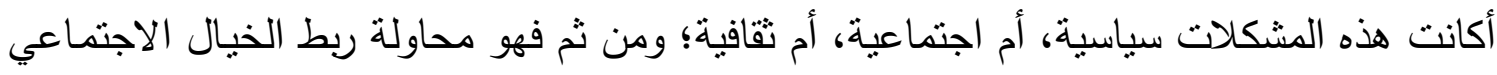

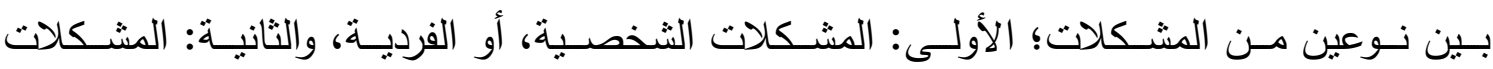


يسهم الخيال الاجتماعي بمجموعة من الفوائد للأفراد، أو الطلاب؛ ومن بينها:

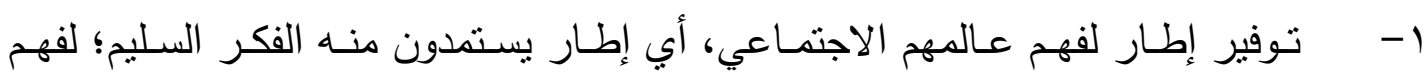
تجاربهم الاجتماعية الدحدودة.

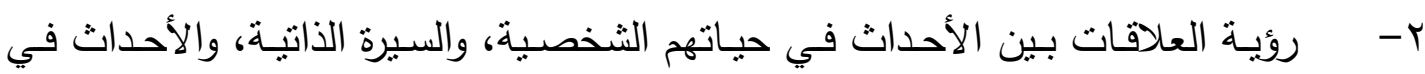
مجتمعهم والتاريخ؛ وبذلك يوفر القدرة للأفراد على إدراك العلاقة بين تجاربهم الثخصية،

ومجتمعهم.

ץ- تعليم الأفراد التمييز بين المستويات الثخصية، والاجتماعية في حياتتا. ع - - - ماتخاذ الخيارات، أو القرارات الثخصية الأفضل.

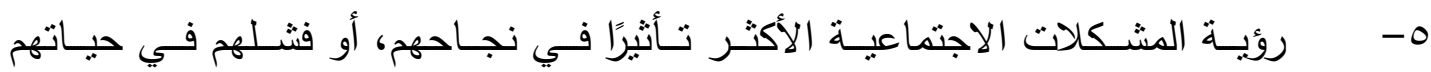

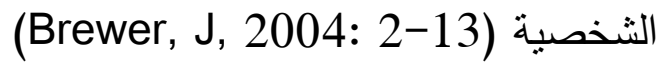
وهناك مجموعة من الفوائد الأخرى للخيال الاجتماعي، فهو بسههم فيما يلي:

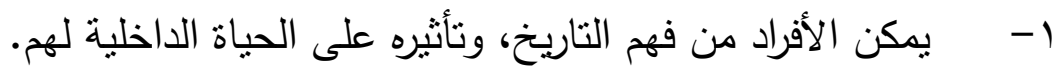

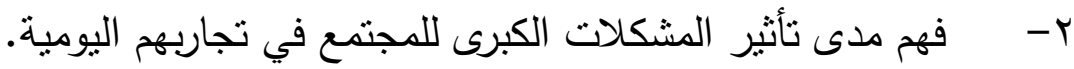

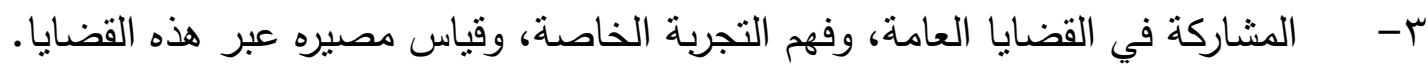

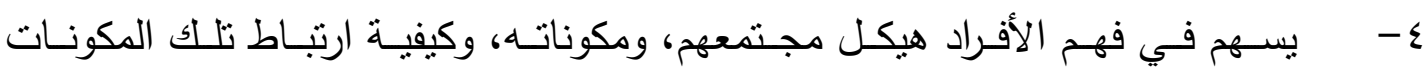
ببعضها،وكيف تختلف النظم الاجتماعية عن بعضها، وأسباب استمرارها، أو تغيرها. 0- - فهم ما يجرى في العالم، وما يجرى في أنفسهم كنقاط دقيقة من تقاطع سيرهم الذاتية

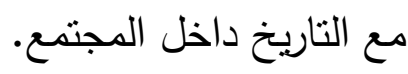
1- يجعل من البيئة الاجتماعية المحلية الخاصة بهم مجالا مفتوحا لتجاربهم الثخصية. V-يحرر الفرد من شعور اللامبالاة، وقيم السلبية، ويسعى به نحو حل مشكلاته الثخصية.

(Glenn, L,2009: 65)

ويمكن حصر فوائد أخري للخيال الاجتماعي بالنسبة للطلاب- كما وُرَدت في عديد من الكتابات، والأدبيات المرتبطة بهذا المجال - في العناصر الآتية: 1- الارتقاء بالوعي الاجتماعي للطلاب: حيث يسهم الخيال الاجتماعي في مساعدة الطلاب الابه

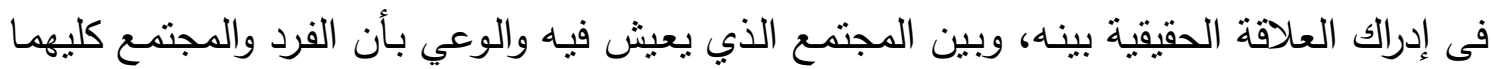

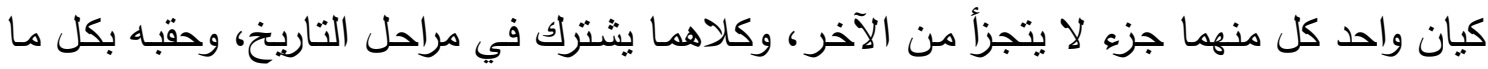

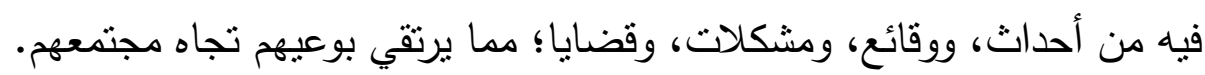

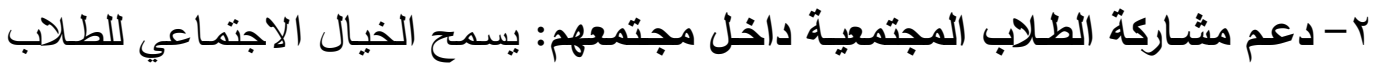
بتجاوز حدود واقعهم الثخصي، وخبراتهم الثخصية إلى فهم القضايا العامة في مجتمعه، وفهم 
أحداث الحياة اليومية؛ مما يشجعه على المشاركة الاجتماعية، أو المتمعية الفعالة في مواجهة تلاك المشكلات، والمساهمة في حلها. ب- تنمية التفكير التحليلي للطلاب: يعد الخيال الاجتماعي نوعًا من التفكير التحليلي فهو عملية مستمرة تتضمن تحليل كافة الأوجه المختلفة من الخبرات، والتفاعلات الإنسانية المتغيرة. ع - تنمية القدرة على نقد الواقع الاجتماعي الراهن: يسهم الخيال الاجتماعي في توجيه

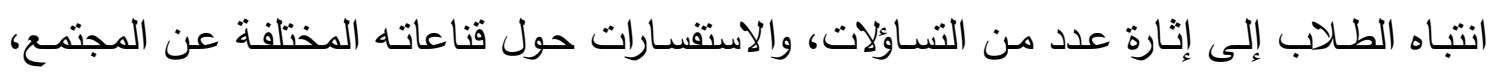
ويساعد ذلك في ممارسة التفكير الناقد لكل ما يدور حولهم من قضايا، ووقائع، وأحداث.

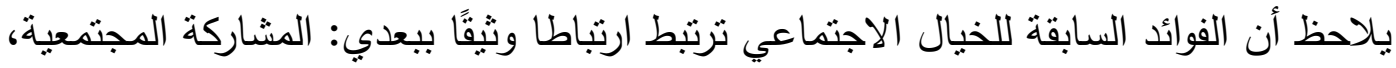
والتفكير التحليلي، وهذا هو الهدف من البحث الحالي أن يستخدم الخيال الاجتماعي في تتمية أبعاد

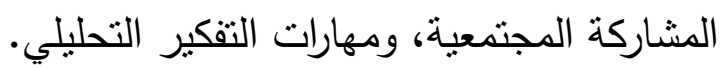

(Hartmann, D,2009:32-33,Brewer,J,2004:7,Sharky,S,2005:56) ثالثا: أبعاد الخيال الاجتماعي.

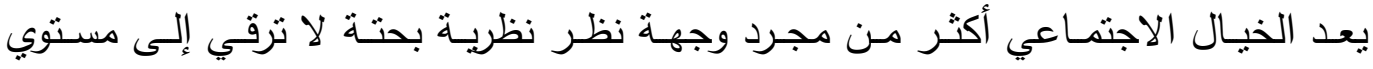

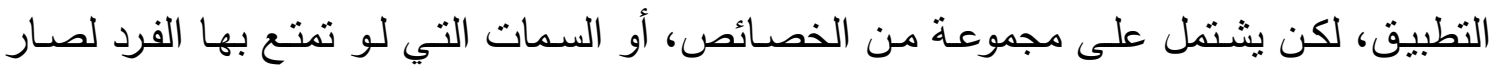

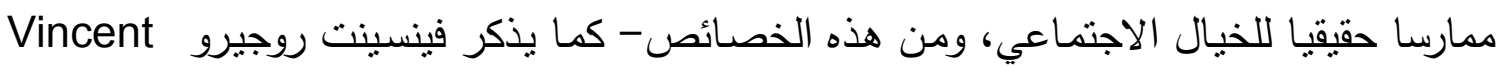
-Ruggiero 1- النقد: عدم التمسك بالمعتقدات الخاصة (المتوارثة)، وإخضاعها للنقد. r- استخدام الجدل: تقييم جوانب كل حجة؛ بدلا من الاتفاق معها فورًا، ومن جانب واحد.

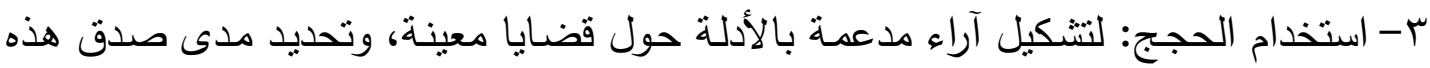

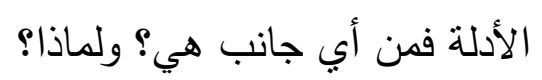

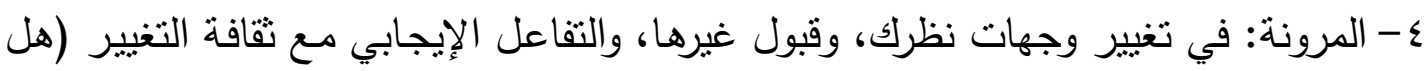

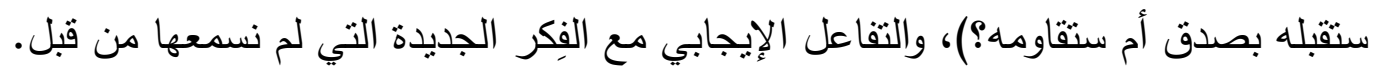

$$
\text { 0- التقكير بوعي، واستجواب المعتقدات، ونقدها. }
$$

ووفق ما سبق، يعد التحلي بتلك الخصائص مؤشرات نساعد الفرد فى التفكير وفق مبادئ

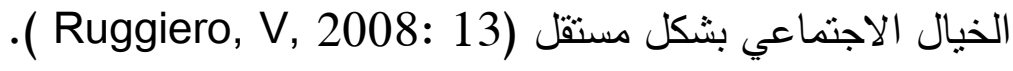

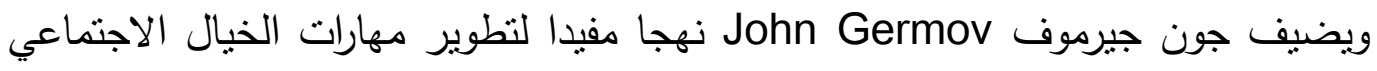
ويتبع ذللك بخطوات للتفسير الاجتماعي للقضايا الاجتماعية؛ وهي:

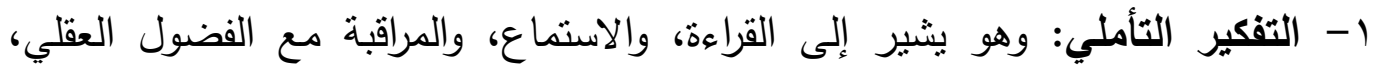

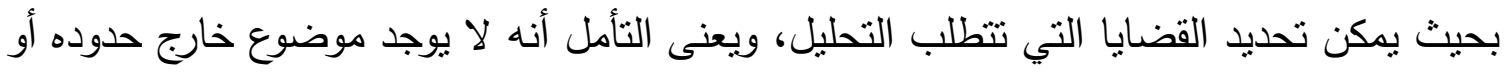

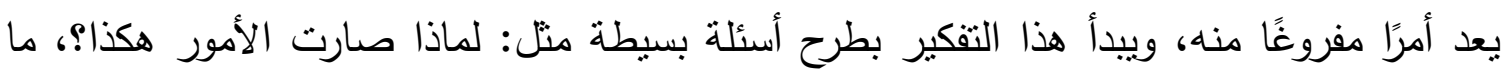


العلاقات القائمة بين مختلف الأجزاء؟، ما وجهات النظر البديلة الموجودة؟، كيف يمكن تحسين

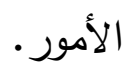

r- التفكير الإبداعي: وهو يشير إلى إنتاج الفكر لحل هذه القضايا، وهو بذلك ينطوي

على استخدام الدفهومات والنظريات المساعدة وتكيفها وإنشائها لثرح ما يحدث.

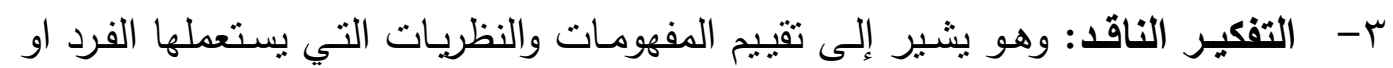

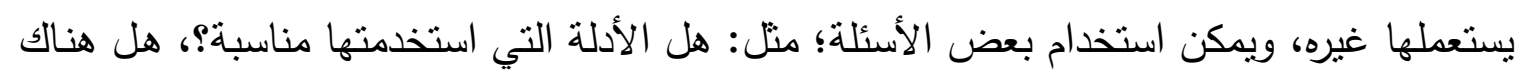

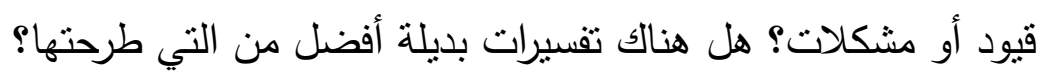

(Germov, J, 2009: 17-18)

ويشير رايت ميلز Wright Mills إلي أن هناك عددا من العوامل التي يمكن من خلالهاتحفيز مهارات الخيال الاجتماعي؛ ومنها: 1- تحقيـق المسـتوى الأكثر تحديـا: يجب عندا: على الفرد إعـادة ترتيب ملفاته (معلوماتـه

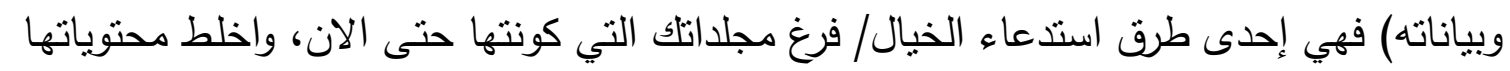

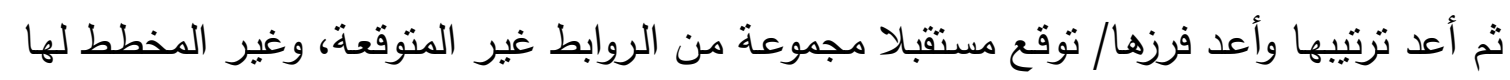

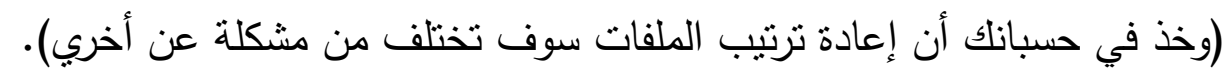

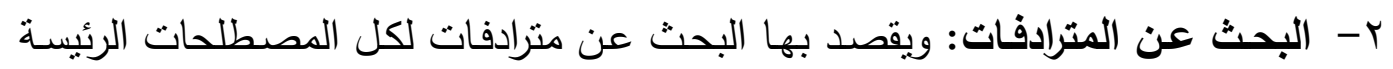
الخاصة بك في القواميس، وفى الكتب المتخصصة؛ لتعرف دلالاتها؛ لأن تحديد دلالاتها يوضح مضمون المشكلة، ومن ثم تحديدها.

r- التصنيف المنهجي للفِكر/ إجراء المقارنات: ويتم ذلك عبر تقسيم العناصر بحسب

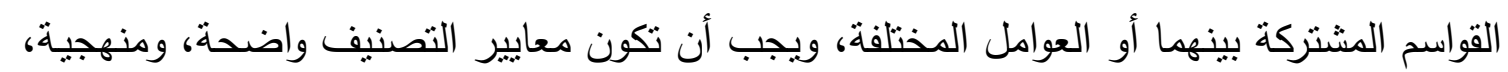
ويمكن استخدام بعض الوسائل؛ لتوضيح ذلك التصنيف عبر المخططات البصرية، والرسوم البيانية

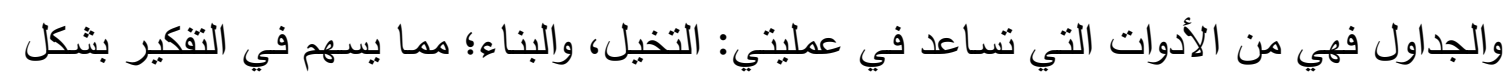

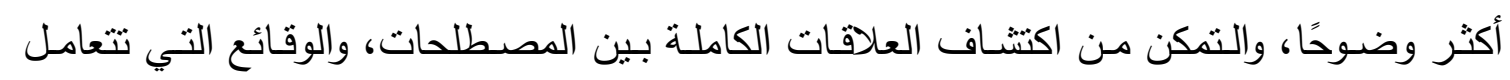
معها.

ع - التحليل النوعي للفِكر: وهنا يُطلق العنان للخيال، والتتبؤ، والتوقع للعقبات، أو الأزمات

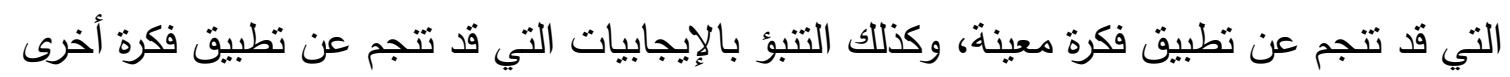
(الفكرة وضدها).

ه- الحصول على أفضل الفِكر: وذلك عبر النظر في الفِكر المتتاقضة، أو الفكرة وعكسها

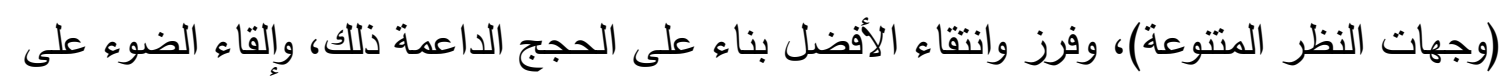
مدى منطقتيها، وسلامتها بالنسبة لباقي الفِكر (28- Mills, W, 2000 ). 


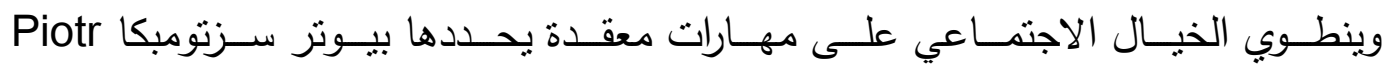
Sztompka

1 - بوية جميع الظواهر الاجتماعية التي تتتج عن بعض العوامل الفردية، أو الجماعية.

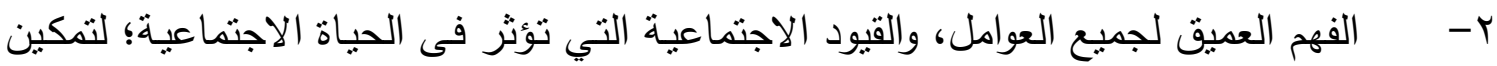
الأفراد من إدراك البنية الاجتماعية الخفية، وغير المرئية.

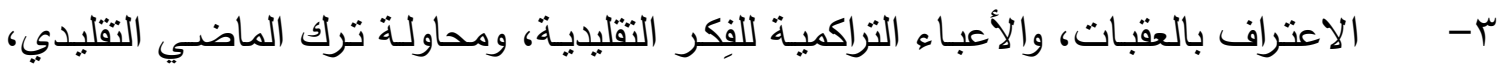

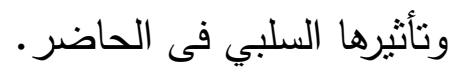
ع - النظر إلى الحياة الاجتماعية بوصفها عملية مستمرة دينامية. o- الاعتراف بالتتوع الهائل في أنماط الحياة الاجتماعية، وأثكالها

(Sztompka , P ,2006: 26)

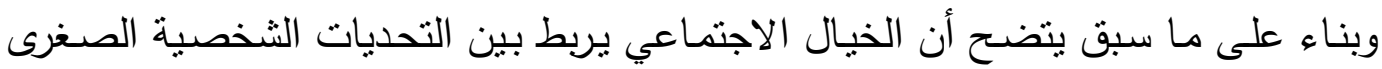

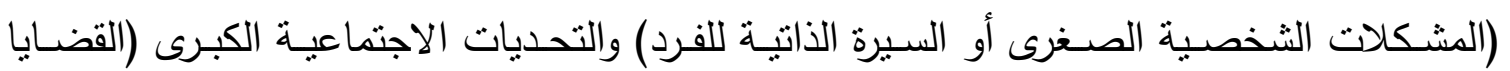
الاجتماعية الكبرى أو التاريخ).

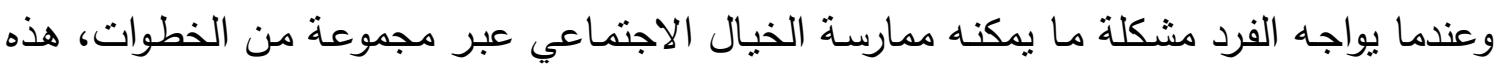
الخطوات تكمن داخلها مهارات الخيال الاجتماعي، وهي: 1- تحديد المفهومات، أو التعريفات التي تعبر عن وعي الأياعي، وهي الأفراد بالموضوع، أو المشكلة

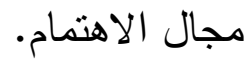
ץ- تحديـ العلاقـات المنطقيـة بين هذه المفهومـات، وتلكك العناصـر على المستويين: الثخصي، وعلى المستوى الاجتماعي (وهي جوهر الخيال الاجتماعي).

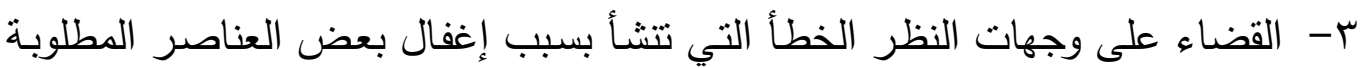
والتعريفات غير السليمة، أو المصطلحات غير الواضحة، والتركيز على مـا هو مهم، ومرتبط بالمشكلة فحسب.

ع - إعادة طرح الأسئلة؛ لتعرف الوقائع المتبقية، والتي لم يُتطرق إلى دراستها، أو فحصها. (Mills, M, 1959: 28-34)

رابعا: الخيال الاجتماعي، وعلاقته بطلم الاجتماع (كمجال - كمادة دراسية):

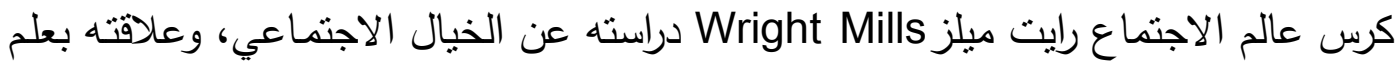

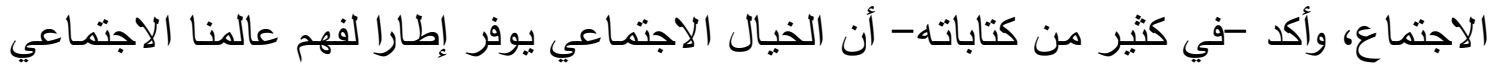
الذي يفوق كثيرًا الاعتماد على الحس، والذي يعتمد عليه البعض في تجاربهم الاجتماعية الدحدودة.

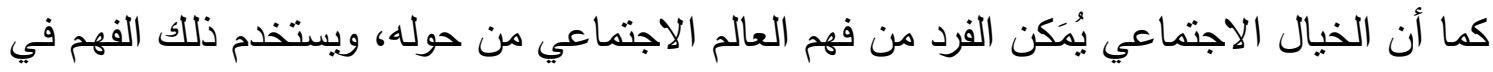

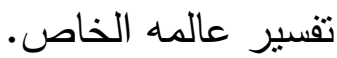


وهناك ارتباط وثيق بين الخيال الاجتماعي، وعلم الاجتماع؛ حيث يُعد الخيال الاجتماعي-

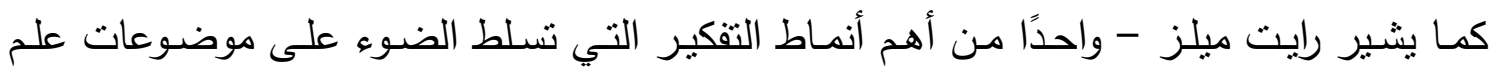

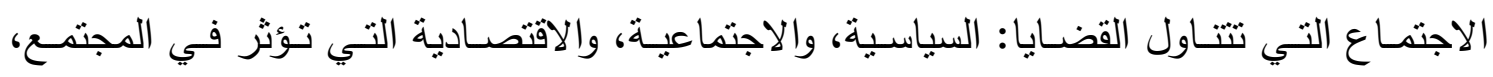

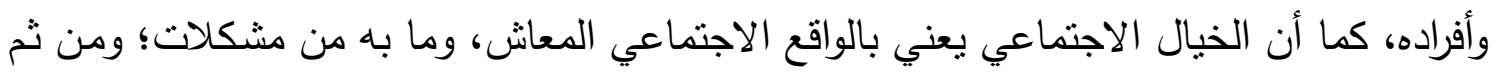

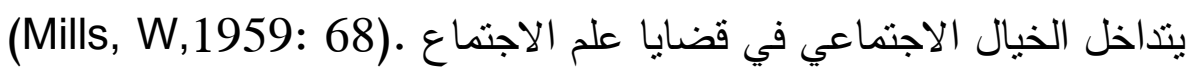

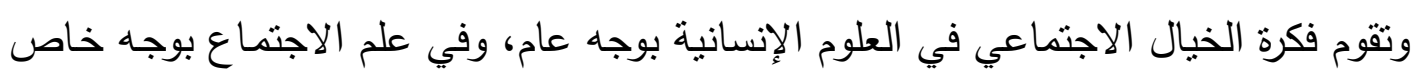

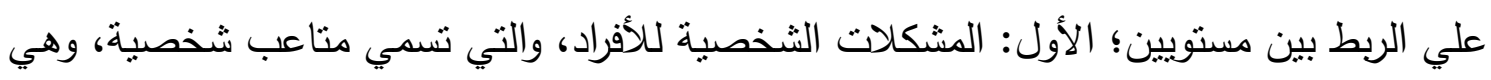

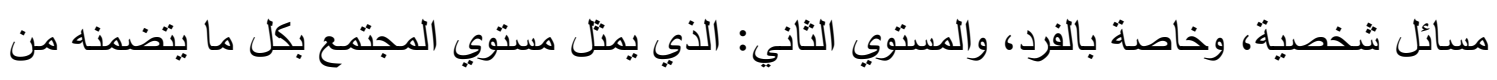

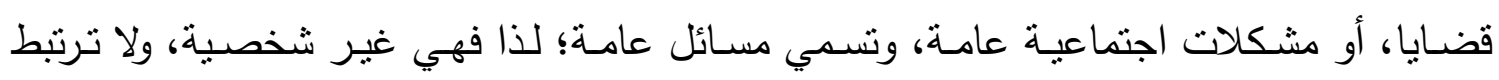
بشخص ما، وإنما ترتبط بينية المجتمع، وعملياته( Burawoy, M, 2010 (356 ).

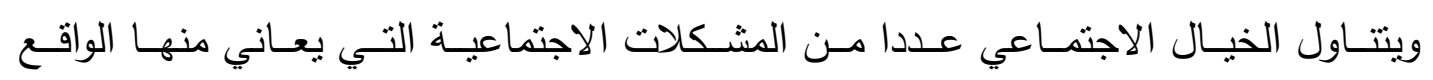

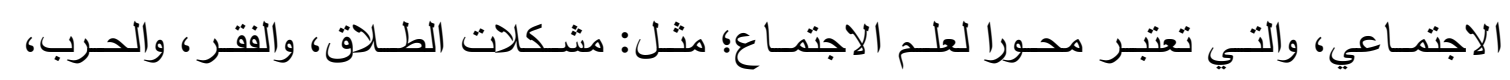

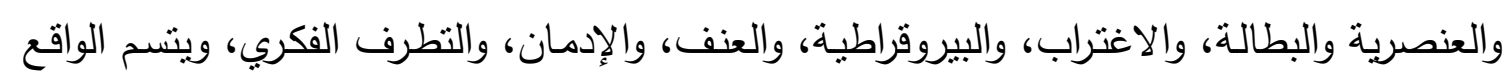

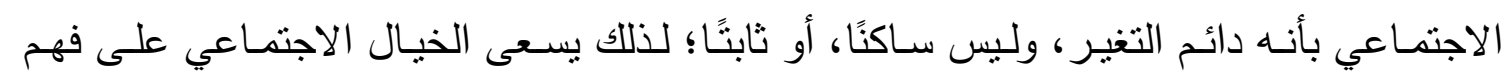

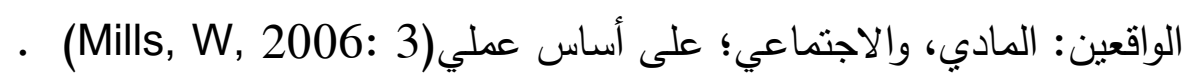

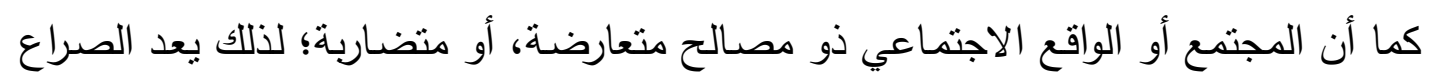

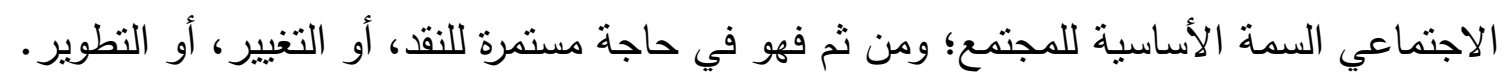

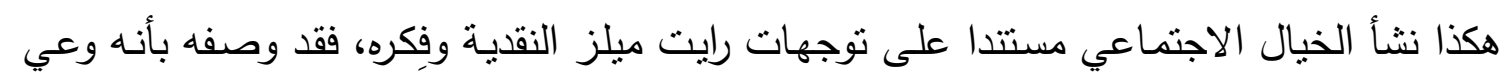

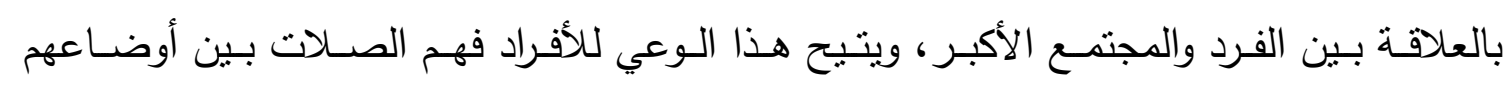

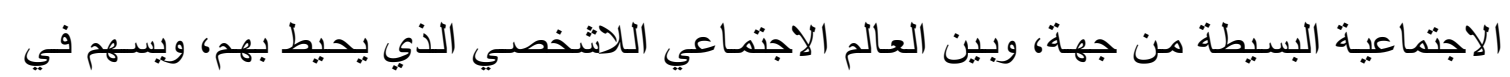

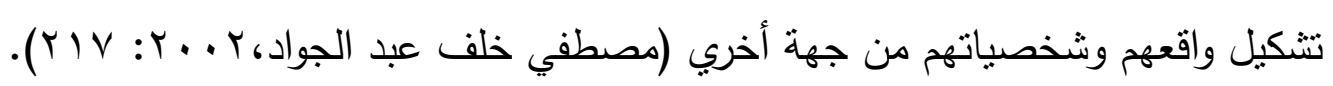

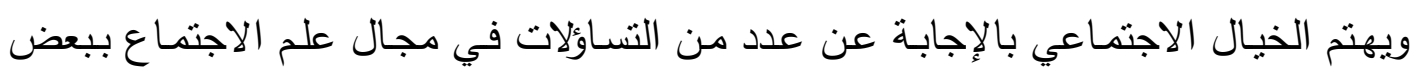

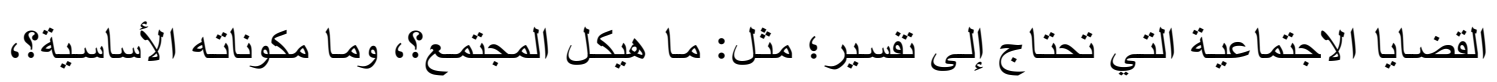

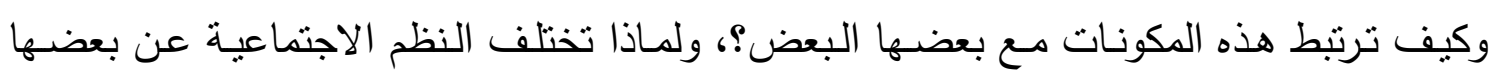

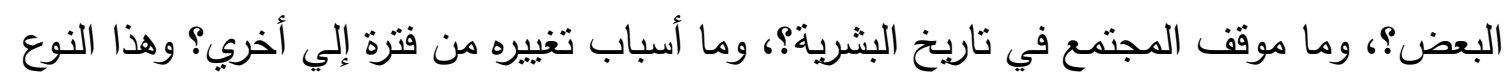

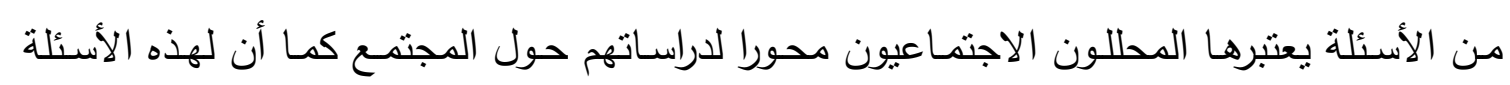
تأثثرها فى العقل الذي يمارس الخيال الاجتماعي( Mills, W, 2006) ـ

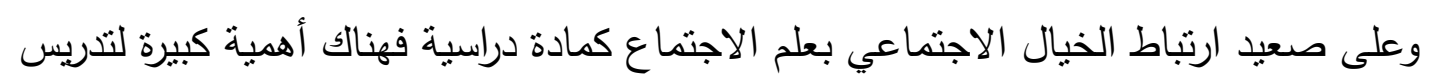

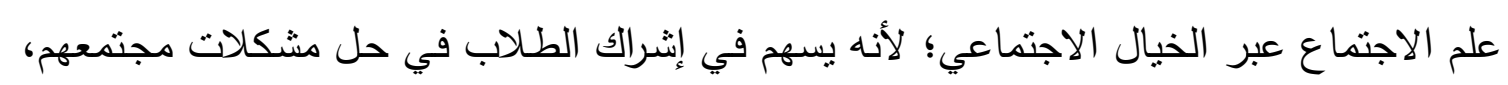

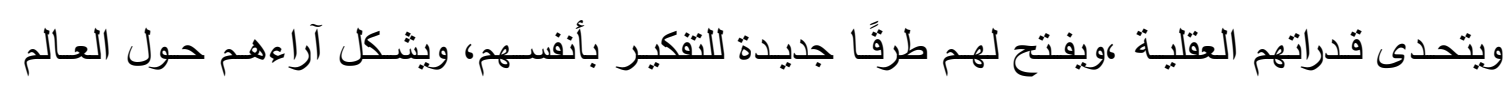


الاجتماعي، كما أنه يعطي قيمة تربوية كبيرة لدروس علم الاجتماع، كما أن علم الاجتماع بعطي

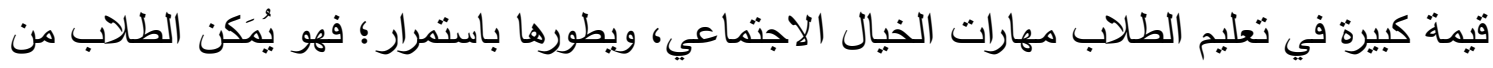
تحويل تركيزهم من القضايا الثخصية الداخلية إلى القضايا: التاريخية، والتقافية، والهيكلية الداخلية

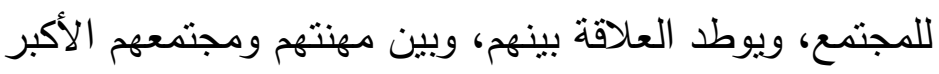

.(Swift, V.A,D, 2009: 18-20)

كما أن تدريس علم الاجتماع عبر الخيال الاجتماعي يسهم في توضيح طبيعة علم الاجتماع،

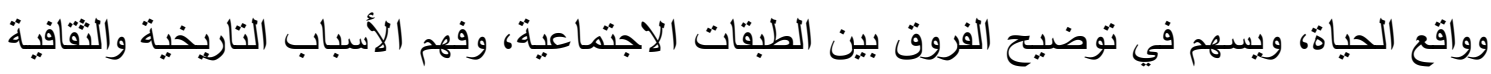

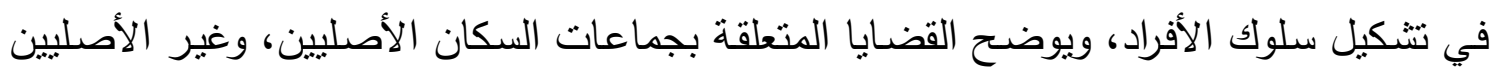

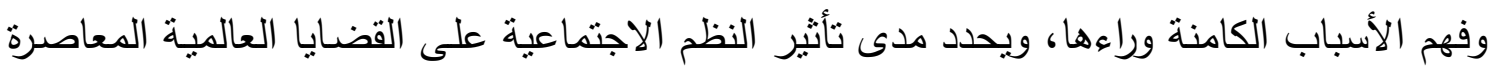
بما في ذللك الإنسان، وقضايا حقوق الإنسان.

(Bigelow, B \& Christensen, L, 2013: 1-3)

وتظهر العلاقة الوثيقة بين الخيال الاجتمـاعي، ودراسـة علم الاجتمـاع عبر منح الفرص

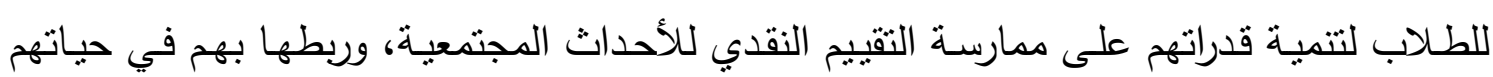

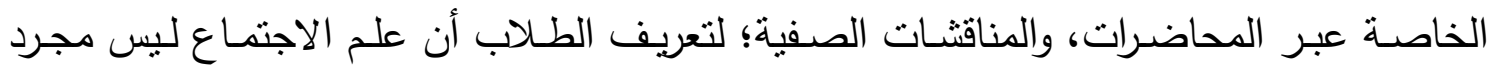

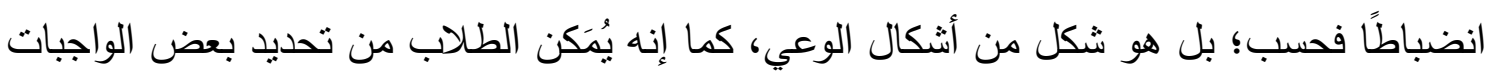

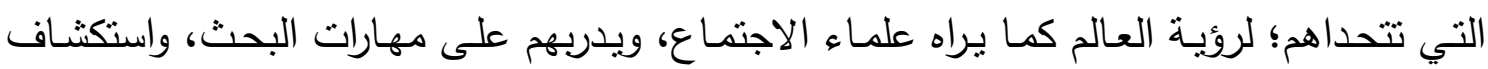

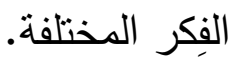

(Duarte, F, 2006: 4-5)

كما أن دراسة علم الاجتماع تساعد الطلاب في اكتثاف خيالهم الاجتماعي الذي يسهم بدوره في الربط بين مشكلاتهم اليومية، ومشكلات الواقع الاجتماعية، ويطور من أنماط تفكيرهم، وذللك

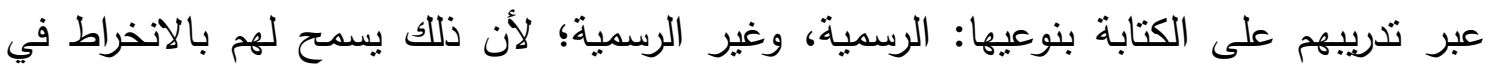

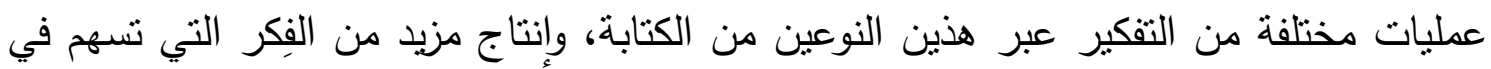
حل عديد من الشكلات الاجتماعية.

(Millar, D.L,B,2008: 2-3)

وهناك عديد من الدراسات التي أكدت علي أهمية الخيال الاجتماعي؛ فقد هدفت دراسة فرناندا

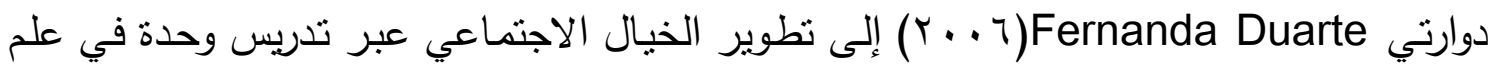

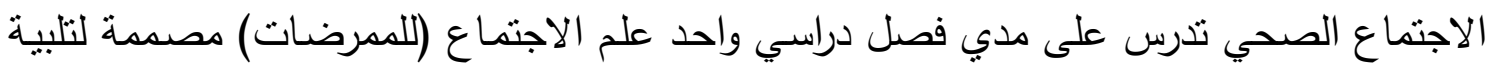

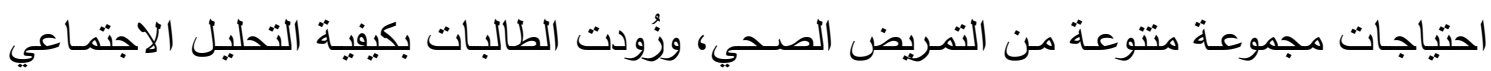

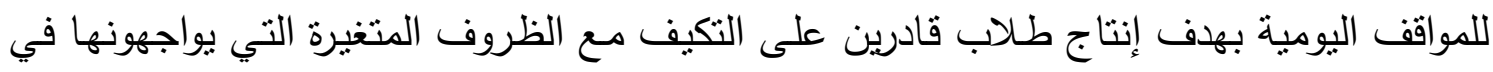
العالم المعاصر، والتي يدعمها الخيال الاجتماعي. 
وهدفت دراسة لي د. ميلار بيدويل Bidwell Leed. Millar (2008) إلى تدريس الخيال

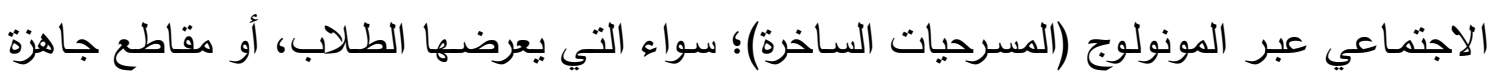

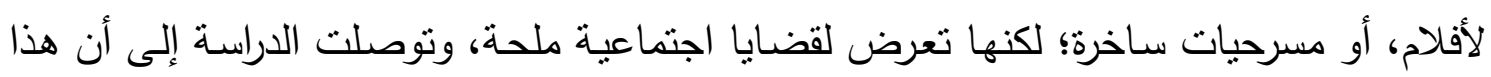

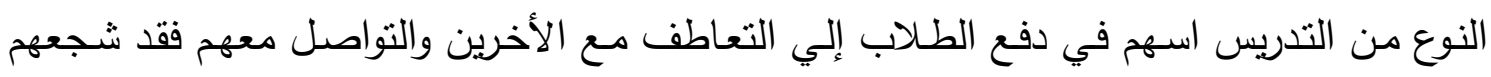

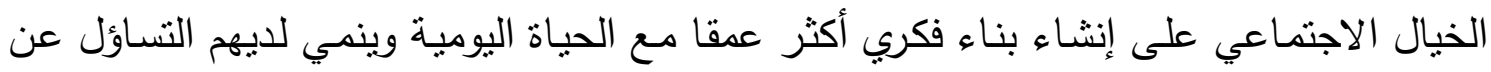

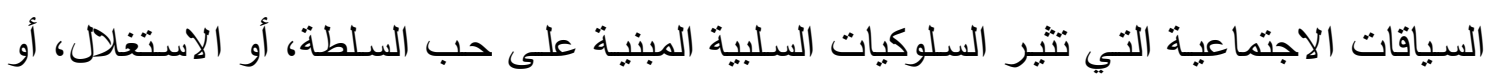

كما هدفت دراسة جوان زاليسكي و فيرا زينل Joan Zaleski and Vera Zinnel (• ( † )

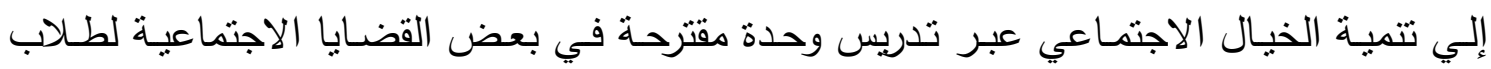

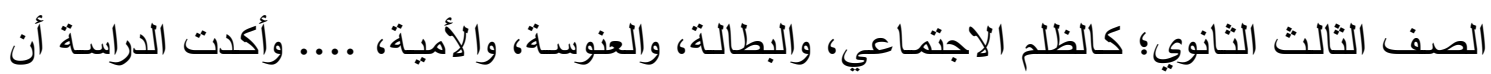
موضوعات علم الاجتماع، ومشكلاته المختلفة كانت مجال خصب، والئه واسطع شجع على تتمية الخيال

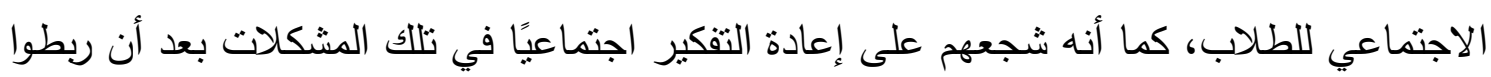
بينها، وبين مشكلاتهم الخاصة.

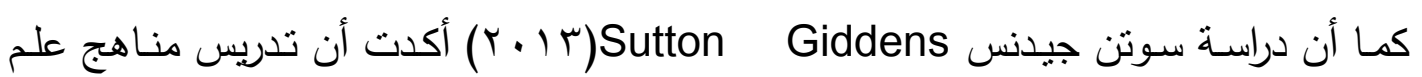

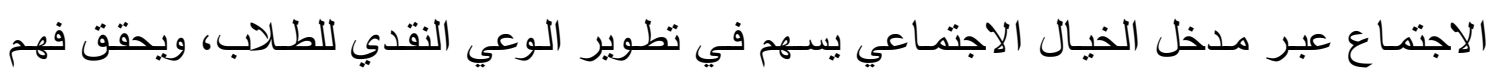
القضـايا في السياقين: المحلي، والعالمي، ويبنى قدرات الطلاب في التفكير في المجتمـع بطريقة

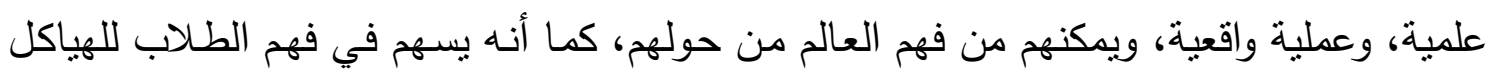
الاجتماعية، والمؤسسات المجتمعية التي تتؤثر في مستقبلهم الاجتماعي بشكل مستتبر ، ومسؤول.

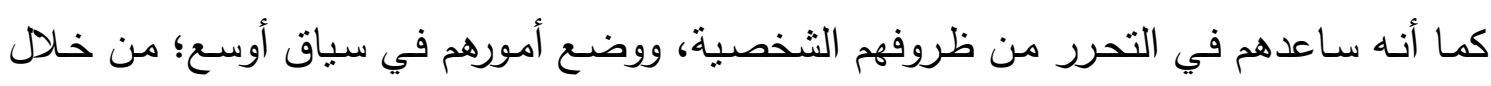

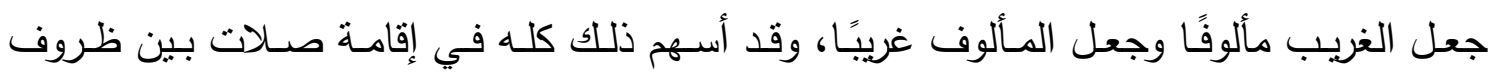
الطلاب الخاصة، والقضايا العامة، وعزز مسؤوليتهم الأخلاقية، والاجتماعية.

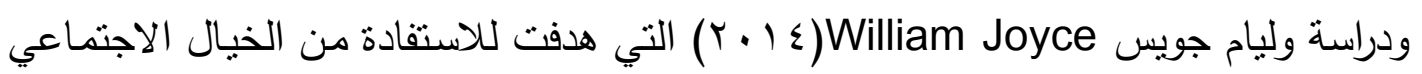

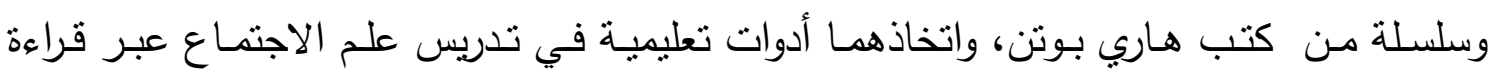

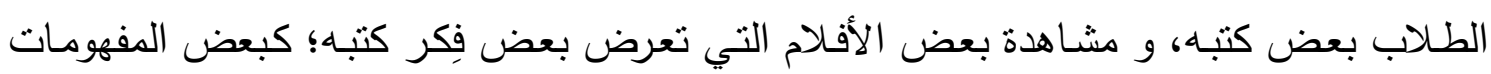

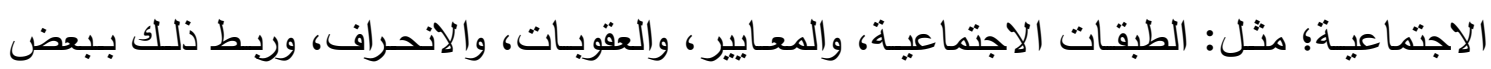

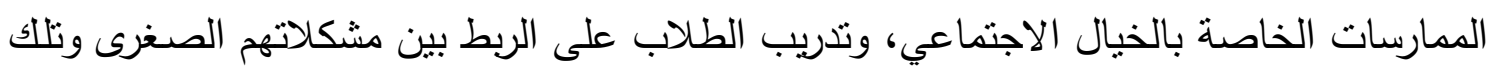

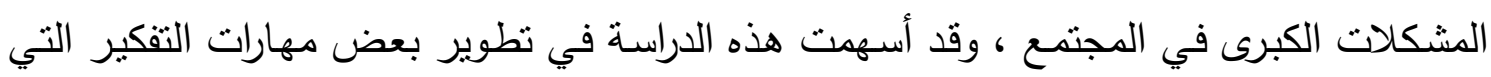

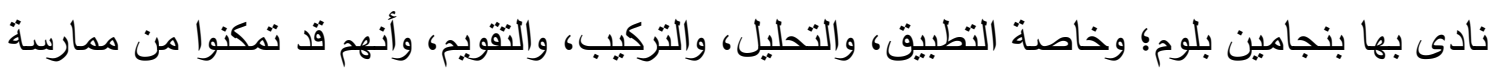

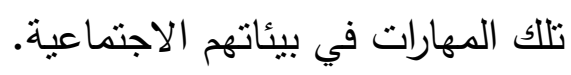


المحور الثاني: المشاركة المجتمعية:

يعرض هذا القسم مفهوم المشاركة المجتمعية، وأهينها، ومستوياتها، وصورها، واتجاهاتها،

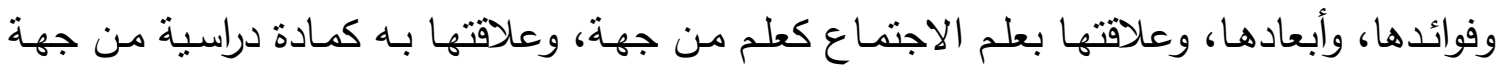
أخرى.

أولا: مفهوم المشاركة المجتمعية:

إن تحقيـق مفهوم الششـاركة المجتمعيـة يعتمـــ بشكل كبيـر - على الفاعليـات الثـعبية،

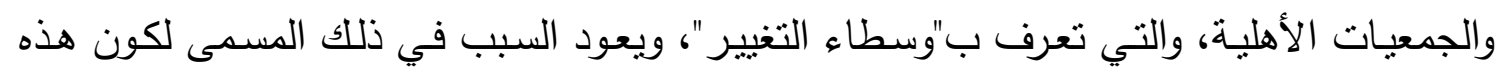

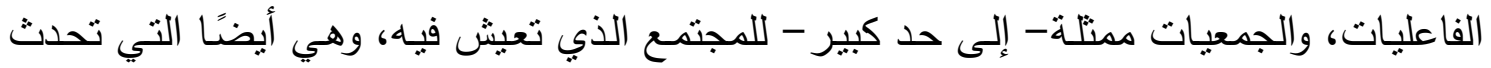

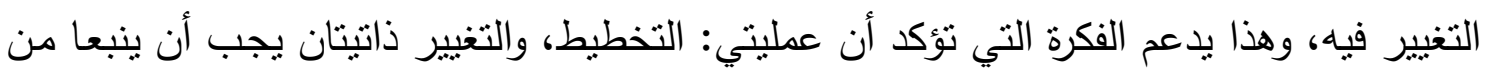

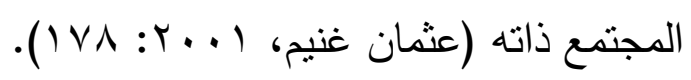

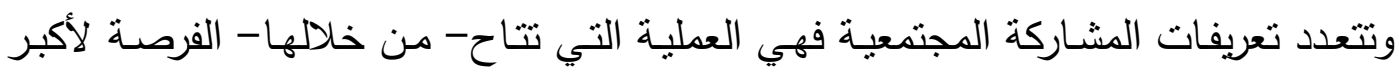

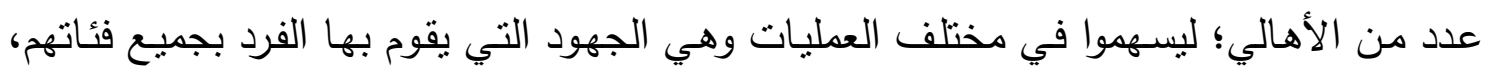
ومؤسسات المجتمع المدني في مجالي: التخطيط، والتقييم.

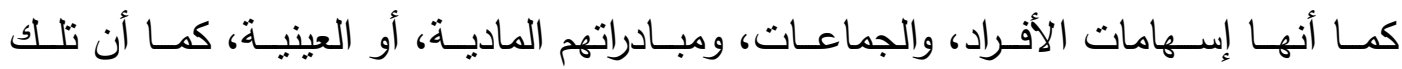

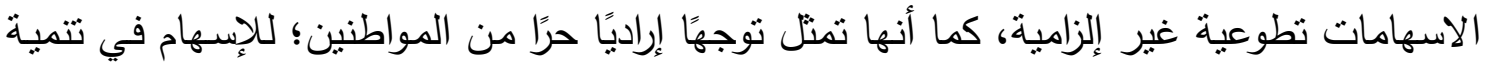

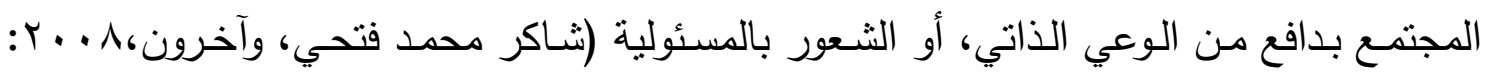

كما أنها مجموعة الجهود التي يقوم بها الأفراد بجميع فئاتهم، ومؤسسات المجتمع المدني في

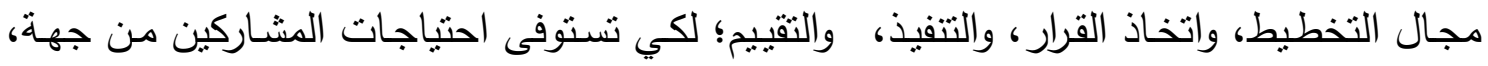

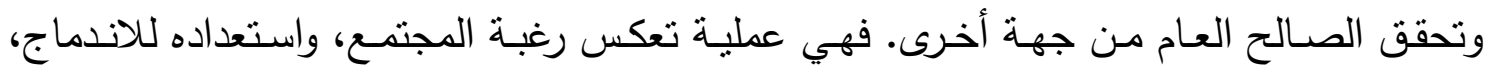

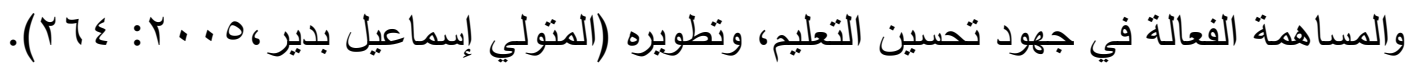

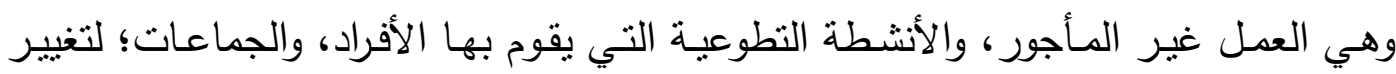

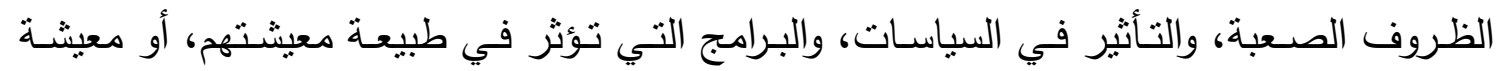

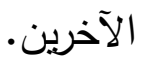

(Weil, G, 2007: 28)

وتعرف بأنها: "كافـة الإسـهامات، والمبادرات، والجهود التطوعيـة غير الملزمـة التي تتيح

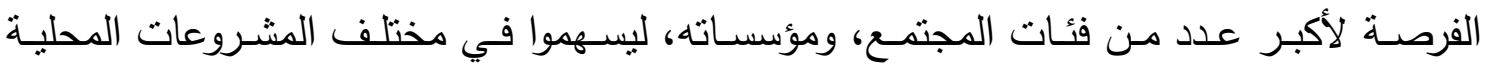

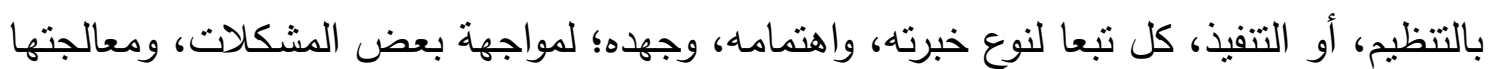

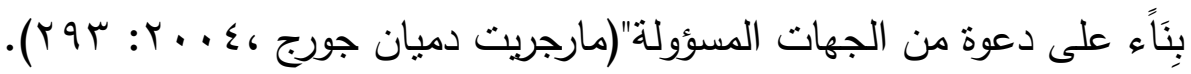




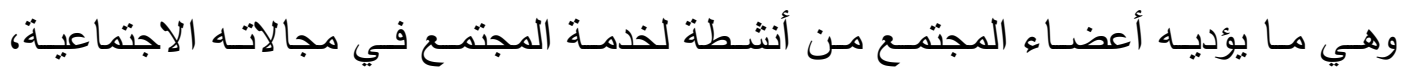

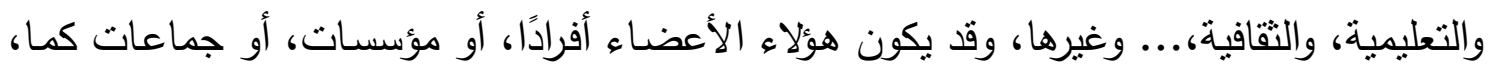

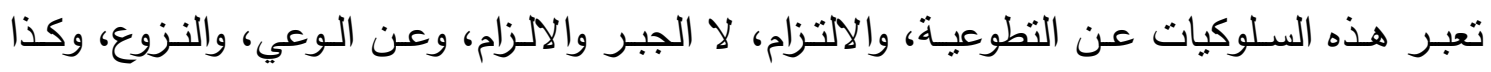

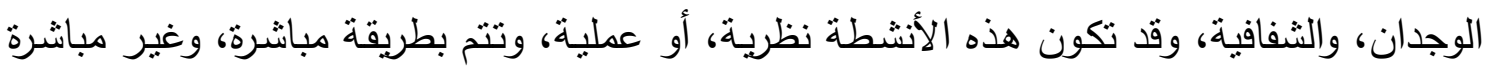

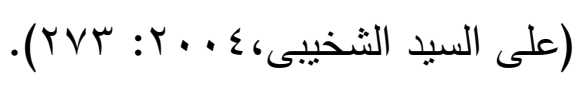

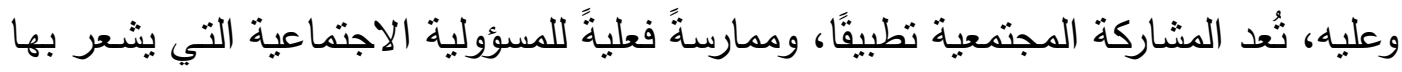

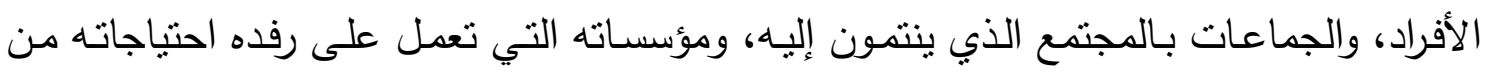

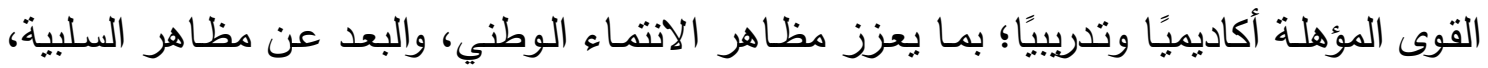

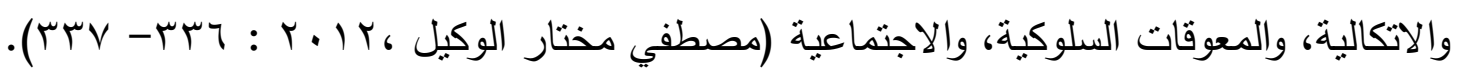

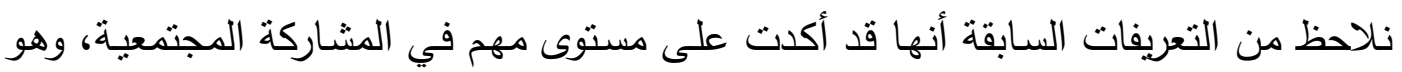
النطوع في تقديم الاسهامات المختلفة للأثخاص لصـالح المجتمع. كما أنها تعد تعبيرا تطبيقيًا

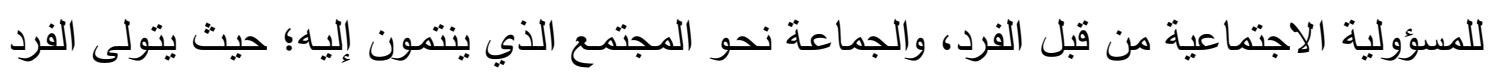

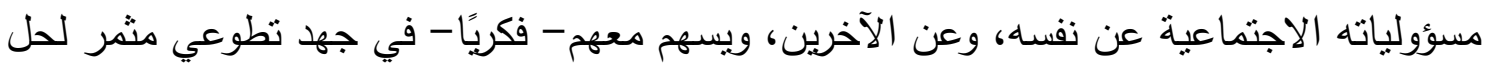
بعض قضايا المجتمع، ومشكلاته.

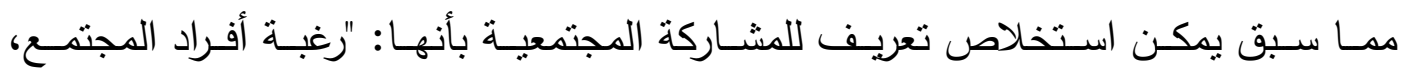
واستعدادهم للمشاركة الفعالة في تحسين بعض الخدمات الموجودة في محيط تواجدهم؛ كالمساهمة

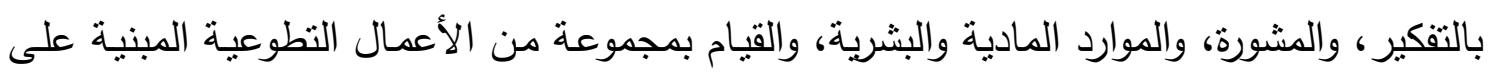
الثعور بالمسؤوليتين: الفردية، والجماعية في عمليات التخطيط، والتتفيذ، واتخاذ القرار . ثانيا: أهمية المشاركة المجتمعية:

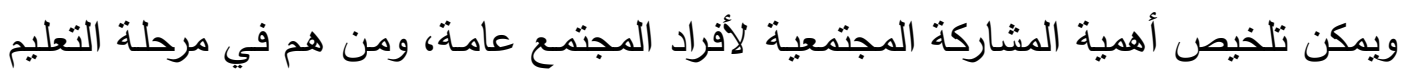

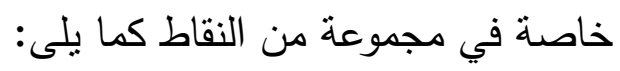
1- تحقيق المشاركة الفعالة التي هي مبدأ أساسي من مبادئ لأئ التتمية؛ فالتتمية الحقيقية لا تتم إلا عبر توافر المشاركة الثعبية. ץ-زيـادة وعسى الطـلاب بكثير مـن القضـايا المجتمعيـة؛ كـالعنف، والإدمـان، والاغتراب...،

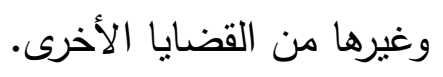
r- غـرس عـد مـن القيم الاجتماعيـة، والإنسـانية؛ مثنل: المواطنـة، والاتنــاء، والمســولية

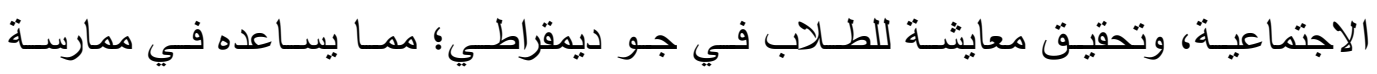

$$
\text { الديمقراطية في كافة نواحى حياته. }
$$

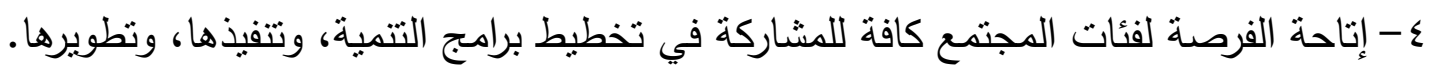
ه- تعليم الطلاب كيفية حل مشكلاتهم المتعلقة بالمجتمع المحلى الذي ينتمون إليه. 
7- انتراك الطلاب فعليا في عمليات التتمية، يسهم في مساندتهم لتلك العمليات، ومؤازرتها؛ مما يجعلها أكثر ثبانًا، وأعم فائدة.

V- تعليم الطلاب بعض المهارات الاجتماعية، والكفايات، والقدرات التي نسهم في نجاحهم

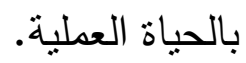

^- دعم القيم الإيجابية نحو الأسرة، والمدرسة، والمجتمع ككل.

9- تحقيق المساهمة الفعلية في ترشيد الإنفاق الحكومي.

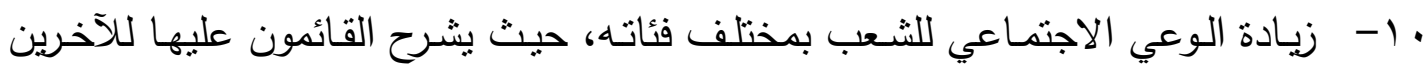

مجموعة الخدمات، والمشروعات المجتمعية التي يمكنهم الاشتراك فيها.

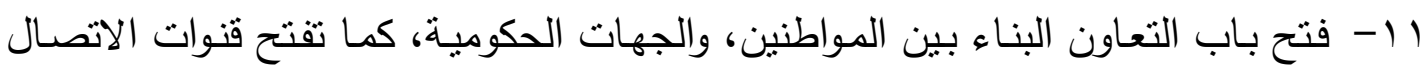

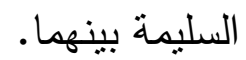

r إ- إدراك المواطنين لحجم مشكلاتهم، والإمكانات المتاحة لحلها.

با ا-تدعيم وتكميل دور الحكومة في بعض الخدمات، والمشروعات النطوعية.

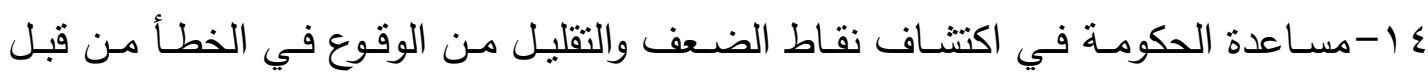

المسؤولين التنفيذيين؛ حيث إن ذلك بمنزلة صمام أمان أمام أية احتمالات للانحراف.

10-نعود المواطنين المحافظة على المال العام للدولة.

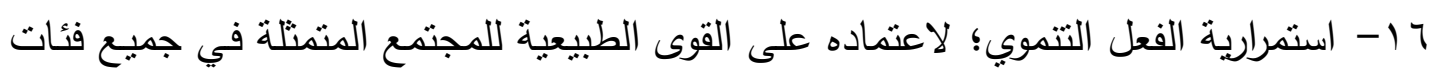

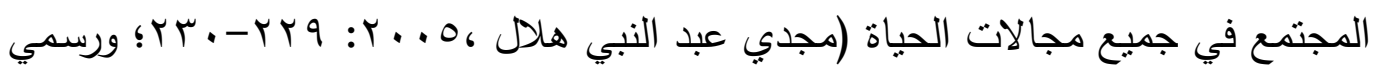

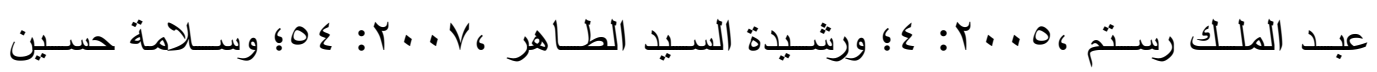

. (r): r. . V،

ثالثا: مستويات المشاركة المجتمعية، وصورها:

تتطوي المشاركة المجتمعية على ممارسة عدد من الأنثطة، كما أن هناك مستويات متفاوتة

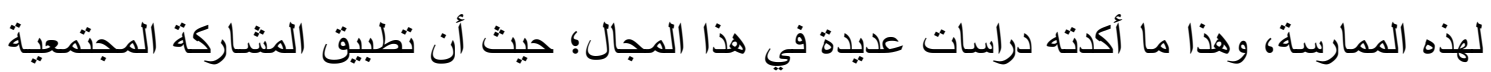

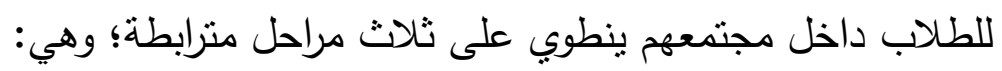

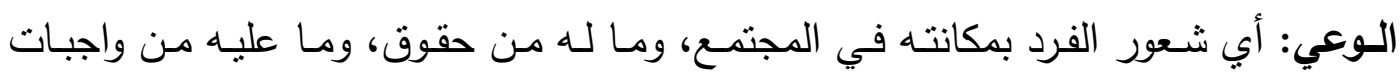
مجتمعية، والوعي هنا أعمق من الفهر.

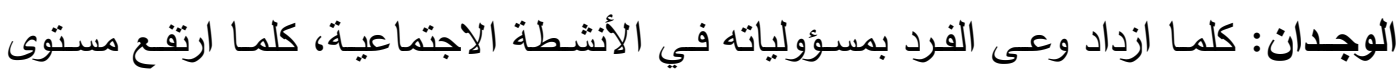

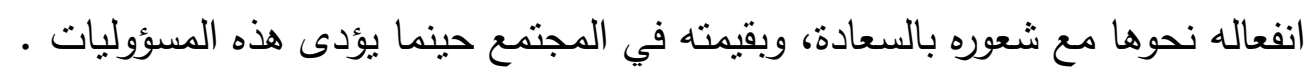

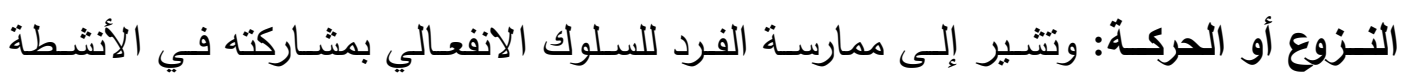

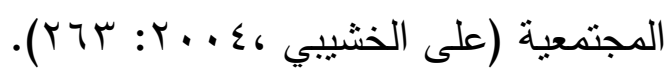


ويتفق معسه في ذلك جمال الدهثـان (1) ـ ب)؛ حيث أكد على أن هناك ثـلاث مستويات متلاحمة للمشاركة المجتمعية في أي مجال؛ وهي:

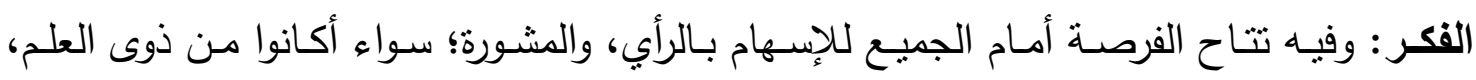

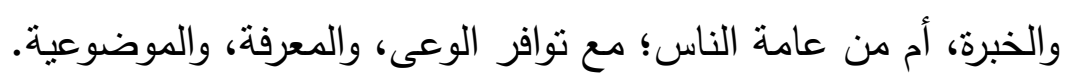

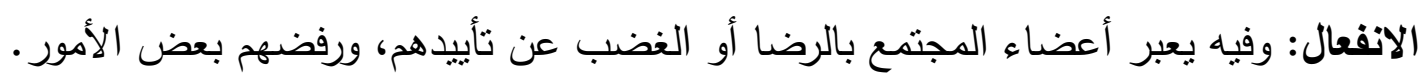

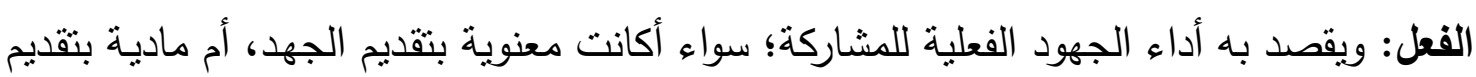

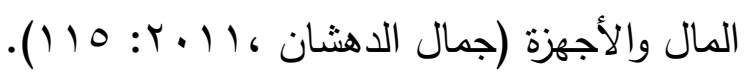
وتُقسم مراحل المشاركة المجتمعية إلى ما يلى:

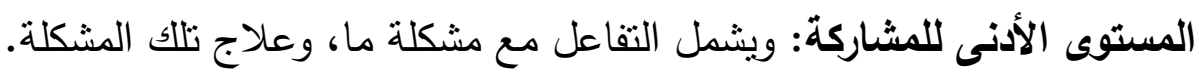

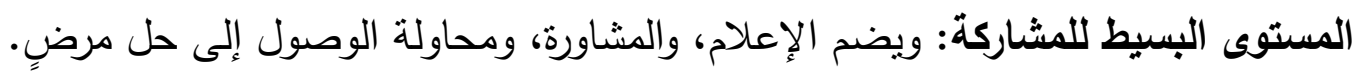

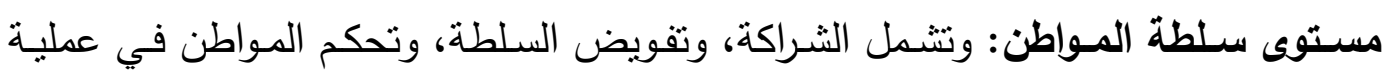

(John, D, 2008: 201)

وأمسا فيما يتعلق بصـور المشـاركة المجتميـة؛ فيمكن تقسيمها إلى صسور المشاركة غير

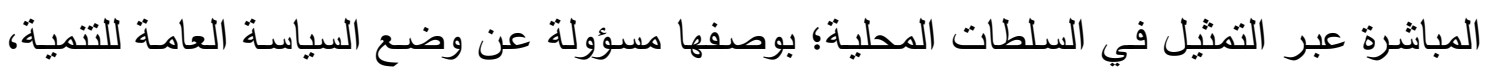

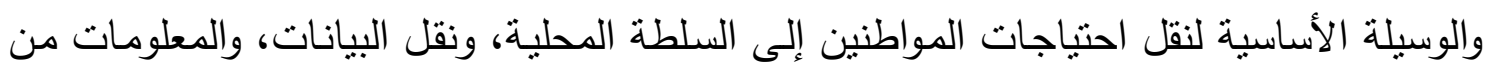

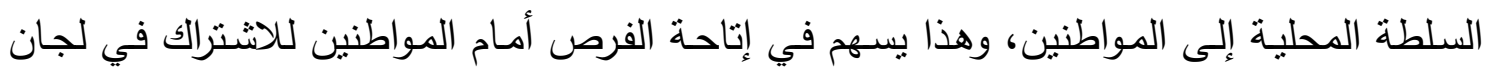

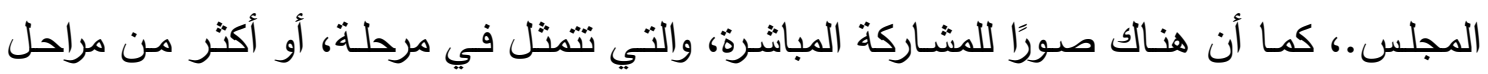

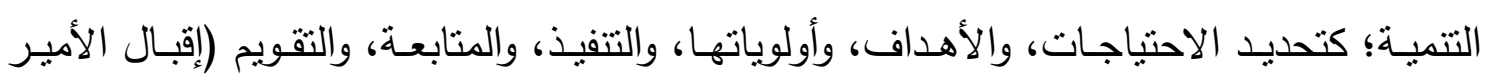

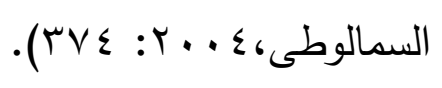

رابعًا: اتجاهات المشاركة المجتمعية.

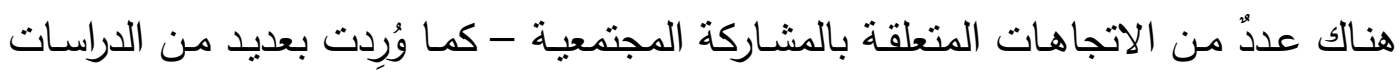

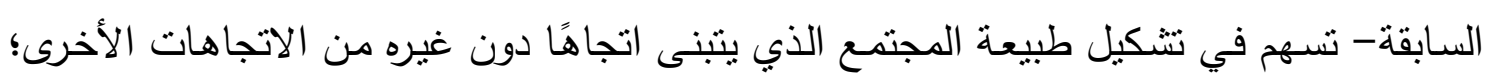

يتمثل الاتجاه الوقائي للمشاركة المجتمعية في أن كل مجتمع يتميز بأنماط سلوكية، وقيم

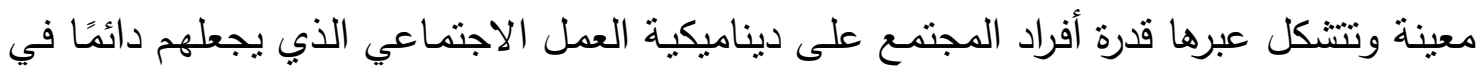

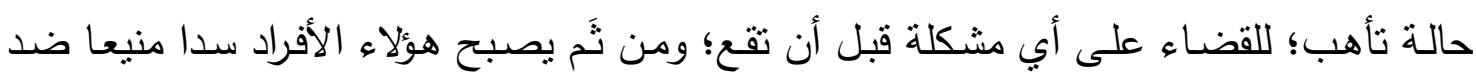

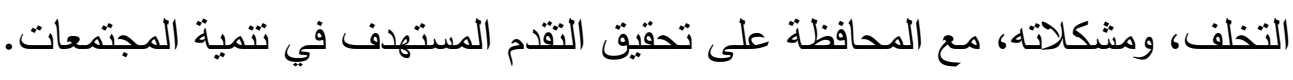


وتعد التربية وسيلة أساسية لتحقيق الاتجاه الوقائي لدى المجتمعات المحلية؛ لكونها تسهح

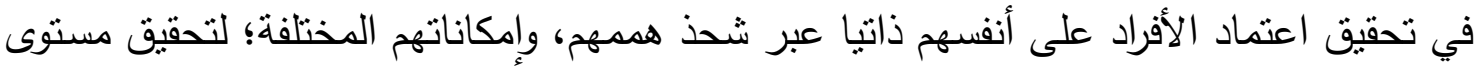
أفضل لهم؛ ومن ثم بسهح هذا الاتجاه في تكوين ديناميكية كبيرة لمقابلة المشكلات قبل وقوعها،

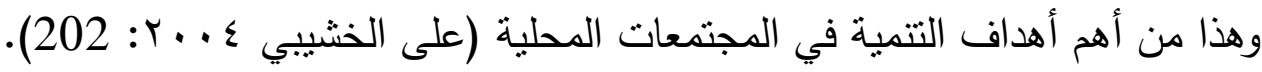

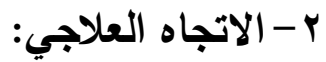

يبنى هذا الاتجاه على معالجة المشكلات القائهـة في المجتمع؛ لا سيما تلك التي تعاني منها الددارس، والمؤسسات التربوية، كما يعمل على تجنب آثار تلك المشكلات، والتي تمتد آثارها

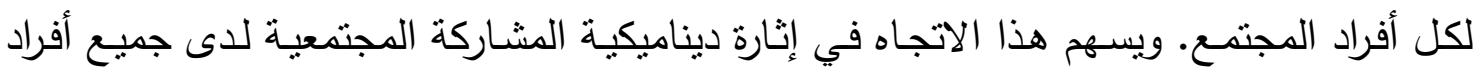

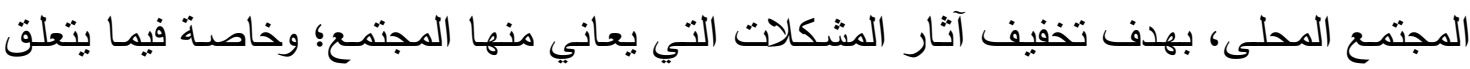
بالمجالات الاقتصادية، والاجتماعية. ويحتاج هذا الاتجاه إلى تفاعل بين الأفراد، والهيئات، والمؤسسـات، والأنظمـة الموجودة؛

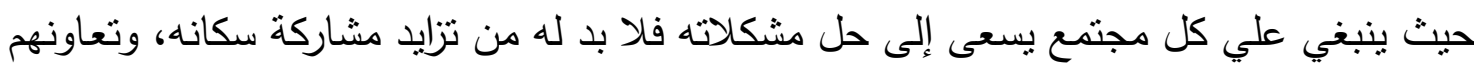

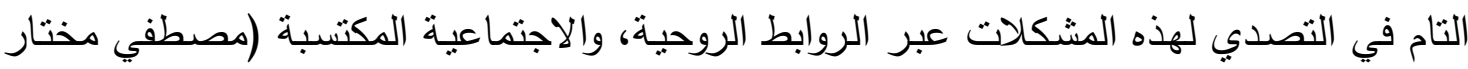

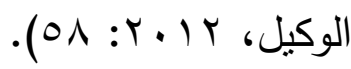

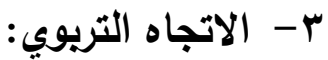

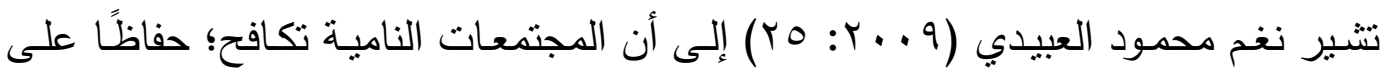
الثخصية الفردية كوحدة مستقلة للشخصية الاجتماعية الوطنية، ولذلك تعمل المدرسة بكل أجزتتها على تقديم نُسق اجتماعية تساعد الثخصيات الفردية فى خدمة المجتمع، وتسهم في تقدمه.

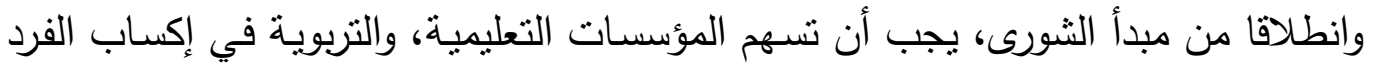

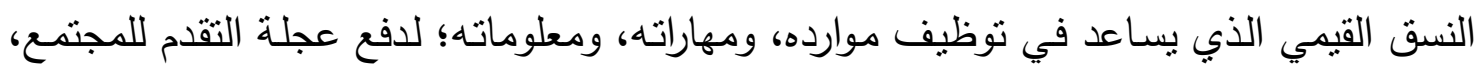

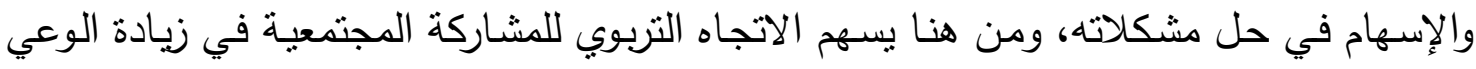

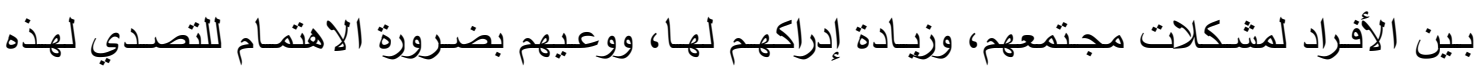

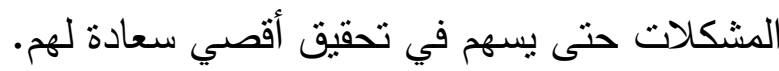

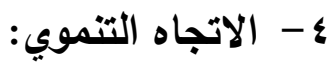

يُبنى هذا الاتجاه على عملية تغيير هادف، ومضبوط تتم فيه السبطرة على عوامل التغيير نفسها، وتوجيهها؛ وفق تخطيط محكم نحو رؤية مستقبلية للمجتمع.

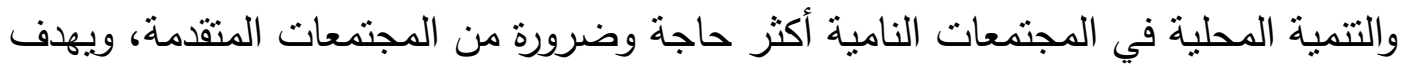

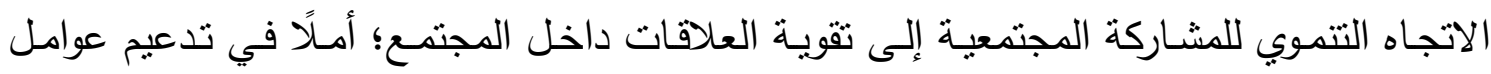

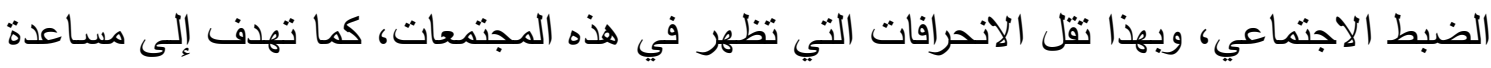

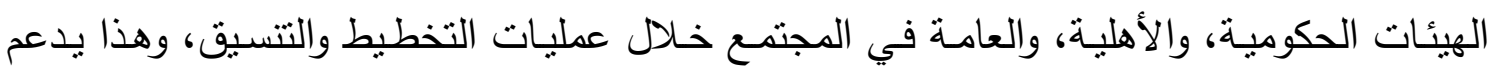




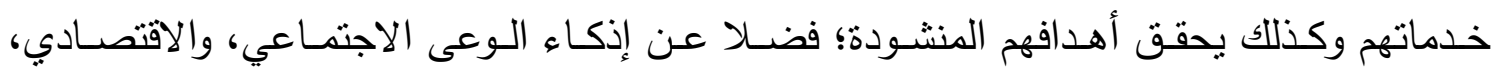

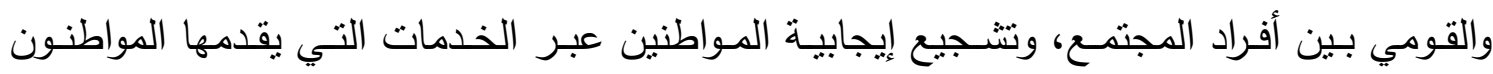

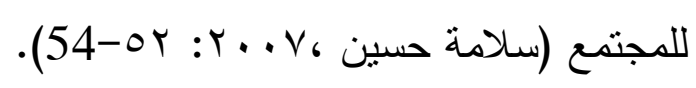

خامسًا: فوائد المشاركة المجتمعية.

تتتوع فوائد المشاركة المجتمعية -كما نتشير بعض الدراسات والكتابات- كما يلي:

1- التمية جوانب الحرية المسؤولة:

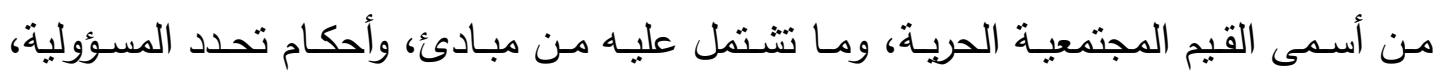

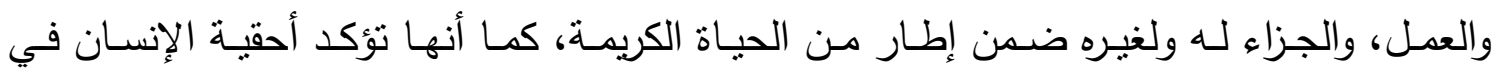

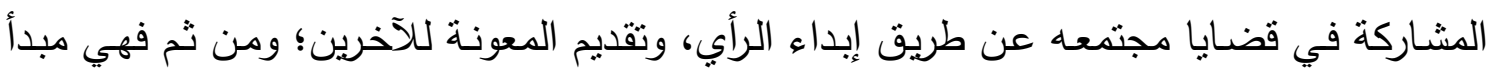

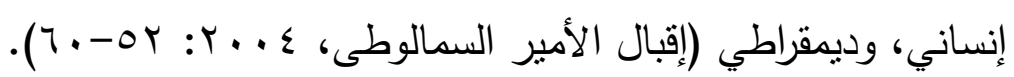
r- تنمية جواتب العمل التعاوني بين الأفراد:

وذللك عبر نتمية قيم المشاركة، والتعاون بين الأفراد، ومن خلال ذلكل يمكن الاهرد المساهمة في حل كثير من المشكلات الهجمعية، كما أنها تتمى الثُعور القومي، والانتماء، وتقضى على مظاهر

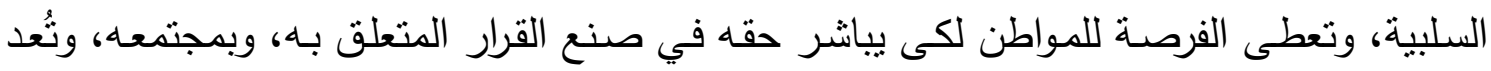

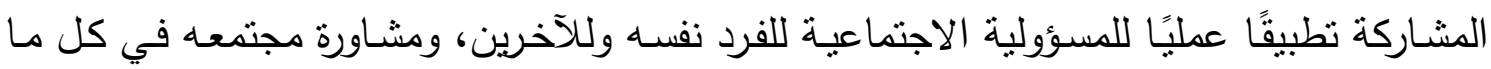
يهمه، ويسهم معهم؛ فكرياً، وماليًا، وفنيًا بجهـ تطوعي لحل قضائا المجتمع، وبذلك تصبح المشاركة

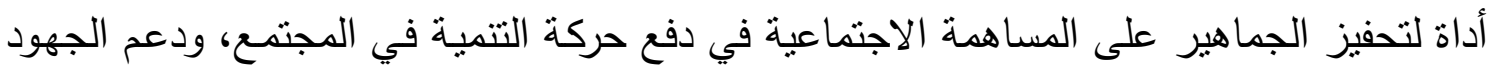

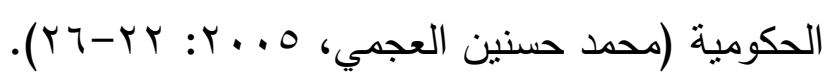

r- تنمية جوانب الانتماء بين الأفراد:

من خال مشاركتهم بعضهم البعض، وسعى كل فرد لتقديم ما بستطيع إلى الطرف الآخر ؛ سعيًا وراء تحقيق التتمية، والتقدم في مستوى الخدمات المقدمة من جهة، وتقدم المجتمع وتطوره

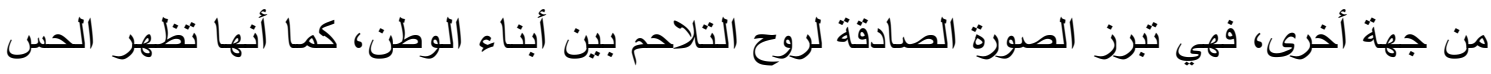

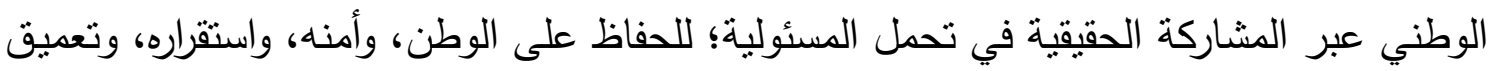

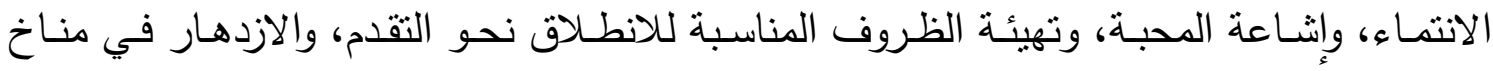

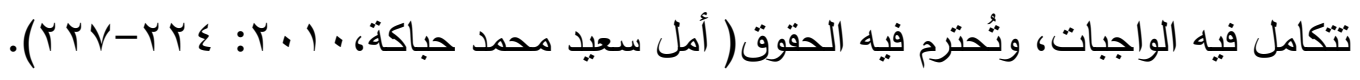
ع - تنمية الجوانب الاقتصادية والاجتماعية:

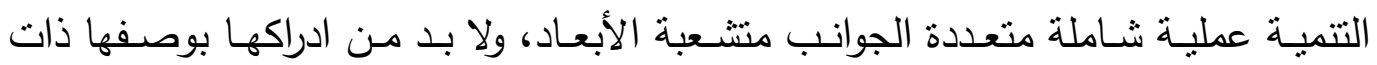

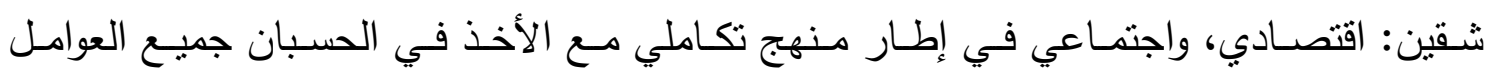

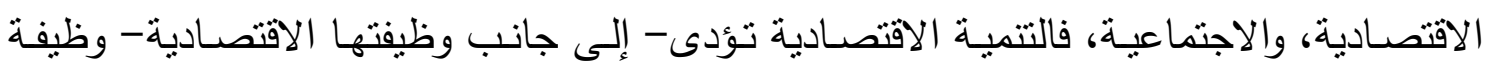

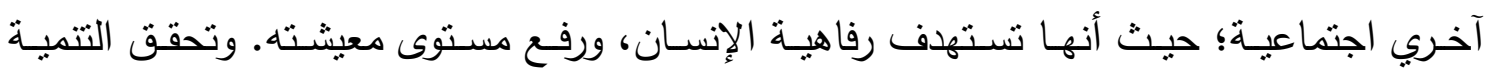


الاقتصـادية أهدافها عبر إنسـان معد، ومدرب، ومنتعلم تعليمـا رشبدا، وهذا مـا تقوم بـه التتميـة

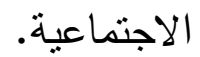

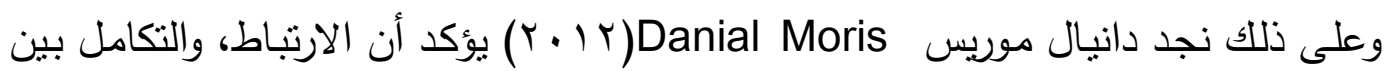

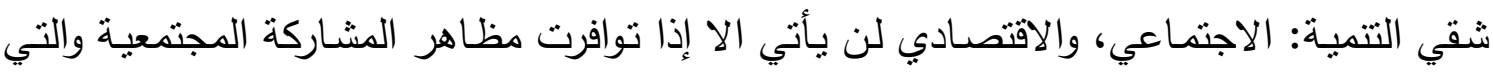

من بينها:

- الاستقلال السياسي مرحلة أساسية؛ لتحقيق الاستقلال الاقتصادي •

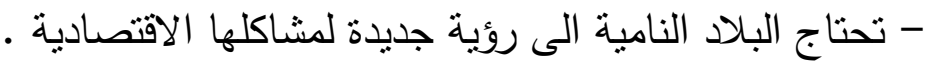

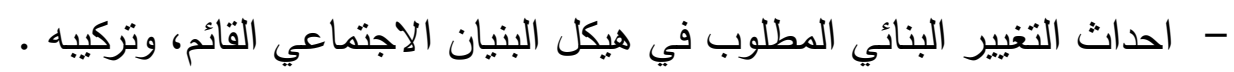

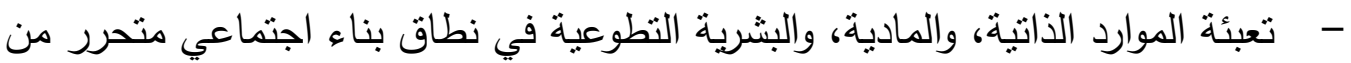

التبعية الاقتصادية، أو الثقافية، أو غير ذلك من ألوان التبعية .

- مشاركة المواطنين -بجميع فئاتهم - في تطوير مجتمعه؛ فهم أصحاب المصلحة الحونة الحقيقة.

(Moris , D, 2012: 204)

سادسا: أبعاد المشاركة المجتمعية.

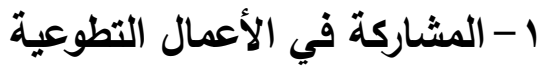

تعد المشاركة في الأعمال التطوعية من أهم أبعاد المشاركة المجتمعية، حيث يكتسب العمل

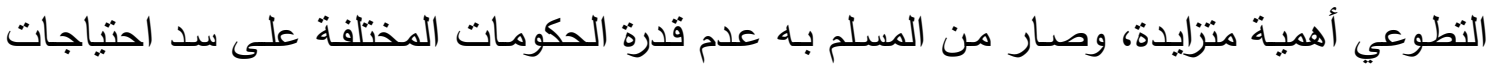
أفرادها، ومجتمعاتها؛ لذلك صارت هناك حاجة ملحة لجهات أخرى لتكمل دور الدولة في تلبية تلك الكي

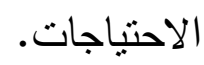

والعمل التطوعي هو العمل الذي يقوم بـه الفرد؛ لتحقيق أهداف اجتماعية محددة دون أن

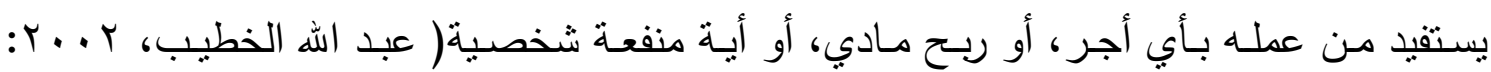

ويعرف بأنه ذلك الجهر الذي يبذله أب إنسان بدون مقابل لمجتمعه، وبدافع منه للإسهام في

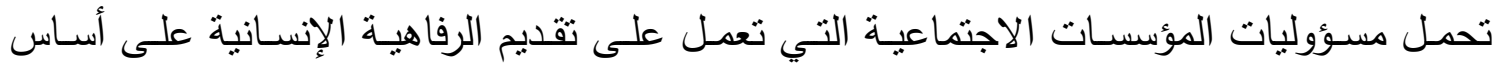

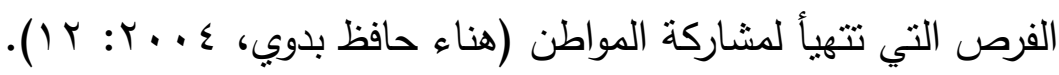
وقد تطور العمل التطوعي إلى التغيير ، وتتمية المجتمع ويعد أحد الركائز الأساسية لتحقيق

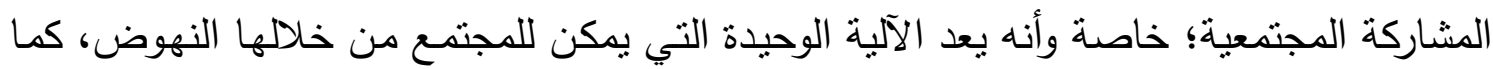

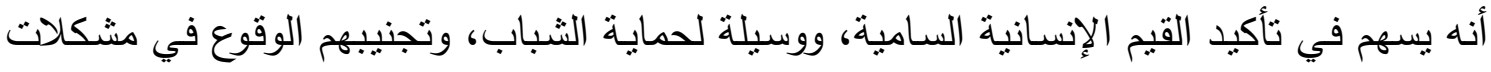

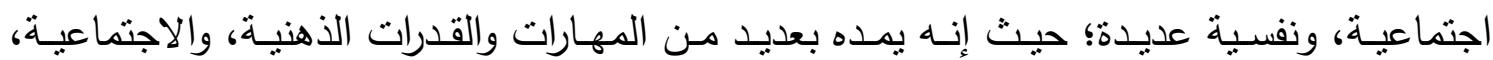
والانفعالية التي تجعله قادرا على أن ينسجم مع الآخرين من أبناء مجتمعه (مختار شعيب ،ع ... ؟؟

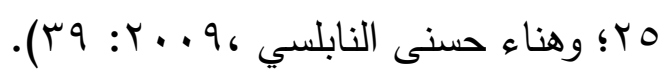


المشاركة الاجتماعية أحد الأسس الأساسية للمشاركة المجتمعية، والتي من خلالها تتحقق

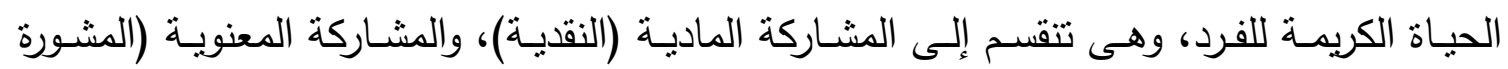

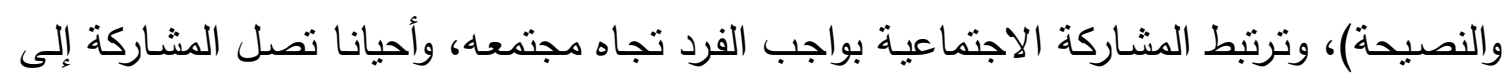

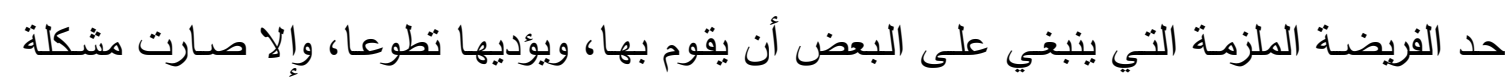
يواجهها المجتمع جميعه. ويعرفها بأنها اثشتراك الفرد مع الآخرين في الأعمال التي تشاند الجماعة على إثباع حاجاتها،

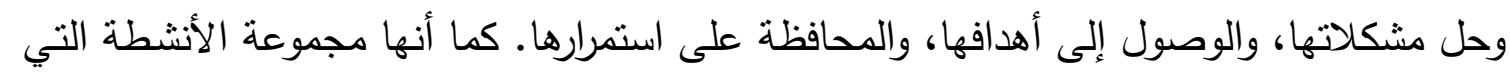

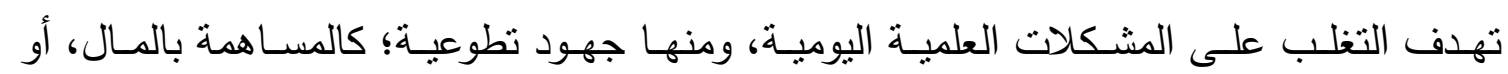

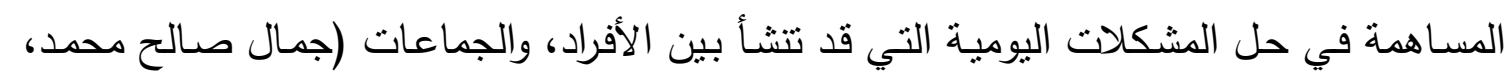

$$
\text { . (Vr- : r. } 9
$$

وتؤدى الدوافع الذاتية دورا جوهريا في درجة المشاركة الاجتماعية للفرد إلي أن الدوافع الذاتية

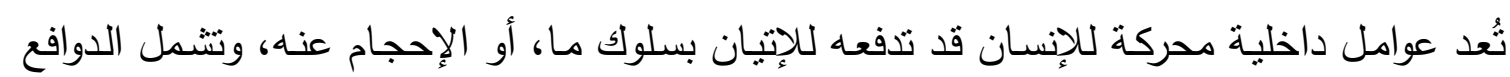

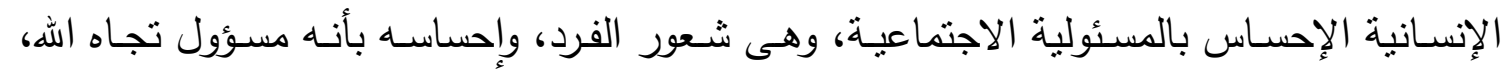

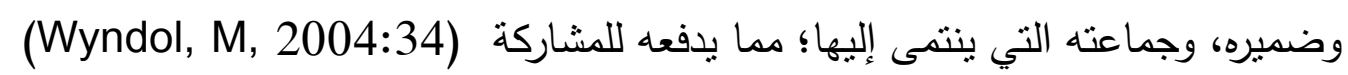
ويوجد نوع أخر من الدوافع التي تؤثر في درجة المشاركة الاجتماعية؛ وهي: الدوافع البيئية؛

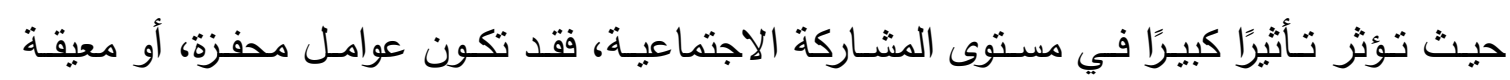
للششاركة الاجتماعية؛ كأحكام الآخرين على مستوى مشاركة أبنائهم، ومستوى المشاركة الاجتماعية

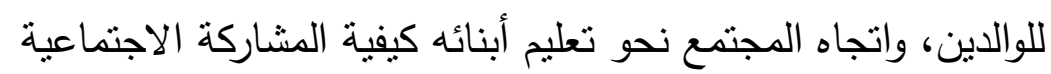
.( Anarino, S, 2009: 173-182)

$$
\text { ويندرج تحت عنصر المشاركة الاجتماعية ثلاثة جوانب؛ وهي: }
$$

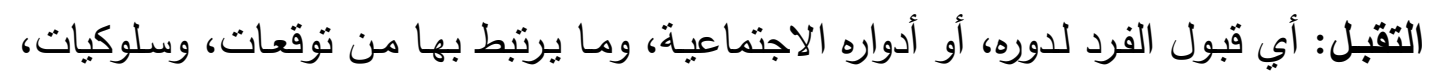

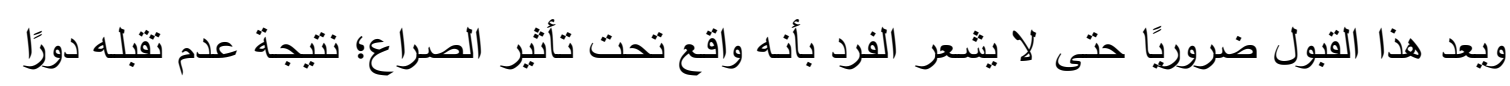
معينًا، أو شعوره بعدم ملائمة الدور لله.

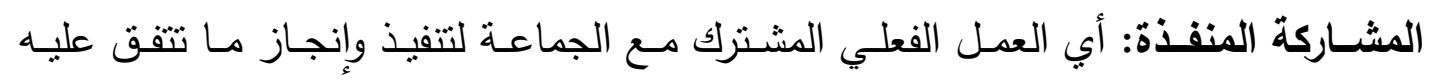

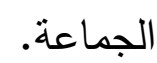
المشاركة المقومة: وهي مشاركة موجهة تهدف إلى تقويم أعمال الجماعة وإنجازاتهم (ميسون

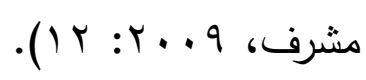


تعد المشاركة السياسية العصب الحيوي لممارسة المشاركة المجتمعية؛ فهي: عملية سياسية

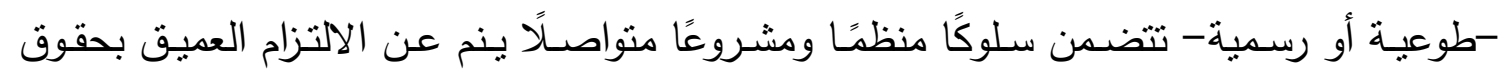

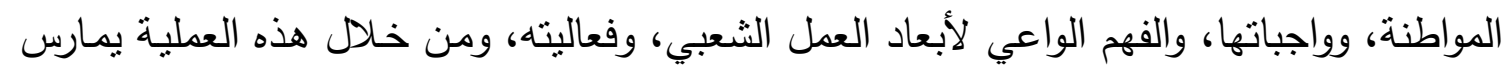

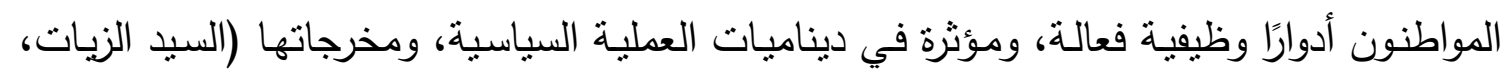
(1) : 1 : r. r

كما تُعد -أيضـا - تعبيرًا صريحًا لسيادة قيم الحرية، والعدالة، والمساواة في المجتمع، كما

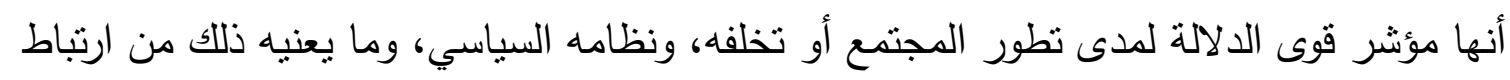

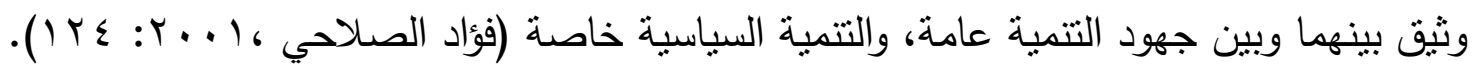

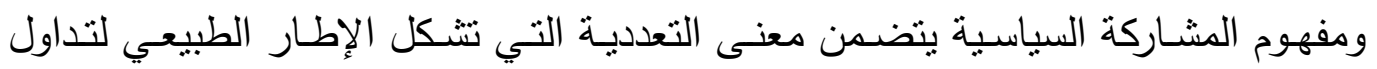

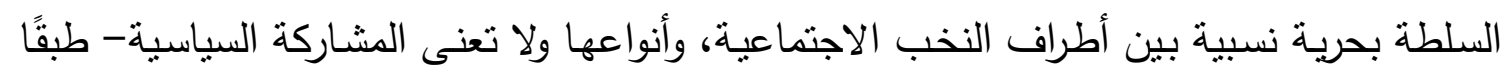

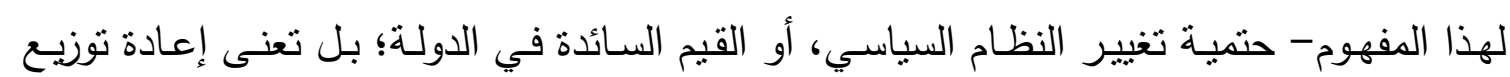

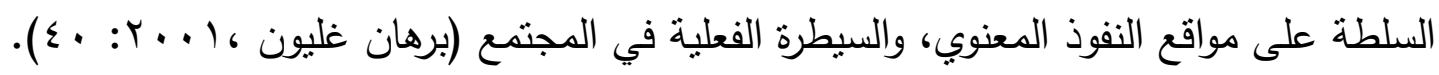

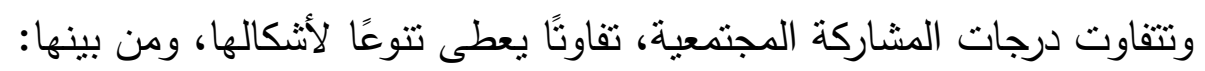

$$
\text { 1- بقلد منصب سياسي، أو إداري. }
$$

r- السعي نحو منصب سياسي، أو إداري. ب- العضوية النشطة في تتظيم سياسي ما (حزب مثثلا). ع - العضوية العادية في تتظيم سياسي ما. 0- العضوية النشطة في تنظيم شبه سياسي. 7- العضوية العادية في تتظيم شبه سياسي. V - المشاركة في الاجتماعات السياسية العامة. 1- المشاركة في المناقثات السياسية غير الرسمية. 9- الاهتمام بالسياسة العامة.

. - التصويت (Huntington, S, 2014: 120). سابعا: المشاركة المجتمعية وعلاقتها بعلم الاجتماع (كمجال -كمادة دراسية).

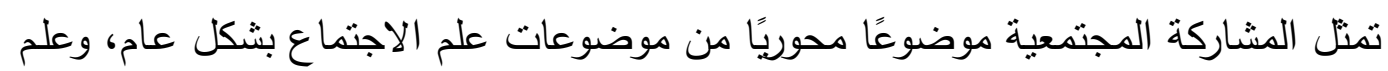

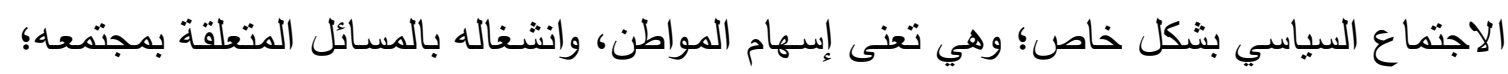

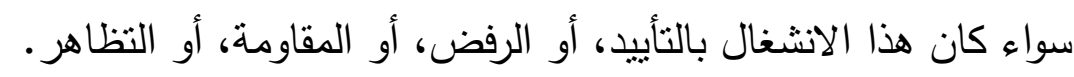

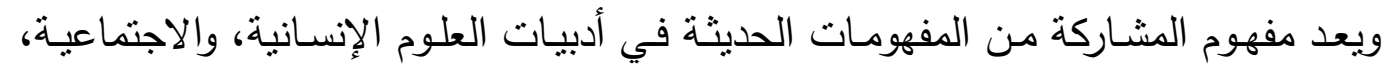

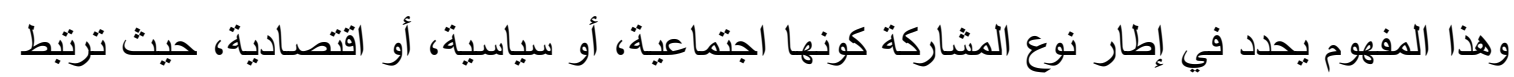


المشاركة بمجال السياسية يتمثل في الأنشطة الإدارية التي يشارك فيها أفراد المجتمع في اختيار

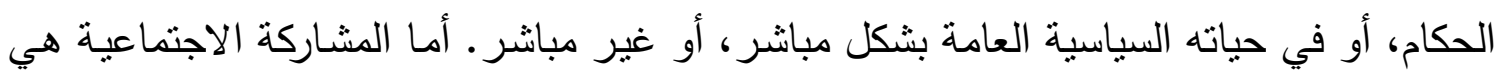
الوجه الآخر لحرية الرأي، والتعبير التي تُعد من أهم الحريات، وحقًا من حقوق الإنسان (إسماعيل

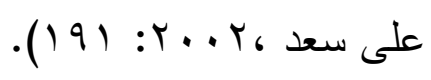

وتعد المشاركة- بكل أنواعها - مبدأ أساسي من مبادئ تتميـة المجتمع؛ لأن التتمية لا تتحقق إلا

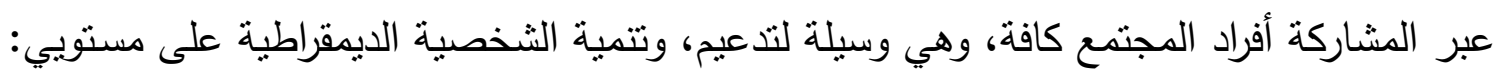
الفرد، والجماعة في المجتمع.

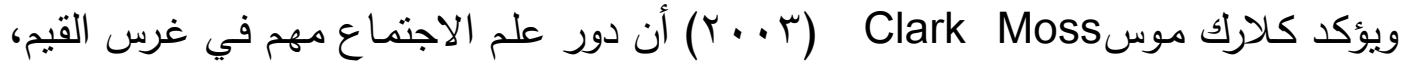

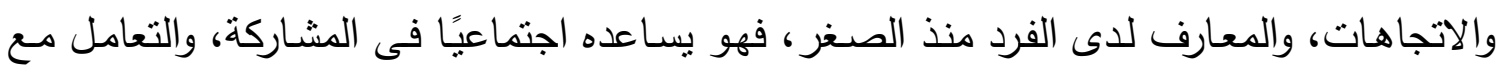

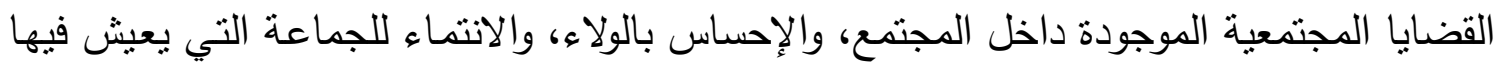

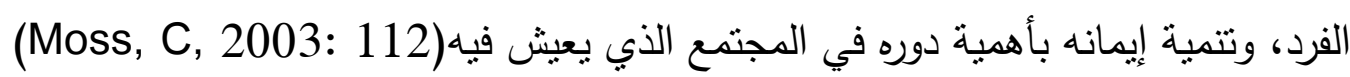

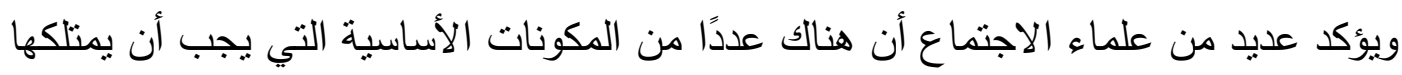

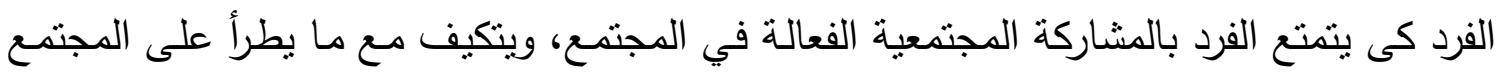
من تغيرات، ويواجه ما يقابله من تحديات، ومن هذه المكونات: 1- السمات الثخصية؛ منل : الثقة بالنفس، وتحمل المسئولية. r- التعددية: وهي قبول التتوع في الفِكر ، والعقائد المختلفة. ץ- المرونة: وهي تقبل كل الفِكر دون تعصب، ورفض فئل الفِكر المسبقة.

(Roker, B, 2004: 128)

وعلى صعيد علاقة المشاركة المجتمعية بعلم الاجتماع كمقرر دراسي، أو كمادة دراسية

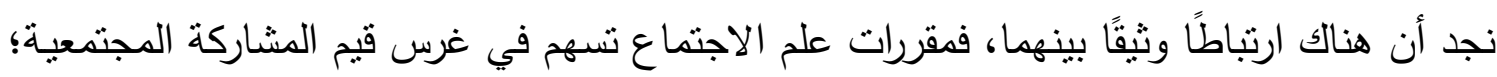

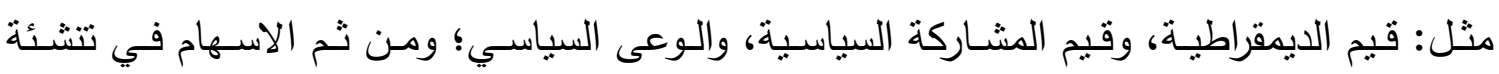
المواطن الديمقراطي المشارك في شؤون وطنه؛ لذللك يجب أن تتخلى مناهج الدراسات الاجتماعية-

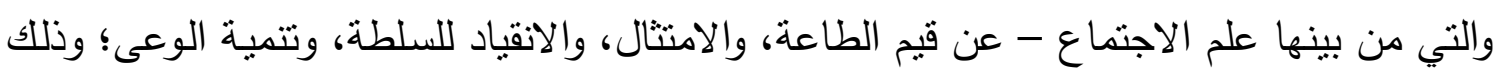

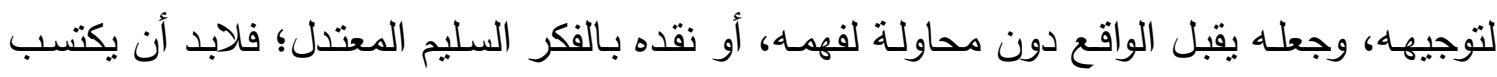

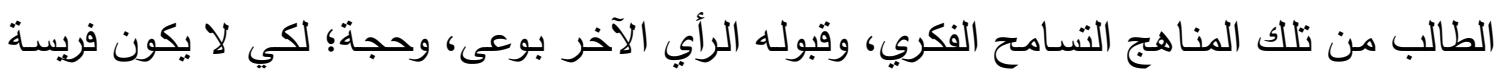

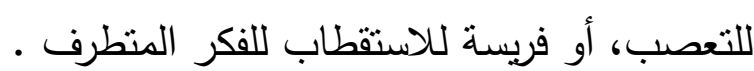

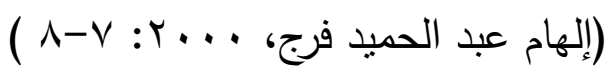

ويعد علم الاجتماع أحد فروع الدراسات الاجتماعية التي يجب أن يهتم بتزويدها، وتدريسها

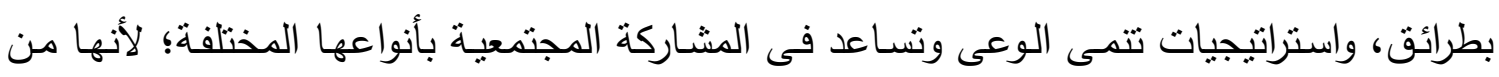

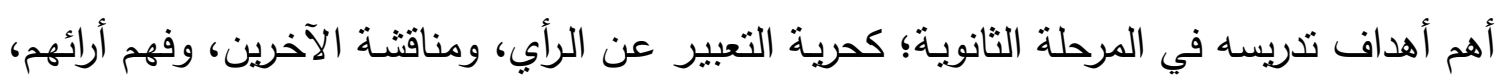


وربطها بغيرها من المعلومات ؛ مما يستدعى ضـرورة تضمين علم الاجتماع في صـورة قضـايا

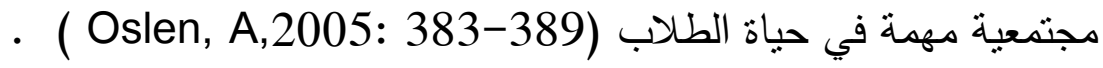
كما أنه من المواد الدراسية التي تُدرس للمرحلة الثانويـة، والتي تحوى قضـايا اجتماعية،

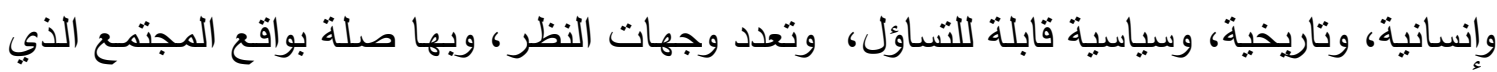

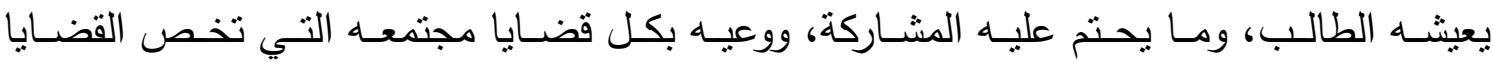
الاجتماعيـة، والسياسية، وقضـايا المواطنة؛ فهى تعد ضـرورة تربويـة، وعصـرية لطالب المرحلـة

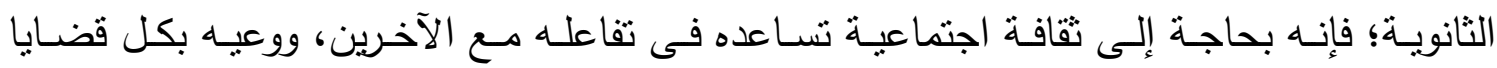

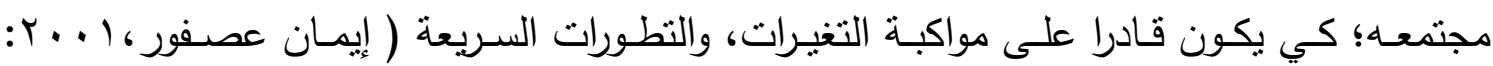
.$(1 \mathrm{VY}$

كما أن منهج علم الاجتماع يجعل الطلاب مرتبطين بمجتمعه، وحياتهم، وهذا يتطلب

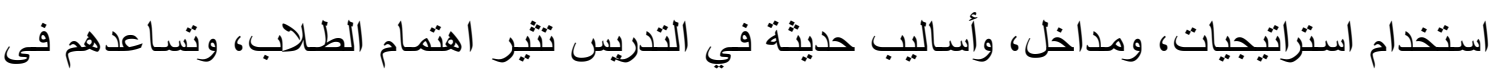

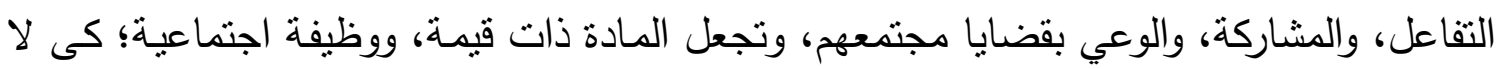

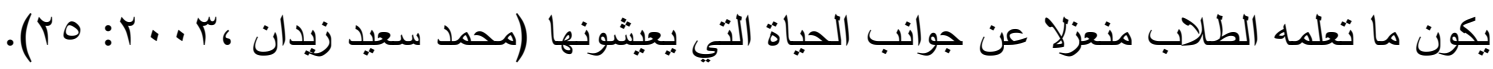

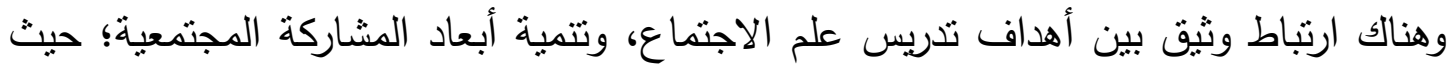

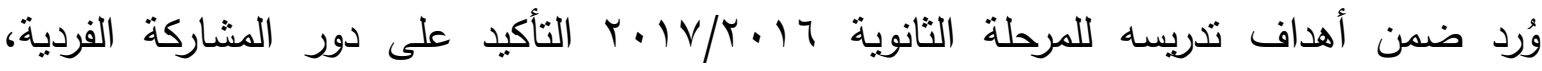
والمجتمعية، والثعبية في مواجهة مشكلات المجتمع؛ لذا فتعد المشاركة المجتمعية من القيم المهمة التي يحرص منهج علم الاجتماع على تتميتها لطلابه.

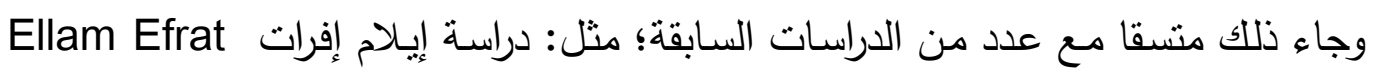

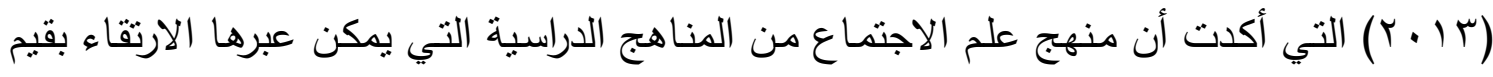

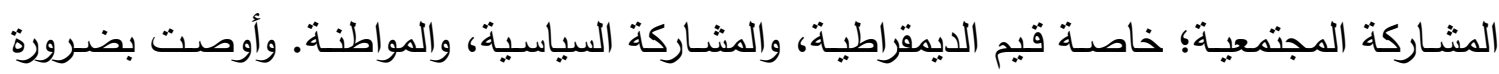

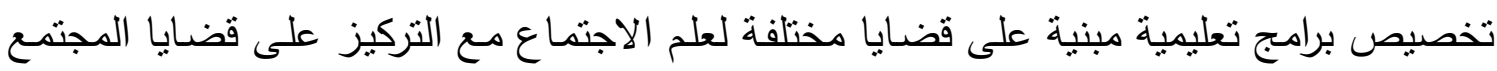
المحلى، نتبلور فيها صور المشاركة المجتمعية التي تحقق قيم التتمية المتواصلة.

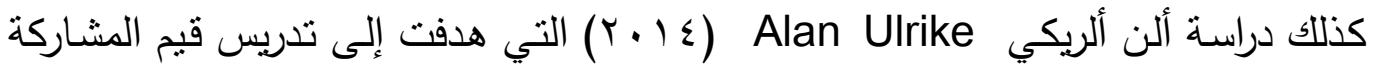

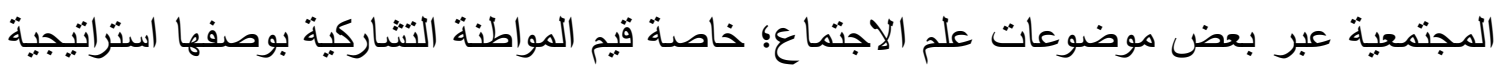

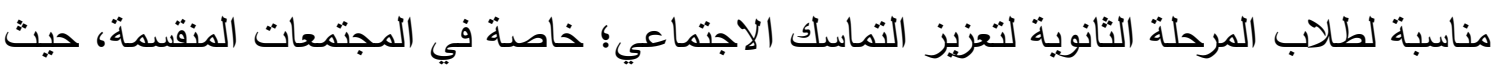
أقترحت بعض موضوعات علم الاجتماع التي تدور حول المنظمات الحكومية، وغير الحكومية؛

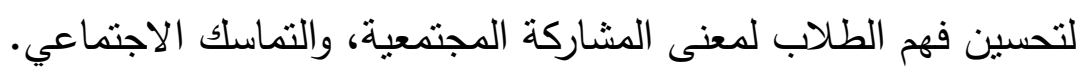

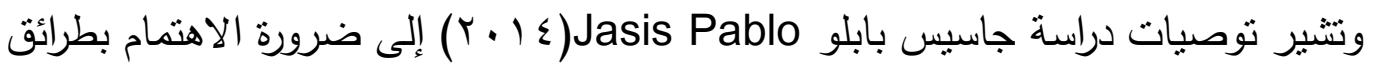

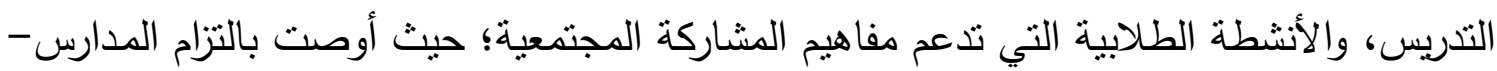
خلال تدريس أي موضوعات أو أي قضايا اجتماعية أو وطنية- باختيار طرائق تدريس، وأنشطة 
طلابية مناسبة، وتفعيلها بشكل يعبر عن أهمية هذه الطرائق والأنشطة، ويزيد من مستوى المشاركة

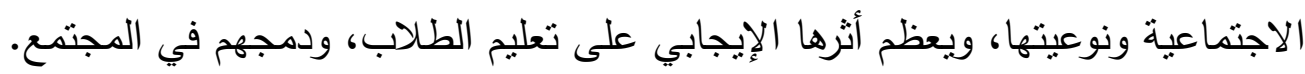

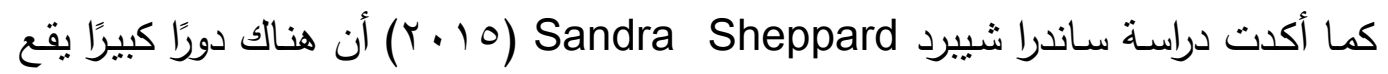
على عـاتق المدرسين الاجتمـاعيين (معلمي الدراسـات الاجتماعيـة) خـلال تدريس قيم المشــاركة الاجتماعية، وأن ضعف المشاركة المجتمعية للطلاب إنما برجع لقلة خبرة الأخصائيين الاجتماعيين

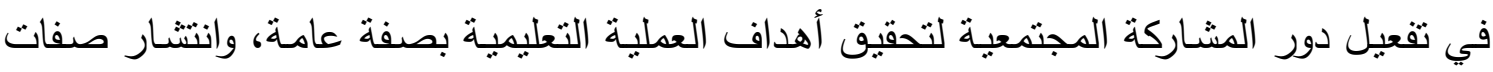
السلبية، واللامبالاة، والتواكل بين الطلاب؛ لذللك اقترحت الدراسة دورًا للمعلم الاجتماعي في مساعدة الهاءة المدرسة؛ لنتشيط المشاركة المجتمعية.

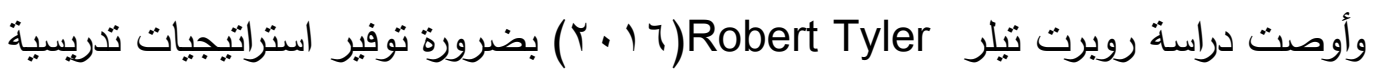

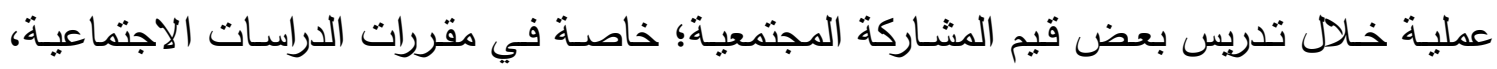

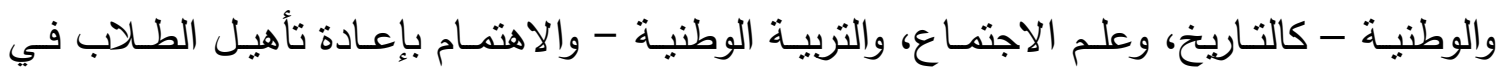

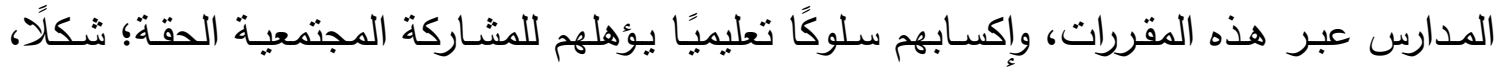
ومضمونًا.

كما تنثير عديد من التوصيات الخاصة ببعض الدراسات العربية؛ متل دراسة كل من: زينب

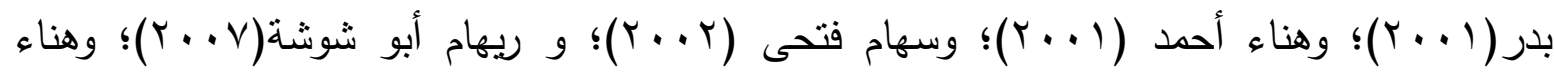

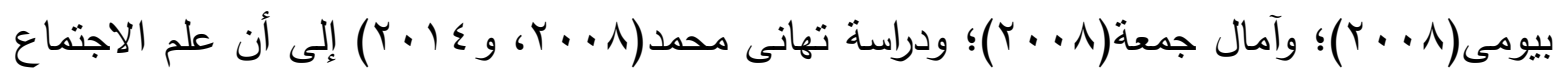
كمقرر دراسي إذا ما أحسن تتظيم محتواه، واستخدمت طرائق واستراتيجيات تدريسية مناسبة قد يساعد ودابه ذللك في تحقيق أهدافه التدريسية، والتي من بينها التأكيد على دور المشاركة الفردية، والمجنمعية، والثعبية في مواجهة مشكلات المجتمع، وهو يعد هدفا وثيق الصلة بالمشاركة المجتمعية؛ مما يؤكد

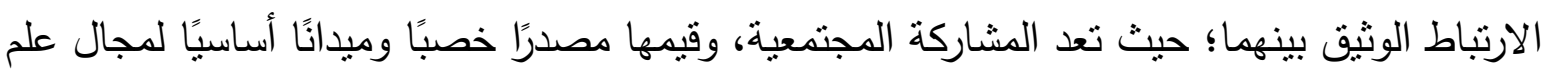

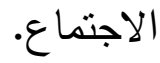

المحور الثالث: مهارات التفكير التحليلي:

يعرض هذا القسم مفهوم التفكير التحليلي، ومهاراته، وخصائصسه، وأهميته، ومراحسه،

$$
\begin{aligned}
& \text { وعلاقته بعلم الاجتماع كمجال، وكمقرر دراسي. } \\
& \text { أولا: مفهوم التفكير التحليلي: }
\end{aligned}
$$

تختلف مفهومـات التفكير التحليلي؛ فالتفكير التحليلي كغيره من أنماط التفكير الأخرى تباينت تعريفاته في مدى أكثر اتسـاعا، وتعددت دلالاته في نطاق كبير ، فعديد مـن البـاحثين يستخدمون مفهوم التفكير التحليلي بمعنى شديد الاتساع، بحيث يبتعد عن طبيعة المفهوم بمعناه وناه

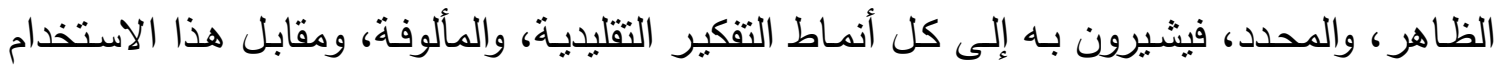


الواسع لمفهوم التفكير التحليلي نجد استخداما آخر يحاول أن يحدد مفهومه (أيمن عامر، ج . . ؟:

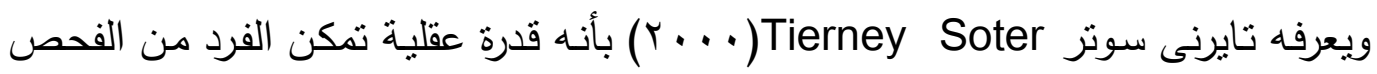

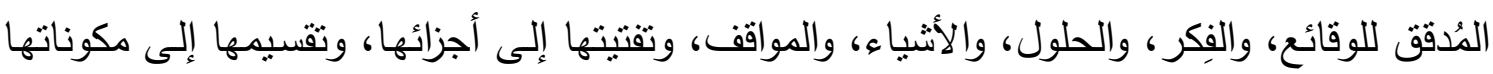

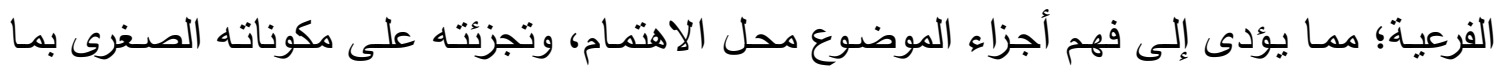

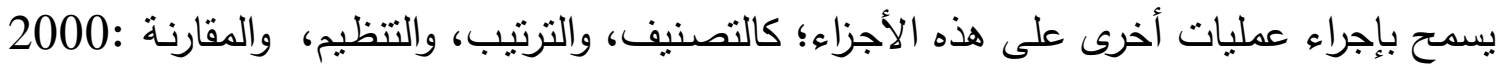

(Soter, T, 35)

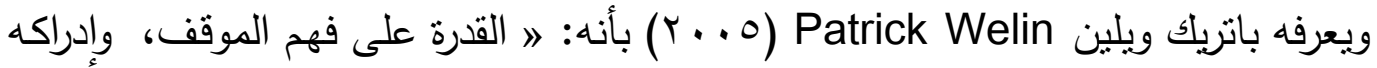
عن طريق تفتيته إلى عناصر ، وتحديد الجوانب المعقدة فيه، وهذا يقود إلى تطوير القدرة على التنظيم المنسلسل، ومعرفة الفروق بين عناصر الموقف؛ لتحديد العلاقات بينها، وصولا إلى الحل المناسب للمشكلة، والتأكد منه/ (Welin, P, 2005: 14 ). كما يُعرف بأنه : اهو ذللك التفكير الذي يعنسي بمواجهة المشكلات بحرص، وبطريقة

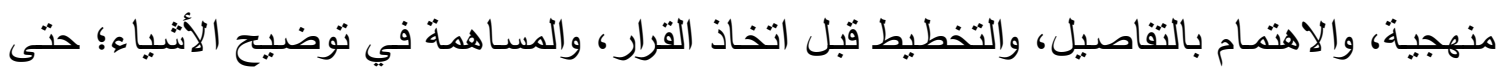

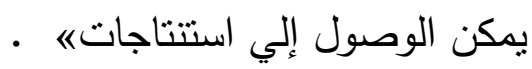
كما أنه: 》ذللك النمط من التفكير الذي يقوم فيه الفرد بتجزئة المادة التعليمية، أو الموقف

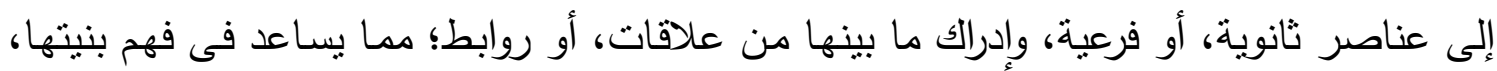

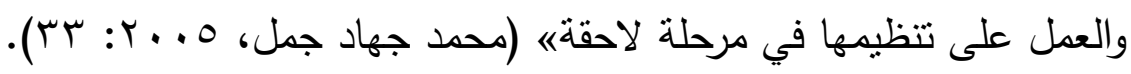

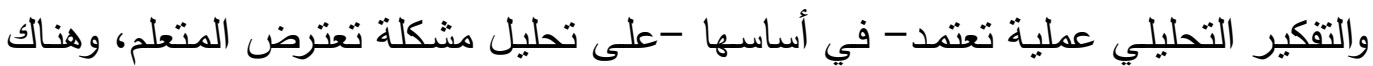

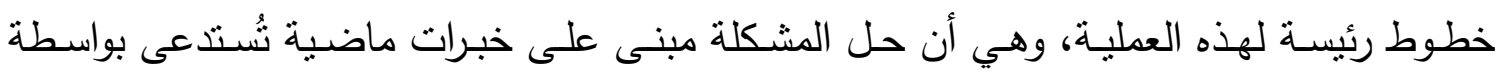
البحث العقلي؛ إذ يوجه الطلاب عقولهم إلى البحث عن تللك الحقائق المنصلة بالموقف، ويتركون

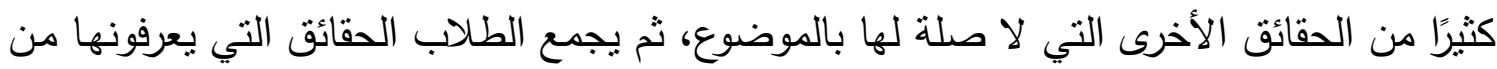

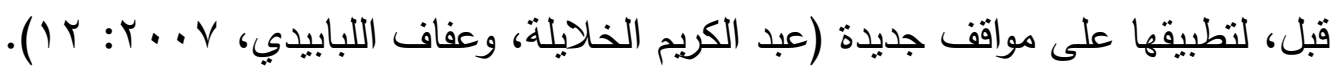

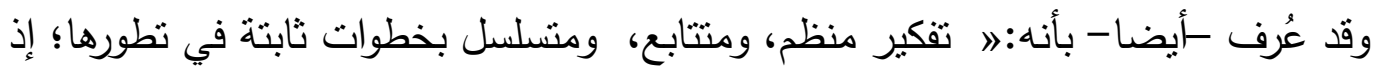

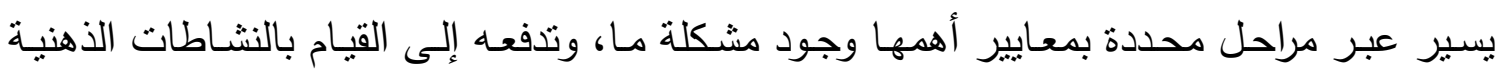

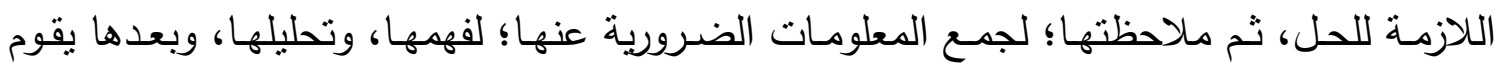
بوضع الفروض، والتحقق من صحتها؛ مستندا في ذلك لما لديه من خبرات سابقة، وفي النهاية

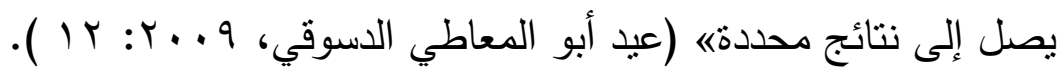

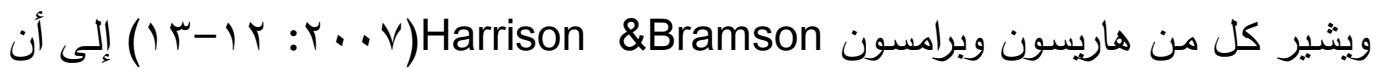

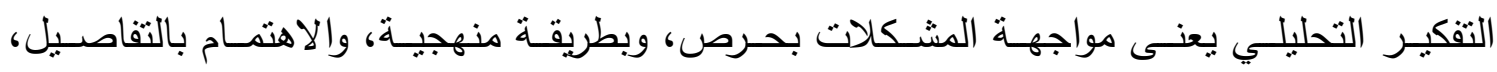
والتخطيط الجيد قبل اتخاذ القرار، وجمع أكبر قدر ممكن من المعلومات. 
وباستقراء التعريفات السابقة يمكن تعريف التفكير التحليلي بأنه: اذللك النوع من التفكير

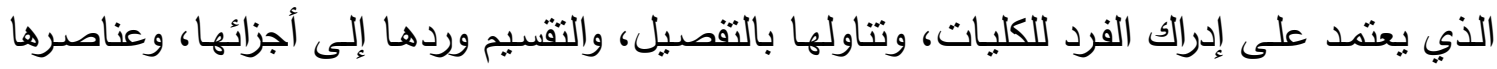
الأولى بشكل منهي، ومنظم بسهم في حل مشكلاته على المستويين: الثخصي، والاجتماعيه . باستقراء التعريفات السابقة يمكن استخلاص مجموعة من الخصائص التي تميز التفكير

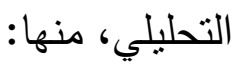
ا-يتطلب التفكير التحليلي استدعاء خبرات سابقة، أو معلومات، وحقائق سابقة مرتبطة بالموقف، التهات

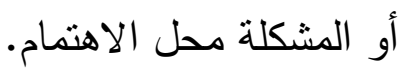

r- يعتمد هذا النوع من التفكير على مهارتي: التصنيف، أو التقسيم بشكل كبير . r- يسير هذا النوع من التفكير وفق خطوات منهجية، ومحددة. ـ - يعنى هذا النوع من التفكير بإدراك التفاصيل الدقيقة.

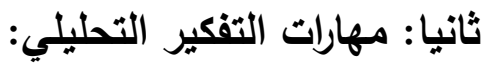
يمثل التفكير التحليلي أحد أنماط التفكير المهمة التي يسعى كثير من الباحثين لتتميتها لدى الطلاب في مراحل التعليم المختلفة، فهو يساعدهم فى مواجهة المشكلات بطريقة منهجية، وبنظرة

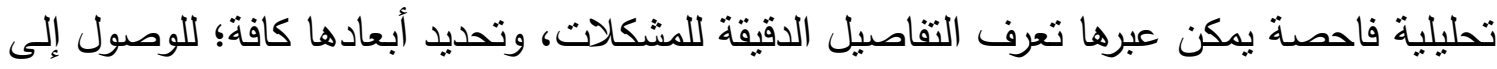
حلول لها.

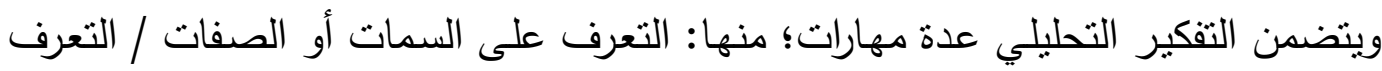

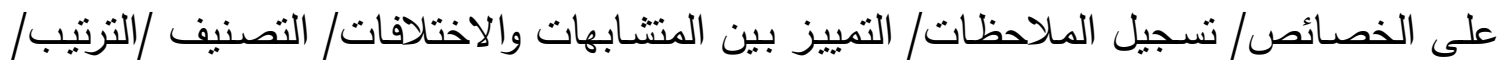
إدراك العلاقات/ تحديد السبب والنتيجة/ الدقارنة والمقابلة/ التنبؤ (Tomlinsom, K,2009: :

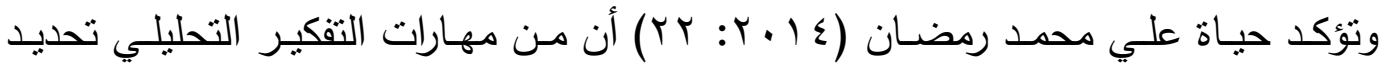

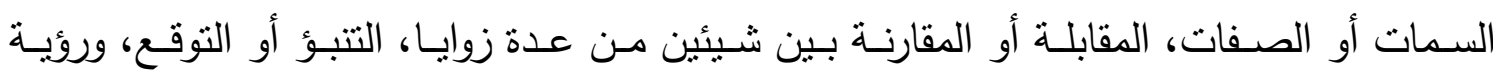

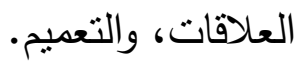
ويمكن تحديد مهارات التفكير التحليلي كما وردت في عديد من الكتابات والأدبيات فيما

1- تحديد السمات، أو الخصـائص/ تحديد الخواص: القدرة على تحديد السمات العامـة

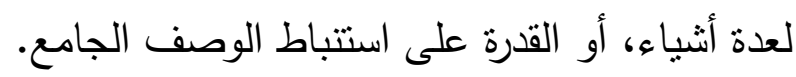
r- إجراء الملاحظة: اختيار الخواص، والأدوات، والإجراءات الملائمة التي ترشد وتساعد الفاء في عملية جمع البيانات.

r- التفرقة بين المتشابه، والمختلف/ المقابلة، وإلمقارنة: التمييز بين شيئين، أو فكرتين أو أكثر من عدة زوايا. 
ع - التجميع، والتبويب:/ التصنيف: القدرة على تصنيف الأثياء، أو العناصر المتثابه في مجموعات. 0- الترتيب، ووضع الأولويات/ عمل المتسلسلات: وضع البنود، أو الأحداث في تسلسل

$$
\text { هرمي بناء على قيم نوعية، أو ترتيب أحداث معينة. }
$$

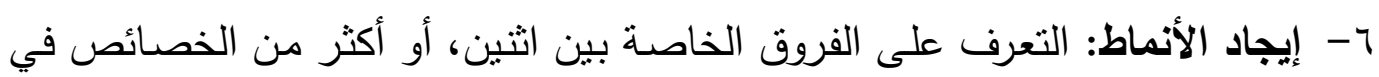
علاقة تؤدى على نسق متكرر . V- روئة العلاقات: المقارنة بين الفِكر، والأحداث؛ لتحديد النظام بين اثثين، أو أكثر من

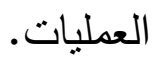

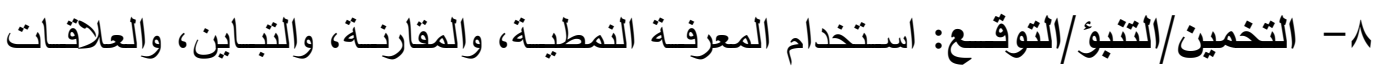
المحددة في توقع أحداث مشابهة في المستقبل. 9- تحديد السبب، والنتيجة: تحديد الأسباب، أو النتائج الأكبر، والأكثر قوة لأفعال، أو

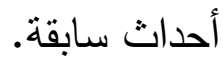
• 1-التعميم: القدرة على بناء مجموعة من العبارات، والجمل التي تشتق من العلاقات بين

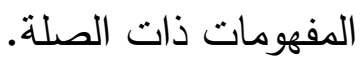

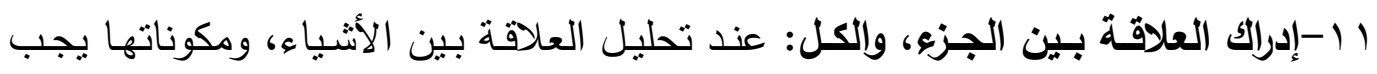

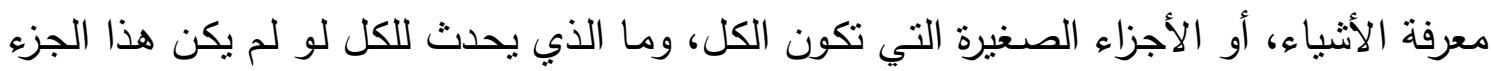
موجودًا.

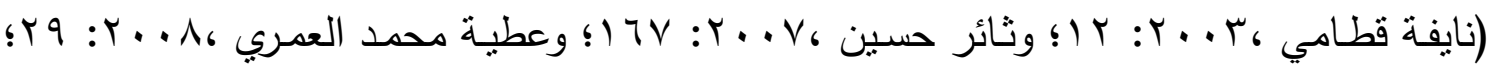

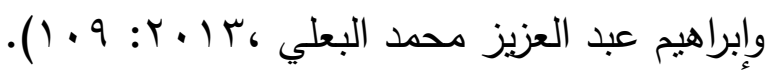

$$
\begin{aligned}
& \text { ثالثا: خصائص التفكير التحليلي: }
\end{aligned}
$$

تثتير عدد من الكتابات والأدبيات إلى تميز التفكير التحليلي بعدد من الخصائص، ومنها

1- على نقيض التفكير الناقد فهو يسعى إلى تفتيت الفِكر إلى أجزائها دون إصدار حكم

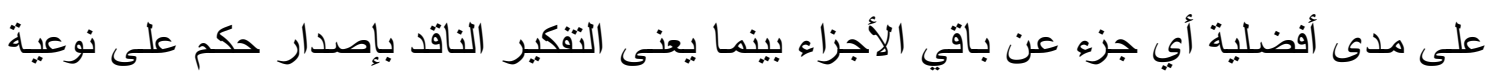
الفِكر بعد المفاضلة بينها.

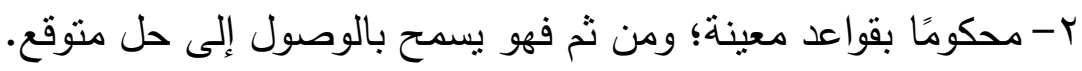

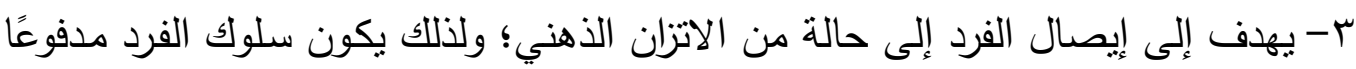
ومضبوطًا بالهدف.

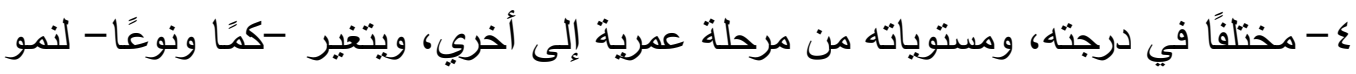

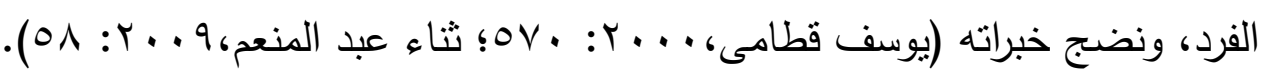


ه- يسير وفق خطوات منظمة، ومتتابعة ويمكن أن تحدد كل خطوة بمعايير ؛ لتحديد مدى صحتها. 1- تفكيرًا ذهنيًا يقوم على ممارسة عمليات ذهنية يُستدل عليها عبر الإجراءات، والأثار ، والفِكر التي تظهر لدى الفرد. V- يعد ذا طبيعـة محوريـة؛ حيث تتمركز جميع عملياته حول الموقف المشكل؛ لفهم طبيعته، وعناصره، والعوامل المؤثرة فيه. ^- يسير فيه الطالب وفق منطق محدد يصل فيه إلي تفسير كثير من المواقف والمشكلات

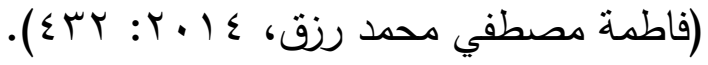

$$
\begin{aligned}
& \text { رابعا: أهمية التفكير التحليلي: } \\
& \text { يساعد التفكير التحليلي الطلاب فيما يلي: }
\end{aligned}
$$

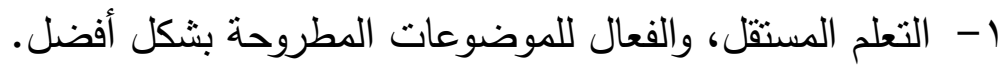
r- تطوير قدرات الاتصال، وتوظيف مهارات الاستيعاب، والتقييم. r- تطوير قدرات التحليل، وحل المشكلات الحياتية، واتخاذ القرار. ع - إعطاء الفرصة الكافية للقراءة، والتحليل والتنظيم.

$$
\text { 0- القدرة على إدراك الأهداف الموضوعة. }
$$

צ- تتمية القدرة التفكير المنظم، والمتتابع، والمتسلسل بخطوات ثابتة.

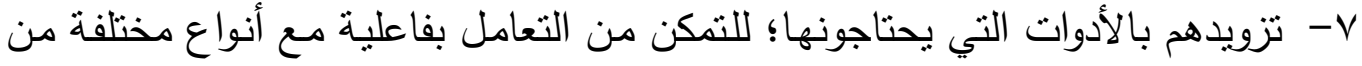

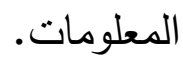
1- تقييم صحة الإدعاءات التي يتعرضسون لها؛ ممـا يؤثر فى فاعلية القرارات التي (Herrington,S, 2007: 35).يتخذونها: 9 - اكتساب المعارف، والخبرات، وفهم طبيعة الأشياء، وتحليلها، وتفسيرها. • 1-المساعدة في الاكتثاف، والتخطيط، واتخاذ القرارات، ومعالجة المعلومات. 11-المساعدة في مواجهة التحديات، والمشكلات التي تواجهه بشكل خلاق. r ا-منح الإحساس بالسيطرة الواعية على تفكيرهم. r ا-تحسين مستوى تحصيلهم، وإكسابهم الثـعور بالثقة بـالنفس في مواجهة المهارات

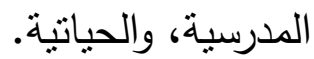

ـ ا-تحقيق التميز، والتفوق في مجموعة واسعة من الميادين، والمجالات؛ منها: المهنية والاجتماعية والثخصية؛ فهي تيسر تحديد الأهداف، وتقييم البدائل، والوصول إلى قرارات سليمة.

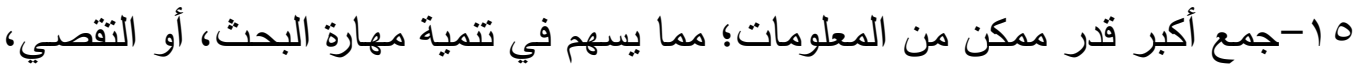
أو الاستقصاء) (Harrison, H, 2006: 36-38) 
يسير التفكير التحليلي ي وفق مراحل محددة وهى:

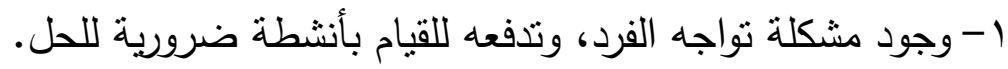
r- الملاحظة، والمشاهدة، وجمع المعلومات الضرورية عن المشكلة؛ لفهمها، وتحليلها. ب- ع-وضع الفروض بعد جمع المعلومات، وتحليلها.

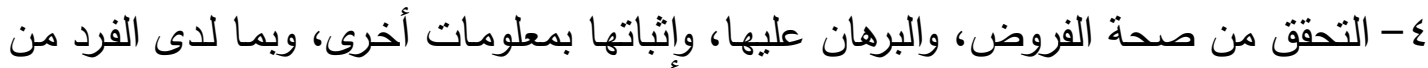
خبرات سابقة (يوسف قطامي، V. . . r: 70 ).

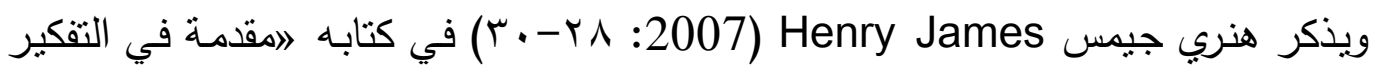
التحليلي Introduction to Analytical Thinking «تحليلًا لهذه الخطوات؛ كما يلي: 1 - المشاهدة المقصودة: ويشترط أن تكون مضبوطة، وشاملة، وأن تحدث في ظروف وأحوال متعددة. r- التحليل والتوفيق: ويشترط فيهما: أ- انتخاب العناصر الضرورية الرئيسة. ب-ملاحظة أوجه الثبه، والاختلاف بين هذه العناصر .

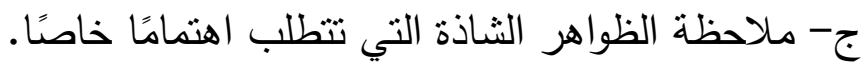
r- بتوظيف خبرات المتعلم السابقة، وترتبط بالموضوع. ع - صياغة الفرضيات التي يمكن الوصول إليها. ه- التحقق من هذه الفرضيات بالتجريب، والاختبار المستمرين.

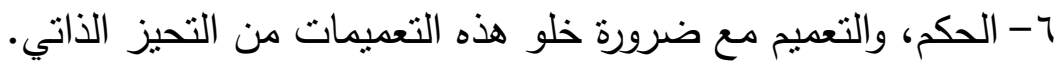

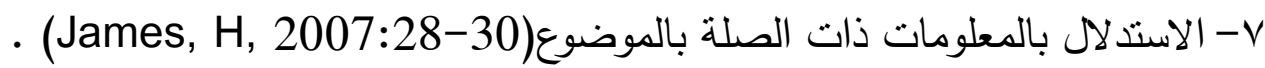

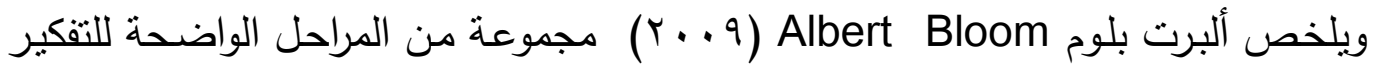

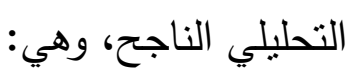

1 - تحديد المشكلة: حيث تحدد المشكلة بتدقيق، وتفحص أسبابها، وتجرى المعطيات المرضية للموقف المشكل؛ وذلك لمعرفة مسببات المشكلة بشكل أكثر تدقيقًا. r-وضع المعايير : إذ يفترض بالفرد تحديد ما يريد إنجازه، وأهدافه، والمراد تحقيقه، وكيفية تحقيقها، والمحكات التي يمكن من خلالها قياس الحلول المتوقعة.

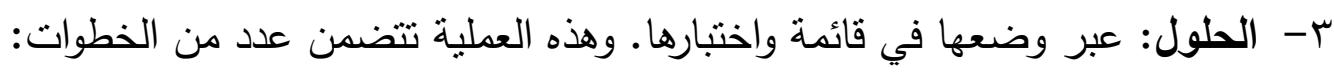
أ- وضع قائمة بالحلول المقترحة التي ستُعتمد. ب-قياس كل حل، والمحك المقابل له، وذلك للتنبؤ بإمكانية الاستفادة من الحل. 
ج- اختيار الحل الأفضل، وفي حال نوفر حل وحيد له الأفضلية يجب العمل على اختبار

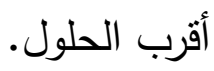

د- تطبيق الحل المقترح، أو مجموعة الحلول المتوفرة. ع - التقييم: يجب في النهاية تقيم الحل بعد تطبيقه، ولا تكتمل عملية حل المشكلة دون تحديد القرار المناسب كتقييم لعملية التفكير التي قام بها الفرد.

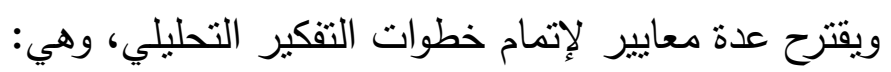
1- الوقوف على المعلومات السابقة أو المعلومات المعطاة مسبقا. r- r اختبارها بتفاصيلها، وبأثكال مختلفة.

r- فحصها فحصا مدققًا عبر التأكد من سير كل حالة منطقيا. ع - التمعن، والنظر في النواقص، والعيوب المحتملة من الاستتناج، أو المناقثة. ه- مقارنة نفس الموقف مع موقف آخر للكاتب نفسه.

צ- متابعة الافتراضات الكامنة، والخفية(100-96 ) سادسا: التفكير التحليلي، وعلاقته بعلم الاجتماع (كمجال - كمادة دراسية):

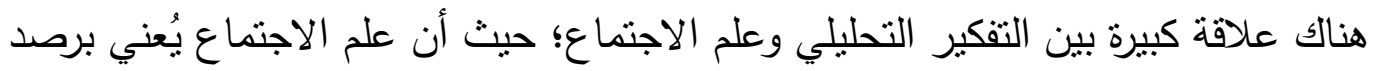

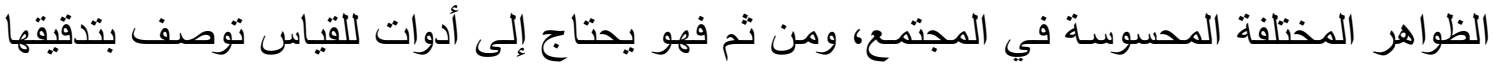

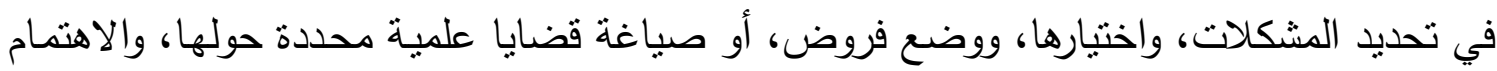

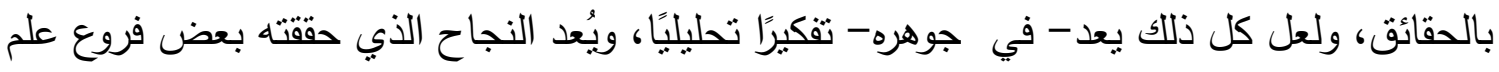
الاجتماع، وإضفاء الطابع العلمي عليها (الدراسات الاجتماعية، والإنسانية) يرجع إلى اعتمادها على لى أنماط محددة من التفكير كالتفكيرين: العلمي، والتحليلي.

( Aron, R,2004: 94)

وعلى صعيد فكرة وظيفية علم الاجتماع؛ فلن يتم ذللك إلا عبر ارتباطه بأنماط متعددة من

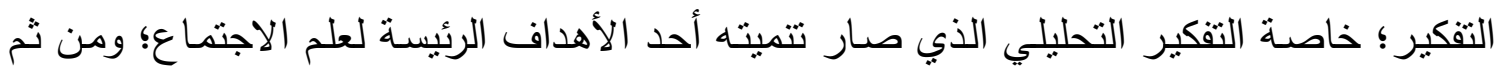
فإن علم الاجتماع سيظل في صورة توازن وتماسك طالما أن هناك عددًا من العوامل الداخلية -

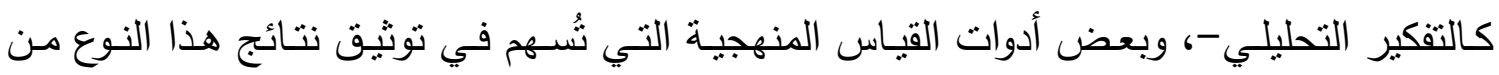
التفكير المنتلة في الحلول، أو المقترحات التي يمكن الاستعانة بها في حل عديد من المشكلات الاجتماعية المختلفة (25-25) :Elder,L,2011).

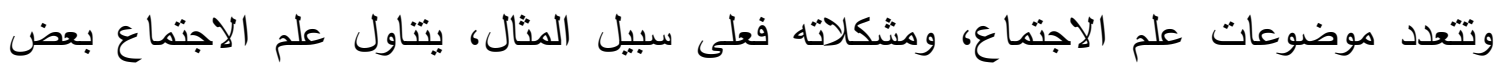

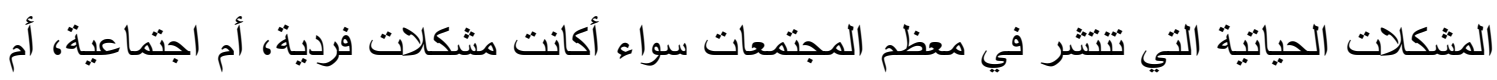
مهنية تلك الششكلات تتطلب حلولا، أو بدائل منتوعة، كما تتطلب استخدام مهارات التفكير التحليلي

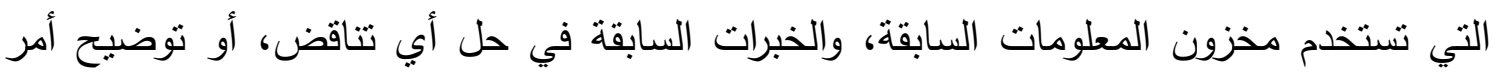


غامض، وتفصيل، أو تجزئة مكونات المشكلة؛ وذلك لاكتشاف بعض العلاقات التي تسهم في حل المشكلة. (Welras, L, 2005: 25)

وتتطلب طبيعة المشكلات الاجتماعية - والتي هي موضوع علم الاجتماع ـاستخدام مهارات التفكير التحليلي، ويتم ذلك عبر تحديدها، وجمع المعلومات عنها، ووضع فرضياتها، وتحديد المعلومات الثخصية الناتجة عن الخبرات الثخصية، وكذلك تحديد المعلومات الإضافية

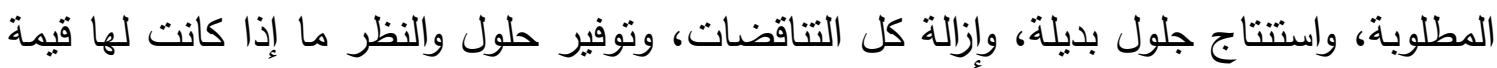

تعميمية من عدمه. (Paxton, D,2005: 22-25)

ويعتمد حل مشكلات علم الاجتماع على التفكير الموجه نحو حل مشكلة ما، وهذا ينطلب القيام بنوعين متداخلين من أنواع التفكير وهما: التفكير التحليلي الذي يهدف إلي تقسيم المشكلة،

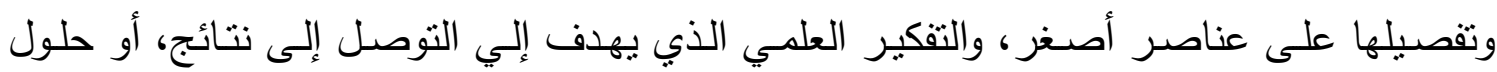

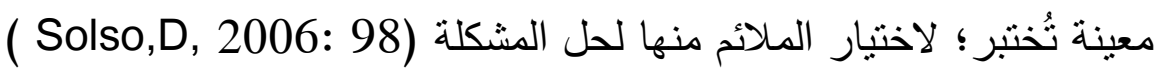

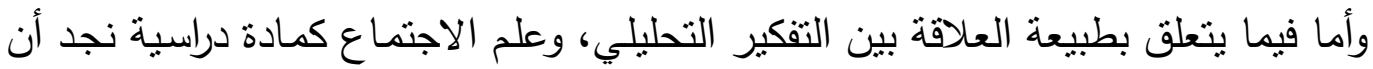

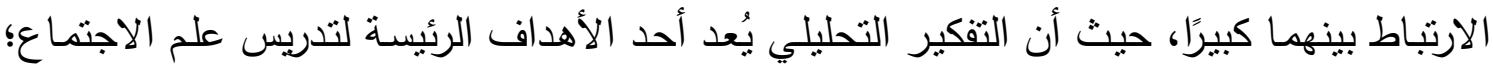

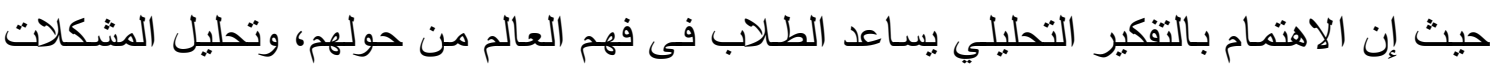
الاجتماعية، والأحداث، والمواقف التي يتعرضون لها، وتكوين رؤية عقلية نقدية تجاهها .(Durham, A,2009: 13) ويؤكد كيلدار ريتشارد Keldar Richard (2006) أهمية تكامل مهارات التفكير التحليلي مع محتوى علم الاجتماع ليصبح أكثر مشاركة في اكتثاف المعرفة التي ترتبط بالهتمع، وتحليلها؛ فالتفكير التحليلي بساعد الطلاب في تكوين رؤية عقلية واضحة، ووجهة نظر مبنية على تحليل

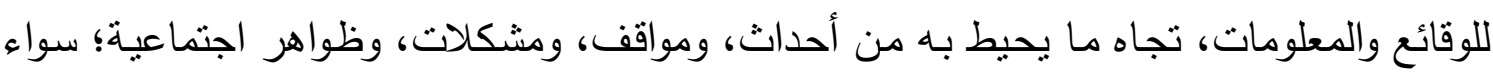

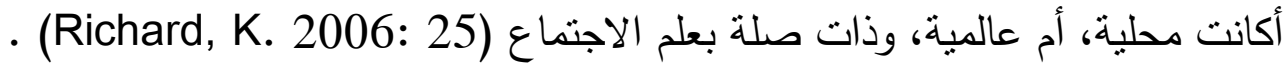

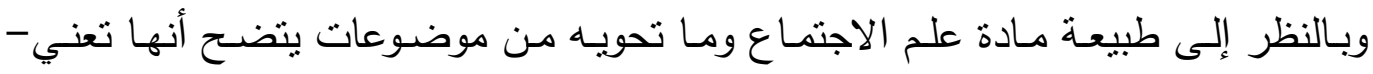
بالدرجة الأولي - بالإنسان، والمجتمع الذي ينتمي إليه، ومن ثم يصبح منهُج علم الاجتماع منهجًا جيدًا عندما ينمى القدرة للطلاب على التحليل الجيد للقضايا، والمشكلات الاجتماعية، وتحسين فهمهم، ووعيهم بهذه القضايا، والمشكلات وذلك باستخدام طرائق تدريس جيدة، وأنشطة تعليمينة

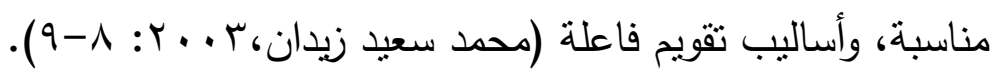

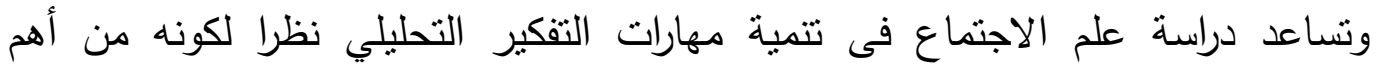

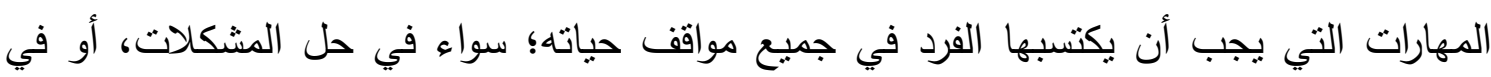
التخطيط للمستقبل؛ خاصة في ظل النطور التكنولوجي الهائل الذي ينطلب من الفرد أن يقابل هذا التطور بتطور مماتل في مهاراته، وقدراته؛ كى بستطيع مواجهة هذا التطور، ويفهمه، ويحلله وبناء 
على ذلك يتخذ قرارًا صائًًا يؤثر في حياته، وفي نفس الوقت يتحمل مسئولية قراراته على المستويين: الفردي، والاجتماعي.(Karin, A: 2005: 21) وهناك ارتباط وثيق بين أهداف تدريس علم الاجتماع، وتتمية مهارات التفكير التحليلي حيث

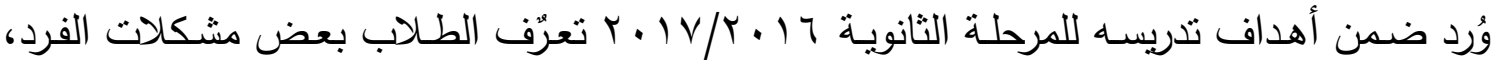

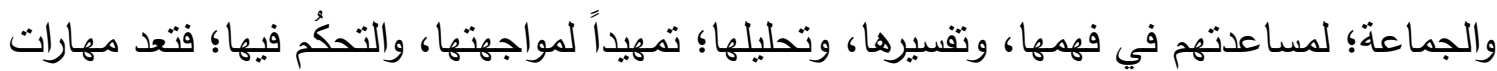

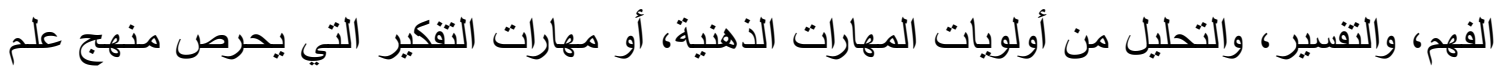
الاجتماع على تتميتها لدى طلابه.

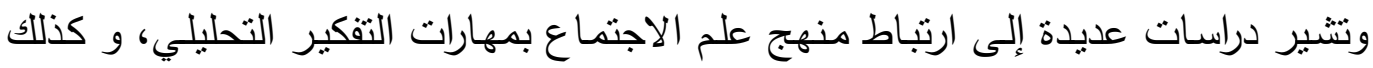

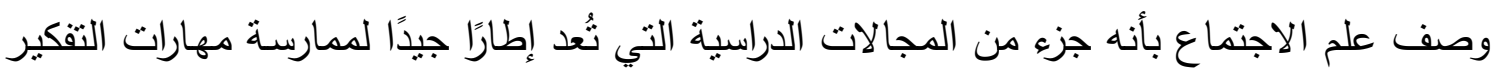

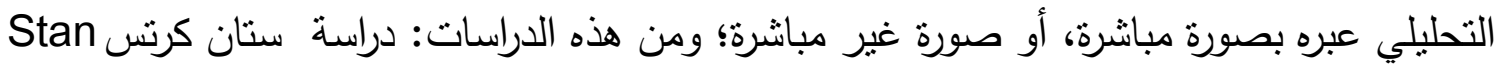
ناله Kurits

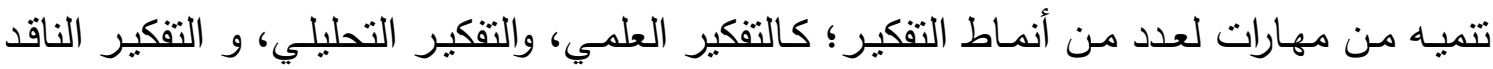
وأكدت نتائج الدراسة أن مناهج علم الاجتماع قد أولت اهنماءمًا لمهارات التفكير العلمي تليها مهارات

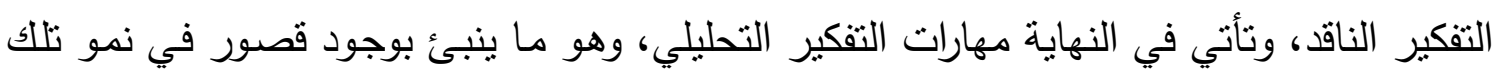

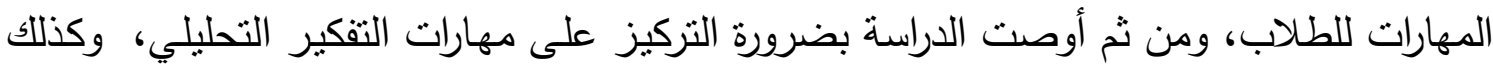
تدريب معلمي علم الاجتماع على تعليم طلابهم منل هذه المهارات. ودراسة ماريان هارديمان Marian Hardiman

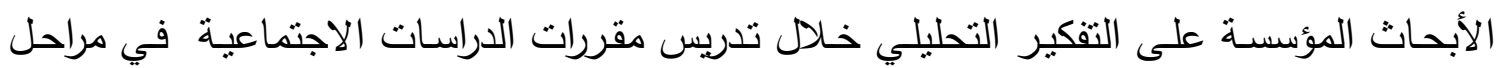

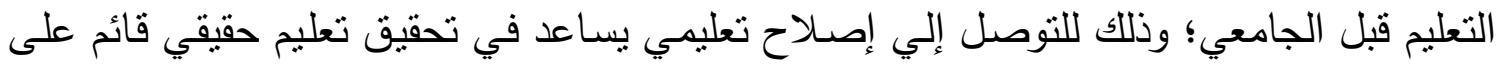
التفكير للطلاب؛ حيث حلل مجموعة من الأبحاث التي عنيت بالتفكير التحليلي في الفترة ما بين

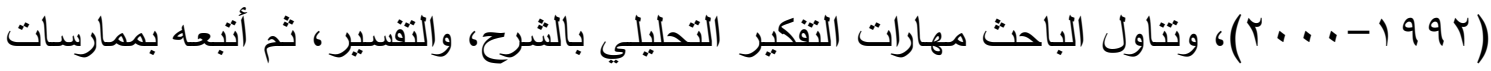
مقترحة لنطبيق كل مهارة، وأوصت في دراستها ضرورة دمـج معلمي الدراسات الاجتماعية لنتائج تللك الأبحاث- الخاصة بالتفكير التحليلي- بإطار عملهم التدريسي؛ مما يجعل ممارساتهم، وخبراتهم التدريسية أكثر فاعلية، وإنجازا.

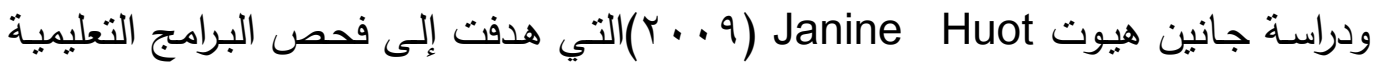
المختلفة، ومراجعتها؛ بهدف توجيه المناهج الدراسية في كلية أورنتاريو المجتمعية، حيث اختيرت

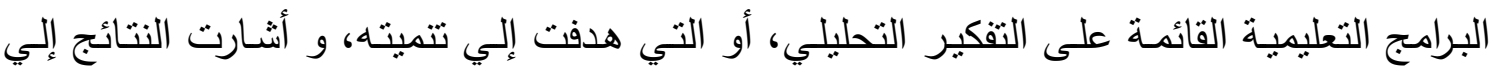

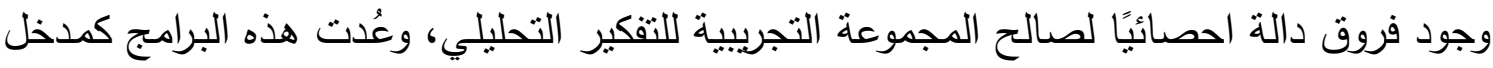

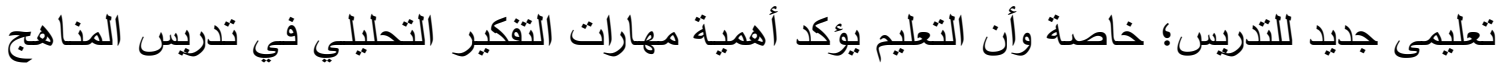

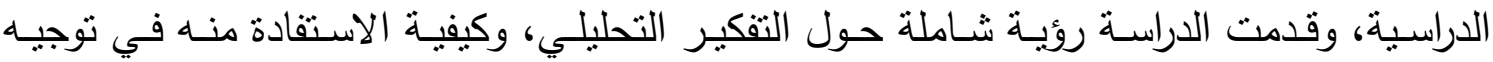


المناهج الدراسية، وكذلك مناقثة الإسهامات التعليمية التي يمكن ان تقدمها مثل هذه البرامج، والتي تسهم في نطوير الكليات.

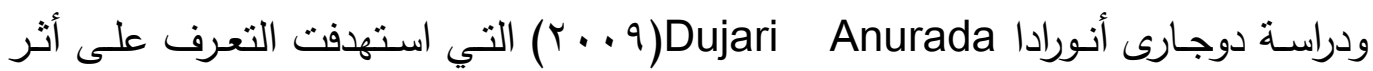
استخدام نموذج أبعاد التعلم في تدريس بعض القضايا الإنسانية؛ لتتمية مهارات التفكير التحليلي

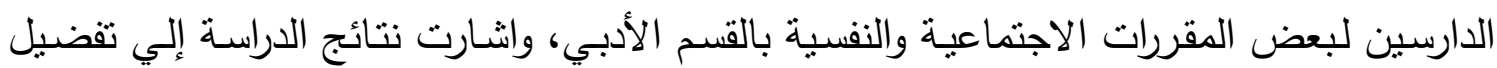

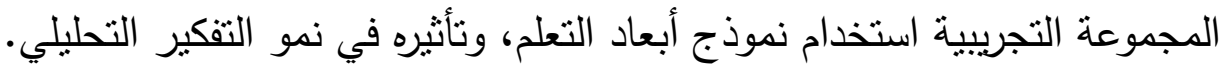

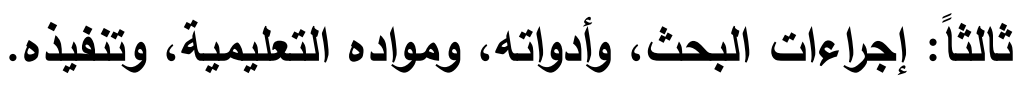

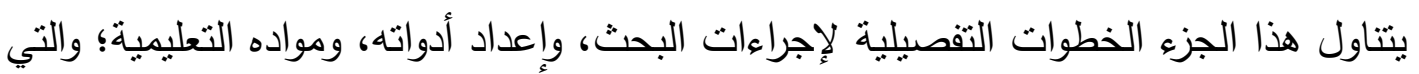

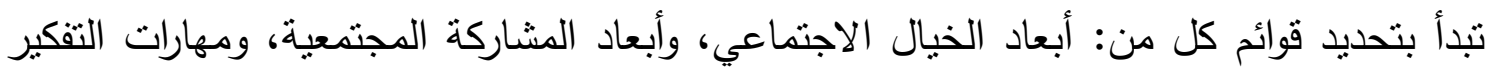
التحليلي، وخطوات إعداد الوحدة المقترحة في علم الاجتماع، ثم إعداد دليل المعلم في تتفيذ هذه الوحدة، وكذللك إعداد مقياس نمو قيم المشاركة المجتمعية، واختبار قيم المشاركة المجتمعية (اختبار

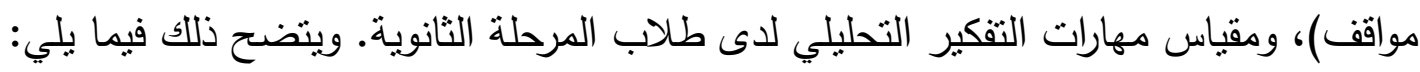

\section{أولًا: إعداد قائمة أبعاد الخيال الاجتماعي: 1 - إنميم مفردات القائمة:}

كان لازمًا لإعداد قائمة أبعاد الخيال الاجتماعي، تحديد هذه الأبعاد واختيارها بشكل صائب،

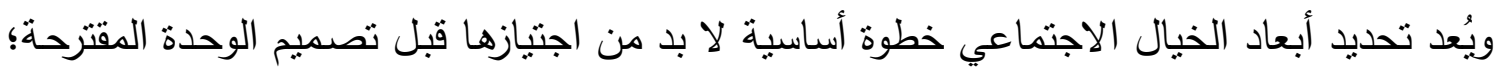

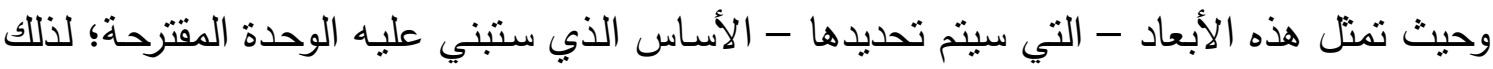
فقد حددت الباحثة دفردات (أبعاد) الخيال الاجتماعي بطريقة وظيفية في ضوهي لابداد عدة محاور ، هي:

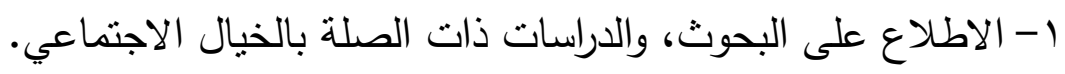
r- دراسة نظرية حول الخيال الاجتماعي. وفي ضوء هذين المحورين حُددت أبعاد الخيال الاجتماعي، وقد راعت الباحثة عدة شروط عند إعدادها هذه القائمة، وهي: 1- البساطة، والوضوح في صياغة أبعاد الخيال الاجتماعي. r- الواقعية: قابلية هذه الأبعاد للتعلم من قبل طلاب البعاد المرحلة الثانوية.

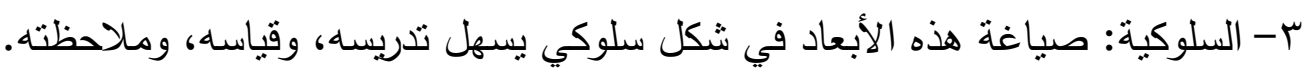
ع - التسلسل: أن تُوضع هذه الأبعاد في نسلسل منطقي. وقد اشتملت القائمة في صورتها الأولية على ثمانية أبعاد. 


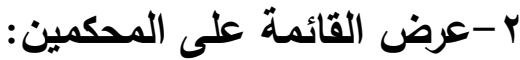

عُرِضَت هذه القائمة على مجموعة من المحكمين في مجال علم الاجتماع، وطرائق تدريسه؛ وذللك للتأكد من صلاحية القائمة للنطبيق، والتعرف على منى آرائهم بشأن: 1- مدى ملاعمة الأبعاد لطبيعة الخيال الاجتماعي.

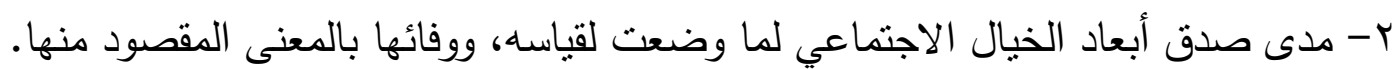
r- مدى مناسبة هذه الأبعاد لمستوى طلاب المرحلة الثانوية.

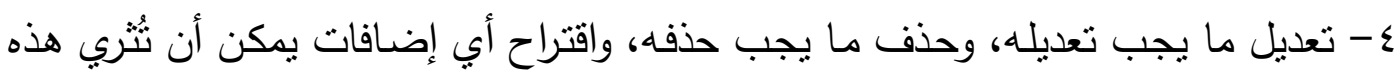
القائمة- إن وجدت- بعد تعديلات السادة المحكمين. وقده جـاءت آراء المحكمين كالتـالي: استبعاد البُعد الخـاص بالجدل العقلي؛ بوصفه بعدًا متضمنا بشكل تلقائي في بعد استخدام الحجج.

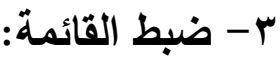

بعد تحكيم القائمة، وإجراء التعديلات اللازمة صارت القائمة في صورتها النهائية * مكونة من

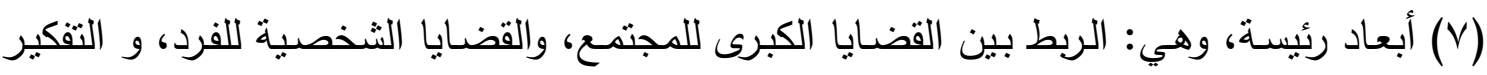

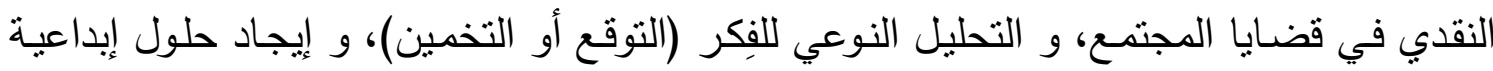

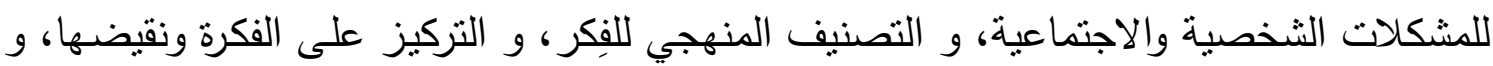

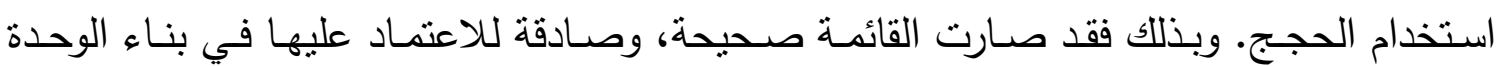

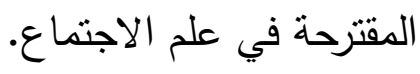

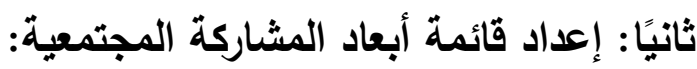

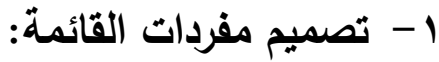

لإعداد قائعـة أبعاد المشـاركة المجتمعيـة كان لا بـد من تحديد هذه الأبعاد واختبارها بشكل

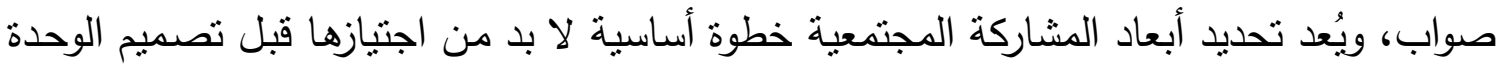

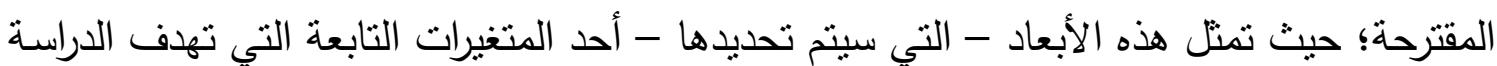
إلى تتميتها عبر الوحدة المقترحة.

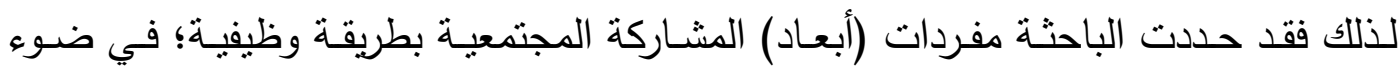

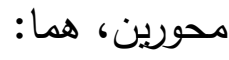

1- الاطلاع على البحوث والدراسات ذات الصلة بالمشاركة المجتمعية. r - براسة نظرية حول المشاركة المجتمعية. وفي ضوء هذين المحورين حُددت أبعاد المشاركة المجتمعية، وقد راعت الباحثة عدة شروط عند إعدادها هذه القائمة، وهي: 
1 - البساطة، والوضوح في صياغة أبعاد المشاركة المجتمعية.

r- الواقعية: قابلية هذه الأبعاد للتعلم من قبل طلاب المرحلة الثانوية.

r- السلوكية: صباغة هذه الأبعاد في شكل سلوكي يسهل تدريسه، وقياسه، وملاحظته. ع - التسلسل: أن تُوضع هذه الأبعاد في تسلسل منطقي.

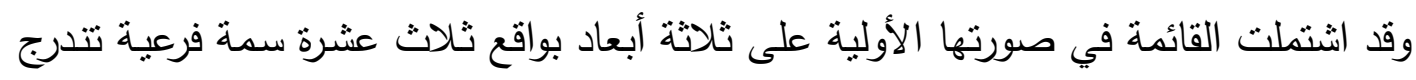
تحت كل بعد رئيس من أبعاد القائمة. ب-عرض القائمة على المحكمين: عُرِضَتَ هذه القائمة على مجموعة من المحكمين في مجال علم الاجتماع، وطرائق تدريسه؛ وذللك للتأكد من صلاحية القائمة للتطبيق، والتعرف على آرائهم بشأن: 1 - هدى ملاعمة الأبعاد لطبيعة المشاركة المجتمعية.

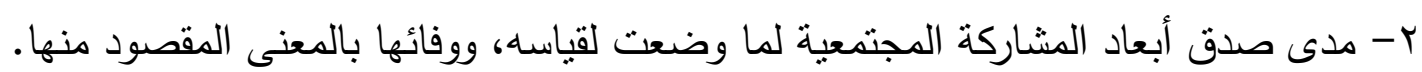
r- عدى مناسبة هذه الأبعاد لمستوى طلاب المرحلة الثانوية.

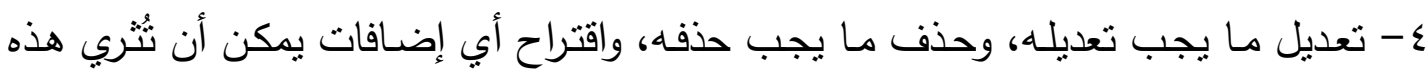
القائمة- إن وجدت - بعد تعديلات السادة المحكمين.

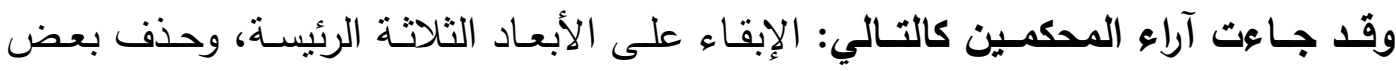
العبارات (السمات) المتثابهة، ودمجهم سويا. ج- ضبط القائمة: بعد تحكيم القائمة، وإجراء التعديلات اللازمة صارت القائمة في صورتها النهائية * مكونة من

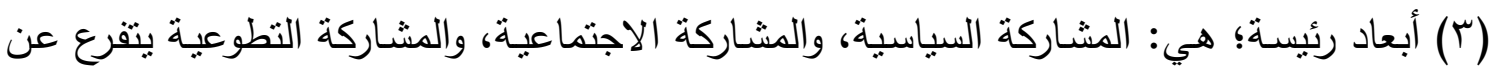
كل بعد عشر سمات فرعية. وبذلك فقد صارت القائمة صحيحة، وصادقة للاعتماد عليها في بناء الوحدة المقترحة في علم الاجتماع. ثالثا: إعداد قائمة مهارات التفكير التحليلي: 1 - تصميم مفردات القائمة:

لإعداد قائمة مهارات التفكير التحليلي كان لا بد من تحديد هذه المهارات، واختيارها بشكل

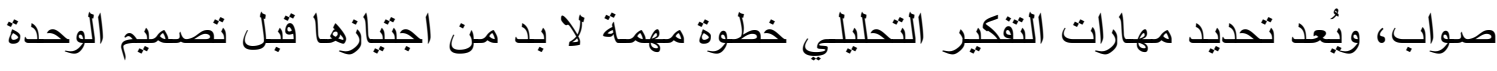

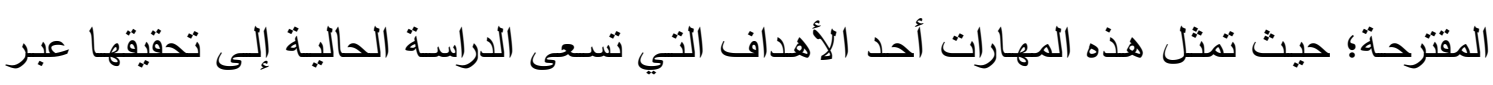
الوحدة المقترحة. لذلك فقد حددت الباحثة مفردات (مهارات) التفكير التحليلي بطريقة وظيفيـة؛ في ضـوء

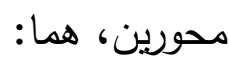

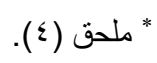


1- الاطلاع على البحوث والدراسات ذات الصلة بالتقكير التحليلي.

r - دراسة نظرية حول التفكير التحليلي.

وفي ضوء هذين المحورين حُدت مهارات التفكير التحليلي، وقد راعت الباحثة عدة شروط عند إعدادها هذه القائمة، وهي:

1 - البساطة والوضوح في صياغة مهارات التفكير التحليلي.

r - الواقعية: قابلية هذه الأبعاد للتعلم من قبل طلاب المرحلة الثانوية.

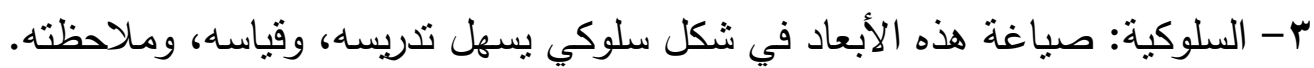

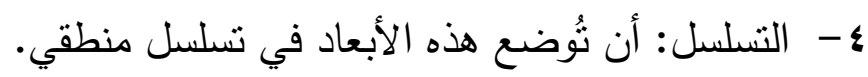

وقد اشتملت القائمة في صورتها الأولية على أحد عشر بُعبدًا.

ץ-عرض القائمة على المحكمين:

عُرِضَتَ هذه القائمة على مجموعة من المحكمين في مجال المناهج، وطرائق التدريس؛ وذلك

للتأكد من صلاحية القائمة للتطبيق، والتعرف على آرائهم بشأن:

1- مدى ملاعمة المهارات لطبيعة التفكير التحليلي.

r- مدى صدق مهارات التفكير التحليلي لما وضعت لقياسه، ووفائها بالمعنى المقصود منها. r- مدى مناسبة هذه المهارات لمستوى طلاب المرحلة الثانوية.

ع - تعديل ما يجب تعديله، وحذف ما يجب حذفه، واقتراح أي إضافات يمكن أن تُري هذه القائمة

- إن وجدت -بعد تعديلات السادة المحكمين.

وقد جاءت آراء المحكمين كالتالي: استبعاد بعض الأبعاد؛ لعدم انتمائها لمهارات التفكير

التحليلي؛ مثل: الملاحظة وإدراك العلاقة بين الكل والجزء، وإيجاد الأنماط.

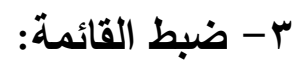

بعد تحكيم القائمة، وإجراء التعديلات اللازمة صارت القائمة في صورتها النهائية * مكونة

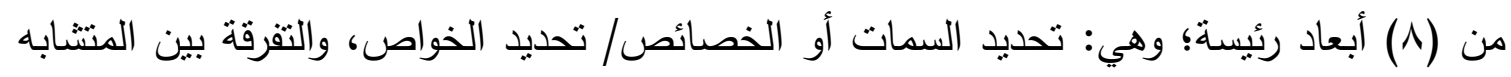

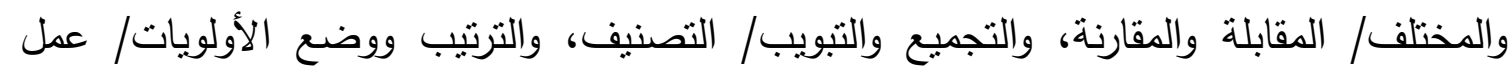

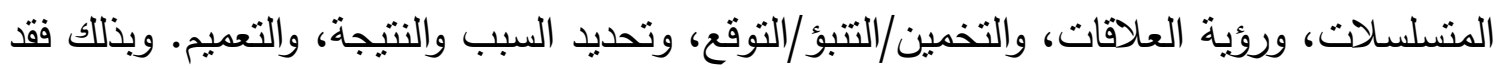
صارت القائمة صحيحة، وصادقة للاعتماد عليها في بناء الوحدة المقترحة في علم الاجتماع. 
رابعًا: إعداد الوحدة المقترحة في علم الاجتماع (كتاب الطالب):

قد مر إعداد تلك الوحدة المقترحة بعدد من الخطوات سعت إلى تحديد أهدافها، وموضوعاتها،

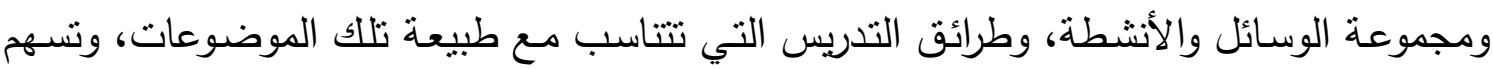

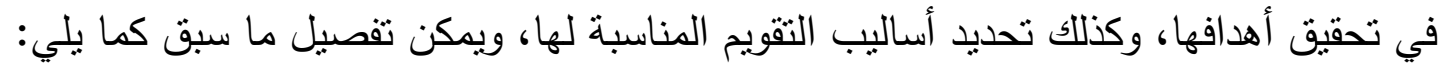
1- إعداد الوحدة المقترحة في ضوء الخيال الاجتماعي في صورتها الأولية:

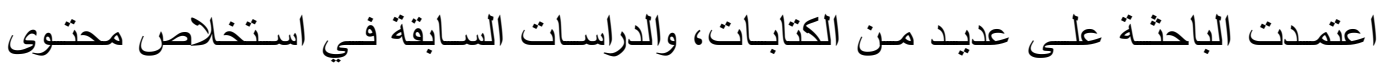
مكوناتها، وقد صُمدت هذه الوحدة بحيث اشتملت على أبعاد المشاركة المجتمعية، وأبعاد الخيال

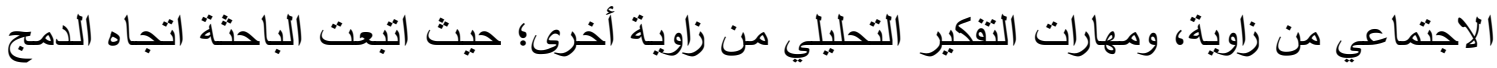

في تدريس مهارات التفكير (التحليلي) مباشرة في مثن، أو محتوى موضوعات التهات الوحدة التعليمية. وقد تم تصميم الوحدة التعليمية في صورتها المبئية بحيث انتملت على المكونات التالية: (العنوان - المقدمة - الأهداف السلوكية - المحتوى العلمي - الوسائل والأنشطة التعليمية أساليب التقويم - المراجع أو المصادر).

\section{r r برض الوحدات التعليمية على مجموعة من المحكمين:}

بعد الإعداد المبئي للوحدة التعليمية عُرضت على على عدئه من من المتخصصين في مجال علم الاجتماع، وطرائق تدريسه؛ للاستفادة من آرائهم، وتوجيهاتهم في ضبط الوحدة الوحدة التعليمية؛ للتأكد مما يلي:

- مدى مناسبة موضوعات الوحدة التعليمية لقيم المشاركة المجتمعية المراد تتميتها.

-مدى مناسبة موضوعات الوحدة التعليمية لمهارات التفكير التحليلي المراد تتميتها.

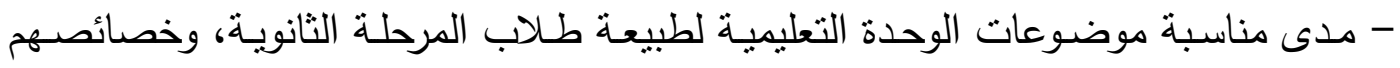

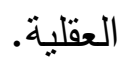

- مدى الارتباط بين الأهداف السلوكية للوحدة التعليمية، ومحتواها، وأساليب تقويمها. - إضافة، أو حذف ما يرونه مناسبًا.

\section{r- تصميم الوحدة التعليمية في صورتها النهائية:}

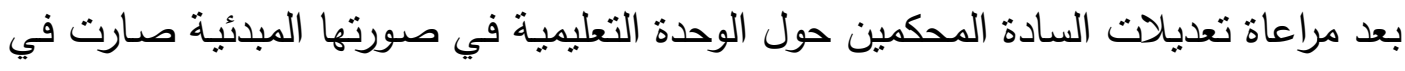

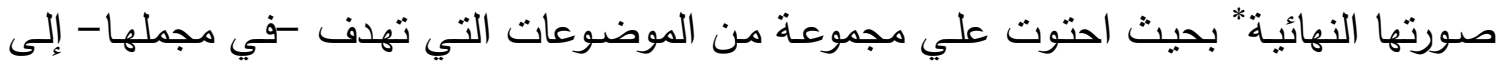
اكتساب قيم المشاركة المتمعية، ومهارات التفكير التحليلي المراد تتميتهما، لدى طلاب المرحلة 
وقد رُوعِي عند تصميم الوحدة بشكل عام وجود العناصر الآتية:

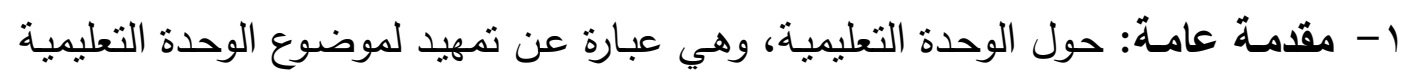
بحيث تحدد للمتعلم أهمية دراستها، وهي توضح الفكرة الرئيسة التي تدور حولها الوحدة التعليمية.

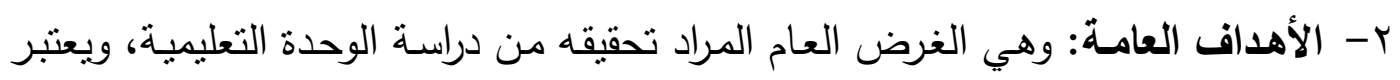
السبب الرئيسي لدراسة هذه الوحدة.

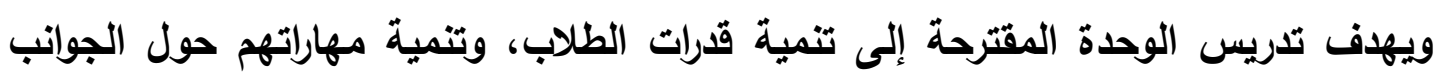
التالية: 1 - تحديد معني المشكلات الاجتماعية، وأبعادها. r- بعرف بعض قضايا المجتمع المصري، ومشكلاته. ץ- تحديد معني البطالة، وأسبابها، ومخاطرها. ـ - تعرف مفهوم التطرف الفكري، وأسبابه، ومخاطره على الفرد والمجتمع. 0- توضيح معني العنف ضد المرأة، ومسبياته، ونتائجه. 7- تفسير معني التغير الاجتماعي، ومظاهره، وعواقبه الثخصية، والاجتماعية. V V - Vديد مفهوم الاغتراب، ومظاهره، وانعكاساته على الفرد والمجتمع. 1- الربط بين مشكلات الفرد الخاصة، ومشكلات مجتمعة العامة. 9- نق الممارسات الاجتماعية الموجودة في المجتمع المصري. . - - تفسير المشكلات الاجتماعية من منظور متعدد.

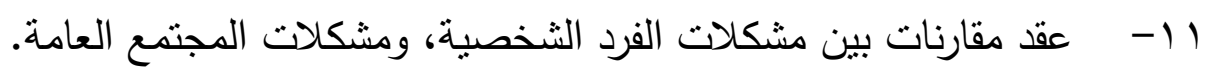
r ا- تقديم أمثلة، وحلول واقعية لهذه المشكلات الاجتماعية.

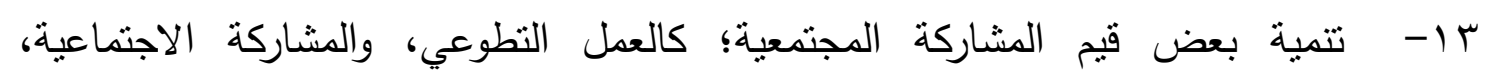
والمشاركة السياسية.

§ ا- - تعرف معنى التفكير التحليلي، ومهاراته.

10- استخدام مهارات التفكير التحليلي في مواقف حياتية مختلفة.

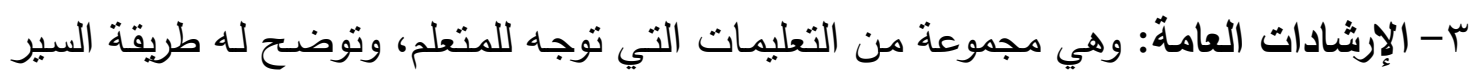
في عملية التعلم، وما ينبغي أن يؤديه من أنشطة تعليمية متتوعة، وكيفية ممارستها.

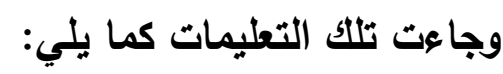

( ) أقرأ المقدمة فهي توضح الإطار العام للوحدة التعليمية.

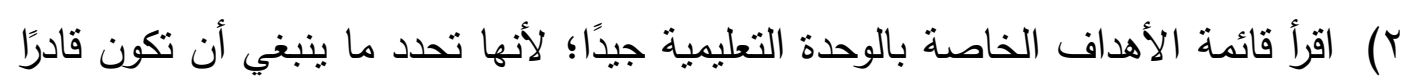
عليه بعد الانتهاء من دراستها. r) اقرأ محتوى الوحدة التعليمية قراءة متأنية. 
§) نفذ الأنشطة التعليمية الموجودة داخل الوحدة التعليمية؛ مسترشدًا بالأمثلة الموضحة

داخلها.

0) حاول الإجابة عن أسئلة التقويم الملحقة في نهاية الوحدة التعليمية.

أما فيما يتعلق بمكونات الوحدة تعليمية على حدة، فقد تضمنت ما يلى: (العنوان - المقدمة -

الأهداف التعليمية أو السلوكية - المحتوى العلمي - الوسائل والأنشطة التعليمية - استراتيجيات

$$
\begin{aligned}
& \text { التدريس - أساليب النقويم - المراجع والدصادر). } \\
& \text { وفيما يلي تفصيل ما سبق: } \\
& \text { > عنوان الوحدة: }
\end{aligned}
$$

تخصص أول صفحة من الوحدة لكتابة العنوان الخاص بها في ضوء المكونات الداخلية

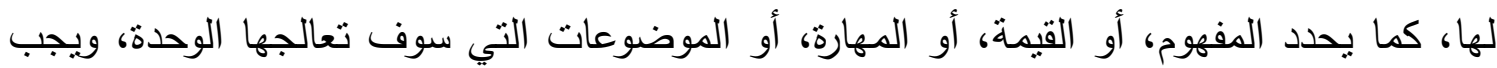

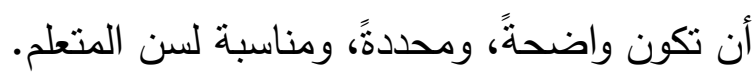

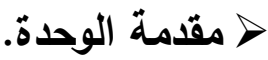

صيغت مقدمة الوحدة التعليمية بحيث تعتبر تمهيدًا لموضوعاتها، وهي تحدد للمتعلم أهمية دراسة الوحدة، وتوضح الفكرة الرئيسة التي تدور حولها الوحدة مع توضيح الفِكر الثنانوية.

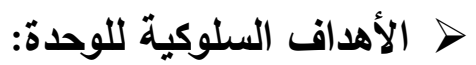

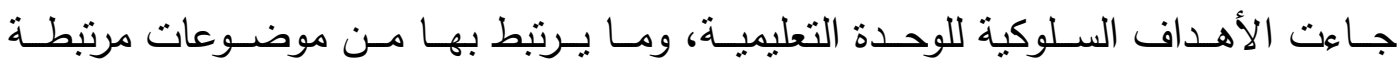
بموضوعات الوحدة، وتصف منتج التعلم الذي يجب أن يصل إليه كل متعلم عند الانتهاء من دراسة لإسة

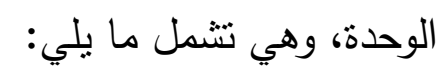

- الجوانب المعرفيَّة: بما تشمله من الحقائق، والدفهومات، والتعميمات، والفروض، والنظريات. - الجوانب الوجدانيَّة: وتنتمل القيم، والاتجاهات، وأوجه التقدير، ، والميول.

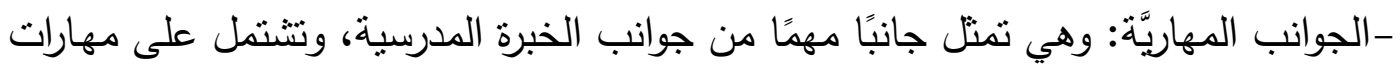
اجتماعيَّة، ومهارات حركيَّة، ومهارات معرفيَّة (مهارات التفكير التحليلي). ويشير جدول( (1) إلى مجموعة الأهداف السلوكية للوحدة التعليمية المقترحة.

$$
\text { جدول (1): }
$$

الأهداف الاجرائية للوحدة التعليمية.

$$
\text { أهدافها الاجرائية. }
$$

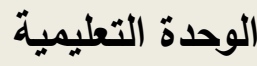

الموضوع الأول: المشكلات الاجتماعية(طبيعتها-ماهيتها). 1. يُعرف معنى المشكلات الاجتماعية. r r بُ بُعدد أبعاد المشكلات الاجتماعية. 


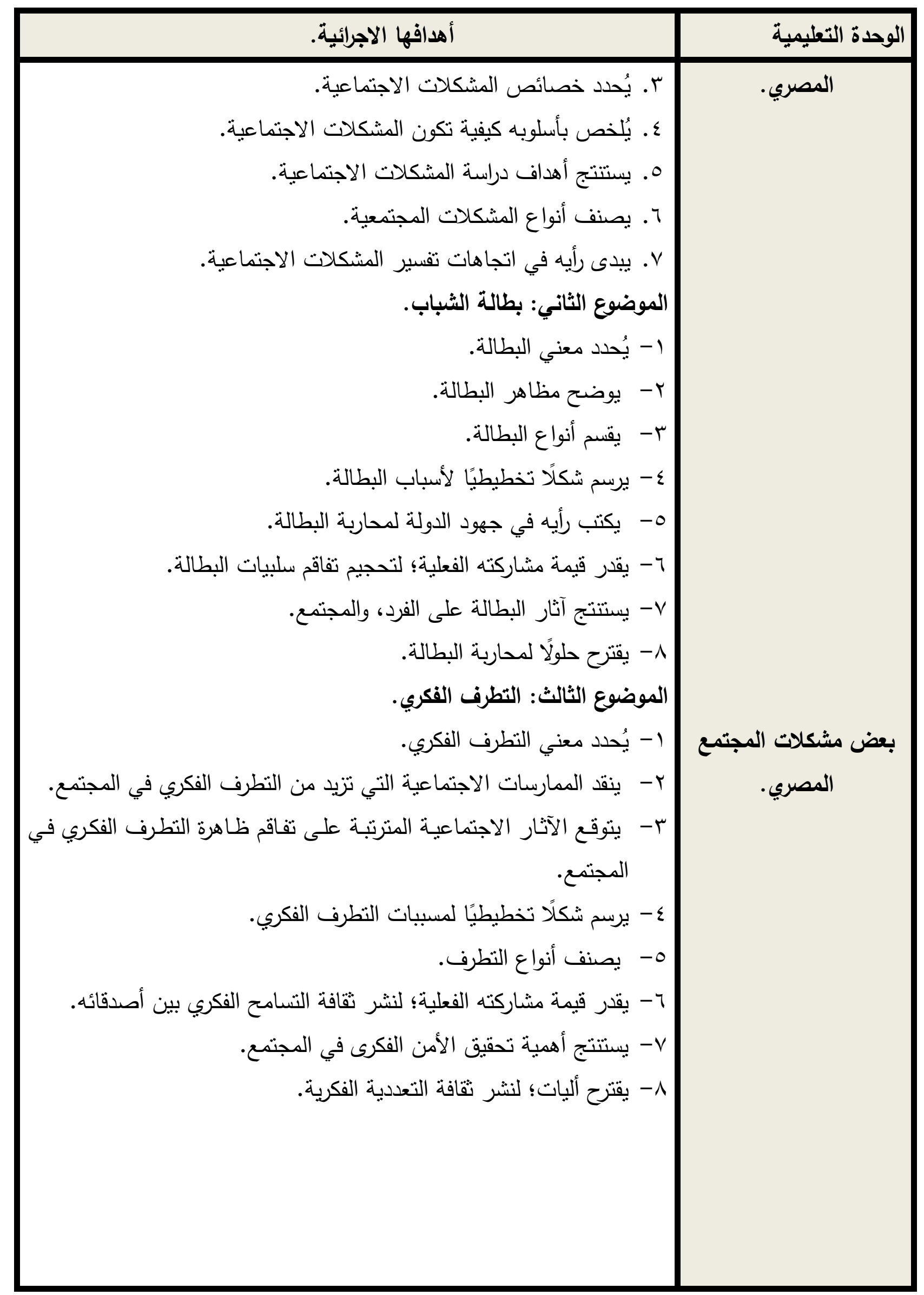




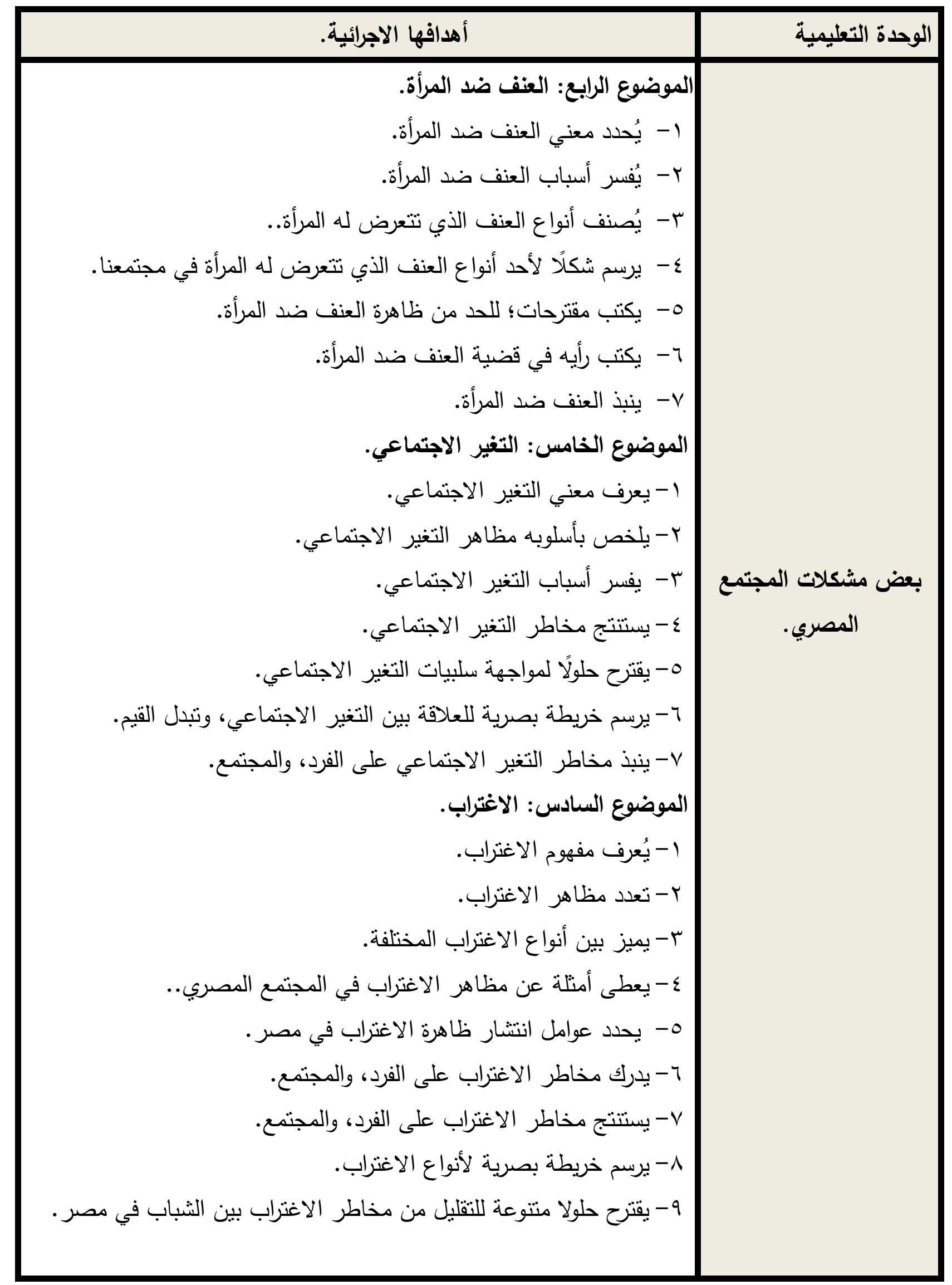


صيغ محتوى الوحدة التعليمية على هيئة مجموعة من العناصر، والفِكر الأساسية، والثنانوية بصورة واضحة، بحيث تسـاعد الطالب في استيعابها بسهولة، ويسر ، وتقدم في صسور متعددة، وبالاستعانة بأكثر من مرجع؛ حتى يتتاسب مع قدرات المتعلمين واستعداداتهم وميولهم.

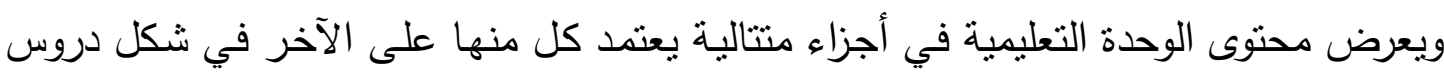
متتالية، وتعتمد هذه الأجزاء على الأهداف المحددة للوحدة التعليمية، والمواد التعليمية المتاحة، ويعتبر

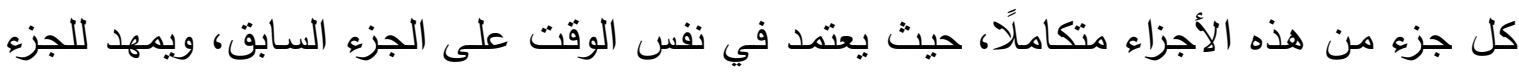

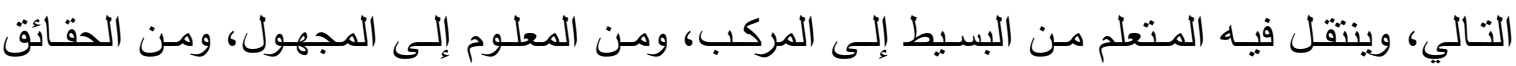

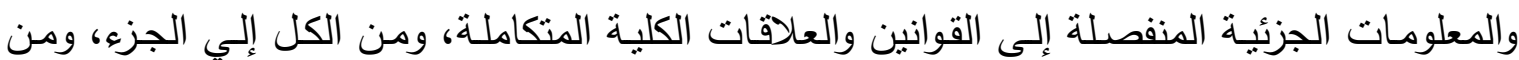
القديم إلي الحديث، ... وهكذا. وقد اختير محتوى هذه الوحدة وفق اختيارات عدد من المتخصصين في مجال علم الاجتماع،

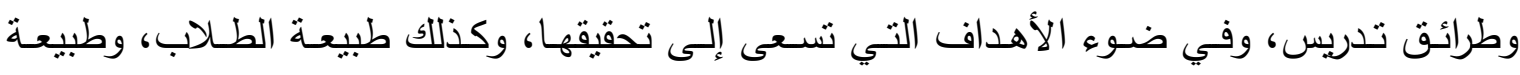

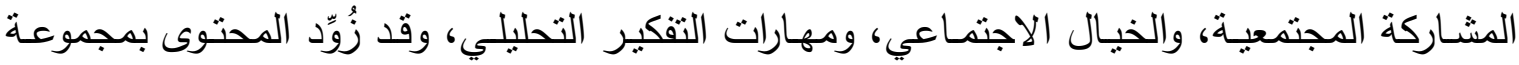

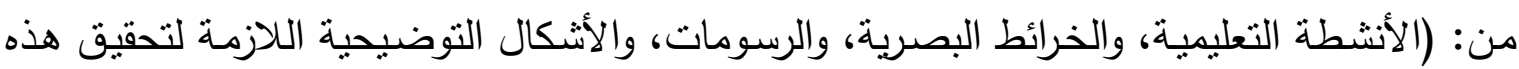
الأهداف)، كذلك اثتمل المحتوى على مجموعة من التدريبات، والأسئلة عقب كل درس من دروسها،

ويمكن توضيح موضوعات هذه الوحدة في جدول: (r). جدول(r):

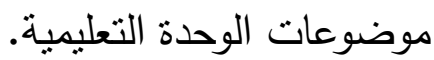

\begin{tabular}{|c|c|}
\hline الموضوعات & الوحدة التعليمية \\
\hline الموضوع الأول: المشكلات الاجتماعية(طبيعتها-ماهيتها). & \multirow{6}{*}{ بعض مشكلات المجتمع } \\
\hline ا الموضوع الثاني: بطالة الثباب. & \\
\hline الموضوع الثالث: النطرف الفكري. & \\
\hline الموضوع الرابع: العنف ضد المرأة. & \\
\hline الموضوع الخامس: التغير الاجتماعي. & \\
\hline الموضوع السادس: الاغتراب. & \\
\hline
\end{tabular}


تضمنت دروس الوحدة التعليمية عددًا من الرسوم والأثكال، أو الخرائط الذهنية التي تيسر

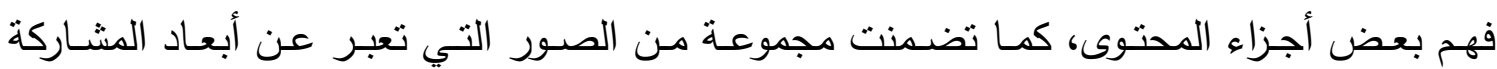

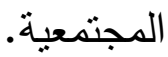

كما تضمنت دروس الوحدة التعليمية عددًا من الأنشطة التي تعكس مدى فهم المتعلم لمحتوى

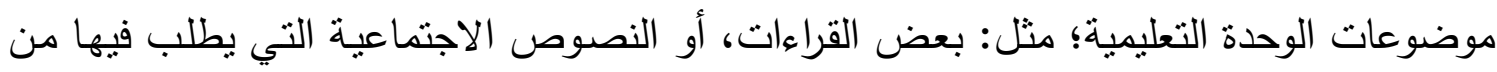

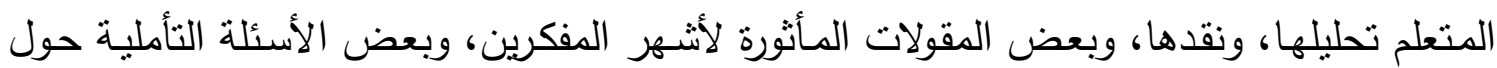
موضوع كل درس من دروس الوحدة التعليمية.

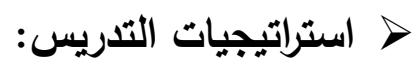

اختيرت مجموعة من الاستراتيجيات التدريسية التي تتلاعم مع طبيعة علم الاجتماع بشكل

عام، ومناسبة للخصائص العقلية لطلاب المرحلة الثانوية، ومنها:

$$
\begin{aligned}
& \text { - - العصف الذهني. } \\
& \text { - - حل المشكلات. } \\
& \text { - فكر -زاوج-شارك. } \\
& \text { - ما وراء المعرفة. } \\
& \text { > أساليب تقويم الوحدة: }
\end{aligned}
$$

تضمنت دروس الوحدات التعليمية مجموعة من الأسئلة، وهي: التقويم المرحلي الذي نتعرف

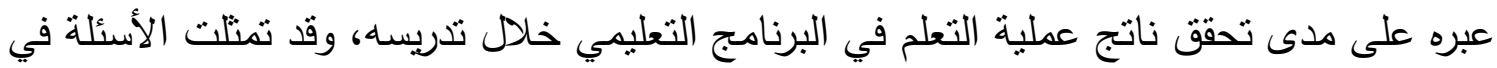

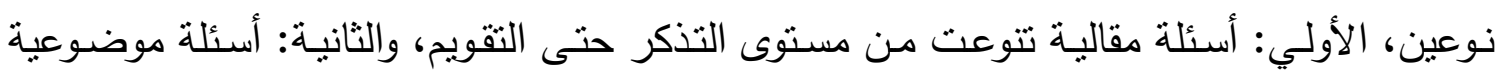
تتتوع ما بين أسئلة التكملة، وأسئلة الصواب والخطأ. وتقويم نهائي يتمثل في مقياس لقيم المشاركة المجتمعية، واختباره، ومقياس مهارات التفكير التحليلي الذي نتعرف عبره على مدى تحقق ناتج عملية التعلم في البرنامج التعليمي بعد تدريسه.

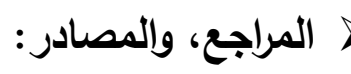

أُلحقِت مجموعة من المواد المطبوعة عقب الوحدة التعليمية في ملحق خاص بها، والتي يمكن للطلاب الاستعانة بها في حالة الاستزادة العلمية حول الوحدة التعليمية. خامسا: دليل المعلم في الوحدة المقترحة: دليل المعلم عبارة عن كتيب مطبوع يعرض: مقدمة عن عن أهمية الوحدة التعليمية، وأهدافها العامة والسلوكية، كما يشمل وصف التقويم، وهو يوفر للمعلم مجموعة من الإرشادات التي تساعده في التوجيه، والتفاعل مع الطلاب خلاد عملية التدريس. 


\section{وقد أُعِدَّ هذا الاليل وفق الخطوات التالية: \\ 1- إعداد الدليل في صورته الأولية:}

أعدت الباحثة دليل المعلم في صورته الأولية متضنيًا الجوانب التالية:

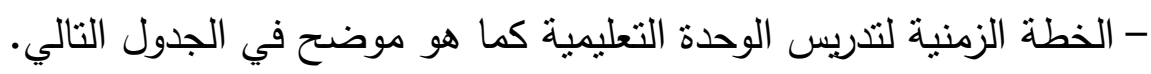

جدول (r):

الخطة الزمنية لتدربس الوحدة التعليمية.

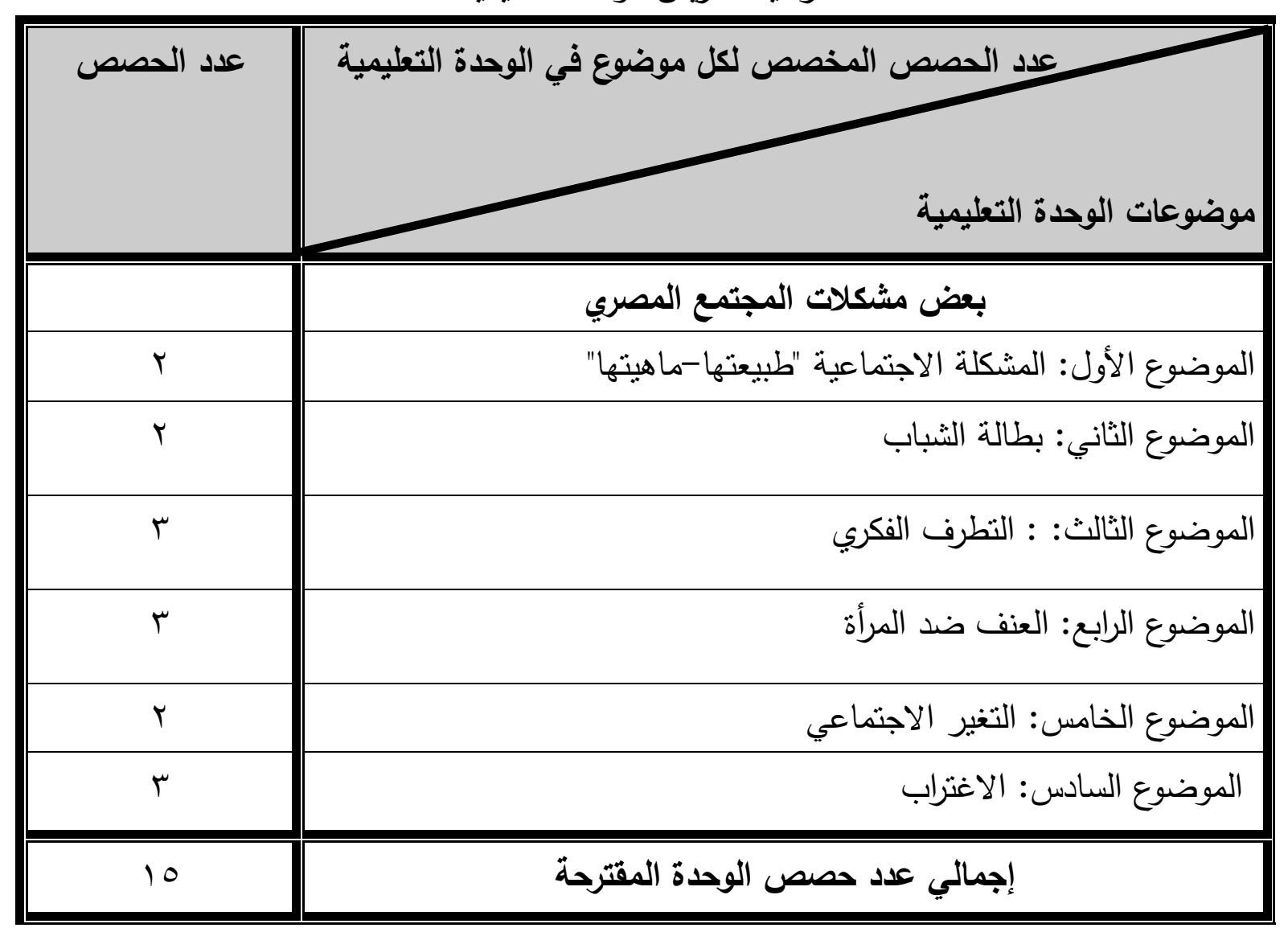

- بعض استراتيجيات التدريس المقترحة لتدريس الوحدة التعليمية.

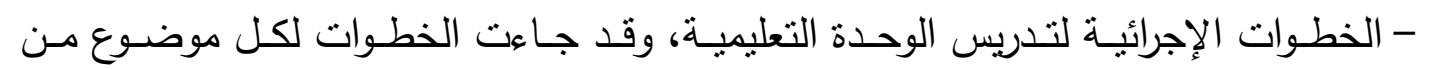

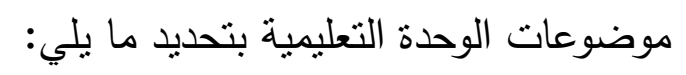

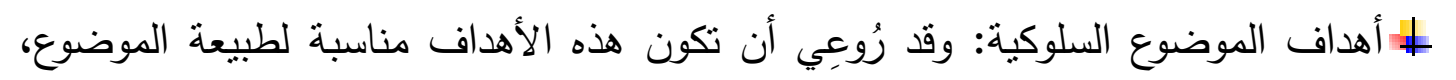
ويمكن تحقيقها، وملاحظتها، وقياسها. \$ الوسائل التعليمية: وقد رُوعي ملائمتها لمحتوى الموضوعات، بحيث تسهم في تيسير تعلم بعض أجزاء المحتوى.

|| الأنشطة التعليمية: وقد رُوعي ملائمتها لمحتوى الموضوعات، ومناسبتها لاحتباجات

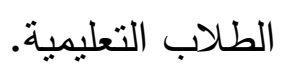


|| أساليب الثقويم: وقد رُوعِي أن تغطي معظم جوانب المحتوى، وتغطي جوانب التعلم المختلفة خاصة المعرفية، وفي الوقت ذاته تركز على قيم المشاركة المجتمعية، ومهارات التفكير التحليلي في هيئة مهارات يطلب من الطلاب ممارستها. - المراجع، والمصادر الخاصة بالوحدة تعليمية. r- عرض الصورة الأولية للاليل على المحكمين:

بعد إعداد الدليل في صورته الأولية يُعرَض على مجموعة من السادة المحكمين؛ للاستفادة من آرائهم، وتوجيهاتهم في ضبط الدليل؛ للتأكد مما يلي: ليعزئ

- مدى مناسبة الاستراتيجيات التدريسية المقترحة لطبيعة الوحدة التعليمية. - مدى ملاعمة خطة سير الدرس لكل موضوع من موضوعات الوحدات التعليمية.

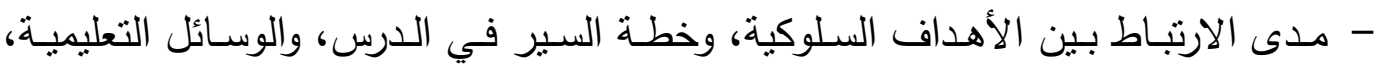
وأساليب التقويم.

- إضافة أو حذف ما يرونه مناسبًا.

وقت تمثلت ملاحظات المحكمين في النقاط التالية:

- تحديد الأهداف العامة، وإدراجها ضمن دليل المعلم، فهي الإطار العام الذي يُرجَع إليه

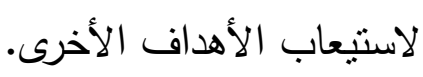
- إدراج الأهداف الخاصة للوحدة التعليمية، فهي تعطي رؤية متكاملة للمعارف، والاتجاهات، والمهارات الإيجابية التي يجب أن يكتسبها الطلاب من تعلم الوحدة. - مراعاة البناء التتابعي للمفاهيم العلمية، والمهارات في الوحدة. - يجب وضع خطوط إرشادية، أو نماذج لإجابات الأنشطة الواردة بكتاب الطالب. - إضافة معيار ، أو هدف عام للوحدة النعليمية. r- إعداد دليل المعلم في صورته النهائية. لقد رُوعِيت ملاحظات السادة المحكمين؛ ليتضمن دليل المعلم* الدكونات التالية:

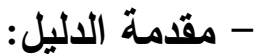
وتتـمل: (التعريف بالدليل، ومكوناته، والهدف من إعداده، والتعريف ببعض قيم المشـاركة المجتمعية، وطبيعة التفكير التحليلي، ومهاراته).

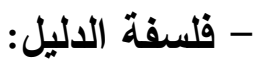

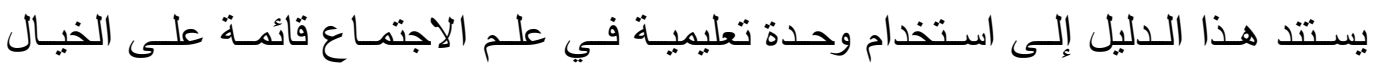
الاجتماعي؛ لتنمية قيم المشاركة المجتمعية، ومهارات التفكير التحليلي، والتي تهدف إلى إيجابية المتعلم، ونشاطه في الموقف التعليمي، وجعله محورًا للعملية التعليمية. 
وتدريس هذه الوحدة لا بد أن يُعنَى في المقام الأول بتتمية قيم المشاركة المجتمعية ومهارات

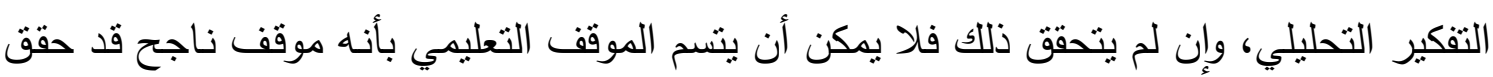

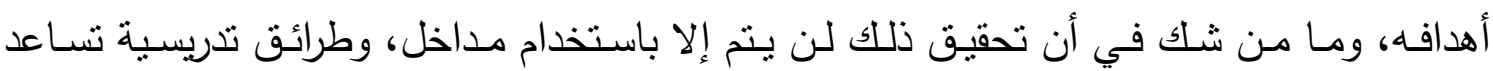

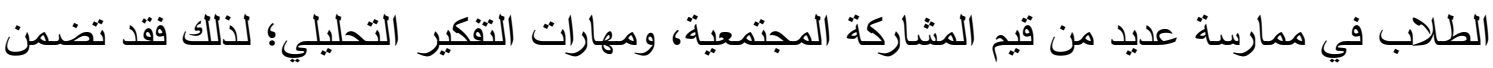
هذا الدليل عددًا من الأهداف، والطرائق، والأنشطة التي تعين على تلى تدريسها.

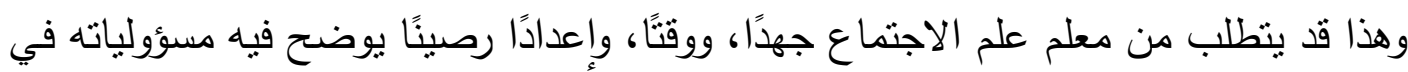
إدارة الموقف التعليمي، كما ينطلب استعانة المعلم بالوسائل والأنشطة وطرائق التدريس التي تتري

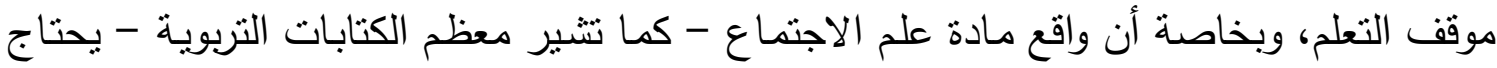
إلى تطوير مستمر لمناهجها وطرائق تدريسها. والدليل وما به من إرشادات يمكن أن يساعد معلم علم الاجتماع في إكساب طلاب المرحلة

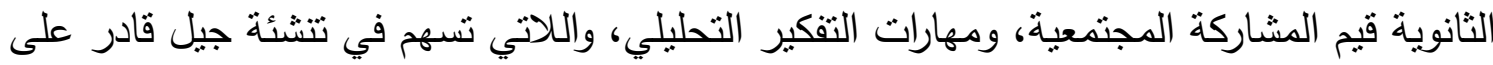
استخدام العقل في تيسير جميع مشكلاته: الثخصية، والمجتمعية.

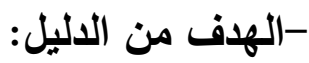

حُدد الهدف من هذا الدليل بحيث يعين المعلم على تتمية بعض قيم المشاركة المجتمعية،

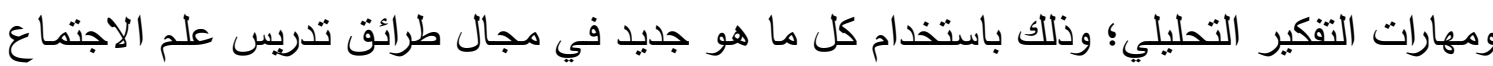
ووسائلها، وأنشطتها النعليمية، وأساليب تقويمها. - الخطة الزمنية لتدريس الوحدات التعليمية:

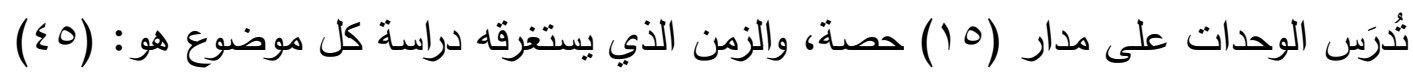

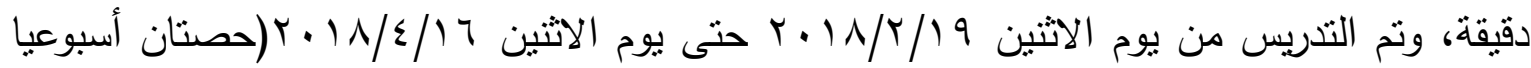
بالنسبة للبنين، وحصتان أسبوعيا للبنات).

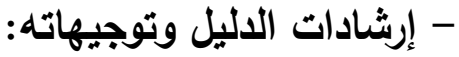

صيغت عدد من التوجيهات، والإرشادات العامة للمعلم عند تتفيذ دروس الوحدة التعليمية، والتي تساعده على تحقيق الهدف الأساسي منها، وهو قيم المشاركة المجتمعية، ومهارات التفكير التحليلي

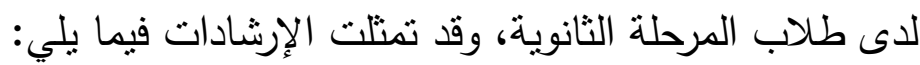
1- اقرأ الدليل بعناية، واطلع على ما جاء به من فِكر مختلفة.

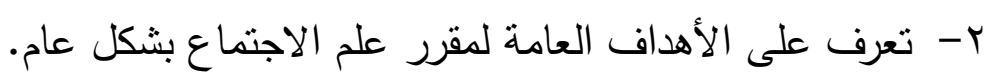
r- اقرأ الأهداف السلوكية الخاصة في دروس الوحدة التعليمية بعناية؛ لأنها ستساعدك في علكي فهم الإجراءات المطلوبة، وتحديدها. ع - تعرف على المفهومات المتضمنة في الوحدة التعليمية. 0- اعتنِ في تدريسك بالتركيز على قيم المشاركة المجتمعية، ومهارات التفكير التحليلي. 
צ- تعرف على الإجراءات المستخدمة في كل درس من دروس الوحدة التعليمية.

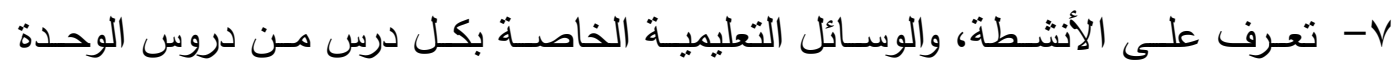
التعليمية، مع مراعاة استخدامها في الوقت المناسب.

^- تعرف على مصادر الوحدة المقترحة، والتي يمكن أن تفيدك في تحقيق أهدافها. 9- ركز على دور الطلاب خلال الأنشطة المختلفة. • ا-ناقش الطلاب في أسئلة التقويم الموجودة في نهاية الوحدة؛ للتأكد من تحقيق أهدافها.

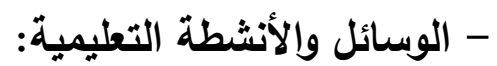
تتوعت الوسائل التعليمية المستخدمة في تدريس الوحدة التعليمية؛ مثل: اللوحات - الخرائط الذهنية - عروض Power Point - الصور والأثكال التوضيحية. كما تنوعت الأنشطة التعليمية في هذا الدليل مـا بين: (بعض الأنثطة البحثية، وكتابـة

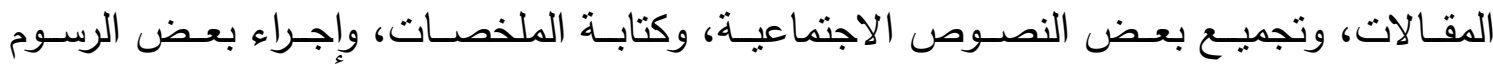
التوضيحية كالخرائط البصرية، وتصميم الجداول). - استراتيجيات التدريس المستخدمة: اعتمد تدريس الوحدة التعليمية على عدد من الاستراتيجيات التدريسية التي تتناءم وطبيعة

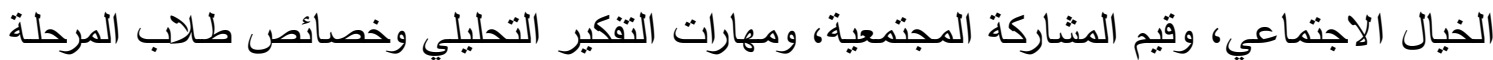

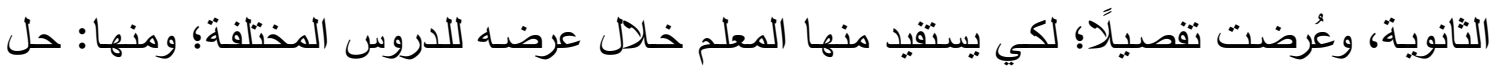
المشكلات- العصف الذهني - استراتيجية فكر -زاوج-شارك -استراتيجيات ما وراء المعرفة.

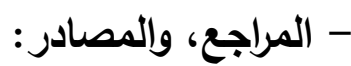

أُلحقِت مجموعة من المواد المطبوعة عقب الوحدة تعليمية في ملحق خاص؛ وذلك في حال رغبة المعلم للاستزادة العلمية حول موضوعات الوحدة التعليمية، والتي ترتبط ارتباطًا مباشرًا بها. خامسًا: إعداد مقياس قيم المشاركة المجتمعية، وضبطه: اعتمد بناء مقياس قيم المشاركة المجتمعية -في جانبه النظري- لطلاب المرحلة الثانوية بعد اطلاع الباحثة على ما يلي: ألئاء - - الكتابات، والأدبيات التي تنتاولت قيم المشاركة المجتمعية.

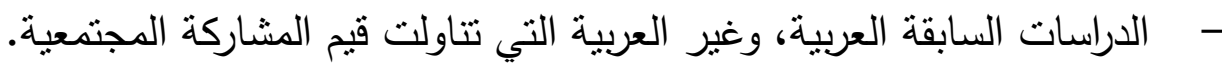

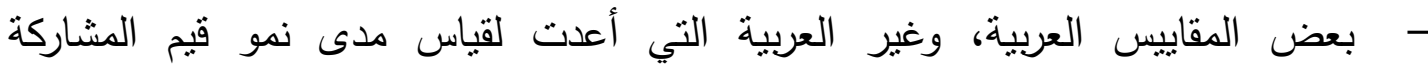

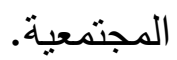


وقد بُنى المقياس وفق الخطوات التالية: 1- تحديد الهدف من المقياس:

يتمثل الهدف منه في قياس مدى امتلالك طلاب المرحلة الثانوية الدارسين لمقرر علم

الاجتماع لقيم المشاركة المجتمعية.

r ب ايد نوع مفردات المقياس:

أُعد المقياس عبر صباغة مفردات موجبة (إيجابية وليست سلبية) وفق مقياس ليكرت ذي الئي الخمس استجابات (موافق بثدة-موافق-غير متأكد-أرفض- أرفض بثدة) ويطلب من الطلاب اختيار استجابة واحدة فحسب.

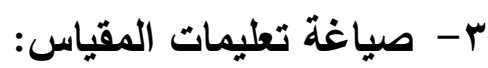

صيغت مجموعة من التعليمات في مقدمة المقياس؛ لإرشاد الطلاب بكيفية الإجابة عن بنود المقياس، وقد حرصت الباحثة -عند صباغة تعليمات الاختبار - على مراعاة عدة اعتبارات، أهمها: - أن تكون التعليمات واضحة، وبسيطة دون استطراد لغوي طويل، أو إيجاز يخل بالمعني. - أن توضح التعليمات الهدف من المقياس. - أن تحدد التعليمات عدد مفردات المقياس. - أن تؤكد التعليمات أن لكل مفردة إجابة واحدة صواب فحسب.

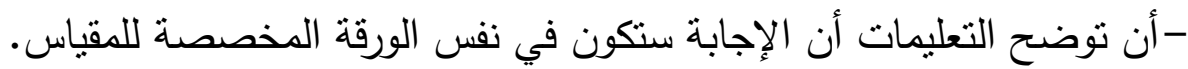
ع - عرض الصورة الأولية للمقياس على مجموعة من المحكمين:

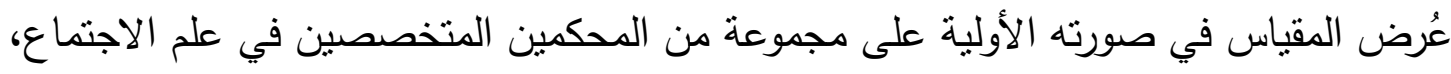
وطرائق تدريسه؛ وذلك من أجل التأكد من: - مدى ملاعهة مفردات المقياس لطبيعة المشاركة المجتمعية. - مدى صدق مفردات المقياس لقياس قيم المشاركة المجتمعية، ووفائها بالمعنى المقصود منها. - - مدى مناسبة هذه المفردات لمستوى طلاب المرحلة الثانوية.

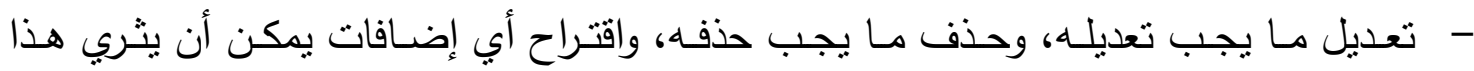
المقياس_ إن وجدت - بعد تعديلات السادة المحكمين. وجاءت تعديلات المحكمين كما يلي: حذف بعض العبارات، ونقل بعضها، وتضمينها في بعد آخر . ه- الاراسة الاستطلاعية للمقياس:

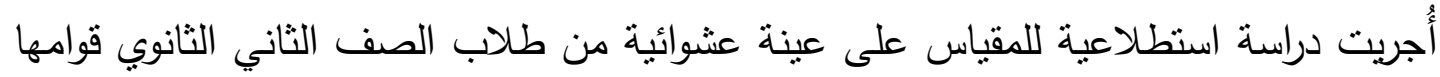

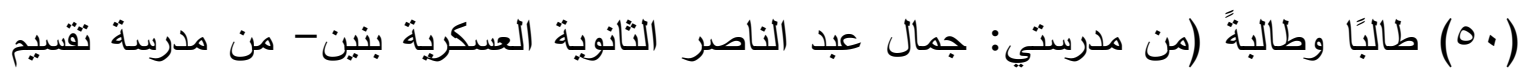

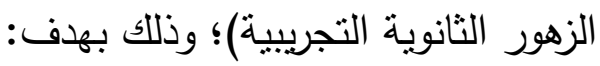


-تحديد الزمن اللازم للانتهاء من المقياس عبر جمع زمن أول طالب أنهى الإجابة على ألى ألمان المقياس ، مع زمن آخر طالب أنهى الإجابة على المقياس مقسمًا على اثثين وقد كان (ب0) دقيقة. - حساب ثبات المقياس عبر إعادة تطبيق المقياس حيث طبقت الباحثة نفس المقياس على العي

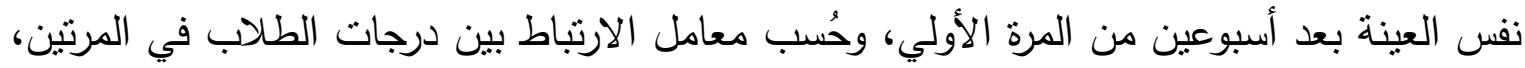
وكان معامل ثبات المقياس ب1\% وهو معامل ثبات مرتفع مما يدل على ثنبات المقياس، وأن مفرداته تقيس ما وضعت لقياسه. - ساب صدق مقياس قيم المشاركة المجتمعية، وحُسب صدق الاختبار بطريقتين:

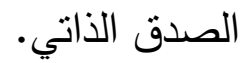

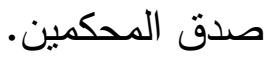

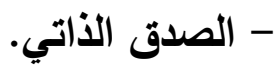

قامت الباحثة بحساب قيمة الصدق الذاتي، والذي يساوي حسابيَّا الجذر التربيعي لقيمة معامل

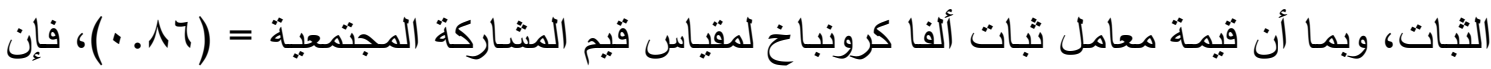

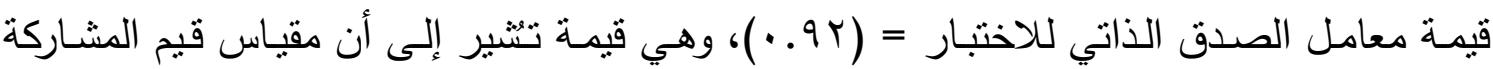

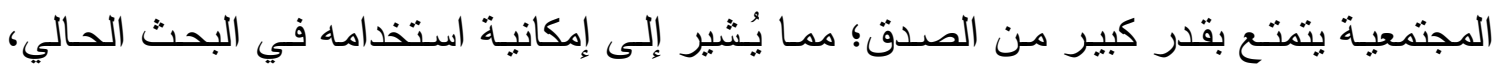
والوثوق بالنتائج التي سيسفر عنها تطبيقه.

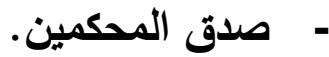
بعد إعداد الصورة المبدئية للاختبار عُرض على مجموعة من المحكمين المتخصصين في المناهج وطرائق التنريس، وكانت نسب اتفاق السادة المحكمين على كل عبارة من عبارات المقياس

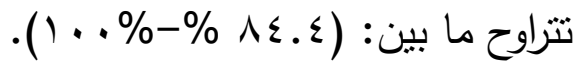
צ- إعداد المقياس في صورته النهائية: بعد التأكد من صلاحية المقياس، وعرضه على مجموعة من المحكمين، وتعديله في ضوء

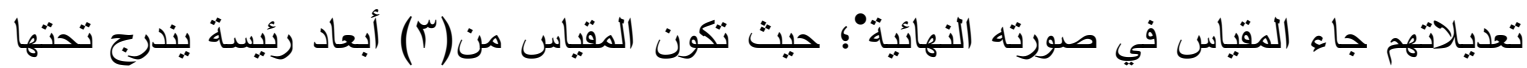

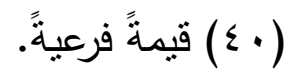

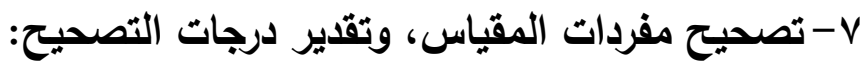

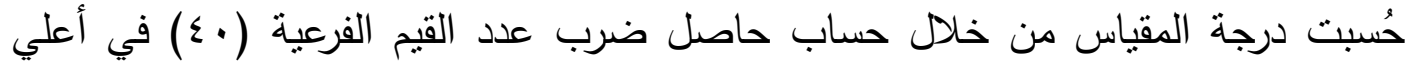

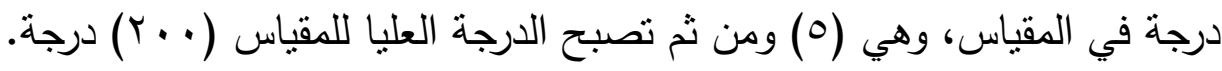


سادسا: اختبار المشاركة المجتمعية (اختبار مواقف).

اعتمد بناء اختبار قيم المشاركة المجتمعية -في جانبه النظري- لطلاب المرابه المرحلة الثانوية بعد اطلاع الباحثة على ما يلي: - الكتابات، والأدبيات التي تنتاولت قيم المشاركة المجتمعية. - - الدراسات السابقة العربية، وغير العربية التي تتاولت قيم المشاركة المجتمعية.

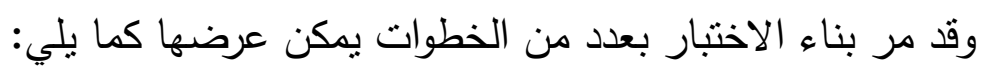

$$
\text { 1- تحديد الهدف من الاختبار: }
$$

يهدف هذا الاختبار إلى قياس قيم المشاركة المجتمعية، التي هدفت الوحدة التعليمية المقترحة

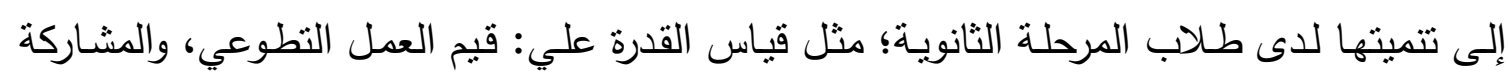
الاجتماعية؛ وذلك بتطبيقه؛ قبليًا، وبعديًا على عينة من طلاب الصف لفئ الثاني الثانوي.

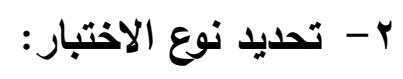

أعد هذا الاختبار بحيث يكون اختبارًا شاملًا لقيم المشاركة المجتمعية السابق تحديدها؛ لذلك الكاري يجب أن يصمم الاختبار على شكل مواقف، بحيث تبرز خلالها القيم المراد تتميتها.

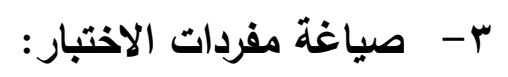

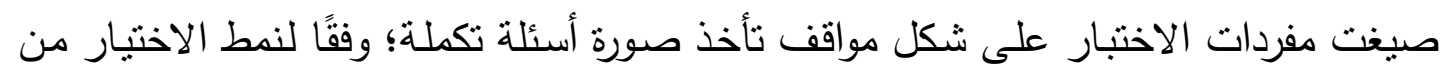
متعدد؛ لأنها تُعد من أكثر الأسئلة الموضوعية شيوعًا، كما أنها تقيس نواتج التعلم بكفاءة شديدة،

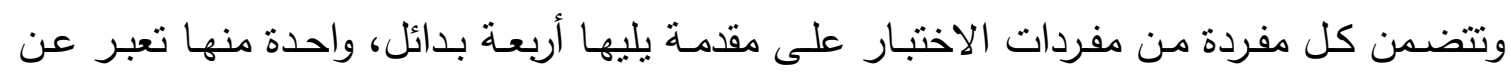

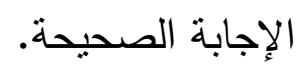

وقد راعت الباحثة عدة أسس عند صياغة مفردات الاختبار ، أهمها:

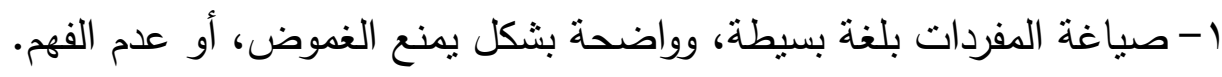

$$
\text { r- ب أن تكون ذات معنى محدد. }
$$
ب- أن تعبر عن المهارة المراد قياسه.

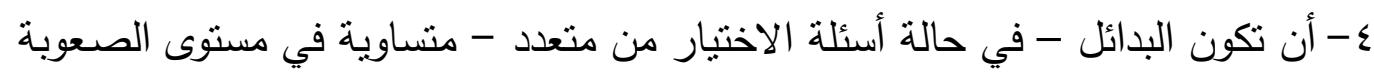
بقدر الإمكان، وخاضعة لترتيب الإجابات الصحيحة في الاختبار ككل للتوزيع العشوائي. ع - صياغة تعليمات الاختبار:

تهذف تعليمات الاختبار إلى شرح فكرة الاختبار ، وتدريب الطلاب على الإجابة بطريقة

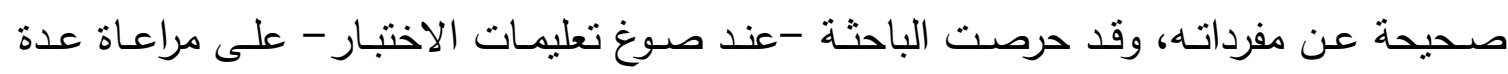

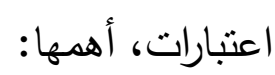

1- أن تكون التعليمات واضحة وبسيطة دون استطراد لغوي طويل أو إيجاز يخل بالمعني. r- أن توضح التعليمات الهدف من الاختبار . 
ب- أن تحدد التعليمات عدد مفردات الاختبار .

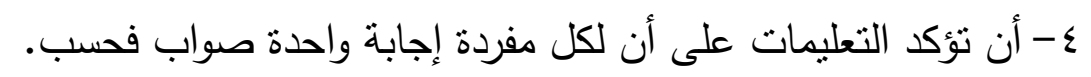

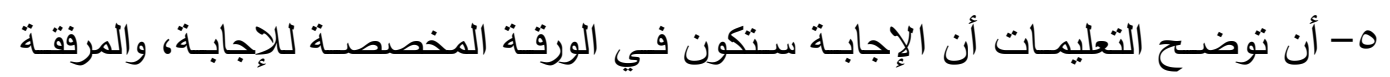

بالاختبار .

ه-الاختبار في صورته المبلئية:

تتكون الصورة المبدئية للاختبار ، والمُعدة للتجريب الاستطلاعي مما يلي: ولئي

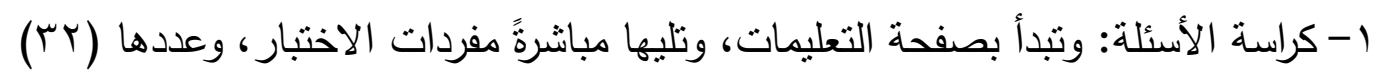

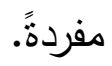

r-ورقة الإجابة: وبها مكان لكتابة بيانات الطالب، تليها أرقام المفردات، وأمام كل رقم

$$
\text { حروف الاستجابات الأربع. }
$$

צ-التجريب الاستطلاعي للاختبار:

بعد صوغ مفردات الاختبار ، ووضع تعليماته قامت الباحثة بتطبيقه في صورته الأولية على الإنى

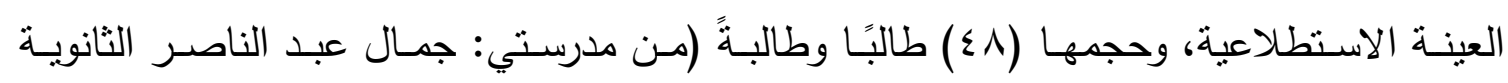
العسكرية بنين - تقسيم الزهور الثانوية التجريبية) بإدارة المنتزه التعليمية بمحافظة الإسكندرية؛ وذلك هلك بهدف قياس ما يلي:

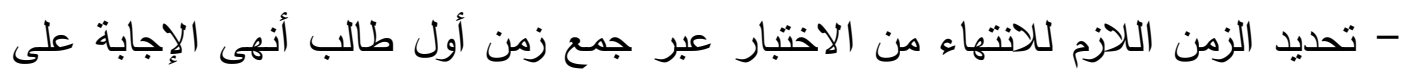

المقياس مع زمن آخر طالب أنهى الإجابة على المقياس مقسما على اثثين وهو :0 ــ دقيقة.

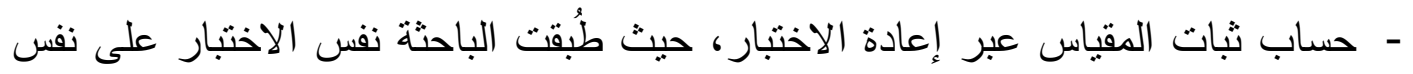

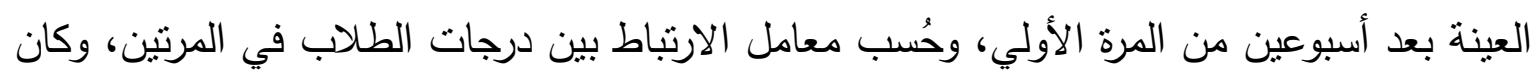

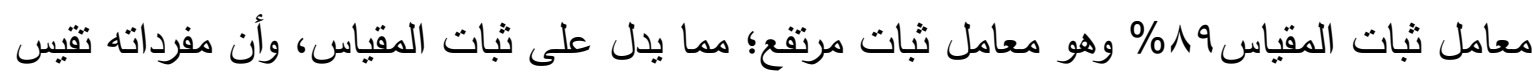
ما وضعت لقياسه.

- كما حُسب معامل الارتباط للاختبار باستخدام طريقة التجزئة النصفية بين الأسئلة ذات

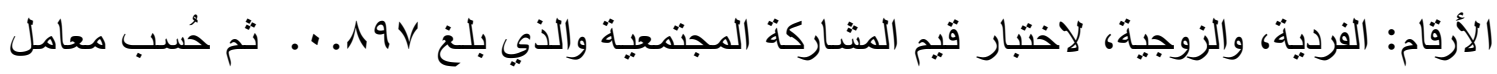

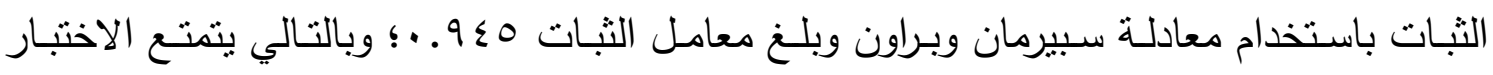

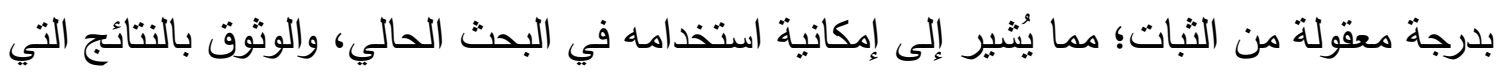
سيسفر عنها. - حساب صدق اختبار قيم المشاركة المجتمعية؛ وحُسب صدق الاختبار بطريقتين:

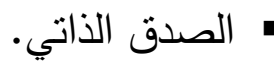
• صدق المحمين. 
- الصدق الأتي:

قامت الباحثة بحساب قيمـة الصدق الذاتي، والذي يسـاوي حسابيًّا الجذر التربيعي لقيمـة

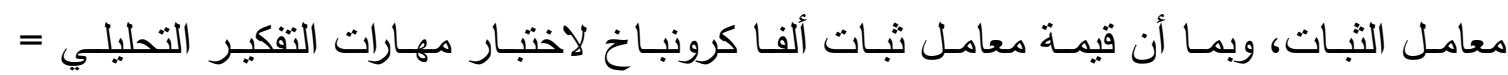

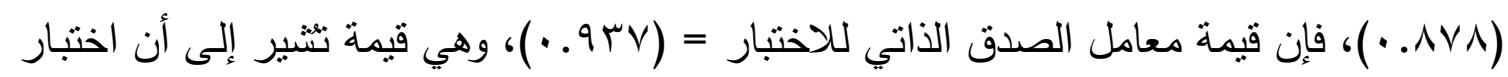

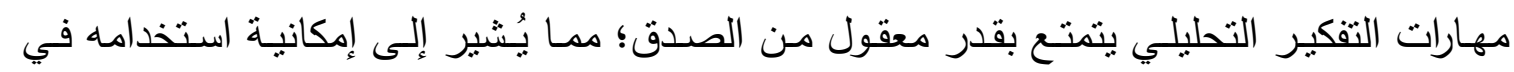

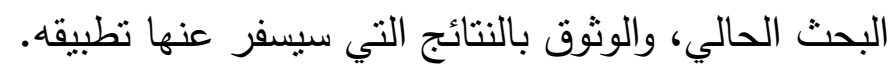

- صدق المحكمين:

بعد إعداد الصورة المبدئية للاختبار عُرض على مجموعة من المحكمين المتخصصين في المناهج، وطرائق التدريس، وكانت نسب اتفاق السادة المحكمين على كل عبارة من عبارات المقياس

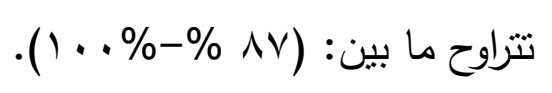
ه- الصورة النهائية للاختبار .

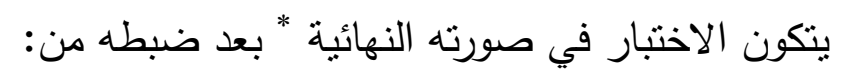

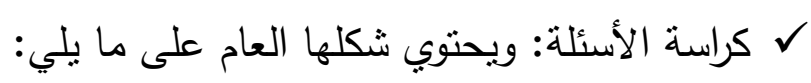

ل كلاف يحمل اسم الاختبار.

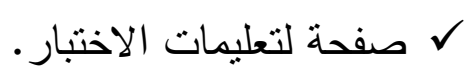

$\checkmark$

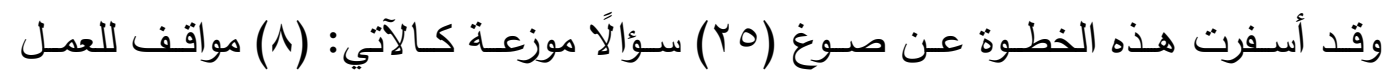

التطوعي، (^) مواقف للمشاركة السياسية، (9) مواقف للمشاركة الاجتماعية.

ورقة الإجابة: ويستخدمها الطالب مرة واحدة، ويتضمن شكلها العام ما يلي:

يوجد أعلاها مكان لكتابة بيانات الطالب.

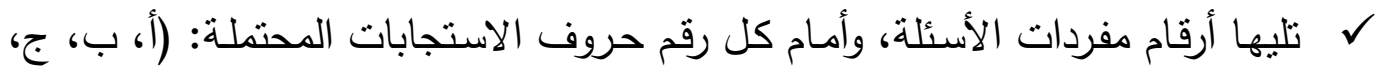

د) بحيث يختار الطالب ما يراه صحيحًا، ويضع علامة (صواب) بجوارها.

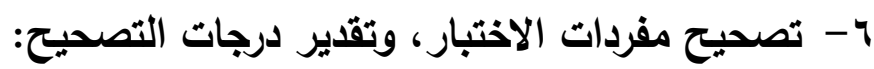

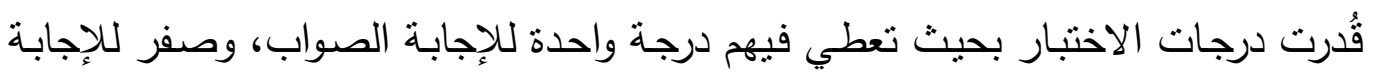

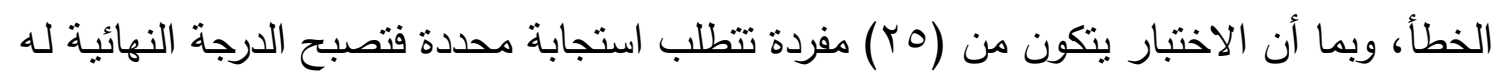

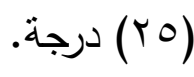

* ملحق (9). 
سابعا: إعداد مقياس مهارات التفكير التحليلي، وضبطه: اعتمد بناء مقياس مهارات التفكير التحليلي -في جانبه النظري- لطلاب المرحلة الثانوية

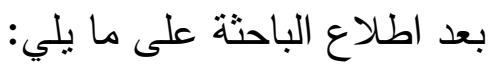
- الكتابات، والأدبيات التي تتاولت مهارات التفكير التحليلي. - - - - الدراسات السابقة العربية، وغير العربية التي تتاولت مهارات التفكير التحليلي. - بعض المقاييس العربية، وغير العربية التي أعدت لقياس مدى نمو مهارات التفكير

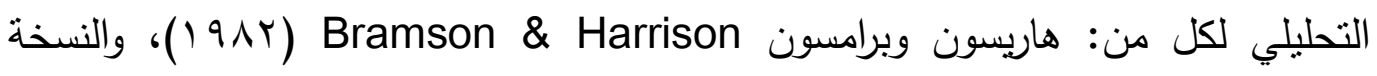
المُعربة للباحث الفلسطيني/ إبراهيم أبو عقيل في كلية التربية جامعة الخليل بدولة فلسطين. وقد بُنى المقياس وفق الخطوات الثالية:

1-تمديد الهلف من المقياس: يتمثل الهدف منه في قياس مدى امتلالك طلاب المرحلة الثانوية الدارسين لمقرر علم الاجتماع لمهارات التفكير التحليلي. ب-تحديد نوع مفردات المقياس:

أُعد المقياس ذو الخمس استجابات والتي تدل فيها رقم ( (1) على الاستجابة الأقل قربًا من المناس التصرف الصحيح، ويدل رقم (0) على الاستجابة الأكثر قربًا من التصرف الصديات الصيح. ب- ب إغة تعليمات المقياس:

صيغت مجموعة من التعليمات في مقدمة المقياس؛ لإرشاد الطلاب بكيفية الإجابة على بنود المقياس، وقد حرصت الباحثة -عند صوغ تعليمات الاختبار - على مراعاة عدة اعتبارات، أهها:

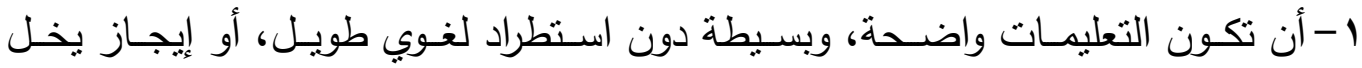
بالمعني. ץ- أن توضح التعليمات الهدف من المقياس. ب- أن تحدد التعليمات عدد مفردات المقياس.

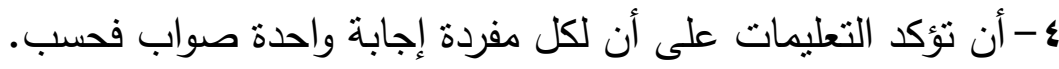

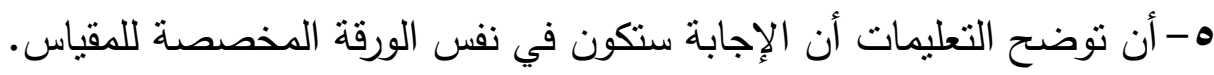
ع - عرض الصورة الأولية للمقياس على مجموعة من المحكمين:

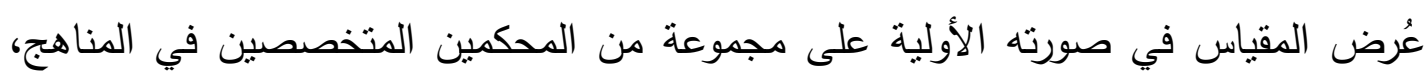
وطرائق التدريس؛ وذللك من أجل التأكد من: - مدى ملاءمة مفردات المقياس لطبيعة مهارات التفكير التحليلي.

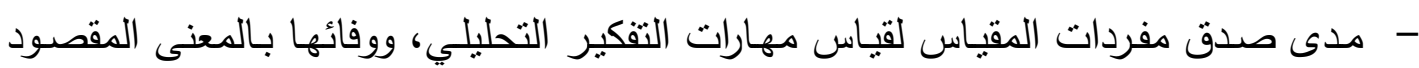


- مدى مناسبة هذه المفردات لمستوى طلاب المرحلة الثانوية.

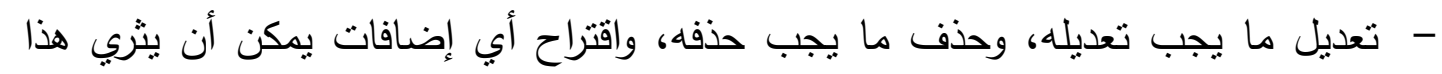
المقياس - إن وجدت- بعد تعديلات السادة المحكمين. وجاءت تعديلات المحكمين كما يلي: حذف بعض العبارات، واستبدالها بعبارات أخري. ه- الاراسة الاستطلاعية للمقياس:

أجريت دراسة استطلاعية للمقياس على عينة عشوائية من طلاب الصف الثانئي الثانياني

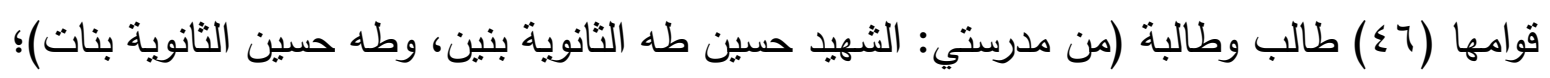
وذذلك بهدف:

- تحديد الزمن اللازم للانتهاء من المقياس عبر جمع زمن أول طالب أنهى الإجابة عن

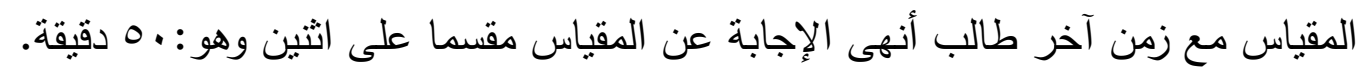

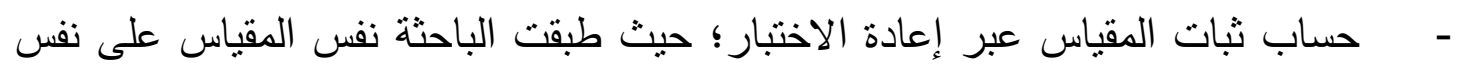

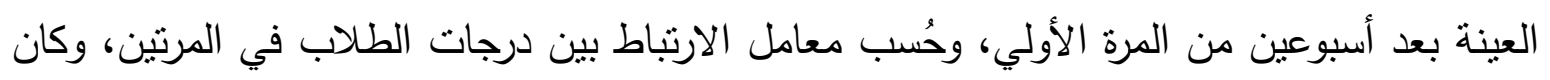

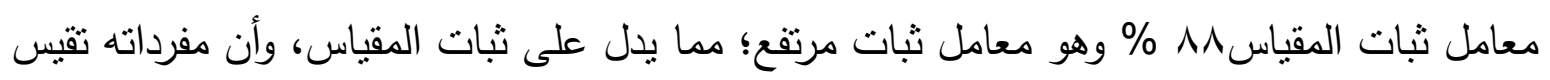
ما وضعت لقياسه.

- حساب صدق مقياس مهارات التفكير التحليلي؛ وحُسب صدق الاختبار بطريقتني:

$$
\begin{aligned}
& \text { - الصدق الذاتي. } \\
& \text { •صدق المحكمين. } \\
& \text { - الصدق الذاتي. }
\end{aligned}
$$

قامت الباحثة بحساب قيمة الصدق الذاتي، والذي يساوي حسابيًّا الجذر التربيعي لقيمة معامل

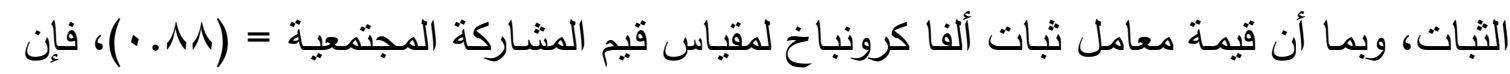

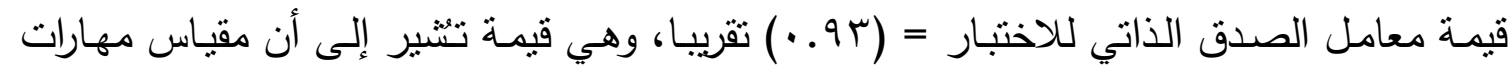

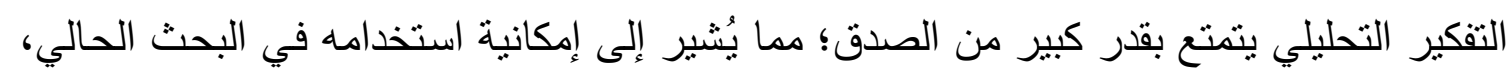
والوثوق بالنتائج التي سيسفر عنها تطبيقه.

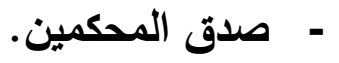

بعد إعداد الصورة المبئية للاختبار عُرض على مجموعة من المحكمين المتخصصين في

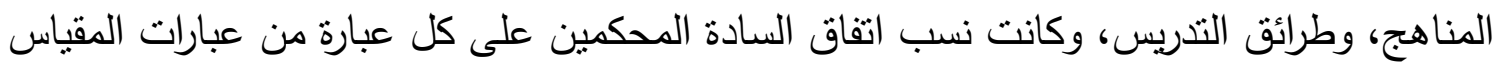

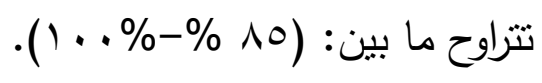


צ- - إعداد المقياس في صورته النهائية: بعد التأكد من صلاحية المقياس، وعرضه على صونه مجموعة من المحكمين، وتعديله في ضوء

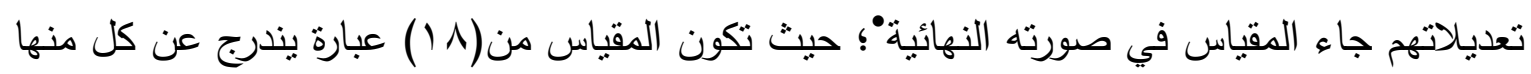
خمس استجابات.

V V -تصحيح مفردات المقياس، وتقدير درجات التصحيح:

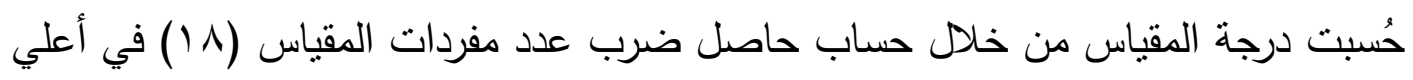

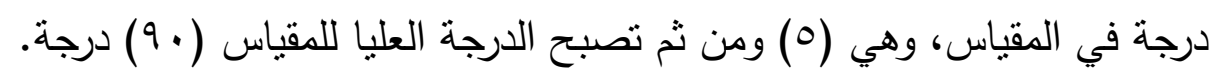
سابعًا: تنفيذ الاراسة الميدانية: 1- تحديد التصميم التجريبي:

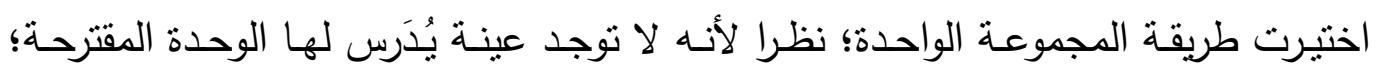
ولذلك اعتمد التصميم التجريبي في هذه الدراسة على وجود مجموعة واحدة. والثكل الآتي يوضح المعالجة الإحصائية لأدوات البحث:

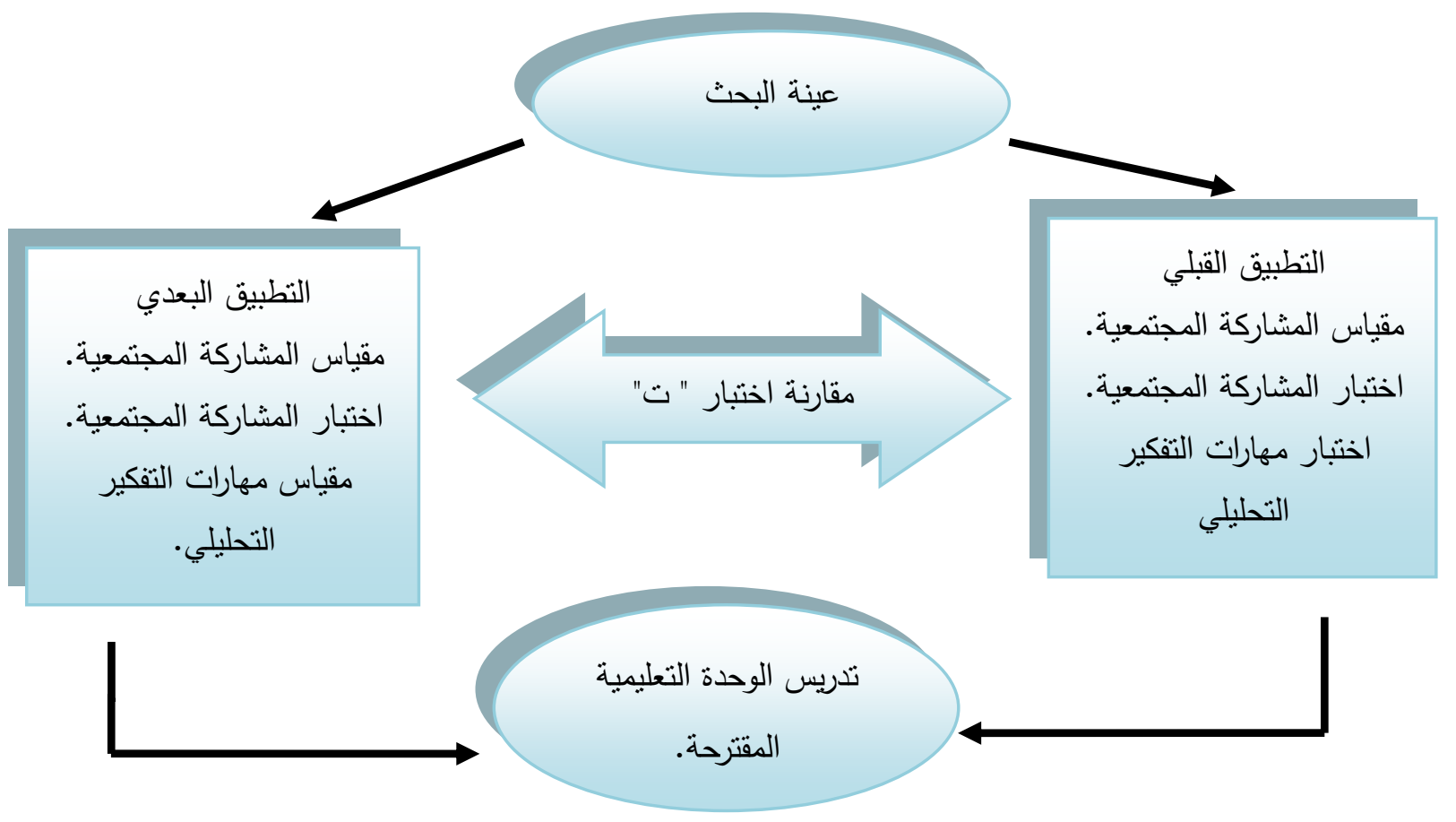

شكل (1) يوضح المعالجة الإحصائية لأدوات البحث. 
هدفت التجربة إلي الحصول علي بيانات تتعلق بمدى فاعلية الوحدة المقترحة القائمة على اليى

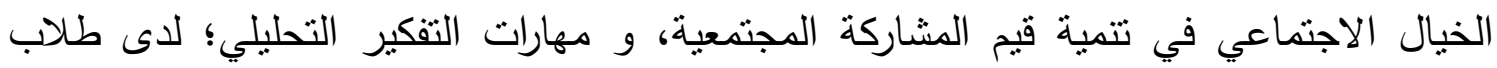
المرحلة الثانوية، والتحقق من صحة الفروض التالية: 1- يوجد فرق دال احصائيًا عند مستوي ا. ..> بين متوسطي درجات طلاب عينة الدراسة في النطبيقين: القبلي، والبعدي لكقياس قيم المشاركة المجتمعية.

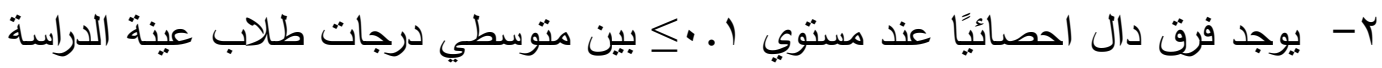
في التطبيقين: القبلي، والبعدي لاختبار قيم المشاركة المجتمعية.

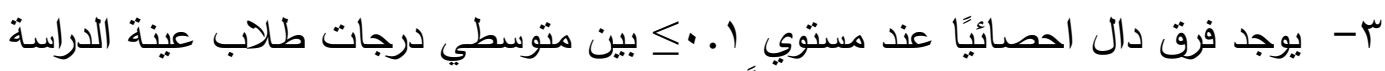
في التطبيقين: القبلي، والبعدي لـقياس دهارات التفكير التحليلي.

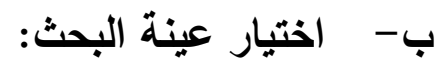
تمثلت عينة البحث في عينة عشوائية من طلاب الصف الثاني الثانوي عددها (^^) بواقع

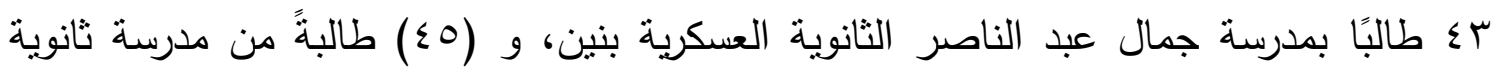
الكويت بنات بإدارة المنتزه التعليمية.

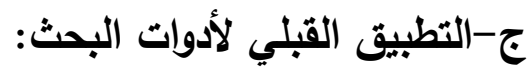
يهدف التطبيق القبلي لأدوات البحث إلى الكثف عن المستوي المبدئي للطلاب فيما يخص مستوى

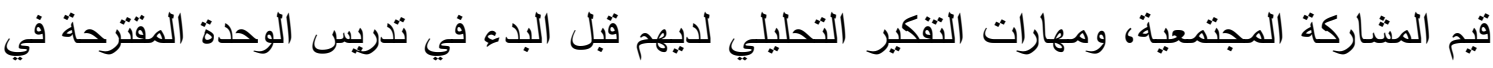
علم الاجتماع. ويوضح جدول ( ) التالي بيان بتاريخ تطبيق أدوات البحث قبليا.

\begin{tabular}{|c|c|c|c|}
\hline تاريخ التطبيق & مدة التطبيق & طلاب المرحلة & الأدوات \\
\hline 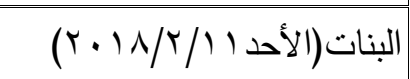 & \multirow[t]{2}{*}{ مبر دقيقةً } & \multirow[t]{2}{*}{$\wedge$} & \multirow[t]{2}{*}{ مقياس المشاركة المجتمعية. } \\
\hline 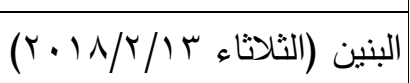 & & & \\
\hline 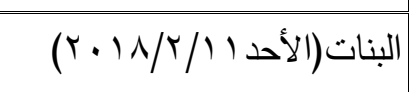 & \multirow[t]{2}{*}{0} & \multirow[t]{2}{*}{$\Lambda \Lambda$} & \multirow[t]{2}{*}{ اختبار المشاركة المجتمعية } \\
\hline 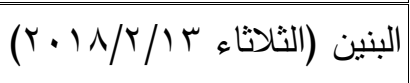 & & & \\
\hline 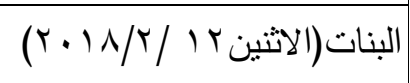 & \multirow[t]{2}{*}{ • ه دقيقةً } & \multirow[t]{2}{*}{11} & \multirow[t]{2}{*}{ مقياس مهارات التفكير التحليلي } \\
\hline 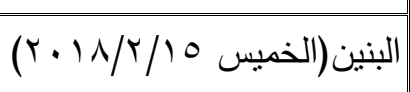 & & & \\
\hline
\end{tabular}




\section{د - تنفيذ الوحدة القائمة على الخيال الاجتماعي:}

نُفذت الوحدة المقترحة القائمة على الخيال الاجتماعي لطلاب الصف الثاني الثانوي للعام

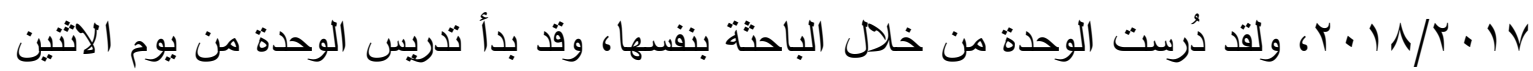

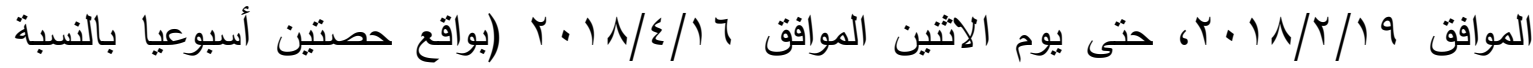
للبنين، وحصنين أسبوعيا للبنات). هـ - التطبيق البعدي لأدوات البحث:

يهدف التطبيق البعدي لأدوات البحث إلي الكثف عن المستوي الذي وصل إليه الطلاب فيما يخص مستوى قيم المشاركة المجتمعية، ومهارات التقكير التحليلي لديهم بعد تدريس الوحدة المقترحة في علم الاجتماع. ويوضح جدول (0) التالي بيان بتاريخ تطبيق أدوات البحث بعديا.

\begin{tabular}{|c|c|c|c|}
\hline تاريخ التطبيق & مدة التطبيق & طلاب المرحلة الثانوية & الأدوات \\
\hline 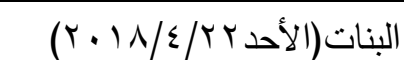 & \multirow[t]{2}{*}{ مَ دقيقةً } & \multirow[t]{2}{*}{$\Lambda \wedge$} & \multirow[t]{2}{*}{ مقياس المشاركة المجتمعية. } \\
\hline 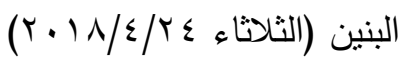 & & & \\
\hline 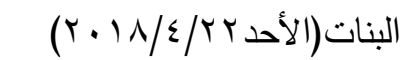 & \multirow[t]{2}{*}{ م د دقيقةً } & \multirow[t]{2}{*}{$\wedge \wedge$} & \multirow[t]{2}{*}{ اختبار المشاركة المجتمعية } \\
\hline 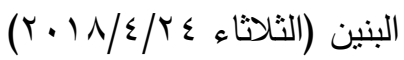 & & & \\
\hline 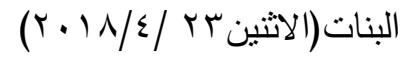 & \multirow[t]{2}{*}{ هم دقيقةً } & \multirow[t]{2}{*}{$\Lambda \wedge$} & \multirow[t]{2}{*}{ مقياس مهارات التفكير التحليلي } \\
\hline 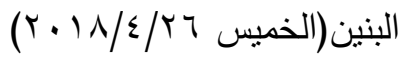 & & & \\
\hline
\end{tabular}

رابعا: نتائج البحث، وتفسيره، والتوصيات، والمقترحات.

يتتاول هذا القسم نتائج البحث، والتحقق من صحة الفروض، وأهم التوصيات، والمقترحات التي أُشتقت في ضوء ما أسفر عنه البحث من نتائج.

اعتمد البحث الحالي في معالجة البيانات معالجة إحصائية على برنامج (SPSS.v21)؛ وذللك للتحقق من صحة فروضه؛ ومن ثم الإجابة عن أسئلته، وتفسير ما ثم التوصل إليه من نتائج في ضوء كل من الدراسات السابقة، والإطار النظري. وقبل التحقق من اختبار صحة فروض البحث اتبعت الباحثة الخطوات التالية: ا ـرصد درجات طلاب المجموعة التجريبية في القياسين: القبلي، والبعدي لمقياس المشاركة المجتمعية واختبارها، ومجموعهما الكلي، ومقياس مهارات التفكير التحليلي. r. استخدام اختبار "ت" (t-test)؛ لحساب الفروق بين درجات طلاب المجموعة التجريبية في القياسين: القبلي، والبعدي لمقياس المشـاركة المجتمعيـة، واختبارها، ومقياس مهارات التفكير 
التحليلي. ويُعد اختبار "ت" اختبارًا بارامتريًا قويًًا لحساب الفروق بين متوسطي مجموعتين مستقلتنين،

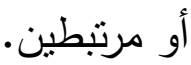

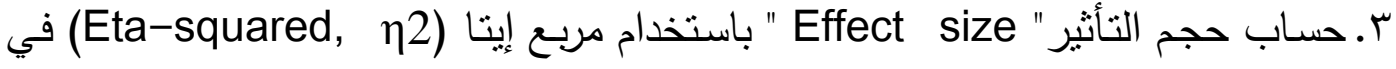
حالة ما إذا كانت قيمة "ت" دالة إحصائيًا؛ وذلك بهذف حساب حجم تأثير المتغير المستقل (الوحدة التعليمية المقترحة) في المتغير التابع (قيم المشاركة المجتمعية ومهارات التفكير التحليلي)؛ لأن

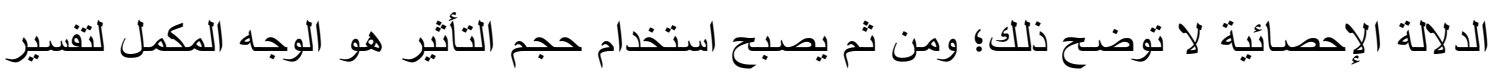

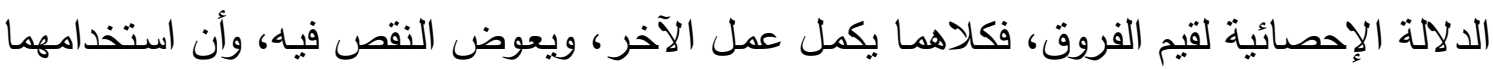

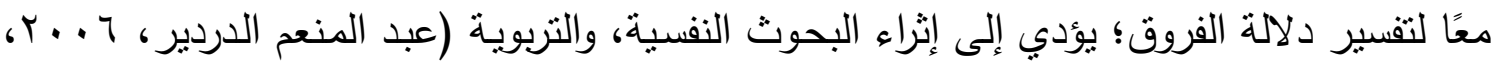
$\cdot($ V ص

وتبين قيمـة معامـل إيتا 2 التأثير التجريبي لنسبة التباين الذي يرجع إلى تأثثر المتغير

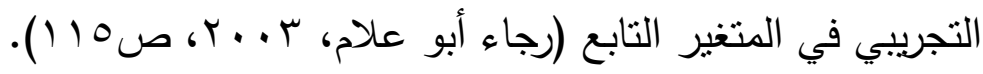
نتائج الاراسة:

للإجابة عن السؤال الأول من البحث، وهو: ما الوحدة المقترحة القائمة على الخيال

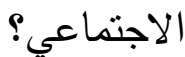

يمكن الرجوع إلى أحد ملاحق البحث * حيث قدم الإطار العام للوحدة التعليمية القائمة على

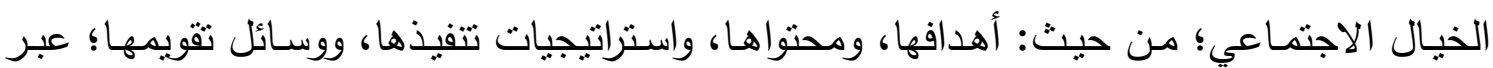
الاعتماد على الأدبيات، والدراسات السابقة.

للإجابة عن السؤال الثاني من البحث، وهو : ما فاعلية الوحدة الدقترحة القائمة على الخيال الاجتماعي في تتمية قيم المشاركة المجتمعية؛ لدى طلاب المرحلة الثانوية؛ تطلب الإجابة عن هذا السؤال التحقق من صحة الفرضين الأول، وإلثاني: وينص الفرض الفئلة الأول

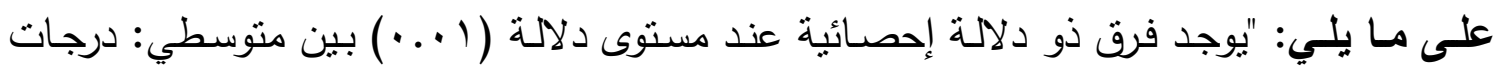

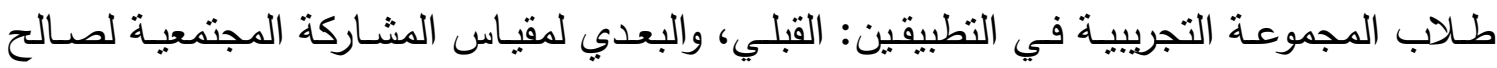
النطبيق البعدي. ويتقرع عن هذا الفرض الفروض الفرعية التالية: ا. يوجد فرق ذو دلالة إحصائية عند مستوى دلالة (1...) بين منوسطي درجات طلاب

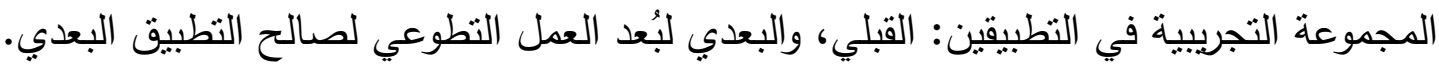
r.يوجد فرق ذو دلالة إحصائية عند مستوى دلالة (1 ...) بين منوسطي درجات طلاب المجموعة التجريبية في التطبيقين القبلي والبعدي لُُعد المشاركة السياسية لصالح التطبيق البعدي. 
r.يوجد فرق ذو دلالة إحصائية عند مستوى دلالة (1 ...) بين منوسطي درجات طلاب

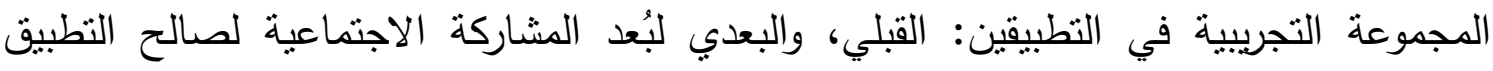

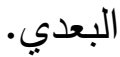

- وللتحقق من صحة الفرض الأول، وفروعه فقد قامت الباحثة بمقارنة متوسطات درجات طلاب المجموعة التجريبية في التطبيقين: القبلي، والبعدي؛ لمقياس المشاركة المجتمعية، واختبارها،

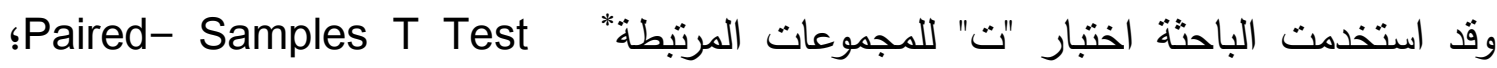

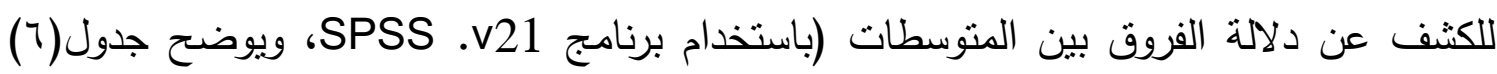
نتائج التطبيقين: القبلي والبعدي لمقياس المشاركة المجتمعية: جدول (†):

المتوسطات والانحرافات المعيارية وقيم "ت" لدرجات طلاب المجموعة التجريبية في التطبيقين القبلي والبعدي لمقياس المشاركة المجتمعية وأبعاده.

\begin{tabular}{|c|c|c|c|c|c|c|}
\hline إيتا & قيمة "ت" & الانحراف & المتوسط & التطبيق & العدد العد & مقياس المشاركة \\
\hline. .91 & $\Lambda \varepsilon . \varepsilon 0$ & 9.77 & $V V \cdot V A$ & قبلي & \multirow[t]{2}{*}{$\wedge \wedge$} & \multirow[t]{2}{*}{ المقياس ككل } \\
\hline كبير & دالة & 1.7. & IVT.YA & بعدي & & \\
\hline. .97 & or.vi & $\varepsilon . \wedge \varepsilon$ & r... & قبلي & \multirow[t]{2}{*}{$\Lambda \Lambda$} & \multirow[t]{2}{*}{ العمل التطوعي } \\
\hline كبير & دالة ل & 7.00 & TY.A & بعدي & & \\
\hline. .91 & $v 1.9 \leq$ & $\varepsilon .01$ & $r \leq .9 V$ & قبلي & \multirow[t]{2}{*}{$\Lambda \Lambda$} & \multirow[t]{2}{*}{ المشاركة السياسية } \\
\hline كبير & دالة ل & $\varepsilon . \cdot r$ & $00 . \wedge \varepsilon$ & بعدي & & \\
\hline. .91 & N1. & $\varepsilon . V T$ & $r \leq .00$ & قبلي & \multirow[t]{2}{*}{$\wedge \wedge$} & \multirow[t]{2}{*}{ المشاركة الاجتماعية } \\
\hline كبير & دالة ل & $r .00$ & $00 . r V$ & بعدي & & \\
\hline
\end{tabular}


- أنه بمقارنة منوسطات درجات طلاب المجموعة التجريبية في التطبيقين: القبلي، والبعدي مائي

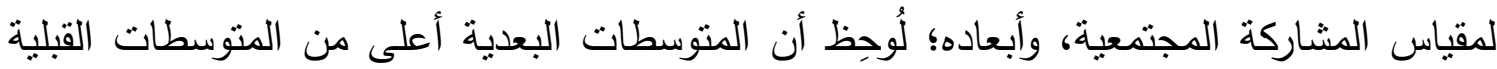
للاختبار ككل، ومن كل بُعد من أبعاده، وقد أرجعت الباحثة ذلك إلى استخدام الوحدة التعليمية المقترحة للمجموعة التجريبية.

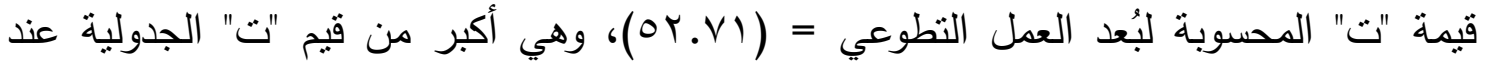
درجات حرية (ץ + ()، ومستوى دلالة (1 (..)؛ مما يُشير إلى وجود فروق دالة إحصائيًا بين

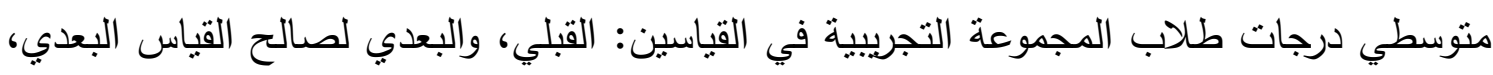

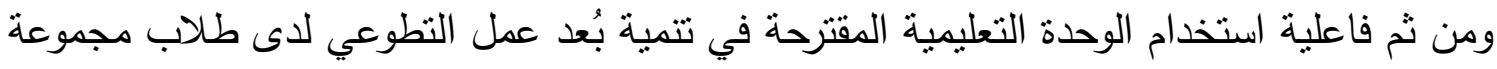
البحث. والتنثيل البياني التالي يوضح نتزيد منوسطات درجات المجموعة التجريبية في النطبيق البعدي عن متوسطات نفس المجموعة في التطبيق القبلي وذللك في بُعد العمل التطوعي.

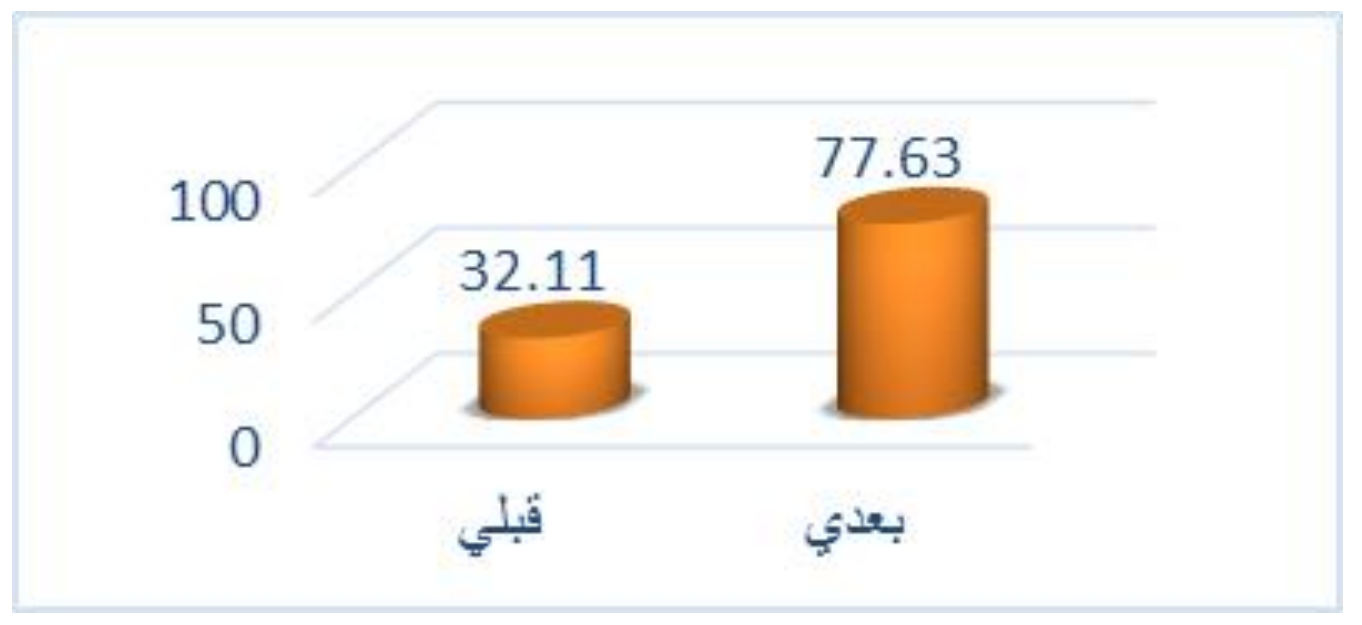

شكل (ץ): التمثيل البياني لكتوسطات درجات طلاب المجموعة التجريبية لُبعد العمل التطوعي.

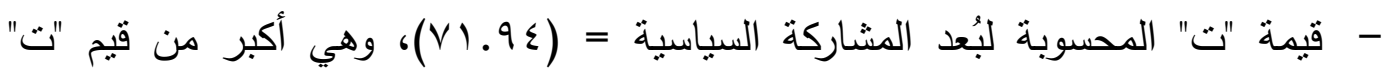

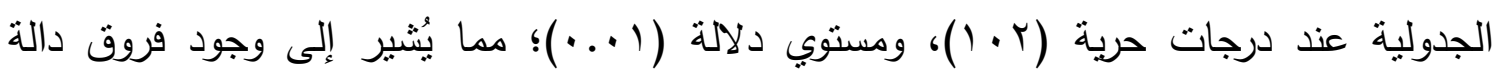

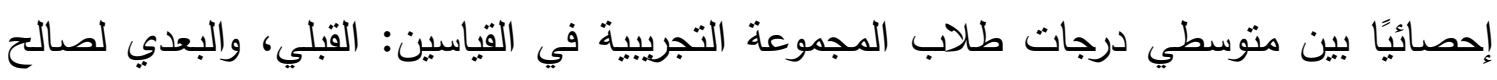

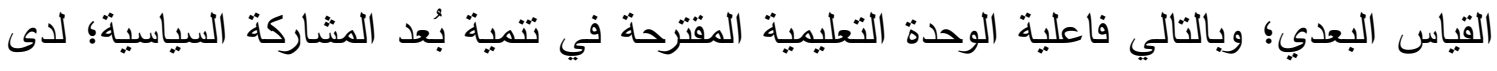

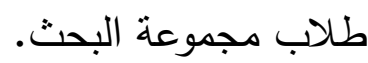

- والتمثيل البياني التالي يوضح تزايد متوسطات درجات المجموعة التجريبية في التطبيق البعدي عن متوسطات نفس المجموعة في النطبيق القبلي؛ وذللك في بُعد المشاركة السياسية. 


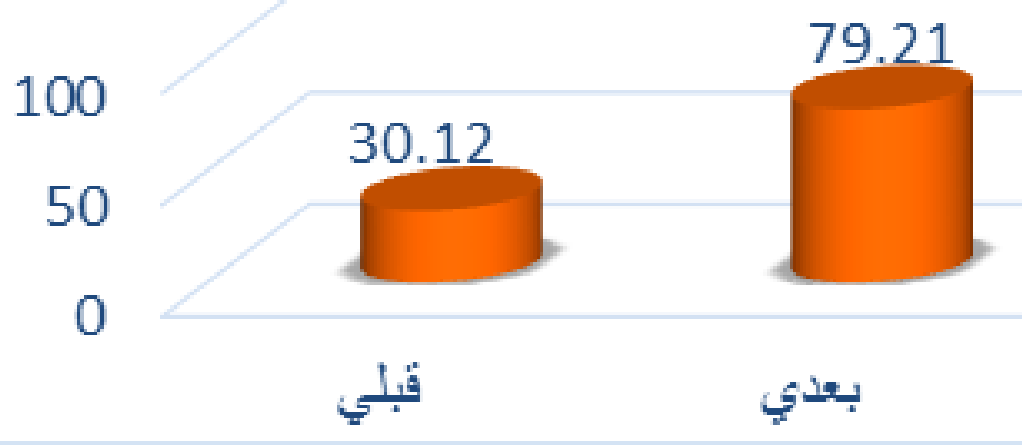

شكل (r): التمثيل البياني لمتوسطات درجات طلاب المجموعة التجريبية لبُعد المشاركة

السباسبة.

- قيمة "ت" المحسوبة لبُعد المشاركة الاجتماعية = (9 (1)، وهي أكبر من قيم "ت"

الجدولية عند درجات حرية (ץ + ()) ومستوي دلالة (1 (..)؛ مما يُشير إلى وجود فروق دالة إحصائًّا بين منتسطي درجات طلاب المجموعة التجريبية في القياسين: القبلي، والبعدي لصالح القياس البعدي؛ وبالتالي فاعلية الوحدة التعليمية المقترحة في تتمية بُعد المشاركة الاجتماعية؛ لدى طلاب مجموعة البحث. والتمثيل البياني التالي يوضح نزايد منوسطات درجات المجموعة التجريبية في التطبيق البعدي عن متوسطات نفس المجموعة في التطبيق القبلي؛ وذلك في بُعد المشاركة الاجتماعية.

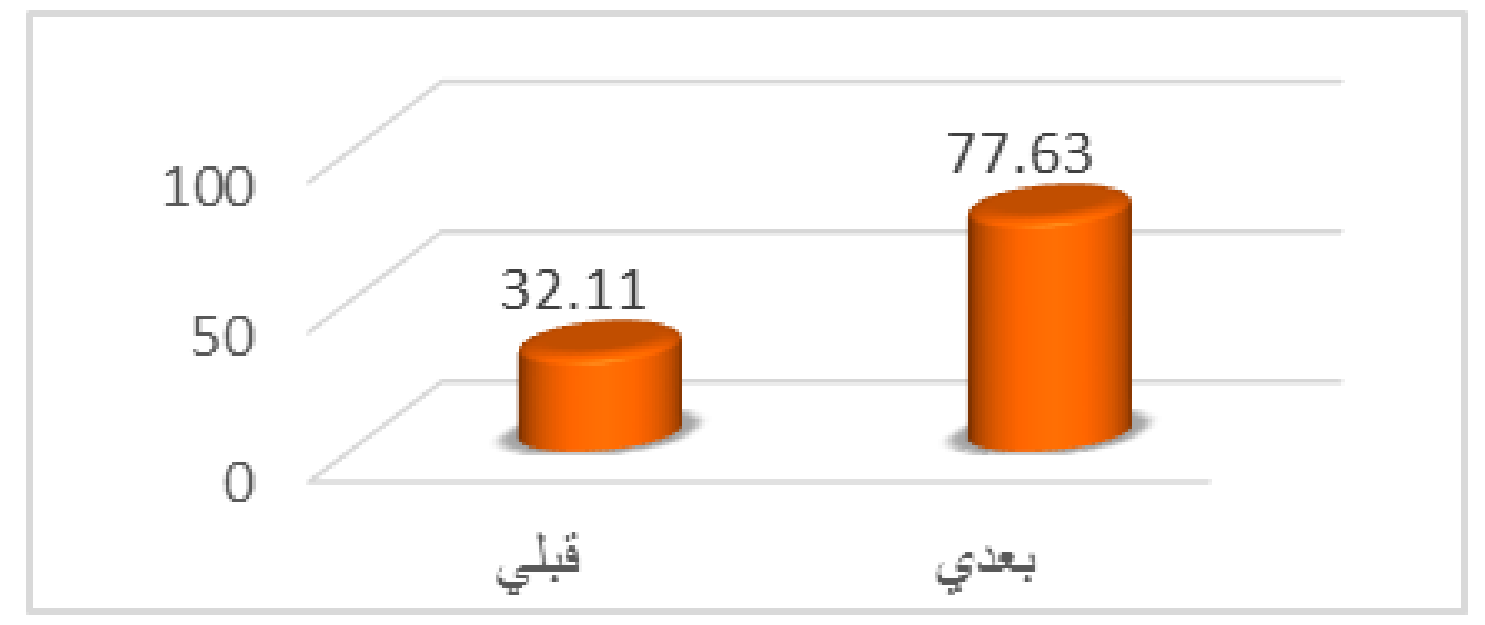

شكل (ع): التمثيل البياني لمتوسطات درجات طلاب المجموعة التجربيية لبُعد المشاركة الاجتماعية.

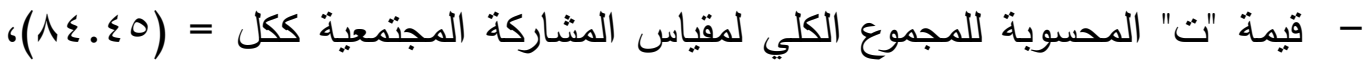
وهي أكبر من قيم "ت" الجدولية عند درجات حرية (r • ())، ومستوي دلالة ( ( . . )؛ مما يُثير إلى وجود فروق دالة إحصائًا بين متوسطي درجات طلاب المجموعة التجريبية في القياسين القبلي 
والبعدي لصالح القياس البعدي؛ وبالتالي فاعلية الوحدة التعليمية المقترحة في تتمية المشاركة

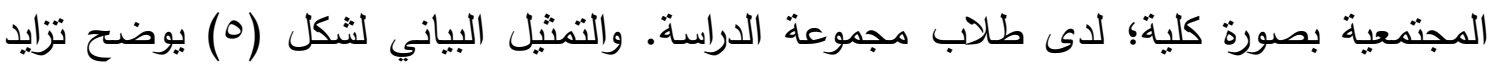
متوسطات درجات المجموعة التجريبية فى النطبيق البعدى عن متوسطات نفس المجموعة فى لى التطبيق القبلى؛ وذللك لمقياس المشاركة المجتمعية ككل.

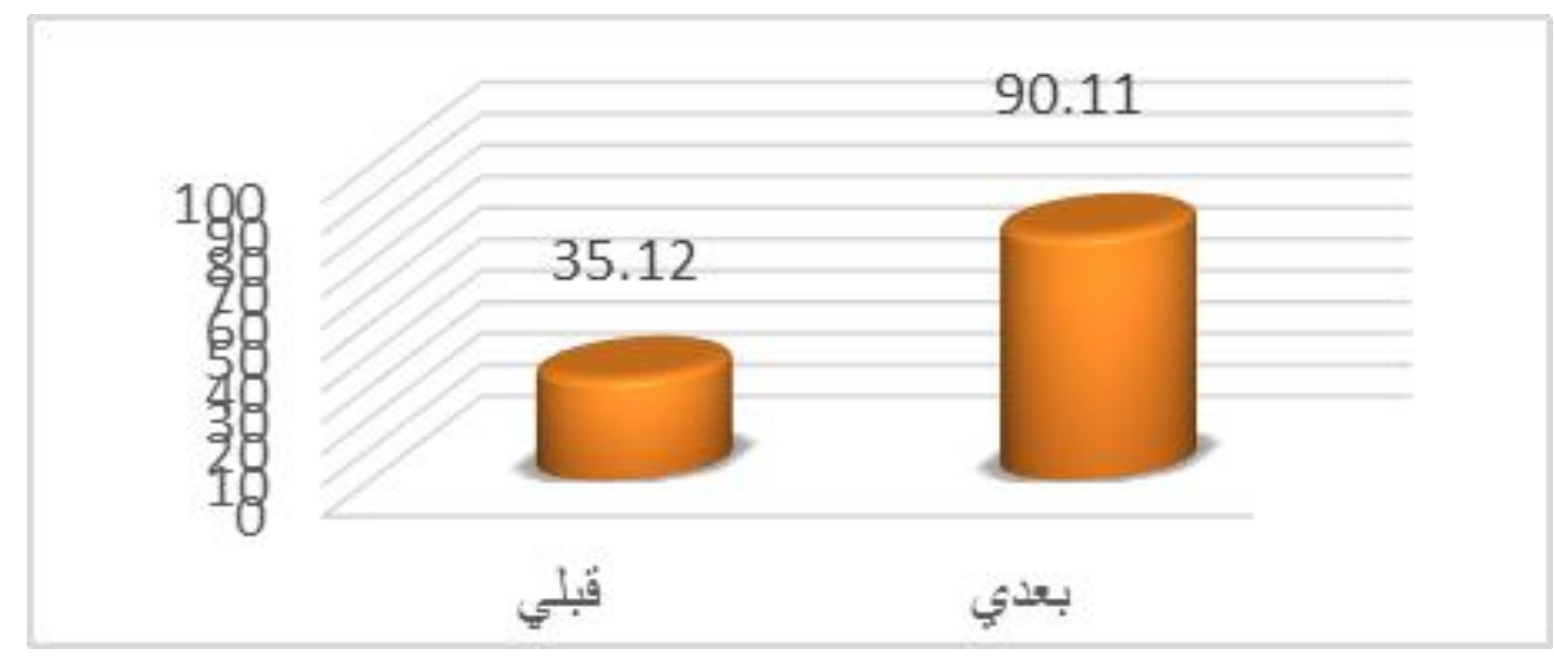

شكل (0): التمثيل البياني لمتوسطات درجات طلاب المجموعة التجريبية لمقياس المشاركة المجتمعية ككل

يتضح مما سبق أن قيم (ت) دالة إحصائًًا عند مستوى دلالة ( ( ...) بين منوسطي درجات المجموعة التجريبية القبلية، والبعدية في مقياس المشاركة المجتمعية، كما استخدمت الباحثة مقياس

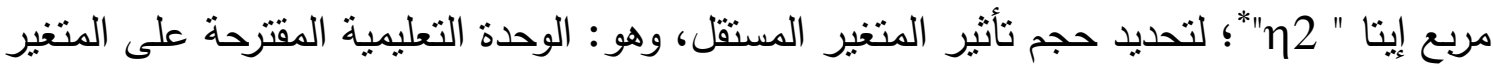

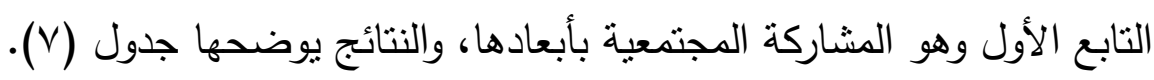

$$
\text { جدول : (v) (a) }
$$

نتائج حسابات حجم التأثير لاستخدام الوحدة التعليمية المقترحة على المشاركة المجتمعية بأبعادها.

\begin{tabular}{|c|c|c|c|c|}
\hline المقياس ككل & المشاركة الاجتماعية & المشاركة السياسية & العمل التطوعي & أبعاد المقياس \\
\hline .991 &. .91 &. .91 &. .97 & مريع ايتا "2" \\
\hline IV.rA & $0.9 \varepsilon$ & $0.9 \leqslant$ & 0.0. & قيمة d \\
\hline كبير & كبير & كبير & كبير & حجم التأثير \\
\hline
\end{tabular}

وبملاحظة قيمة كل من "2" وقيمة "d" المقابلة لها يتضح أن حجم تأثير الوحدة التعليمية

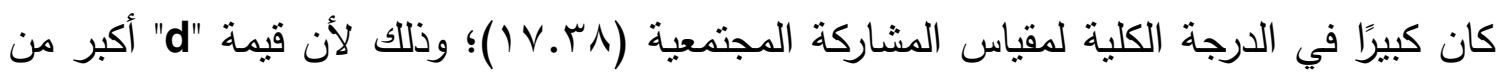

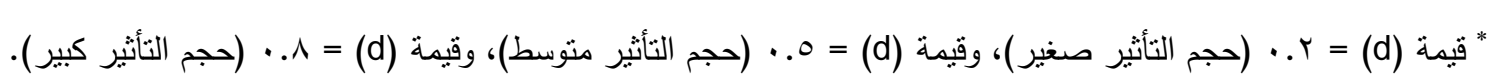


(1. ·)، كما كان حجم تأثير التدريس بالوحدة التعليمية كبيرًا في الدحاور الفرعية لأبعاد المشاركة

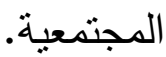

وينص الفرض الثاني علي "يوجد فرق ذو دلالة إحصائية عند مستوى دلالة ( (...) بين متوسطي درجات طلاب المجموعة التجريبية في النطبيقين: القبلي، والبعدي لاختبار المشاركة المجتمعية لصالح التطبيق البعدي. ويتقرع عن هذا الفرض الفروض الفرعية التالية:

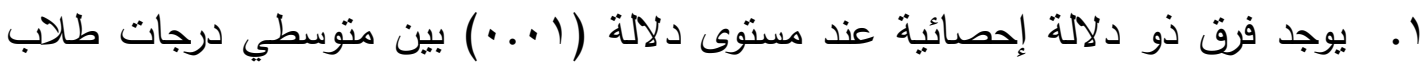

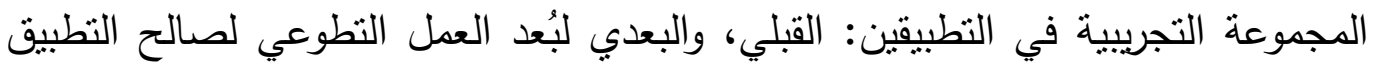

$$
\text { البعدي. }
$$

r. يوجد فرق ذو دلالة إحصائية عند مستوى دلالة (1 ...) بين منوسطي درجات طلاب المجموعة التجريبية في النطبيقين: القبلي، والبعدي لبُعد المشاركة السياسية لصالح التطبيق البعدي.

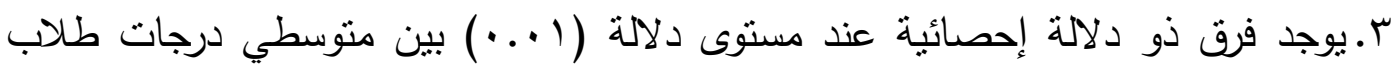

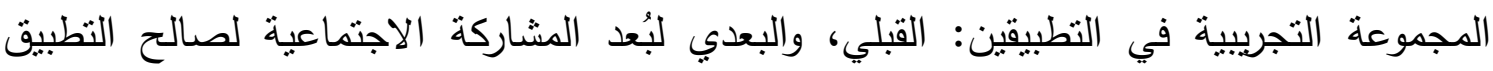

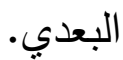
وللتحقق من صحة الفرض الثاني، وفروعه؛ فقد قامت الباحثة بمقارنة متوسطات درجات طلاب المجموعة التجريبية في التطبيقين: القبلي والبعدي؛ لاختبار المشاركة المجتمعية (اختبار Paired- Samples T مواقف)، وقد استخدمت الباحثة اختبار "ت" للمجموعات المرتبطة Test الجدول التالي(^) نتائج النطبيقين: القبلي والبعدي؛ لاختبار المشاركة المجتمعية. 


\section{جدول (^)}

المتوسطات والانحرافات المعيارية وقيم "ت" لدرجات طلاب المجموعة التجريبية في التطبيقين القبلي والبعدي لاختبار المشاركة المجتمعية وأبعاده.

\begin{tabular}{|c|c|c|c|c|c|c|}
\hline مربع إيتا & قيمة "ت & الانحراف & المتوسط & التطبيق & العدد & اختبار المشاركة \\
\hline. .91 & 91.0 & $1 . r V$ & 11.99 & قبلى & \multirow{2}{*}{$\wedge \wedge$} & \multirow{2}{*}{ الاختبار ككل } \\
\hline كبير & دالة & $1 . .0$ & גז.וז & بعدي & & \\
\hline $.9 \mathrm{~V}$ & $0 . .19$ &.$v r$ & $r . \varepsilon r$ & قبلي & \multirow{2}{*}{$\wedge \wedge$} & \multirow{2}{*}{ العمل التطوعي } \\
\hline كبير & دالة &. $.7 V$ & v.l. & بعدي & & \\
\hline. $.9 V$ & $0 V .19$ &. .79 & r.vi & قبلي & \multirow{2}{*}{$\wedge \wedge$} & \multirow{2}{*}{ المشاركة السياسية } \\
\hline كبير & دالة & .07 & $v .19$ & بعدي & & \\
\hline .991 & $01 . .1$ & .99 & $r .9 r$ & قبلي & \multirow{2}{*}{$\wedge \wedge$} & \multirow{2}{*}{ الاجتماركة } \\
\hline كبير & دالة & .00 & v.l. & بعدي & & \\
\hline
\end{tabular}

ويتضح من نتائج الجدول السابق مايلي:

- أنه بمقارنة متوسطات درجات طلاب المجموعة التجريبية في التطبيقين: القبلي، والبعدي لاختبار المشاركة المجتمعية، وأبعاده، لُوحِظ أن المتوسطات البعدية أعلى من المتوسطات القبلية للاختبار ككل، ومن كل بُعد من أبعاده، وقد أرجعت الباحثة ذلك إلى استخدام الوحدة التعليمية المقترحة للمجموعة التجريبية.

- قيمة "ت" المحسوبة لبُعد العمل التطوعي = (19. • (0)، وهي أكبر من قيم "ت" الجدولية عند درجات حرية (r • ())، ومستوى دلالة (1 ( . ·)؛ مما يُثير إلى وجود فروق دالة إحصائيًا بين متوسطي درجات طلاب المجموعة التجريبية في القياسين: القبلي، والبعدي لصالح القياس البعدي، ومن ثم فاعلية استخدام الوحدة التعليمية المقترحة في تتمية بُعد العمل التطوعي؛ لدى طلاب 
والتتنيل البياني التالي يوضح تزايد منوسطات درجات المجموعة التجريبية في التطبيق البعدي عن منوسطات نفس المجموعة في النطبيق القبلي، وذلك في بُعد العمل التطوعي. دربط

100

78.99

31.12

0

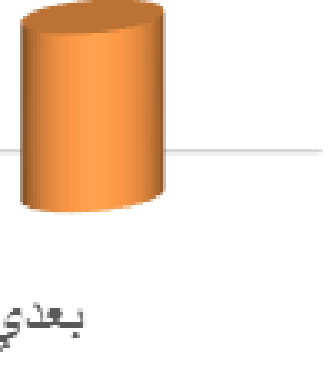

شكل

التمثيل

البياني

لمتوسطات درجات طلاب المجموعة التجريبية لبُعد العمل النطوعي.

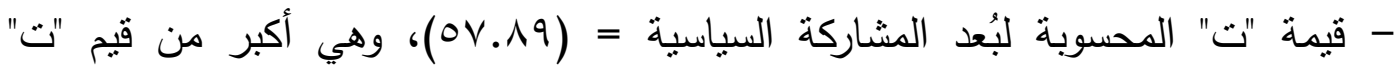

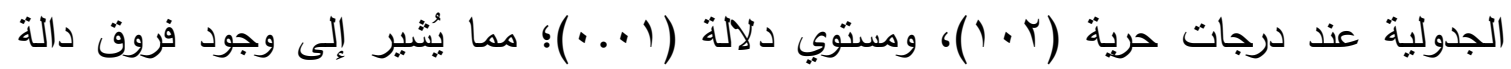

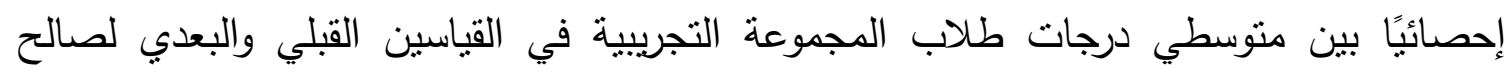
القياس البعدي؛ وبالتالي فاعلية الوحدة التعليمية المقترحة في تتمية بُعد المشاركة السياسية لدى

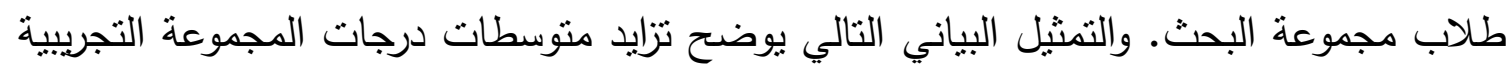
في التطبيق البعدي عن متوسطات نفس المجموعة في النطبيق القبلي؛ وذلك في بُعد المشاركة

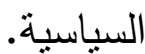

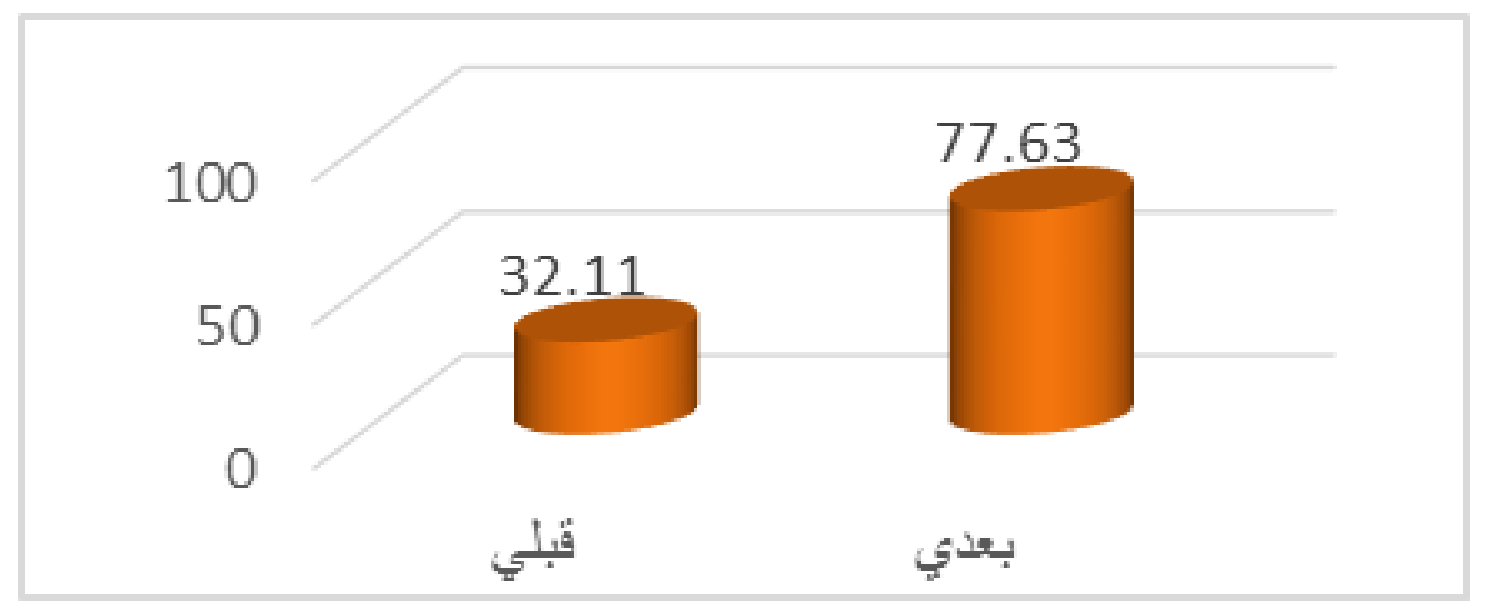

شكل (V): التمثيل البياني لمنتوسطات درجات طلاب المجموعة التجرييية لبُعد المشاركة 


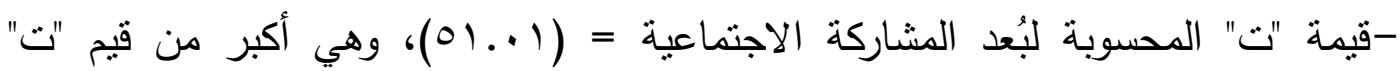

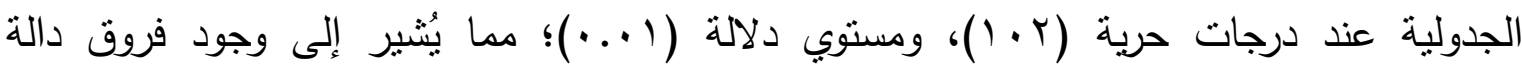

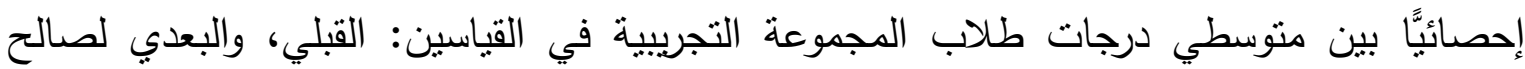
القياس البعدي؛ وبالثالي فاعلية الوحدة التعليمية المقترحة في تتمية المشاركة الاجتماعية لدى طلاب

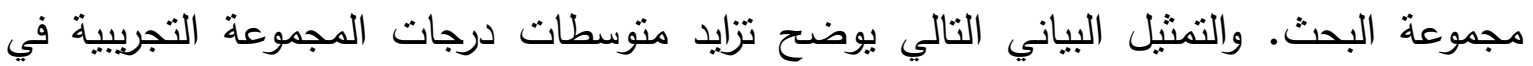
التطبيق البعدي عن متوسطات نفس المجموعة في التطبيق القبلي؛ وذلك في بُعد المشاركة

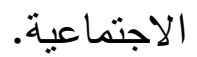

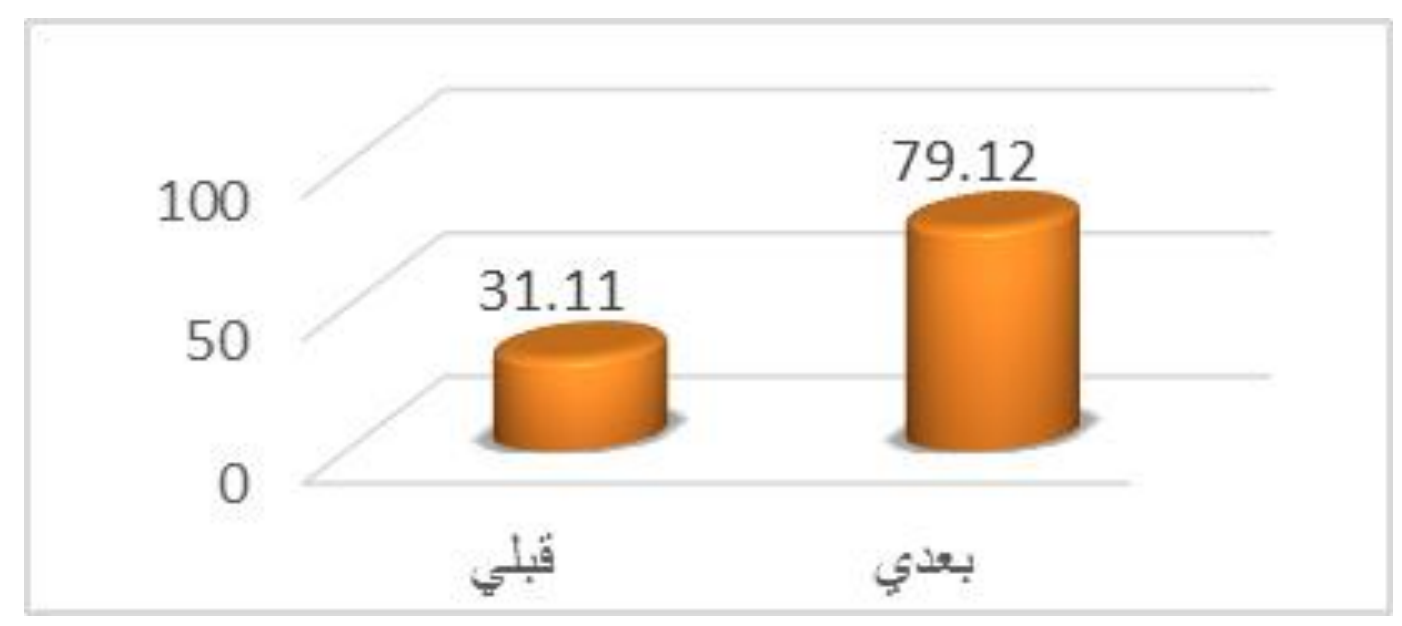

شكل (^): التمثيل البياني لمتوسطات درجات طلاب المجموعة التجريبية لبُحد المشاركة

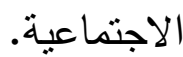

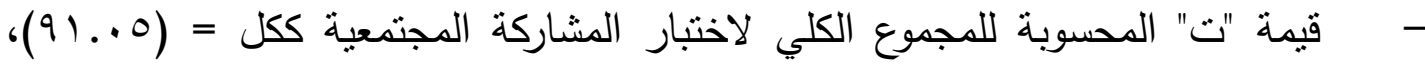

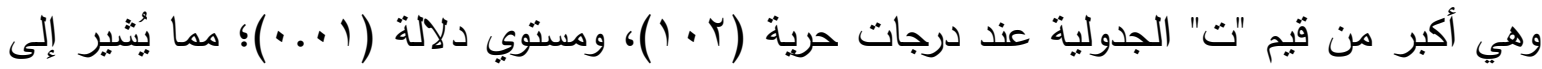
وجود فروق دالة إحصائًًا بين متوسطي درجات طلاب المجموعة التجرييية في القياسين: القبلي والبعدي لصالح القياس البعدي؛ وبالتالي فاعلية الوحدة التعليمية المقترحة في تتمية المشاركة المجتمعية بصورة كلية لدى طلاب مجموعة البحث. والتمثيل البيانى يوضح تزايد متوسطات درجات المجموعة التجريبية فى التطبيق البعدى عن متوسطات نفس المجموعة فى التطبيق القبلى؛ وذلك

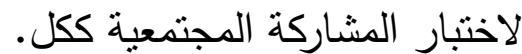




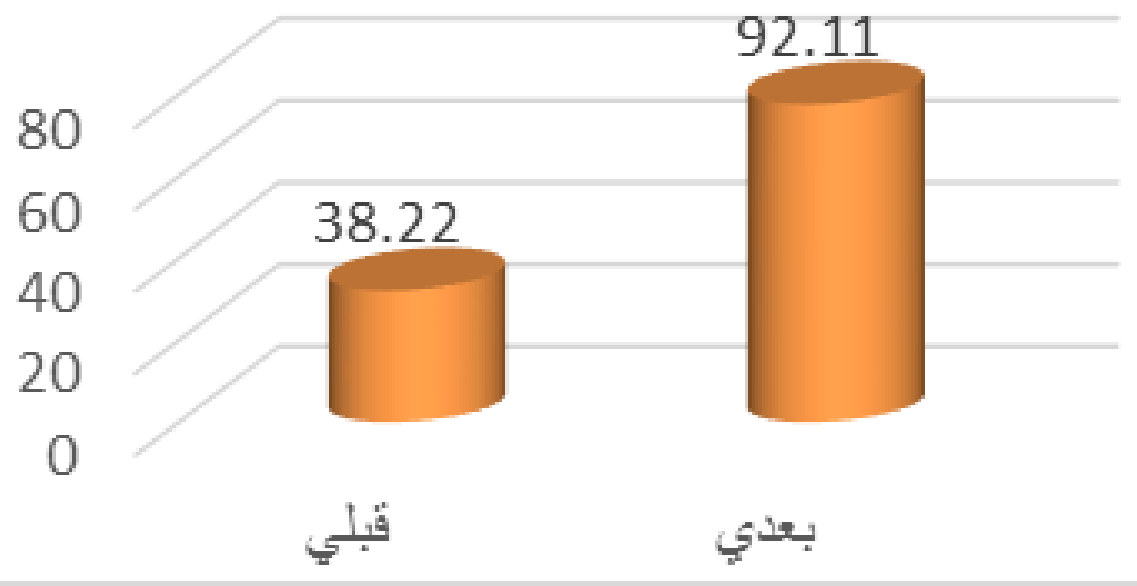

شكل(9): التمنيل اليياني لمتوسطات درجات طلاب المجموعة التجريبية لاختبار المشاركة المجتمعية ككل

يتضح مما سبق أن قيم (ت) دالة إحصائًا عند مستوى دلالة (1 (..) بين منوسطي

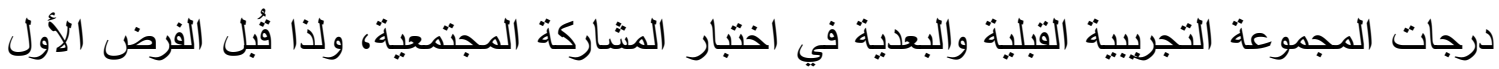
وفروعه. كما استخدت الباحثة مقياس مربع إيتا " †2 ؛ لتحديد حجم تأثير المتغير المستقل، وهو: الوحدة التعليمية المقترحة على المتغير التابع الأول وهو المشاركة المجتمعية بأبعادها،

والنتائج يوضحها جدول (9).

\section{جدول (9):}

نتائج حسابات حجم النأثثر لاستخدام الوحدة التعليمية المقترحة على المشاركة المجتمعية بأبعادها.

\begin{tabular}{|c|c|c|c|c|}
\hline الاختبار ككل & المشاركة الاجتماعية & المشاركة السياسية & العمل التظوعي & أبعاد المقياس \\
\hline. .91 & .91 & $.9 \mathrm{~V}$ &. $.9 V$ & " مريع ايتا "2" \\
\hline 10.9 & $\varepsilon . \wedge 7$ & $0.0 r$ & $0.0 r$ & قيمة d \\
\hline كبير & كبير & كبير & كبير & حجم التأثير \\
\hline
\end{tabular}

وبملاحظة قيمة كل من: "d"

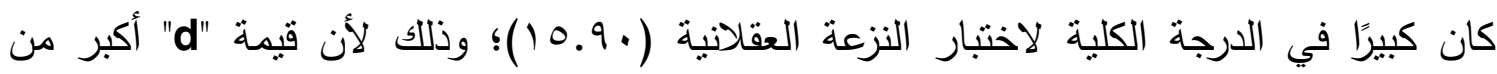
(1. •)، كما كان حجم تأثير التدريس بالوحدات التعليمية كبيرًا في المحاور الفرعية لأبعاد المشاركة

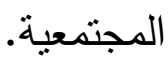

للإجابة عن السؤال الثالث للبحث؛ وهو: ما فاعلية الوحدة المقترحة القائمة على الخيال الاجتماعي في تتمية مهارات التفكير التحليلي؛ لاى طلاب المرحلة الثانوية؟ 
تطلب الإجابة عن هذا السؤل التحقق من صحة الفرض الثالث:

وينص الفرض الثالث على ما يلي: "يوجد فرق ذو دلالة إحصائية عند مستوى دلالة

(1. (·) بين متوسطي درجات طلاب المجموعة التجريبية في التطبيقين: القبلي، والبعدي لمقياس

مهارات التفكير التحليلي لصالح التطبيق البعدي.

وللتحقق من صحة الفرض الثالث؛ فقد قامت الباحثة بمقارنة متوسطات درجات طلاب

المجموعة التجريبية في التطبيقين: القبلي والبعدي؛ لمقياس مهارات التفكير التحليلي، وقد استخدمت الباحثة اختبار "ت" للمجموعات المرتبطة Paired- Samples T Test؛ للكثف عن دلالة الفروق بين المتوسطات (باستخدام برنامج SPSS. v21، ويوضح جدول: (• () نتائج التطبيقين؛ القبلي، والبعدي لمقياس مهارات التفكير التحليلي.

\section{جدول (1.) - (1)}

المتوسطات والانحرافات المعيارية وقيم "ت" لدرجات طلاب المجموعة التجريبية في التطبيقين القبلي والبعدي لمقياس مهارات التفكير التحليلي.

\begin{tabular}{|c|c|c|c|c|c|c|}
\hline مستوى الدلالة & قيمة ت & الانحراف المعياري & المتوسط & العدد & القياس & \multirow{3}{*}{ التفكير التحليلي. مهارات. } \\
\hline .99 & سT.T & $7 . .1$ & Tr.ll & $\wedge \wedge$ & القبلي & \\
\hline حجم التأثير كبير & دالة & $9 . . r$ & VV.Tr & $\Lambda \Lambda$ & البعدي & \\
\hline
\end{tabular}

ويتضح من نتائج الجدول السابق مايلي:

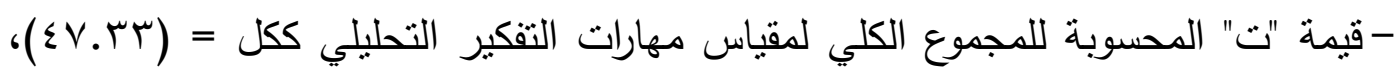

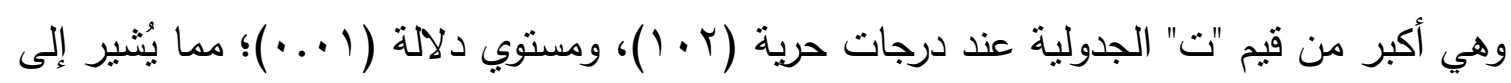
وجود فروق دالة إحصائيًا بين منوسطي درجات طلاب المجموعة التجريبية في القياسين: القبلي، والبعدي لصالح القياس البعدي؛ وبالتالي فاعلية الوحدة التعليمية المقترحة في تتمية مهارات التفكير

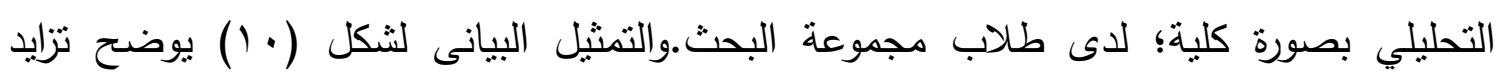

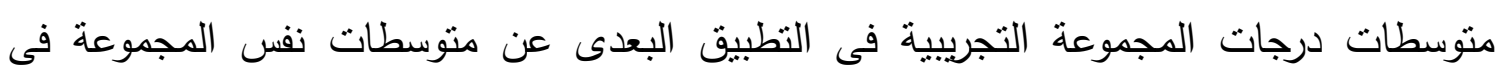
التطبيق القبلى؛ وذللك لمقياس مهارات التفكير التحليلي ككل. 


\section{0}

\subsection{1}

50

\subsection{1}

0

\section{قُب}

\section{بعدي}

شكل( • (): التمثيل البياني لمنتسطات درجات طلاب المجموعة التجريبية لمقياس مهارات التفكير التحليلي ككل.

يتضح مما سبق أن قيم (ت) دالة إحصائيًا عند مستوى دلالة (1 ...) بين متوسطي درجات المجموعة التجريبية القبلية، والبعدية في مقياس مهارات التفكير التحليلي؛ ولذا قُبل الفرض الثالث. كما استخدمت الباحثة مقياس مربع إيتا " †2 ؛ لتحديد حجم تأثثر المتغير المستقل، وهو: الوحدة التعليمية المقترحة على المتغير التابع الأول وهو مهارات التفكير التحليلي، والنتائج يوضحها

جدول(1) (1)

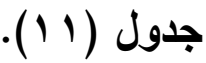

نتائج حسابات حجم التأثير لاستخدام الوحدة التعليمية المقترحة على مهارات التفكير التحليلي.

\begin{tabular}{|c|c|}
\hline \multicolumn{2}{|c|}{ مقياس مهارات التفكير التحليلي } \\
\hline .97 & " مربع ايتا " \\
\hline 0.0. & قيمة d \\
\hline كبير & حجم التأثير \\
\hline
\end{tabular}

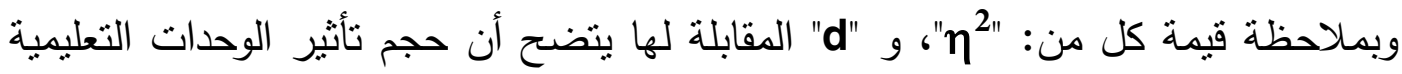
كان كبيرًا في الدرجة الكلية لاختبار النزعة العقلانية (0.0)؛ وذلك لأن قيمة "d" أكبر من (^. •)، كما كان حجم تأثير التدريس بالوحدة التعليمية كبيرًا في تتمية مهارات التفكير التحليلي. تفسير نتائج البحث:

يمكن أن يُعزى الأثر إلى الرغبة في معرفة ماهية المشاركة المجتمعية، والتفكير التحليلي، وأهميتهما، وكيفية استخدامهما، والرغبة الجادة في تطبيقها؛ فضلً عن التخطيط الجيد للوحدة التعليمية المقترحة ابتداءً من الأهداف العامة، ومرورًا بالمحتوى العلمي لها، ومصادر التعليم 
والتعلم، وأنشطة التعليم والتعلم، واستراتيجيات التدريس المتتوعة وانتهاءً بأساليب التقويم؛ ويمكن تقصيل ذلك كما يلي: ا - الأهداف الإجرائية للوحدة التعليمية المقترحة

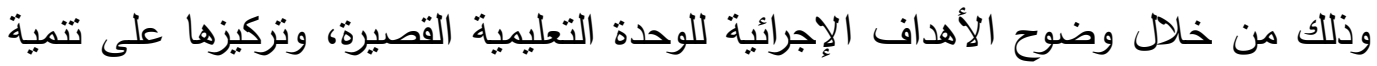

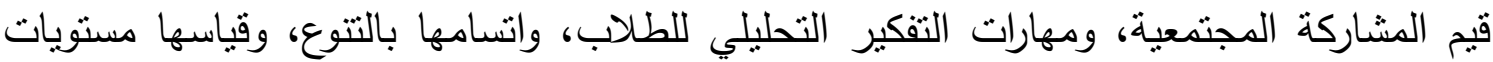
عقلية مختلفة. r- بحتوى الوحدة التعليمية المقترحة. وذللك من خلال تصميم الوحدات التعليمية القصيرة بشكل دُميج فيه المحتوى بقيم المشاركة المجتمعية، ومهارات التفكير التحليلي؛ من خلال: عرض عدد من الكتابات النظرية، والوقفات

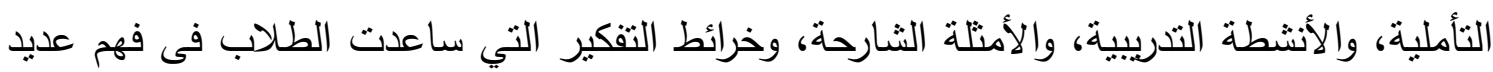
منهما.

كذللك ركَّز المحتوى على موضوعات، وقضايا بعينها، جعلت الطلاب يتعاملون - مباشرة -

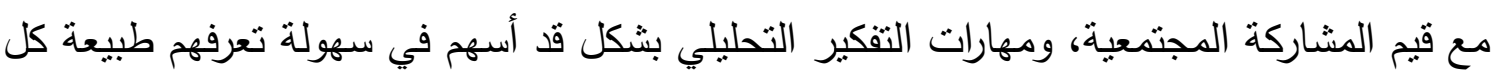
منها، وكيفية تطبيقهما. r- اختيار استراتيجيات التعليم، والتعلم: وكئه وذللك عبر ملاعمة طرائق التدريس لطبيعة المتعلمين، وطبيعة محتوى الوحدة التعليمية،

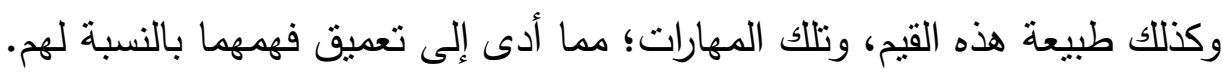

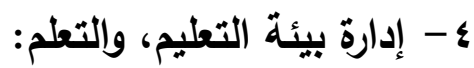
وذلك عبر تتظيم بيئة التعليم والتعلم أثناء تدريس الوحدة التعليمية القصيرة، والتي اتست

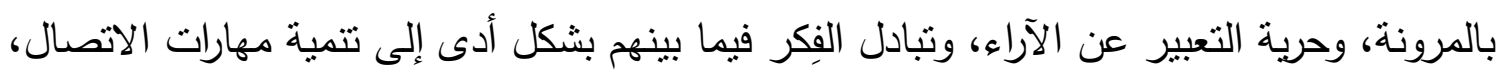
والمشاركة الفعَّالة فيما بينهم حول ما يعرض عليهم من قضايا، وموضوعات. ه- أنثطة التعليم، والتعلم. لقد أسهمت أنثطة التعليم، والتعلم في مشاركة جميع الطلاب في موضوعات الوحدة

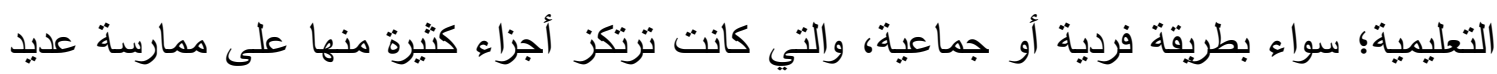

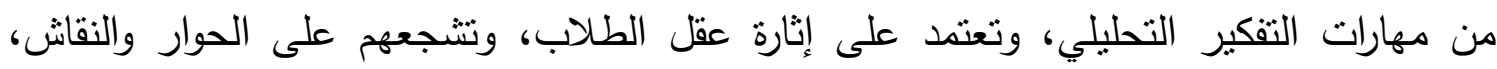

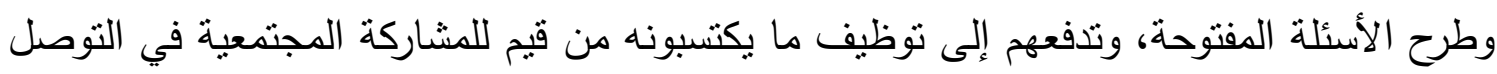

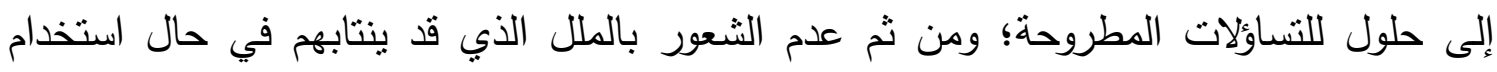


צ- - مصادر التعليم، والتعلم:

لقد كان لمصادر التعلم المختلفة - التي تم توجيه أنظار الطلاب إليها - دور حيوي في

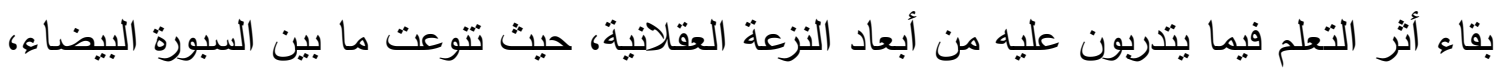

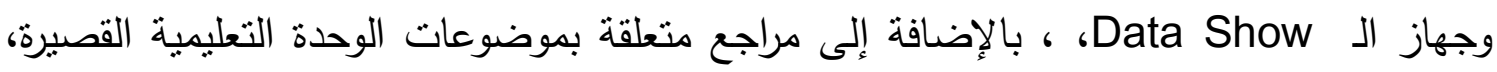
ومواقع على الإنترنت قد عمقت فهم قيم المشاركة المجتمعية، ومهارات التفكير التحليلي، وكيفية

$$
\begin{aligned}
& \text { ممارستها في حياتهم اليومية. } \\
& \text { V- أدوات التقويم: }
\end{aligned}
$$

تتوعت أساليب التقويم المستخدمة في موضوعات الوحدة التعليمية القصيرة، حيث أتاحت

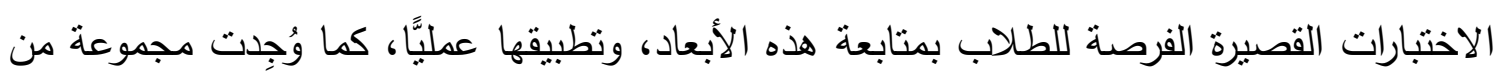
الأسئلة جعلت الطالب يعرف نواحي القوة، والضعف في أدائه؛ مما أدى إلى ارتقاء مستواهم في

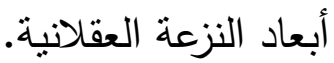

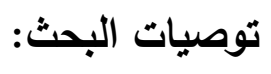

انطلاقا من نتائج البحث الحالي فإن الباحثة توصي بما يلي: الباد

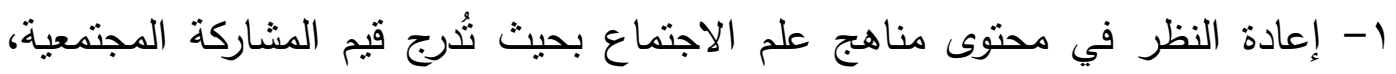

ومهارات التفكير التحليلي ضمن محتواها.

r- تجنب الاختزالية التي يتميز بها المحتوى العلمي في مناهج علم الاجتماع؛ خاصة فيما يتعلق بعلاقة الفرد بمجتمعه، وما يمكن أن يقدمه لها من خدمات مجتمعية.

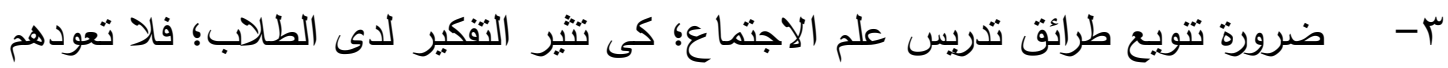

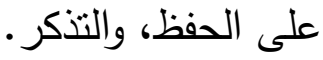

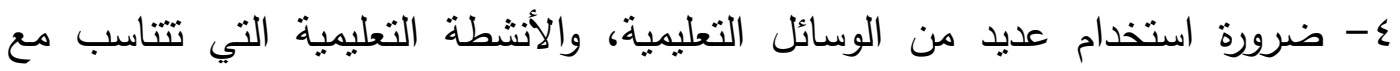

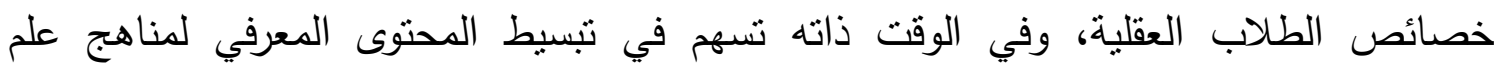

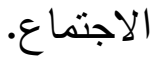
ه- ضرورة الاهتمام بإعداد أدلة للمعلمين تتضمن المراجع، والقراءات المختلفة عن طبيعة تدريس قيم المشاركة المجتمعية، ومهارات التفكير التحليلي. 1- تشجيع معلمي علم الاجتماع على تحديد قيم المشاركة المجتمعية، ومهارات التفكير

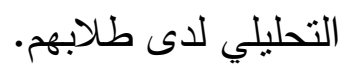

V- تدريب معلمي علم الاجتماع على استخدام طرائق، ومداخل تدريسية تسهم في تتمية قيم المشاركة المجتمعية، ومهارات التفكير التحليلي. 
ا - إجراء دراسات، وبحوث مماثلة لمختلف فروع المواد الفلسفية، كالفلسفة، والمنطق، وعلم النفس، والتربية الوطنية.

ץ- تطـوبر منـاهج علم الاجتمـاع؛ في ضـوء قيم المشـاركة المجتمعيـة، ومهـارات التفكيـر التحليلي.

ب- تقويم أداء معلمي علم الاجتمـاع في أثناء الخدمـة؛ في ضوء مدى تمكنهم من مهارات تدريس قيم المشاركة المجتمعية، ومهارات التفكير التحليلي. ع- برنـامج مقترح؛ لإعداد معلم علم الاجتمـاع مهنيًا في كليات التربية؛ في ضوء مهارات التقكير التحليلي. ه- تقويم الجانب المهني في برنامج إعداد معلم علم الاجتماع؛ في ضوء ما ينميه من قيم المشاركة المجتمعية، ومهارات التفكير التحليلي. צ- - دراسـات تعنـي باسـتخدام مـداخل تدريسية مختلفـة؛ لتتميـة قيم المشـاركة المجتمعيـة، ومهارات التفكير التحليلي في مادة علم الاجتماع. V - منهج مقترح في علم الاجتمـاع قائم على المشاركة المجتمعية، وأثره في اتجاه الطـلاب نحو علم الاجتماع. ^- ثقويم منـاهج علم الاجتمـاع الحاليـة؛ في ضوء مـا تتميـه من قيم المشـاركة المجتمعيـة، ومهارات التفكير التحليلي لدى الطلاب. 9- برنامج تدريبي للمعلمين في أثناء الخدمة؛ لتدريبهم على تدريس قيم المشاركة المجتمعية لتتمية المواطنة المسؤولة لدى طلابهم. • 1 - برنامج تدريبي مقترح قائم على الخيال الاجتماعي؛ لتتمية مهارات التفكير العليا؛ لدي الطلاب المعلمين (علم الاجتماع). 


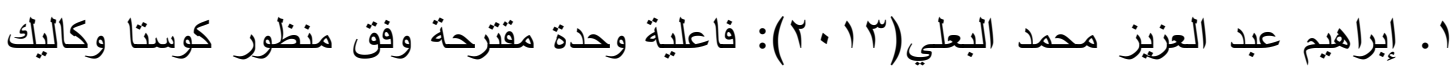

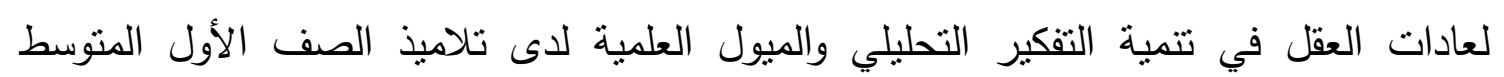

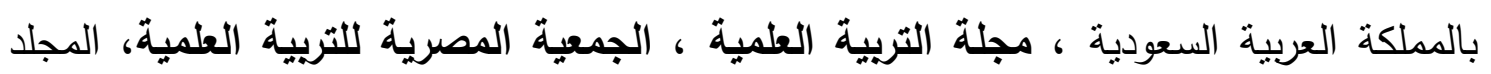

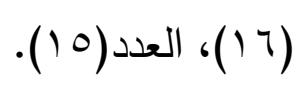

r. أحمد عبد الله زايد (9 . . r): الأطر الثقافية الحاكمة لسلوك المصريين واختياراتهم دراسة لقيم النزاهة والثفافية والفساد، دراسة مقدمة إلى لجنة النزاهة والثفافية، وزارة الدولة للتنمية الإدارية: القاهرة.

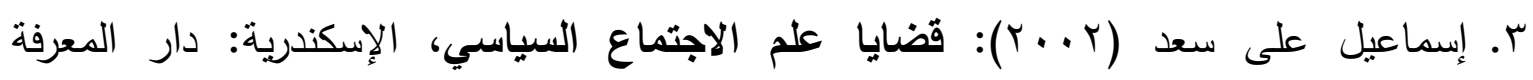
الجامعية.

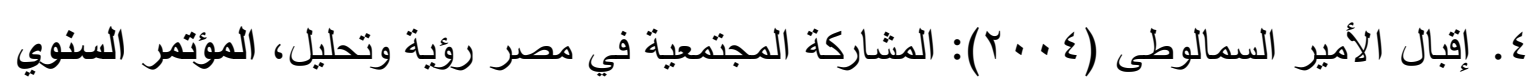

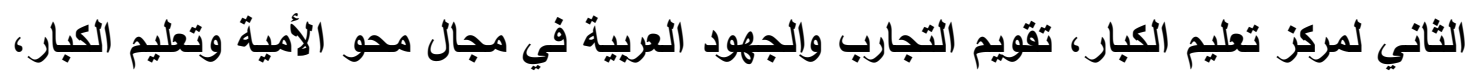

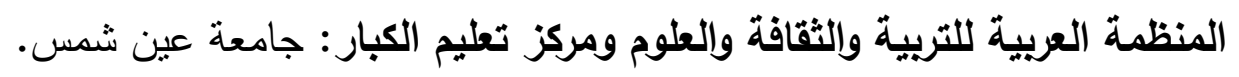

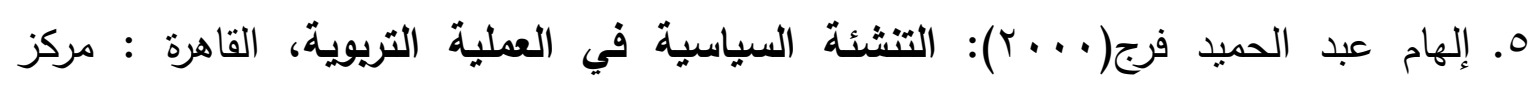
المحروسة للنشر . المام

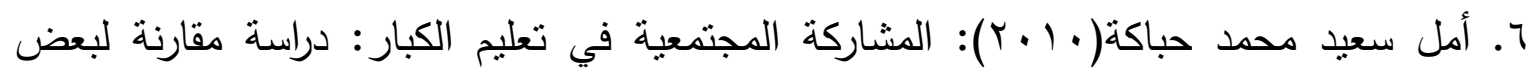

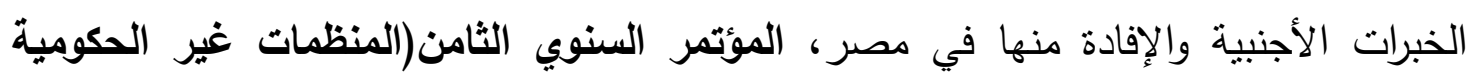

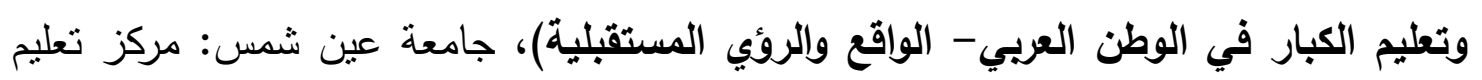
الكبار .

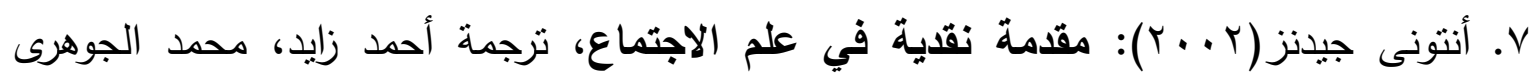

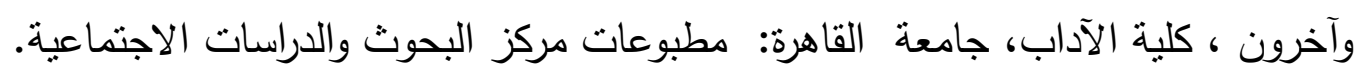

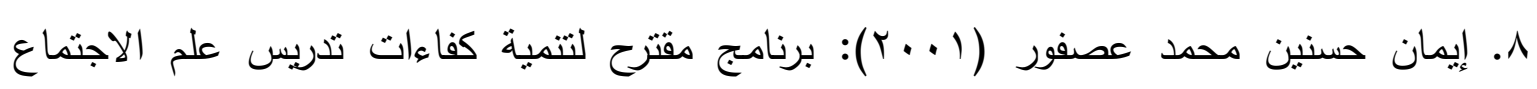

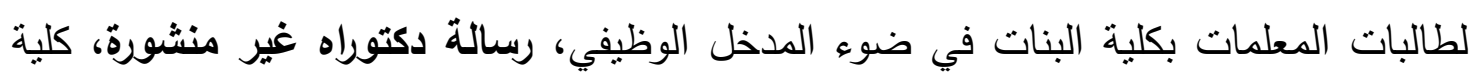
البنات: جامعة عين شمس.

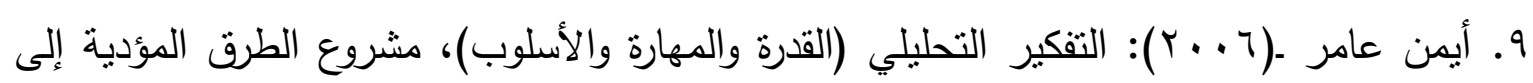

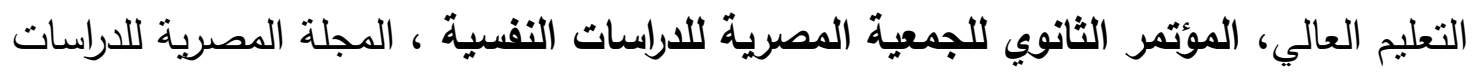

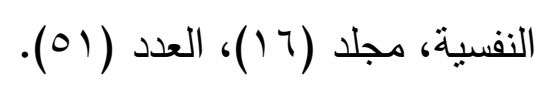

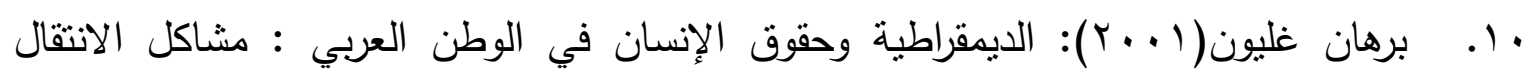

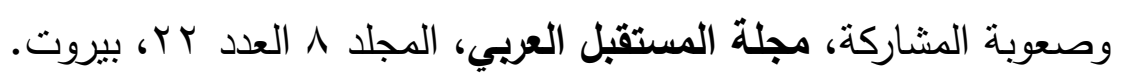


11.

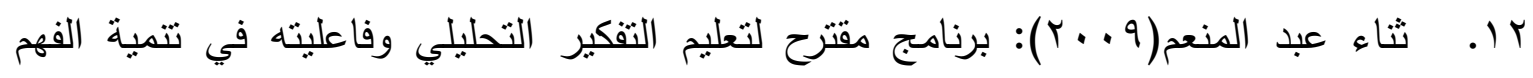
القرائي والوعي بعمليات التفكير لدي تلاميذ المرحلة الإعدادية ، مجلة دراسات في المناهج وطرائق التتريس ، الجمعية المصرية للمناهج وطرائق التتريس، العدد (ع ـ ().

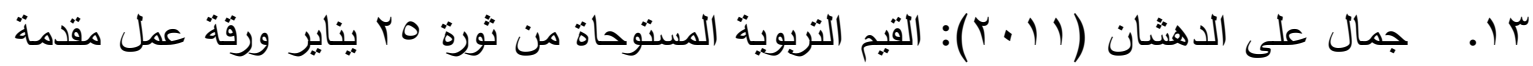

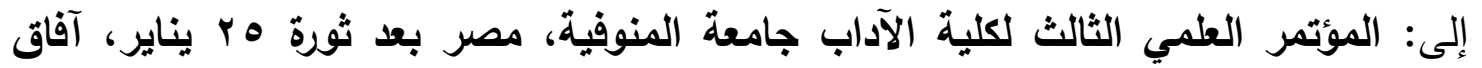

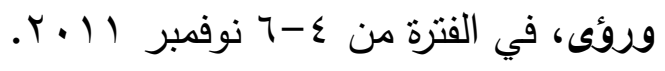

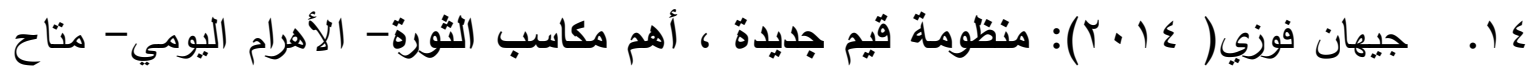

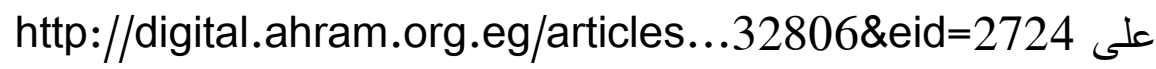

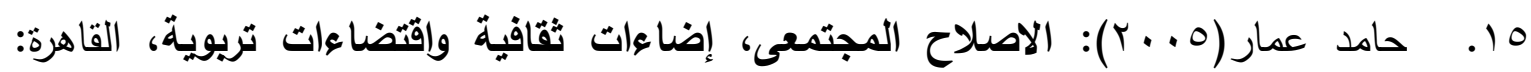

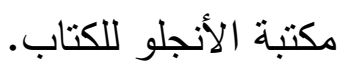

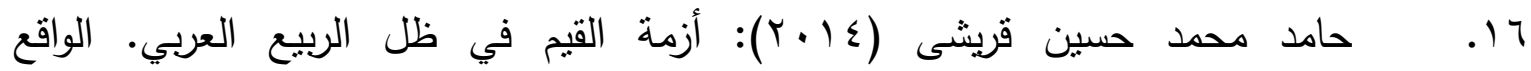

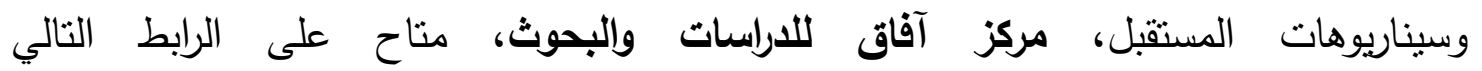

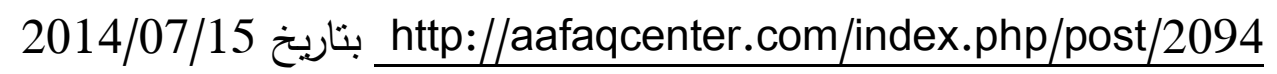

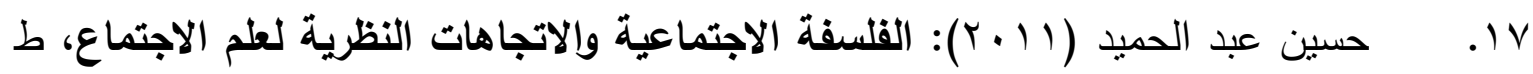
ع ، القاهرة: المكتب الجامعي الجديد.

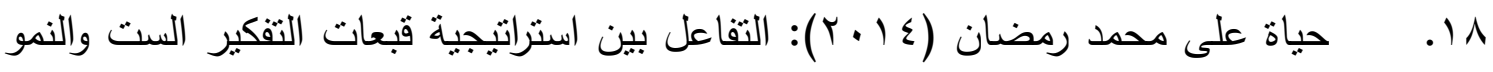
العقلي في تحصيل المفهومات الفيزيائية وتتمية مهارات التفكير التحليلي واتخاذ القرار لدى

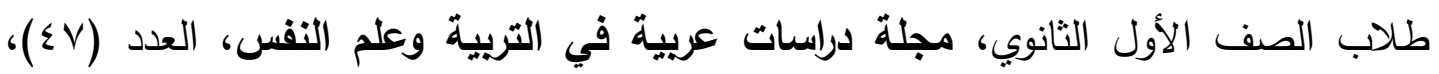
الجزء (ع) ).

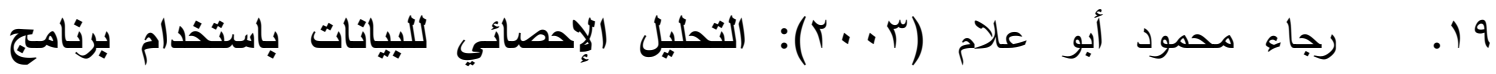
(SPSS)

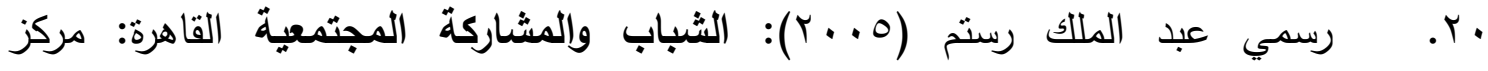

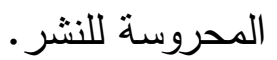

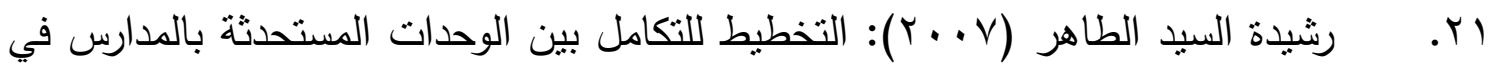

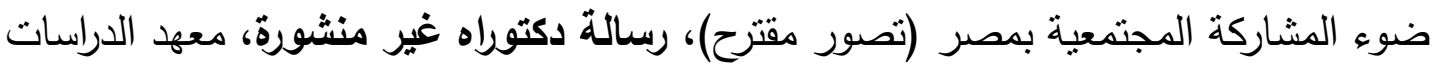
والبحوث: جامعة القاهرة.

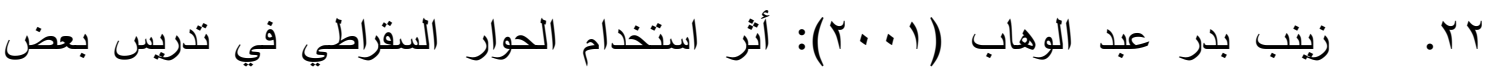

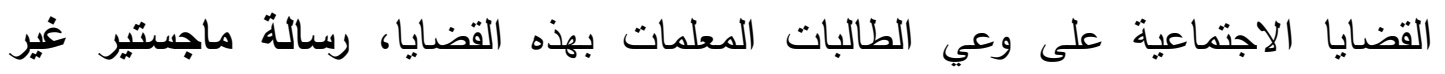
منشورة، كلية التربية: جامعة عين شمس. 


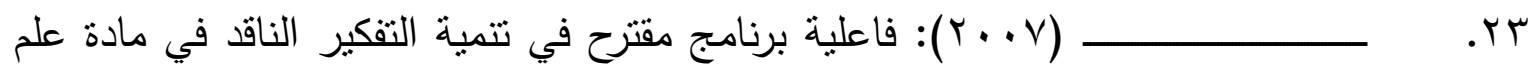
الاجتماع لاى الطالبات المعلمات بكلية البنات، رسالة دكتوراه، كلية البنات: جامعة عين شمس.

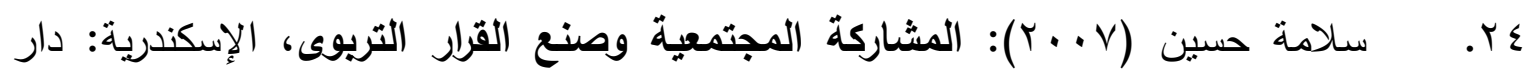
المعرفة الجامعية.

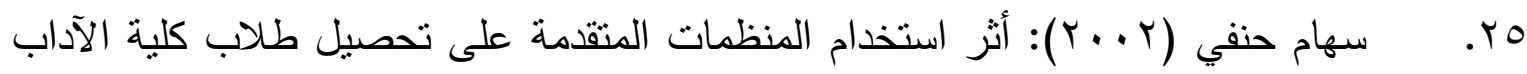
لمفاهيم علم الاجتماع السياسي والاحتفاظ بها وتتمية اتجاهاتهم نحو هذه المادة، مجلة دراسات في المناهج وطرائق التدريس، الجمعية المصرية للمناهج وطرائق التدريس، العدد VV.

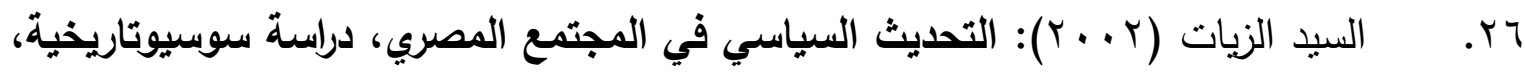
الإسكندرية: دار المعرفة الجامعية.

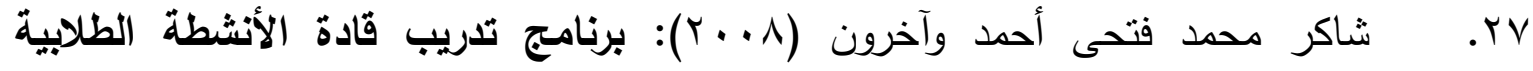
بمدارس التعليم الثانوي العام(المدير-الناظر -الوكيل)، القاهرة: وحدة التخطيط والمتابعة بالبنك الدولي.

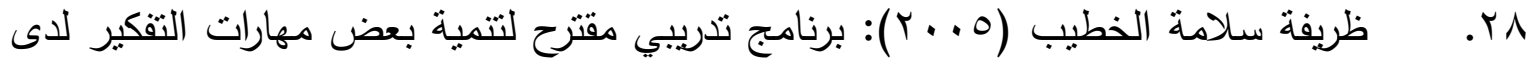
طلاب المرحلة الثانوبة عبر مادة علم الاجتماع، رسالة دكتوراه، معهد الدراسات التربوبة: جامعة القاهرة.

9. . عاطف غيث (990 (1)): قاموس علم الاجتماع، الإسكندرية: دار المعرفة الجامعية.

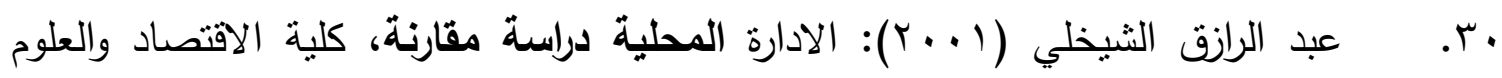
الادارية، جامعة مؤته.

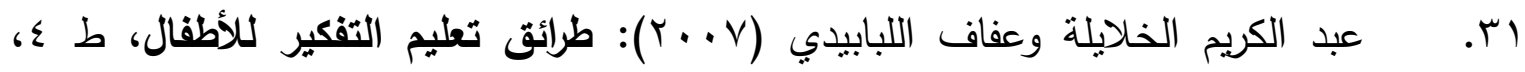
عمان: دار الفكر للطباعة والنشر والتوزيع.

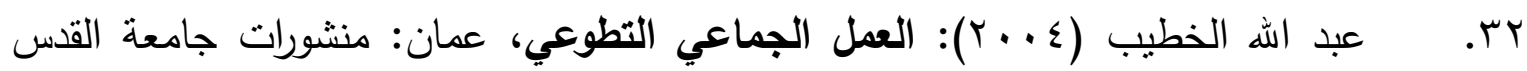
المفتوحة. rr. عبد الله محمد عبد الرحمن (q. . ب): النظرية في علم الاجتماع، دار المعرفة الحديثة ، الإسكندرية.

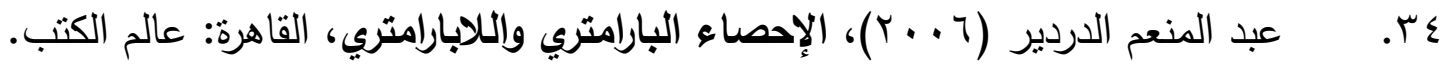
هr. عبد الهادي الجوهري (1 (ب): البعد الاجتماعي للتطوع، القاهرة: الهيئة المصرية العامة

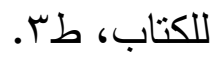
بr. عثمان غنيم (1) (ب): التخطيط والمشاركة المجتمعية، عمان: دار الصفاء للنشر والتوزيع. 


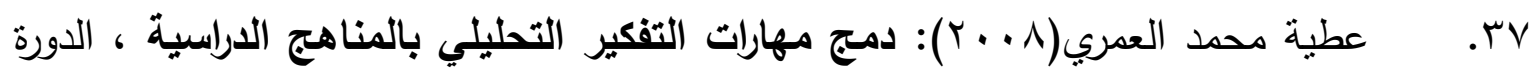
التدريبية الثنتوية، يناير، مركز القطان للبحث والتطوير التربوي.

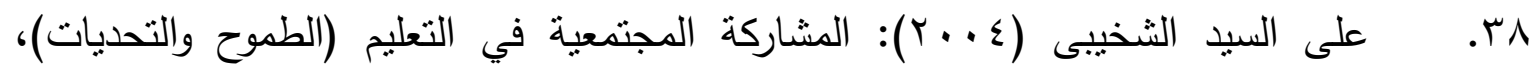
المؤتمر العلمى السنوي لكلية التربية جامعة المنصورة بالاثتراك مع مركز الدراسات المعرفية

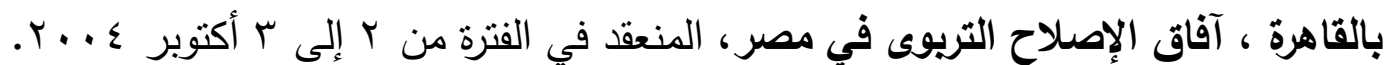

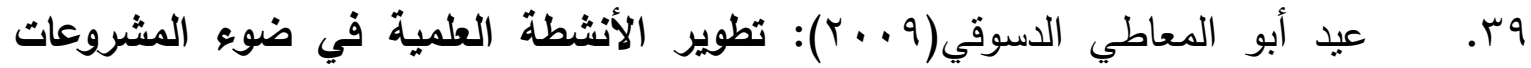
العلمية، الإسكندرية: المكتب الجامعى الحديث.

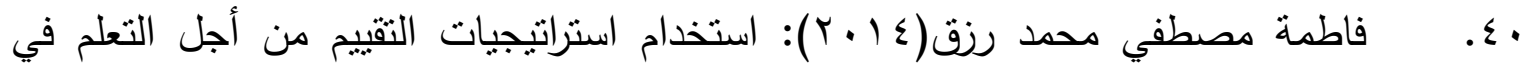
تحسين التفكير التحليلي والتواصل العلمي في العلوم لدى تلاميذ الصف السادس الابتدائي، مجلة دراسات عربية في التربية وعلم النفس، اتحاد التريويين العرب، المجلد(ع ()، العدد(ه) (ه).

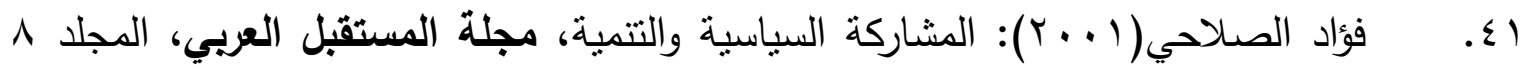
العدد r r، بيروت.

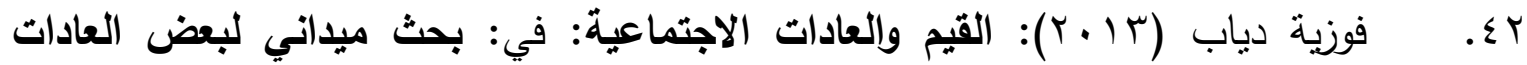
الاجتماعية، القاهرة: مكتبة الأسرة.

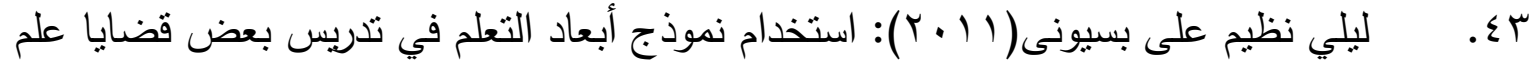

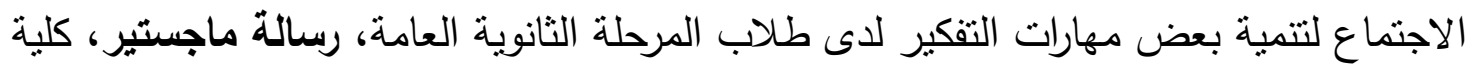
التربية: جامعة الاسكندرية

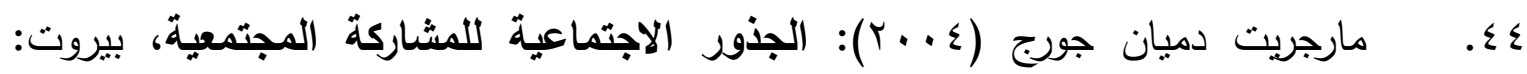
المؤسسة الجامعية للدراسات والنشر والتوزيع.

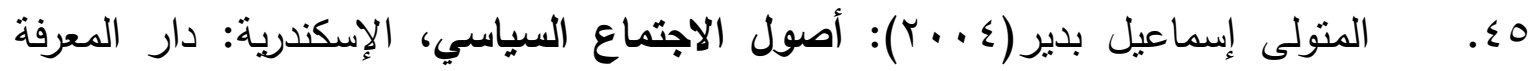

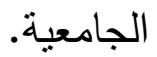

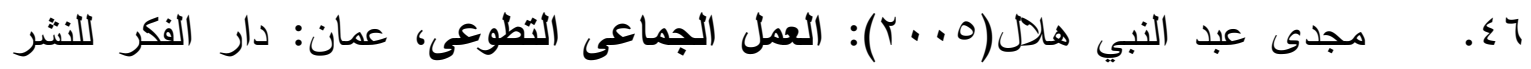
والتوزيع.

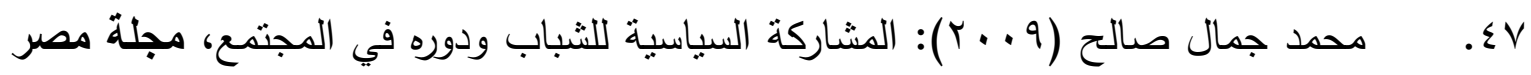

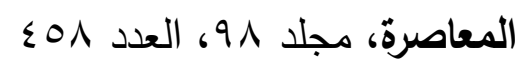

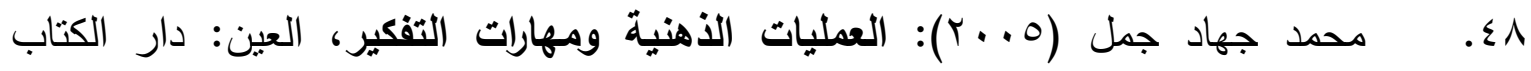
الجامعي.

9؛. محمد حسنيين العجمي (ب0.0): المشاركة المجتمعية المطلوبة لتفعيل مدخل الإدارة

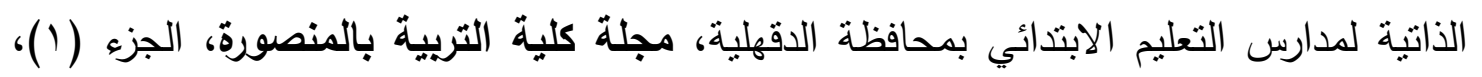

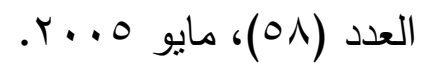




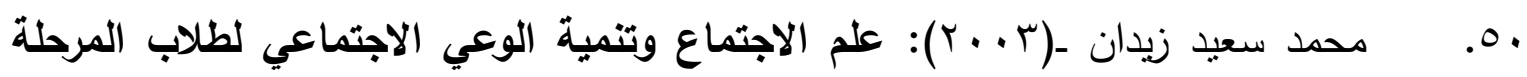

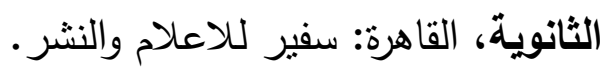

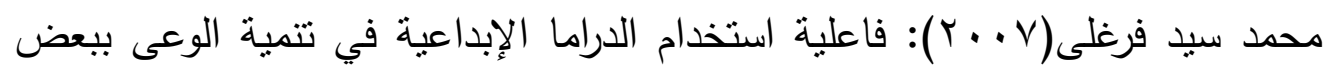

القضايا الاجتماعية لاى الطلاب الدارسين لمادة علم الاجتماع، رسالة ماجستير، كلية لإعلية التربية: جامعة عين شمس.

ror. مختار شعيب (2014): ما بعد ثورة · ب يونيو، الليبراليون والفرصة الثانية، القاهرة: مركز الأهرام للترجمة والنشر . ماب.

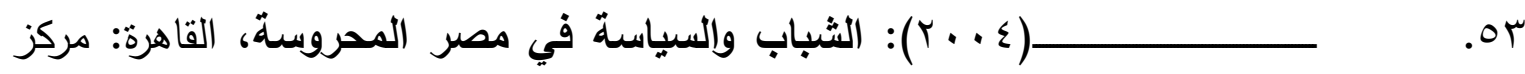

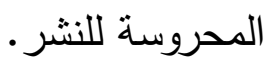

مصطفي خلف عبد الجواد(Y . . Y) : قراءات معاصرة في نظرية علم الاجتماع، مركز .05 البحوث والدراسات الاجتماعية، كلية الآداب: جامعة القاهرة.

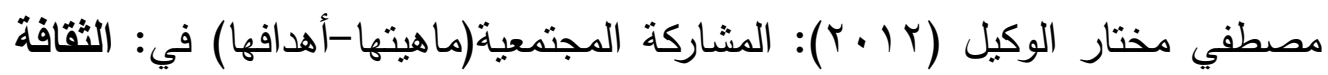

والتنمية في مصر، المجلدسا ، العدد 09، متوفر على الرابط التالي:

https://search.mandumah.com/Record/346899

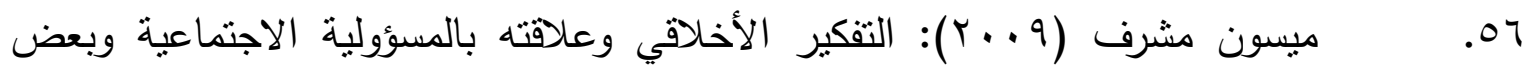

المتغيرات لاى طلبة الجامعة الإسلامية، رسالة ماجستير، غزة: الجامئ الجامعة الإسلامية.

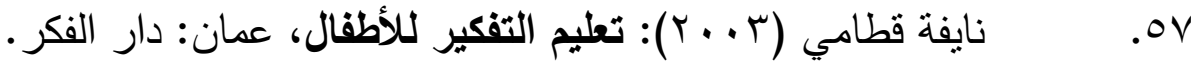

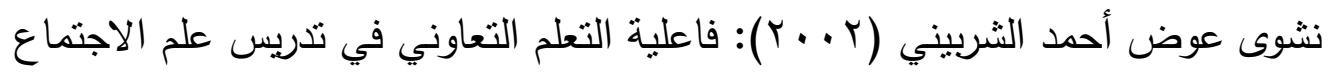

لطلاب المرحلة الثانوية، رسالة ماجستير، كلية التربية: جامعة الإسكندرية.

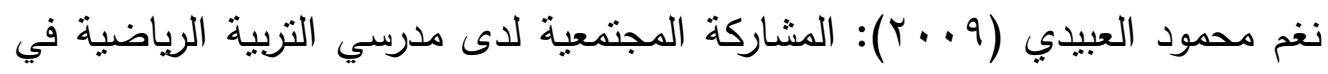

جامعة الموصل، مجلة أبحاث كلية التربية الأساسية، مجلد با، العدد ؟.

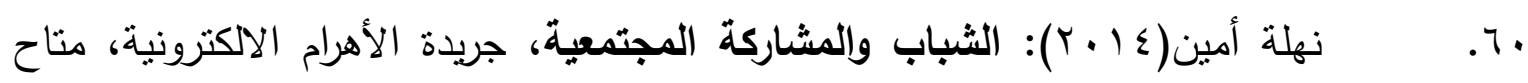

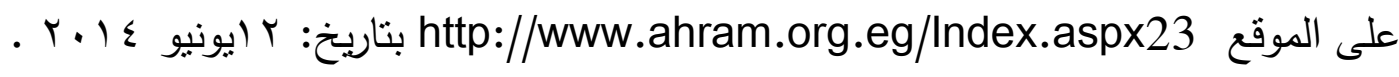

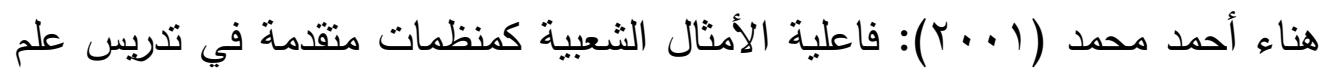
.71

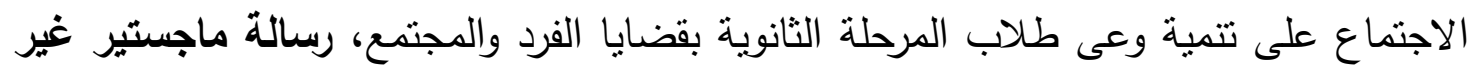

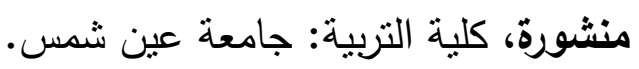
(Y.V.V)

المعايير العالمية القومية، رسالة دكتوراه، كلية التربية: جامعة عين شمس.

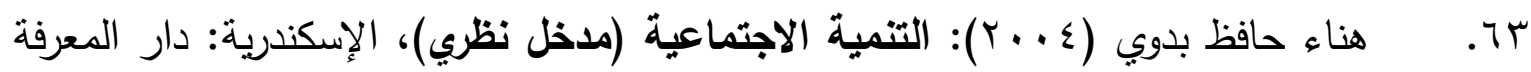




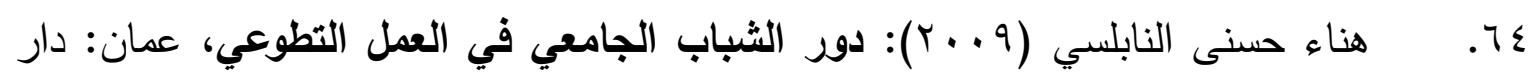
مجدلاوي للنشر والتوزيع.

10. وفاء محمد أحمد البرعى(1990): دور التعليم الثانوي العام في إعداد الطلاب لمواصلة التعليم الجامعى (دراسة تقويمية)، رسالة ماجستير، كلية التربية: جامعة الإسكندرية.

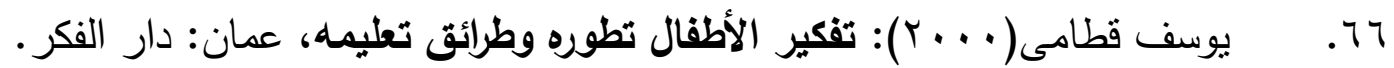

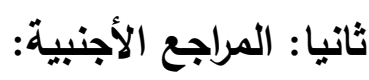

1. Abe, K(2008):The Present Condition of Sociological Imagination: Surveillance Studies on Resistance, History of Post-War Social Science, Seminar Series ,London School of Economics, $4^{\text {rd }}$ May 2008.

2. Abott, $R:(r \cdots v)$ Community Participation: What Is It? London: Blackwell.

3. Anarino, S (2009): Social Participation skills and Communication skills, Journal of Humanistic education and development. Vol 33 no 4 Jun 2009.

4. Anurada, H (2009): Using the model of Dimensions learning in teaching some humanitarian issues to develop analytical thinking skills, Journal of Educational Leadership, Vol (3), No (3).

5. Aron, R, (2004): Sociology and Social Awareness, Cambridge: A Harvard University Press.

6. Bigelow, B \& Christensen, $L(Y \cdot, r)$ : Promoting Social Imagination Through Interior Monologues-Zinn Education Project, Sociology, Vol (101), No (25).

7. Bloom, A ( r..9): Critical and Analytical Thinking, New York: McGraw- Hill.

8. Bramson, H (2007): Developing analysis and synthetic thinking in technology education. Euro journals publishing, INC 2012. 
9. Brewer, J (2004): C. Wright Mills, the LSE and the sociological imagination History of Post-War Social Science, Seminar Series London School of Economics, 23rd January 2004

10. Burawoy,M $(r \cdot 10)$ : Open Letter to wright Mills Antipode , $\mathrm{Vol} 40$, No 3,

11. Durham, A (2009): Goals of Teaching Social Studies, London Macmillan publishing.

12. Efrat, E (2013): Teaching Sociology for Social Participation, Journal of Science Education, Vol (8), No (2).

13. Elder, L, $(r+1)$ : The Sociological Thinker's Guide to Analytic Thinking, New York: Random House.

14. Gellen, L(2009): The sociological imagination, New York: Random House.

15. Germov ,J(2009): Health Sociology and Your Sociological Imagination Oxford : Oxford University Press

16. Giddens, S (2013): Sociology Teaching and Learning Guide, Cambridge, UK: Polity Press.

17. Goldin, I. \& Reinert, K. (2009) Developing a Sociological Imagination Through, Journal of the American Sociological Association, Teaching Sociology, Volume 37, Number 1 January 2009.

18. Goldin, I. \& Reinert, K. (2012) Globalization for Development, Oxford: Blackwell.

19. Guerrero, L (2005): Sociology and the Study of Social Problems, Boston: Northeastern University Press.

20. Hardiman, $M(r \ldots v)$ : Teaching Analytical Thinking in Social Issues for Reforming Education, Nova University, ERIC54782. 
21. Hartmann, D(2009): Reclaiming the Sociological Imagination : A Breif Overview and Guide, the series of advancing the Sociological Imagination, London: Paradigm Publishers.

22. Harrison A.F \& Bramson ,R. M (1982): Styles of Thinking, Doubleday ,New york.

23. Harrison, H, (2006) Teaching for comprehension and Analytic Thinking, London: Heine Mann.

24.Harrison, H, (2006): Introduction to analytical thinking, London: Routledge.

25.Herrington, S (2007) Enhancement of Analytic Thinking Through, London: Macmillan.

26. Huntington, S (2014): Political Participation in Developing Countries, Cambridge: Harvard University Press.

27.Huot, J (2009): The use of analytical thinking programs in the development of curricula at the University of Ontario, Journal of Urban Education, Vol (4), No (5).

28.James, H (2007): Introduction to Analytical Thinking, London Macmillan publishing.

29.John, D (2008): Social Participation and Social Status, Journal of Health and Social Behavior. Vol (92), No (20).

30.Karin, A (2005): Development of Analytical Thinking skills and environmental concern through Sociological Activities, Journal of Environmental Education Research, Vol 15 no 2.

31.Kemeny, J (2008): C.W. Mills The Sociological Imagination (extended review), Oxford: Oxford University Press.

32.Kennedy, K (2010): Introduction to the sociological imagination, London: Rutledge. 
33.Kurtis, S (2006): Evaluation of sociology curricula in secondary schools according to some types of thinking, Journal of Teaching and Techer Education, vol 5, no 8.

34.Martell, L. (2010) the Sociology of Globalization, Cambridge: Polity Press.

35.Marzano, R\& Kendall, J. (2008) Implementing standards. Based Education, of the United States. National Education Association. Vol (33), No $(1)$.

36.Miilar, B, L (2008): Teaching sociology, Sociology, Vol. 23. No 25. 36.Mills, W (1901) The Promise [of Sociology]" Excerpt from The Sociological Imagination (originally published in 1959;

37.Mills, W (1959): The Sociological Imagination, Oxford: Oxford press. 38.Mills, W (2000): Sociology and the Sociological Imagination, Oxford: Oxford University Press.

39.Mills, $W$ (2006): The Promise of the Sociological Imagination, Sociology, Vol (101), No (25).

40. Moris, D(2012): Social Participation, Self-Concept and Interpersonal Valuation, Journal of General Psychology .135 (3).

42.Moss, C (2003): prompting participation in practice: children and young people as partners in change, London: Savuti.

43.Oslen, A (2005): Social Participation and Happiness, American Journal of Sociology Vol. 72, No. 5 .

44.Pablo, S (2014): Measuring Social Participation in social studies, Journal of Urban Education, Vol (5), No (8).

45.Paxton, D ( $\ldots .0)$ : The Role Of Sociology In Thinking, Advanced Economic Education in Secondary Schools, Retrieved22/2/2007 from http://www.sciencestorm.com.

46.Renuwat, P (2009). Comparisons of Mathematics Achievement, Attitude towards Mathematics and Analytical Thinking between Using the 
Geom- eter's Sketchpad Programs Media and Conventional Learning Activities, Journal of Basic and Applied Sciences, Vol (3), No (3): 30363039.

47.Richard, K (2006): The Role of Sociology in Transforming Teacher candidates' Teaching Analytical Thinking, Journal of Teaching and Techer Education ,vol 25 no 8.

48.Roker, B (2004): Social Participation and Social Structure, Journal of Social Forces, Vol. 45, No. 2.

49.Ruggiero, V (2008) :Haunting and the Sociological Imagination, London: University of Minnesota Press Minneapolis.

50. Sharky,S.(2005):Beyond Mills Sociological Imagination : Using a pedagogy Based on Sorokin،s Integralism to Reach today introductory Sociology Students, The Catholic Social Science Re-view ,vol (10),PP 53-81.

51.Scanlan,S. J: (2009) Special Issue on 50 Years of Wright Mills and The Sociological Imagination, Journal of the American Sociological Association, Teaching Sociology, Vol 37, No 1 January 2009

52.Sheppard, S (2015): The roles of social studies teachers in supporting the principles of social participation. Journal of Education, Vo;(8), No (25).

53.Solso, D (2006): Analytical thinking and social awareness issues, New York, Harcourt Brace collage publishers

54.Soter, $T(Y \ldots$... Analytical Thinking Skills, London: Longman group.

55.Swift, V.D ( $\ldots$. q): Developing a Sociological Imagination: Teaching Introductory Sociology to Nurses, La Trobe University: Bendigo.

56.Sztompka, P (2006): Shaping Sociological Imagination the Importance of Theory, Oxford: Blackwell.

57.Tomlinson, K (2009): The parallel curriculum A design to develop learner potential and challenge advanced learners. Second edition, growing press. publication national association for gifted children, Vol 42 no 5. 
58.Tyler, R (2016): Community Participation (Reality and Hope), Citizenship and Social Justice. Vol (7), No (2).

59.Ulrike, A (2014): The role of sociology in teaching the values of social participation for high school students, Journal of Humanities and Social Sciences, Vol (4). No (32).

60.Weil, G (2007): Social Mobility and Social Participation, The Annals of the American Academy of Political and Social Science, Vol. 435, No 20. 61.Welras, W (2005): Nature of sociology, American Journal of Sociology Vol. 72, No. 5.

62.Wilen, P. (1985). Questioning, Thinking and Effective Citizenship, Journal of Social Science Record. V0 122, No 14.

63.William Joyce (2014): Harry Potter, Benjamin Bloom, and the Sociological Imagination, International Journal of Teaching and Learning in Higher Education, Volume 19, Number 2.

64.with Third Graders, National Council for the Social Studies, Social Studies and the Young Learner, 25 (3),

65.Wndol, M (2004): Social Participation, New York, Harcourt Brace collage publishers, 2 nd ed.

66.Zaleski, J \& Zinnel, V (2010): Developing a Social Imagination Journal of the American Sociological Association, Teaching Sociology, Vol 38, No 2. 